\title{
Functional analysis of mitochondrial sirtuins in C. elegans and mammalian cells
}

\section{PhD Thesis}

\author{
in partial fulfillment of the requirements \\ for the degree "Doctor rerum naturalium" \\ in the Molecular Biology Program \\ at the Georg August University Göttingen, \\ Faculty of Biology
}

submitted by

Martina Wirth

born in

Lauingen a.d. Donau, Germany 



\section{Affidavit}

I hereby declare that the presented thesis "Functional analysis of mitochondrial sirtuins in C. elegans and mammalian cells" has been written independently and with no other sources and aids than quoted.

Göttingen, September 30, 2010 


\section{List of publications}

Wirth, M., and Jedrusik-Bode, M. (2009). Interplay between histone deacetylase SIR-2, linker histone $\mathrm{H} 1$ and histone methyltransferases in heterochromatin formation. Epigentics 4:6, 1-4.

Wirth, M., Paap, F., Fischle, W., Wenzel, D., Agafonov, D.E., Samatov, T.R., Wisniewski, J.R., and Jedrusik-Bode, M. (2009). HIS-24 linker histone and SIR-2.1 deacetylase induce H3K27me3 in the Caenorhabditis elegans germ line. Mol Cell Biol 29, 3700-3709.

Illarionov B., Eisenreich W., Wirth M., Yong Lee C., Eun Woo Y., Bacher A., Fischer M. (2007). Lumazine proteins from photobacteria: localization of the single ligand binding site to the N-terminal domain. Biol Chem. 388(12), 1313-23.

Vutova, P., Wirth, M., Hippe, D., Gross, U., Schulze-Osthoff, K., Schmitz, I., and Luder, C.G. (2007). Toxoplasma gondii inhibits Fas/CD95-triggered cell death by inducing aberrant processing and degradation of caspase 8. Cell Microbiol 9, 1556-1570. 


\section{Table of contents}

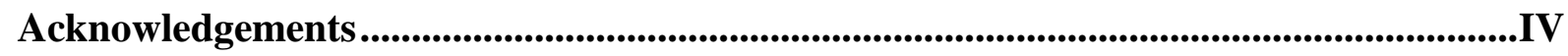

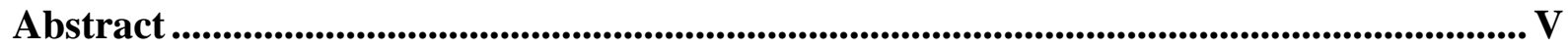

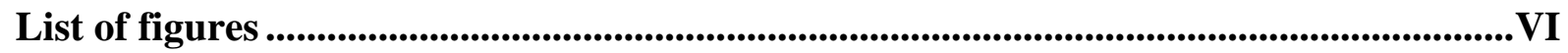

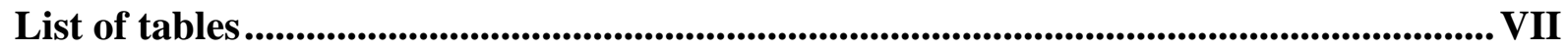

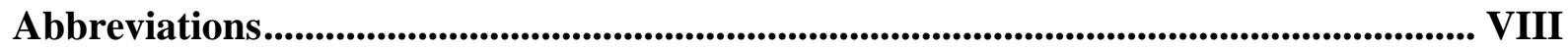

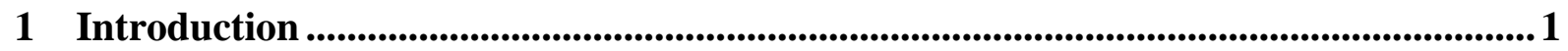

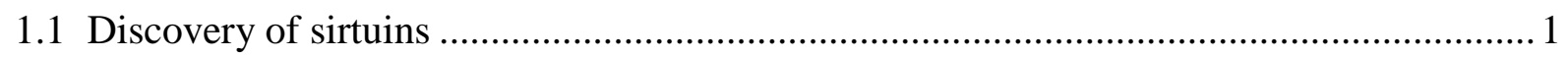

1.2 Biochemical function and structural features of sirtuins .............................................. 1

1.2.1 Enzymatic activity of sirtuins - Deacetylase vs. ADP-ribosyltransferase activity .............. 1

1.2.2 Catalytic reaction mechanism of $\mathrm{NAD}^{+}$-dependent deacetylation .................................... 2

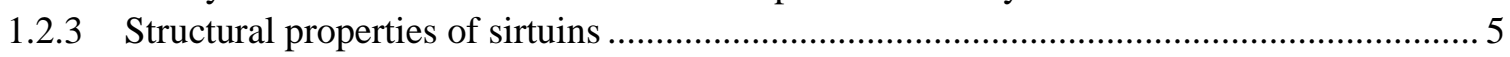

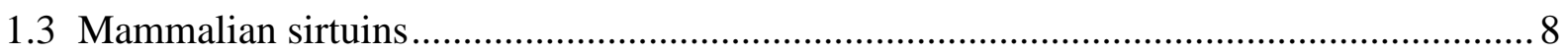

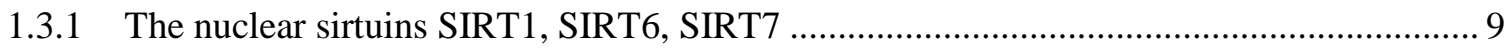

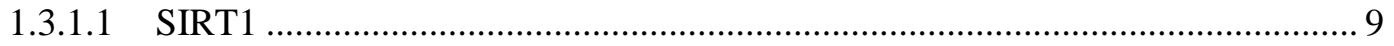

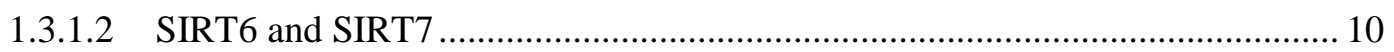

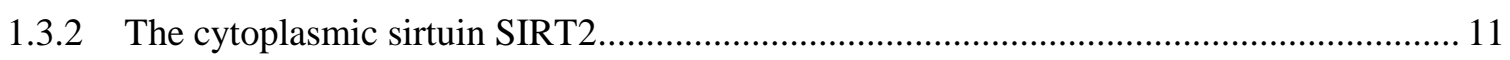

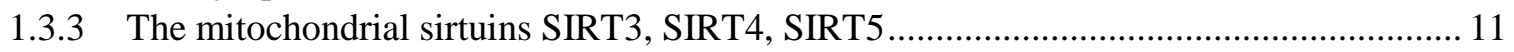

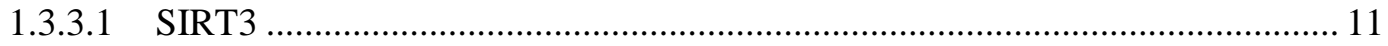

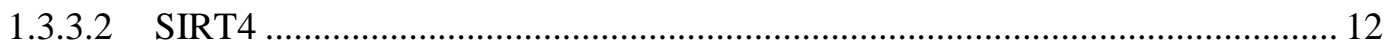

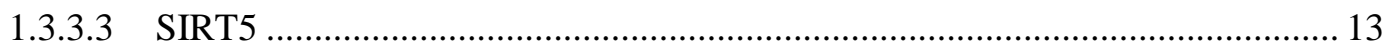

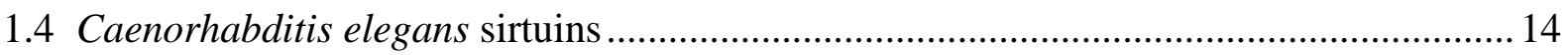

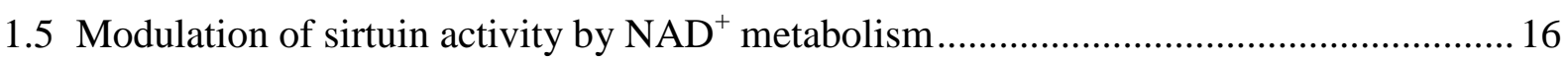

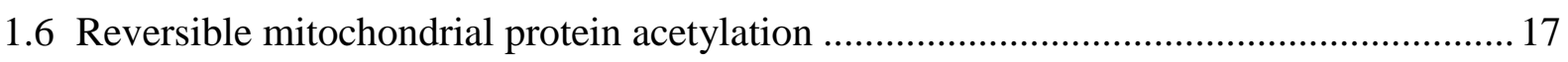

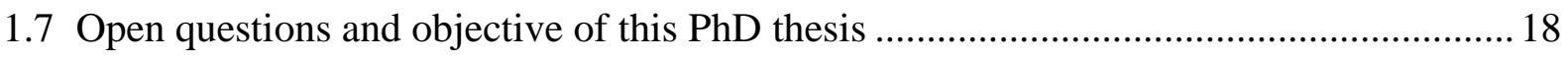

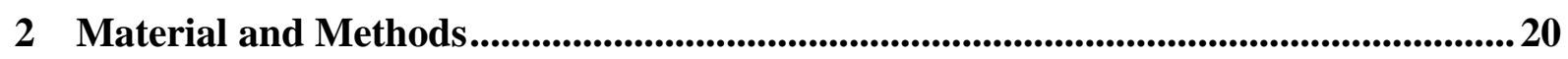

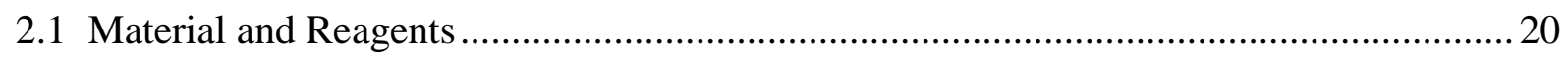

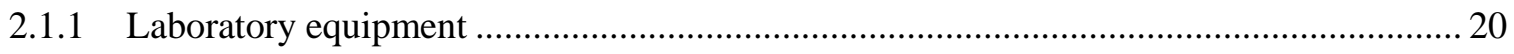

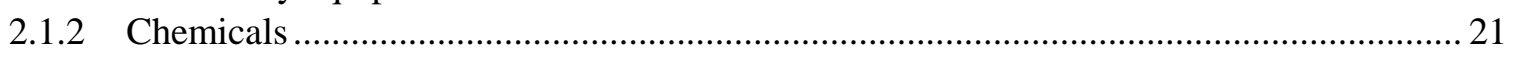

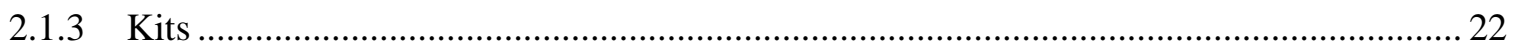

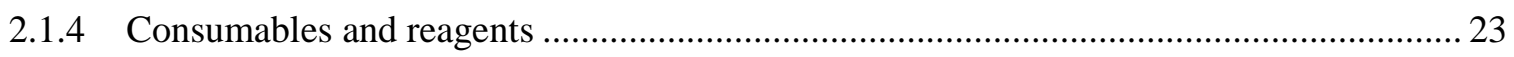

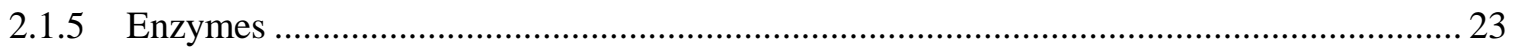

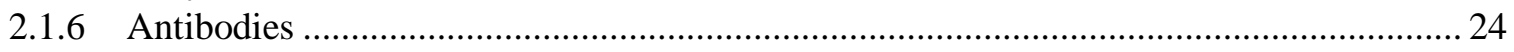

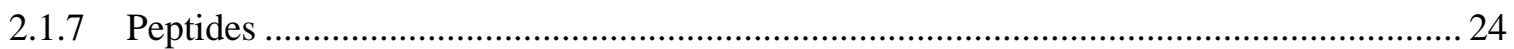

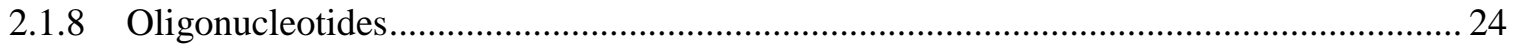

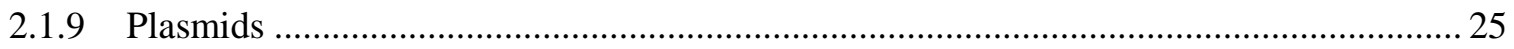

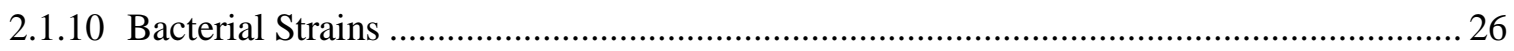

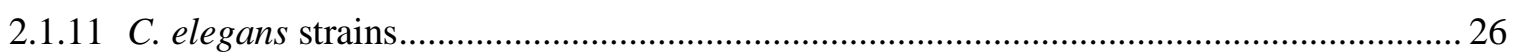

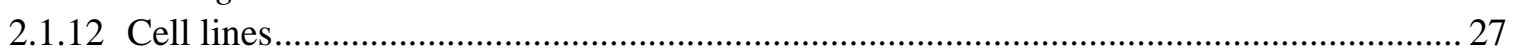

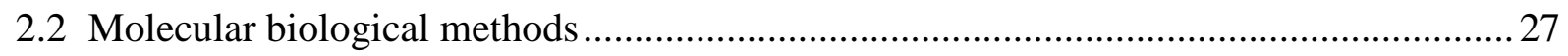

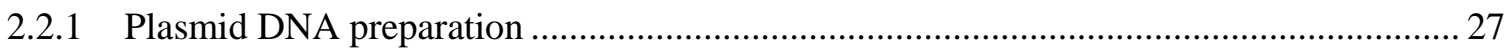

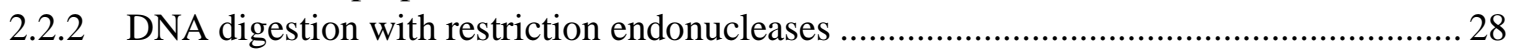




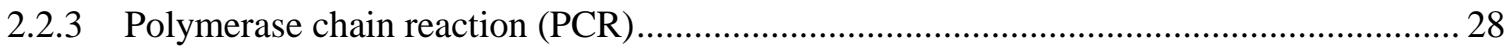

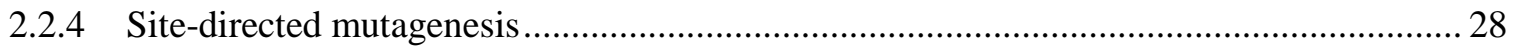

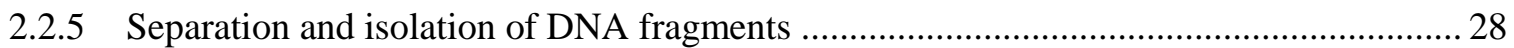

2.2.6 Transformation of plasmids into chemically competent bacteria ...................................... 29

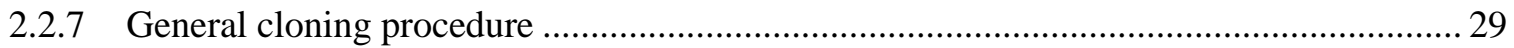

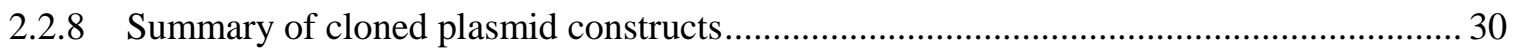

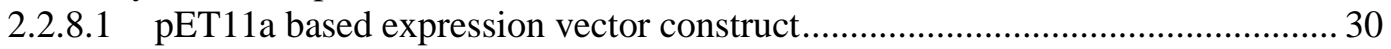

2.2.8.2 pEU3-NII-StrepII based expression vector constructs ...................................... 30

2.2.9 pCDNA3.1(+)-FLFL-HAHA-N mammalian expression vector based constructs ............. 30

2.2.10 pCDNA3.1(+)-FLFL-HAHA-C mammalian expression vector based constructs ............. 32

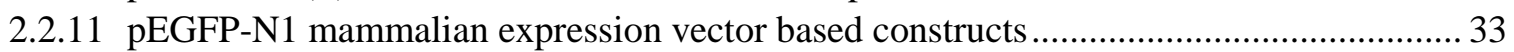

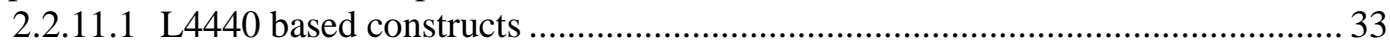

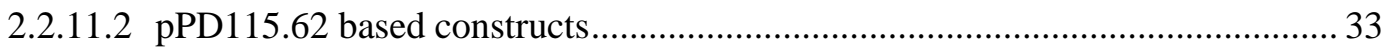

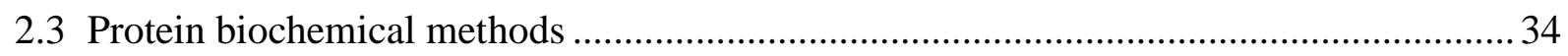

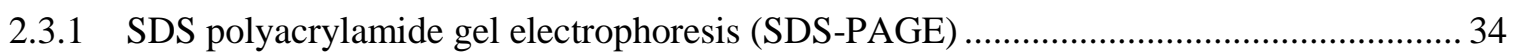

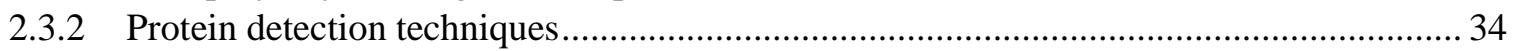

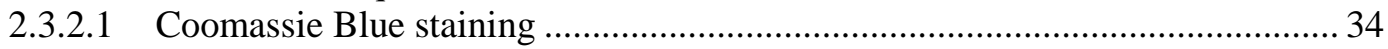

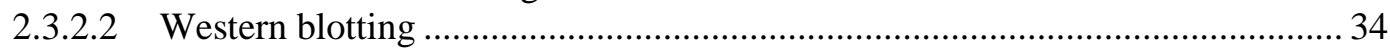

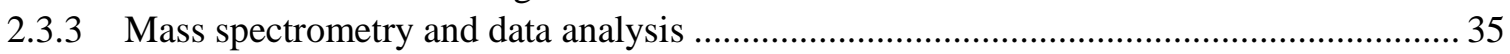

2.3.4 Generation of SIR-2.2-specific antibodies using recombinant protein for immunization. 35

2.3.4.1 Expression of recombinant SIR-2.2 in E. coli ................................................ 35

2.3.4.2 Purification of recombinant SIR-2.2 from inclusion bodies............................... 35

2.3.4.3 Gelfiltration and ion exchange chromatography .............................................. 36

2.3.4.4 High-performance liquid chromatography (HPLC) …....................................... 36

2.3.4.5 Immunization, purification and characterization of SIR-2.2-specific antibodies

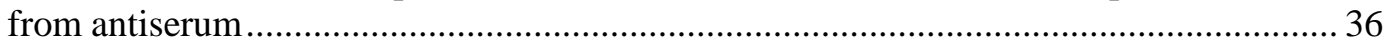

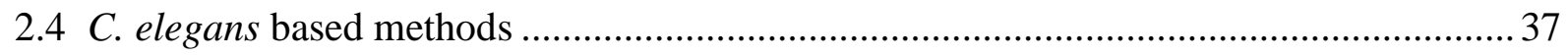

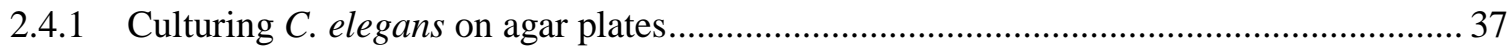

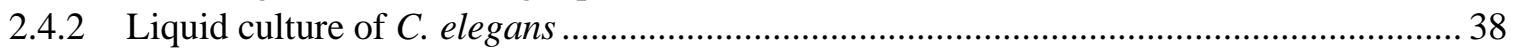

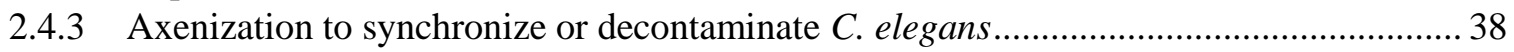

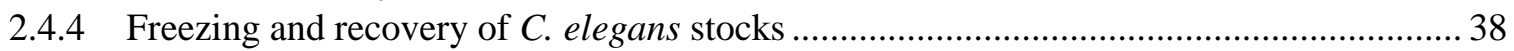

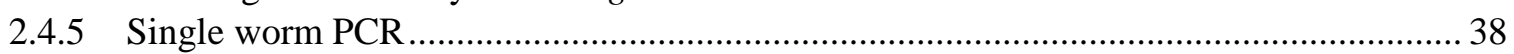

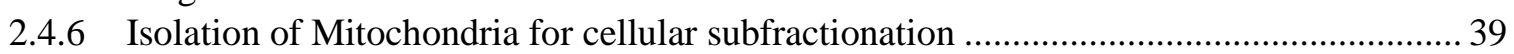

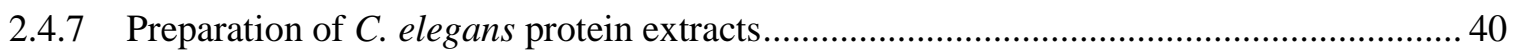

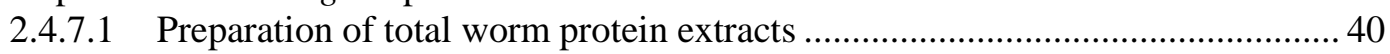

2.4.7.2 Preparation of mitochondrial protein extracts .................................................... 40

2.4.7.3 Preparation of crude C. elegans lysate for Western blot analysis ...................... 41

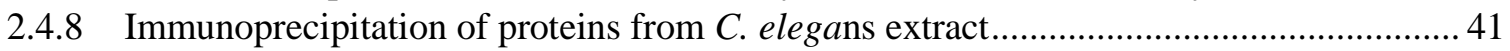

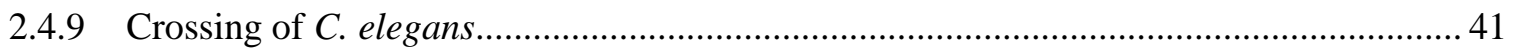

2.4.10 Isolation of RNA from C. elegans and reverse transcription ......................................... 42

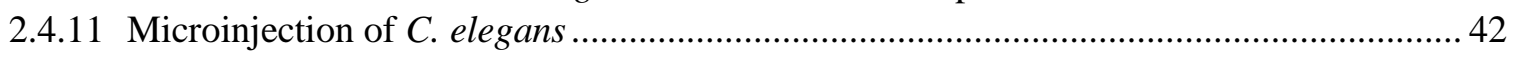

2.4.12 Generation of GFP/mCherry reporters using a PCR fusion-based approach ..................... 43

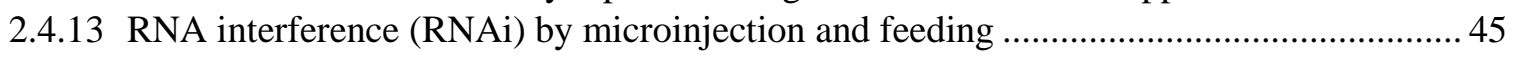

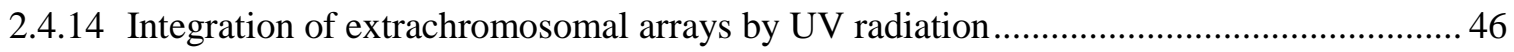

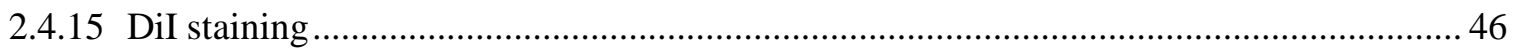

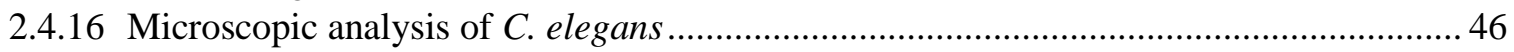

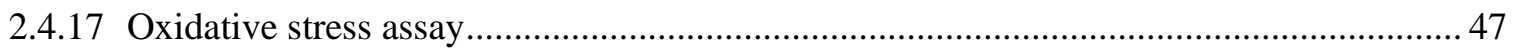

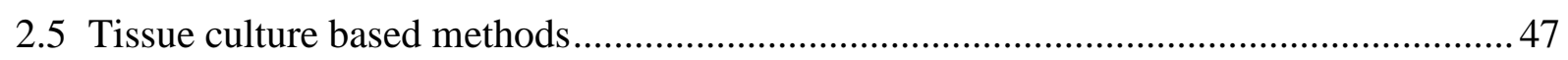

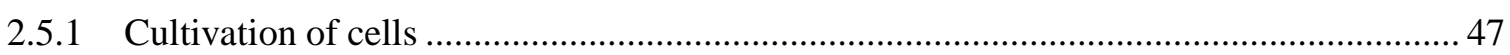

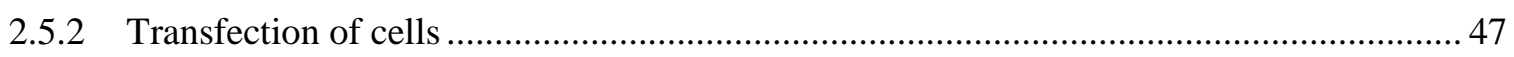

2.5.3 Immunoprecipitation of proteins from transfected cells................................................ 47

2.5.4 Analysis of protein acetylation using acetyllysine-specific antibodies .............................. 48 


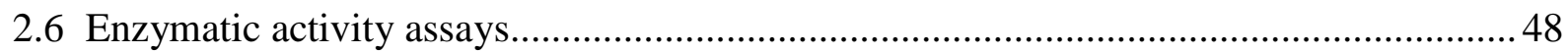

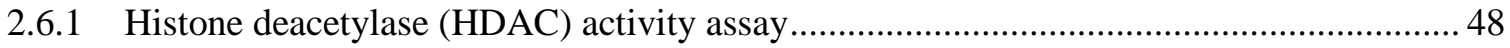

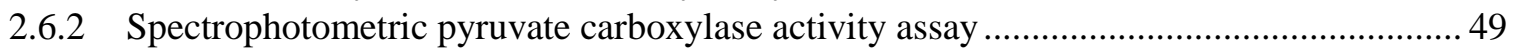

2.6.3 Deacetylase activity assay in combination with mass spectrometry ................................ 49

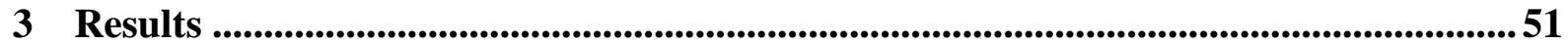

3.1 Analysis of SIR-2 protein expression and localization in C. elegans ...............................51

3.1.1 SIR-2.2 and SIR-2.3 do not localize to the cell nucleus.................................................. 51

3.1.2 SIR-2.2 and SIR-2.3 expression and localization patterns partially overlap .....................53

3.1.3 Analysis of SIR-2.3 expression in head neurons by DiI staining ...................................... 54

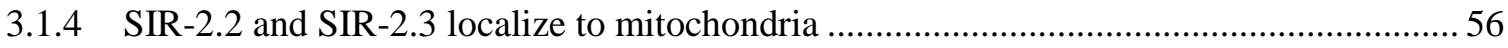

3.2 Characterization of $\operatorname{sir}-2.2$ and $\operatorname{sir}$-2.3 deletion mutant $C$. elegans strains .......................58

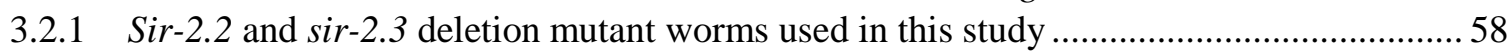

3.2.2 Knockdown of sir-2.2 in a sir-2.3 mutant background leads to a very mild phenotype ... 62

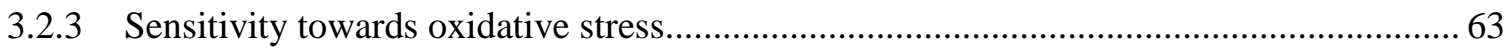

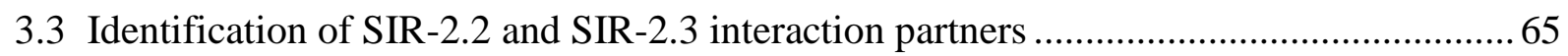

3.3.1 Identification of mitochondrial biotin carboxylases as factors interacting with SIR-2.2 and

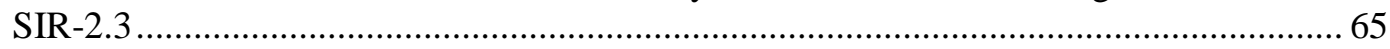

3.3.2 Evolutionarily conserved interaction of mammalian SIRT4 with mitochondrial biotin-

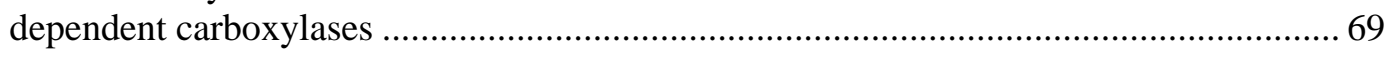

3.3.3 Analysis of the interaction specificity of C. elegans and mammalian sirtuins with

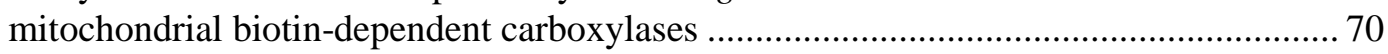

3.3.4 Mapping of the biotin carboxylase domain mediating interaction with SIRT4 ................ 72

3.4 Regulation of biotin carboxylase function by mitochondrial sirtuins .............................. 75

3.4.1 Mitochondrial biotin carboxylases are acetylated proteins .......................................... 75

3.4.2 Analysis of the enzymatic activities of C. elegans SIR-2.2, SIR-2.3 and mammalian

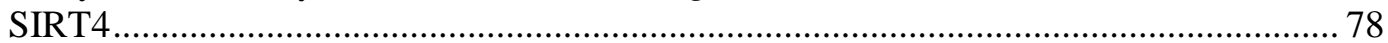

3.4.2.1 In vitro histone deacetylase activity (HDAC) assay .......................................... 80

3.4.2.2 Mass spectrometry based in vitro deacetylase activity assay ............................ 81

3.4.3 Analysis of bovine PC activity after deacetylase reaction with C. elegans sirtuins .......... 84

3.4.4 Reduced acetylation levels of MCCC1 and PCCA in cells overexpressing SIRT4 …....... 85

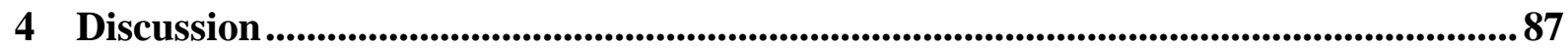

4.1 SIR-2.2 and SIR-2.3 are mitochondrial proteins strongly expressed in tissue with high

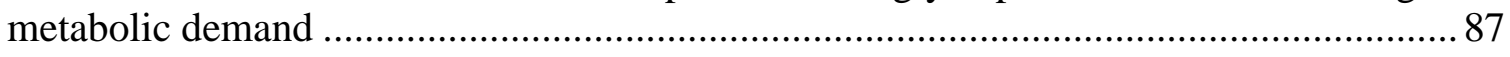

4.2 Is there genetic redundancy between SIR-2.2 and SIR-2.3 in C. elegans?...................... 88

4.3 SIR-2.2 and SIR-2.3 mediate resistance to oxidative stress.......................................... 89

4.4 Evolutionary conserved interaction with mitochondrial biotin carboxylases .................. 91

4.5 Mitochondrial biotin-dependent carboxylases are acetylated proteins ........................... 92

4.6 Are mammalian SIRT4 and C. elegans SIR-2.2 and SIR-2.3 protein deacetylases?........ 92

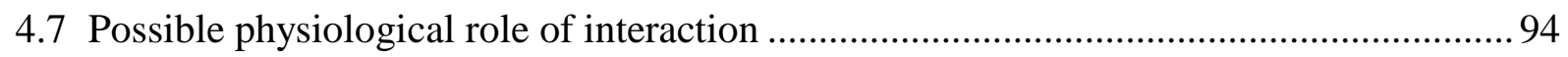

5 Summary and Conclusion ........................................................................................................ 101

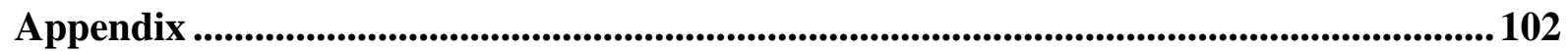

A.1 SIR-2.2 protein levels in sir-2.2.:gfp and sir-2.3(ok444); sir-2.2RNAi worms ............. 102

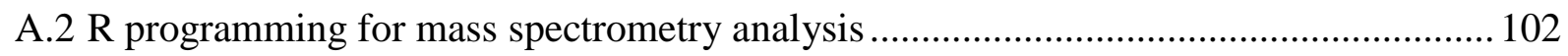

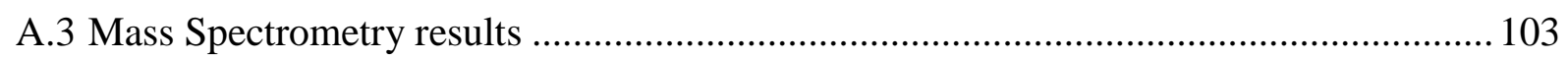

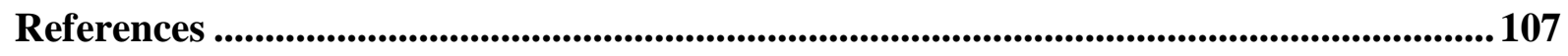

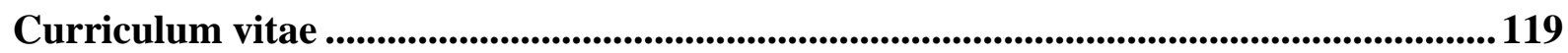




\section{Acknowledgements}

Firstly, I would like to thank my two supervisors Dr. Monika Jedrusik-Bode and Dr. Wolfgang Fischle for giving me the chance to work on this project, for their support, encouraging ideas and patience over these years.

I am also very grate full to my $\mathrm{PhD}$ Thesis committee Prof. Herbert Jäckle and Prof. Frauke Melchior for their great interest, helpful comments and support in scientific and challenging non-scientific matters.

I am grateful for support from the Deutsche Forschungsgemeinschaft (DFG JE 505/1-1).

I want to thank Dr. Steffen Burkhardt, Ivana Bacakova and Kerstin Grüniger from the coordination office for their great support, help and commitment during all phases of my Master and $\mathrm{PhD}$ years.

I want to thank Jennifer Seefeldt for great work and commitment during her lab rotation.

I am grateful to all my collaborators:

Prof. Eric Verdin and Linh Ho for the analysis with the anti-acetyllysine antibodies and reagents;

Dr. Henning Urlaub and his group for their excellent mass spectrometry work and help;

Dr. Dirk Wenzel for the excellent electron microscopy analyses, his enthusiasm and helpful ideas;

Dr. Dmitry Agafonov and Dr. Timur Sumatov for wheat germ extract protein expressions.

I am very grateful to Dr. Dieter Klopfenstein and his group members for teaching me microinjection of $C$. elegans, sharing the microinjection aperture, reagents and helpful advice.

I also would like to thank Christian Wurm and Prof. Peter Rehling for helping me with reagents, protocols and advice when I started to explore the exciting field of mitochondrial research. In addition, I want to thank Mathias Beller for help with lipid assays, although I could not include them in this thesis.

I am grateful to Prof. Heidi Tissenbaum, the Caenorhabditis Genetics Center (CGC) and the Mitani Laboratory (National BioResource Project) for C. elegans strains.

Many thanks to all members of the Fischle group, for their help, friendship and assistance in the lab. I'm very grateful to Franziska, DingDing and Jenni for their help and essential constant support of the "worm folk". Moreover, a big thank you goes to my worm fellow Nora for sharing knowledge, reagents, Brezen, chocolate and especially the passion for Jonny Cash with me. Many big thanks also to Henriette, Kerstin, Nora and Sabi for their support, for great laughs, "Cisciscis's" and "Ha's", Cafe Kreuzberg and later on Gromo breakfast sessions, and the Bananenweizen or Bierle at the end of the day.

Many, many thanks also to the best flatmate ever, "ooooh Konstantina!", for supporting, feeding and spoiling me together with Christoph especially in the last three months. I'm also very grateful to Ieva and Achim for many funny moments and hopefully more to come.

I am grateful to my family, for their trust in me and their continued support.

Last but not least, I am most indebted to Stefan. Thank you for your love, trust, support, the many kilometers you drove for me, .....,for keeping me sane and keeping my back clear especially in the last weeks. 


\section{Abstract}

Silent information regulator 2 (SIR-2) proteins, also referred to as sirtuins, are highly conserved $\mathrm{NAD}^{+}$-dependent protein deacetylases that are emerging to be important energy sensors and regulators of metabolism, stress responses and aging. The mammalian sirtuin protein family is quite complex, comprising seven members (SIRT1 to SIRT7) with different subcellular localization (nucleus, cytoplasm, and mitochondria). The mitochondrial SIRT4 remains the only mammalian sirtuin of which ADP-ribosyltransferase activity, but no NAD ${ }^{+}$dependent deacetylase activity could be detected. SIRT4 negatively regulates insulin secretion and might be a therapeutic target for treatment of diabetes. However, this requires a better understanding of its biological and enzymatic function as well as identification of novel substrates.

The simple multicellular organism C. elegans possesses only four SIR-2 variants (SIR-2.1 to SIR-2.4) that all show high sequence conservation to mammalian sirtuins. Overexpression of SIR-2.1 increases the life span of $C$. elegans, suggesting that these are also intriguing players in regulating longevity and in linking metabolism to aging-related processes. Whereas the majority of studies have focused on SIR-2.1, the variants SIR-2.2 and SIR-2.3, which are most homologous to mammalian SIRT4, remain by and large uncharacterized.

In this PhD thesis I showed that SIR-2.2 and SIR-2.3 are also localized to mitochondria and are predominantly expressed in C. elegans tissues with high energy demand, e.g. pharynx and body wall muscles. Sir-2.2 and sir-2.3 deletion mutant worms did not exhibit an obvious phenotype under normal growth conditions. However, overexpression and loss of SIR-2.2 and SIR-2.3 resulted in increased sensitivity to oxidative stress, suggesting that both proteins function in oxidative stress responses. Using immunoprecipitation experiments in combination with mass spectrometry, I was able to identify all three mitochondrial members of biotin-dependent carboxylases, pyruvate carboxylase (PC), propionyl-CoA carboxylase (PCC) and methylcrotonyl-CoA carboxylase (MCC), as factors interacting with SIR-2.2 and SIR-2.3. The interaction was evolutionarily conserved with mammalian SIRT4 and mediated by the homologous biotin carboxylation domain, which is present in all three proteins. Mitochondrial biotin carboxylases play an important role in gluconeogenesis, amino acid catabolism, $\beta$-oxidation and ketone body formation. Since all three proteins were found to be acetylated on multiple lysine residues, their enzymatic activity might be regulated by $\mathrm{NAD}^{+}$dependent deacetylation through mammalian SIRT4 and C. elegans SIR-2.2 and SIR-2.3. SIRT4, SIR-2.2 and SIR-2.3 did not exhibit NAD ${ }^{+}$-dependent protein deacetylase activity on PC peptides containing the conserved acetylated lysine residues K273 and K741. However, overexpression of SIRT4 specifically reduced the acetylation levels of the $\alpha$-subunits of PCC and MCC, indicating for the first time that SIRT4 might be indeed a $\mathrm{NAD}^{+}$-dependent deacetylase.

Overall, this study showed that C. elegans SIR-2.2 and SIR-2.3 and mammalian SIRT4 have conserved functions. Their interaction with mitochondrial biotin carboxylases indicates an important role as energy sensors and regulators of metabolic adaptation during nutrient deprivation. 


\section{List of figures}

Figure 1-1: $\mathrm{NAD}^{+}$-dependent protein deacetylation reaction catalyzed by sirtuins............................. 2

Figure 1-2: Proposed chemical reaction mechanism of $\mathrm{NAD}^{+}$-dependent protein deacetylation

catalyzed by sirtuins. 3

Figure 1-3: Multiple sequence alignment of the catalytic core domain region of sirtuins with known

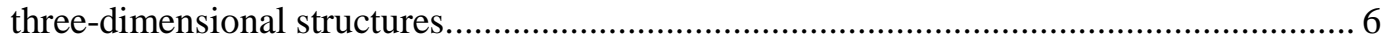

Figure 1-4: Three-dimensional crystal structures of different sirtuins............................................... 7

Figure 1-5: Tissue-specific regulation of metabolism by SIRT1 ................................................. 10

Figure 1-6: Metabolic functions of mitochondrial sirtuins. .............................................................. 14

Figure 2-1: Western blot analysis of generated SIR-2.2-specific antibodies.................................... 37

Figure 2-2: $\quad$ PCR-fusion based approach for generating a C-terminal $g f p$ reporter construct............... 44

Figure 3-1: Expression and localization pattern of SIR-2 proteins in C. elegans. .............................. 52

Figure 3-2: The expression and localization patterns of SIR-2.2 and SIR-2.3 partially overlap. ....... 53

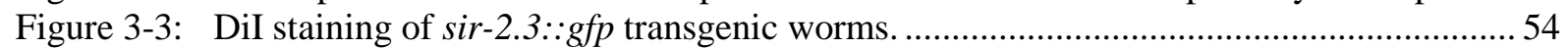

Figure 3-4: Analysis of SIR-2.2 and SIR-2.3 subcellular localization by electron microscopy. .........56

Figure 3-5: Subcellular fractionation of $\mathrm{N} 2$ and sir-2.3::gfp transgenic worms by differential

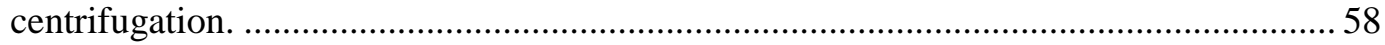

Figure 3-6: RT-PCR analysis of the sir-2 deletion mutant alleles .................................................. 59

Figure 3-7: Characterization of truncated proteins resulting from sir-2 deletion mutant alleles........ 60

Figure 3-8: Increased sensitivity to oxidative stress in worms overexpressing or deficient in SIR-2.2

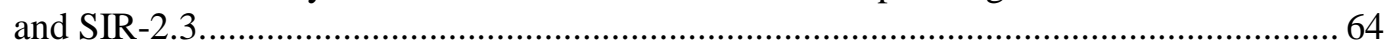

Figure 3-9: Identification of mitochondrial biotin carboxylases as factors interacting with SIR-2.2. 66

Figure 3-10: Role of mitochondrial biotin-dependent carboxylases in anaplerosis and generation of ketone bodies.

Figure 3-11: Verification of mitochondrial biotin-dependent carboxylases as interaction partners of $C$. elegans SIR-2.2 and SIR-2.3.

Figure 3-12: Identification of endogenous mitochondrial biotin-dependent carboxylases as interacting factors of SIR-2.3.

Figure 3-13: Evolutionarily conserved interaction of mammalian SIRT4 with mitochondrial biotin carboxylases. ..................................................................................................... 70

Figure 3-14: Analysis of specificity of interaction with C. elegans SIR-2.1, SIR-2.2 and SIR-2.3...... 71

Figure 3-15: Interaction specificity of human mitochondrial sirtuins with mitochondrial biotin-

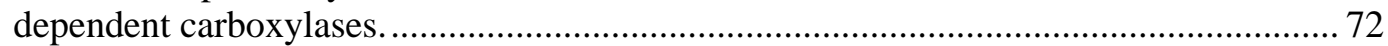

Figure 3-16: Mapping of the domain of PC, PCCA and MCCC1 mediating interaction with SIRT4.. 75 Figure 3-17: Lysine acetylation sites identified in PC, PCCA and MCCC1 by different mass spectrometric approaches.

Figure 3-18: Analysis of protein acetylation levels by Western blotting with anti-acetyllysine-specific

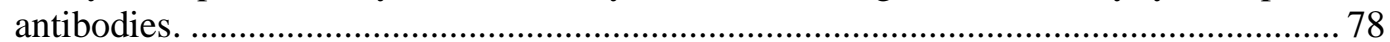

Figure 3-19: Highly conserved catalytic core domain of $C$. elegans sirtuins......................................... 78

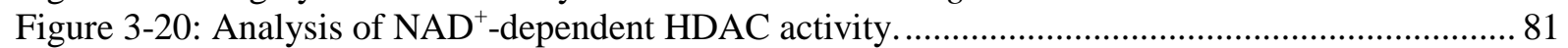

Figure 3-21: Mass spectrometric analysis of in vitro deacetylase reactions using acetylated peptides. 82 Figure 3-22: No changes in bovine PC activity after treatment with C. elegans SIR-2.2 and SIR-2.3. 84

Figure 3-23: Overexpression of SIRT4 specifically reduces the acetylation levels of PCCA and

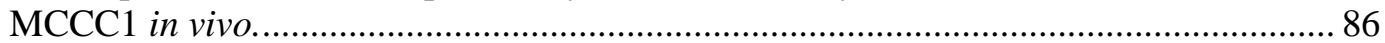

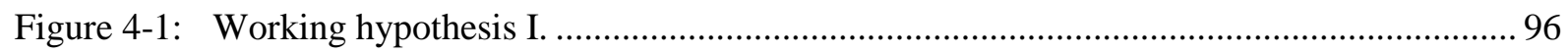

Figure 4-2: Role of mitochondrial biotin carboxylases in insulin secretion. .................................... 98

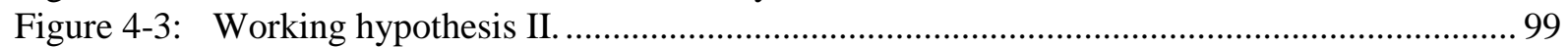

Figure A-1: Analysis of SIR-2.2 protein levels in sir-2.2::gfp and sir-2.3(ok444); sir-2.2RNAi

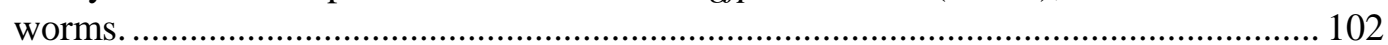




\section{List of tables}

Table 1-1: Diversity of mammalian sirtuins.

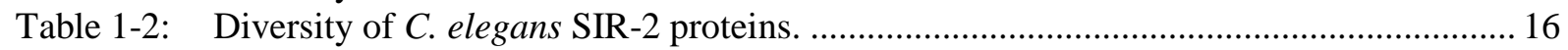

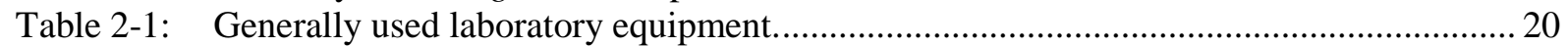

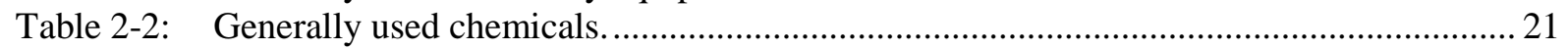

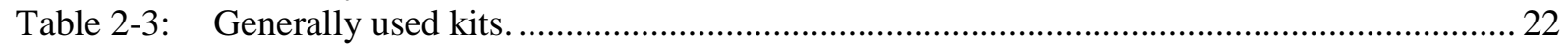

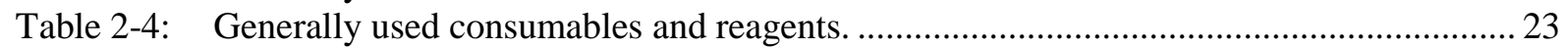

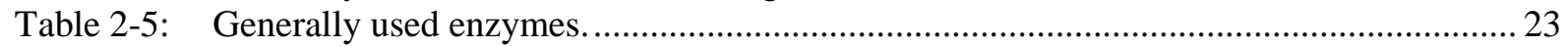

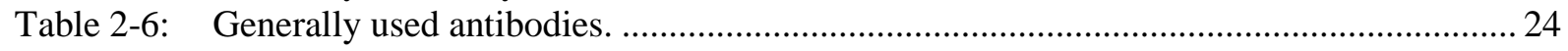

Table 2-7: Peptides used for deacetylase activity assays............................................................... 24

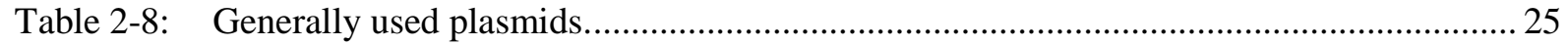

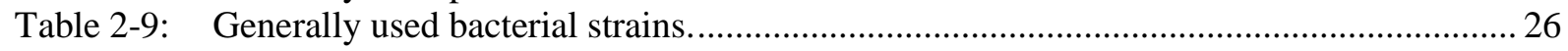

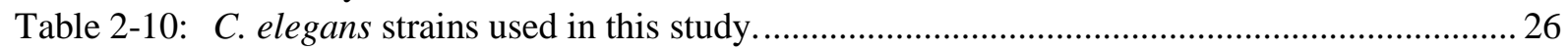

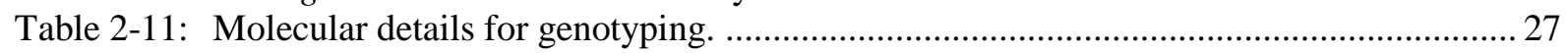

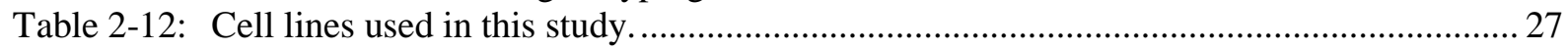

Table 3-1: Overview on available sir-2 mutant deletion strains..................................................... 59

Table 3-2: Knock down of sir-2.2 in sir-2.3(ok444) mutant worms did not cause an obvious phenotype.

Table 3-3: $\quad$ Summary on observed $\mathrm{NAD}^{+}$-dependent deacetylase activity on acetylated peptides analyzed by mass spectrometry. 


\section{Abbreviations}

0

$\begin{array}{ll}\Delta & \text { delta }=\text { deletion } \\ \text { aa } & \text { amino acid(s) } \\ \text { ac } & \text { acetylation } \\ \text { ATP } & \text { adenosine triphosphate } \\ \text { bp } & \text { base pair(s) } \\ \text { BC } & \text { biotin carboxylase } \\ \text { BCCP } & \text { biotin carboxyl carrier protein } \\ \text { C } & \text { Celsius } \\ \text { cDNA } & \text { complementary DNA } \\ \text { C. elegans } & \text { Caenorhabditis elegans }\end{array}$

\section{CoA Coenzyme A}

cpm

CGC

$\mathrm{CR}$

CT

DMEM

DMSO

DNA

DNase

dNTP

DIC

DiI

dsRNA

DTT

EDTA

E. coli

g

GDH glutamate dehydrogenase

GFP green fluorescent protein

$\mathrm{h}$

HDAC

HEK293

HP1

HRP

Ile

IP

IPTG

$\mathrm{kb}$

$\mathrm{kDa}$

1

LB

$\mathrm{m}$ count(s) per minute

Caenorhabditis Genetics Center

Caloric restriction

carboxyltransferase

Dulbeccos Modified Eagle's Medium

Dimethyl sulfoxide

deoxyribonucleic acid

deoxyribonuclease

deoxyribonucleic acid

differential interference contrast

1,1'-dioctadecyl-3,3,3',3'-

tetramethylindocarbocyanine perchlorate

double-stranded ribonucleic acid

DL-1,4-dithiothreitol

ethylenediaminetetraacetic acid

Escherichia coli

hour(s)

histone deacetylase

human embryonic kidney 293 cell line

heterochromatin protein 1

horse-radish peroxidase

isoleucine

immunoprecipitation

isopropyl $\beta$-D-thiogalactopyranoside

kilo bases

kilo Dalton

liter

Luria-Bertani (broth)

milli
MCC

$\mathrm{MCCC} 1$

$\mathrm{M}$

$\min$

Met

MNase

mRNA

MS

$\mathrm{NAD}^{+}$

$\mathrm{NADH}$

NAM

NGM

PBS

PC

PCC

PCCA

PCR

PCT

PTM

rDNA

RNA

RNAi

ROS

rpm

RT

RT-PCR

SDS-

PAGE

sec

S.E.M.

SIR-2

SIRT

TCA

Thr

U

UTR

UV

v/v

Val

w/o

$\mathrm{w} / \mathrm{v}$

wt

$\mu$
Methylcrotonyl-coenzyme A carboxylase

Methylcrotonyl-coenzyme A $\alpha$-subunit

molar

minute(s)

methionine

Micrococcus nuclease

messenger ribonucleic acid

mass spectrometry

nano

nicotinamide adenine dinucleotide

nicotinamide adenine dinucleotide

(reduced form)

nicotin amide

Nematode growth medium

phosphoate buffered saline

Pyruvate carboxylase

Propionyl-coenzyme A carboxylase

Propionyl coenzyme A carboxylase $\alpha$ -

subunit

polymerase chain reaction

pyruvate carboxyltransferase

post-translational modification

ribosomal deoxyribonucleic acid

ribonucleic acid

RNA interference

reactive oxygen species

rotations per minute

room temperature

reverse transcriptase polymerase chain reaction

sodium dodecyl sulfate polyacrylamide gel electrophoresis

second(s)

standard error of mean

silent information regulator- 2

sirtuin

Tricarboxylic acid

Threonine

unit(s)

untranslated regions

ultraviolet

volume per volume

valine

without

weight per volume

wild type

micro 


\section{Introduction}

\subsection{Discovery of sirtuins}

Silent information regulator 2 (SIR-2) proteins, also referred to as sirtuins, are a family of $\mathrm{NAD}^{+}$-dependent protein deacetylases [1], which are highly conserved and are found in all three domains of life (eubacteria, archaea and eukaryotes) [2, 3]. Unlike other protein deacetylases, SIR-2 requires NAD ${ }^{+}$as a cofactor [4-6]. Deacetylation of a substrate is coupled to hydrolysis of $\mathrm{NAD}^{+}$and the acetyl group is transferred from its substrate to a $\mathrm{NAD}^{+}$ cleavage product to form O-acetyl-ADP-ribose (Figure 1-1) [7, 8].

Saccharomyces cerevisiae SIR-2, the founding member of this large and diverse protein family, was originally identified as a factor necessary for epigenetic silencing of the mating type loci, telomeres and ribosomal DNA (rDNA) [9]. But it is also involved in DNA replication [10], DNA repair, suppression of recombination [11] and aging [12, 13]. Since increased dosage of SIR-2 and its orthologs leads to longevity in yeast [12, 14], worms [15] and flies [16-18], sirtuins have become intriguing players in regulating longevity and linking metabolism to aging and age-related diseases such as diabetes, neurodegenerative diseases and cancer [1, 19]. Mammalian sirtuins comprising seven members (SIRT1 to SIRT7, Table 1-1) are emerging to also have roles in regulating age-related processes. In recent years numerous target proteins of sirtuins, primarily of mammalian SIRT1, have been identified. Mammalian sirtuins are important regulators of diverse cellular processes such as cell survival, genome stability, stress responses and metabolism [20].

Although $\mathrm{NAD}^{+}$-dependent deacetylase activity has been demonstrated for SIR-2 proteins of many organisms, their physiological role in invertebrates and vertebrates has just began to be investigated and therefore still remains largely elusive. Sirtuins might be critical regulators and novel targets for treating age-associated diseases [21]. However, a better understanding of sirtuins and the pathways regulated by them is required for that.

\subsection{Biochemical function and structural features of sirtuins}

\subsubsection{Enzymatic activity of sirtuins - Deacetylase vs. ADP-ribosyltransferase activity}

The first insight into the enzymatic activity of sirtuins provided the characterization of Salmonella typhimurium CobB, a bacterial SIR-2 protein. In the cobalamin biosynthesis pathway CobB was able to substitute CobT. As CobT is a known phosphoribosyltransferase catalyzing the transfer of phosphoribose from nicotinate mononucleotide to dimethylbenzimidazole, a pyridine nucleotide transfer reaction was also anticipated for SIR-2 proteins [22].

In 1999 Frye [23] showed that the E. coli SIR-2-like protein CobB and human SIRT2 were both able to transfer ${ }^{32} \mathrm{P}$ from $\left[{ }^{32} \mathrm{P}\right]-\mathrm{NAD}^{+}$to bovine serum albumin (BSA). Shortly after this the group of Danesh Moazed reported that yeast SIR-2 transfers ADP-ribose from NAD ${ }^{+}$to histones, which was thought to mediate gene silencing in yeast [24]. However, the weak 
mono-ADP-ribosyl transferase activities described by both groups were soon attributed to non-enzymatic labeling, since a more robust $\mathrm{NAD}^{+}$-dependent deacetylase activity on acetylated histones was discovered for numerous SIR-2 proteins including yeast, mammals and bacterial CobB [4-6].

$\mathrm{NAD}^{+}$-dependent deacetylase activity has been demonstrated now for the majority of mammalian sirtuins (Table 1-1), except for mammalian SIRT4 where only mono-ADPribosyltransferase activity has been detected [25, 26]. Thus, it is still under debate whether sirtuins exhibit dual activities $\left(\mathrm{NAD}^{+}\right.$-dependent deacetylases and mono-ADPribosyltransferase) or are true deacetylases.

\subsubsection{Catalytic reaction mechanism of $\mathrm{NAD}^{+}$-dependent deacetylation}

The fact that sirtuins require $\mathrm{NAD}^{+}$and catalyze a novel mechanism of histone/protein deacetylation distinguished them from known histone deacetylases and consequently sirtuins were classified as a new HDAC class, i.e. HDAC class III. Whereas class I and class II HDACs remove acetyl groups by hydrolysis, sirtuins catalyze protein deacetylation via an energetically costly mechanism consuming $\mathrm{NAD}^{+}[27]$.

Deacetylation of an acetylated substrate is coupled to hydrolysis of $\mathrm{NAD}^{+}$generating deacetylated lysine, nicotine amide (NAM) and the unique compound O-acetyl-ADP-ribose (O-acetyl-ADPR) (Figure 1-1) [7, 8].
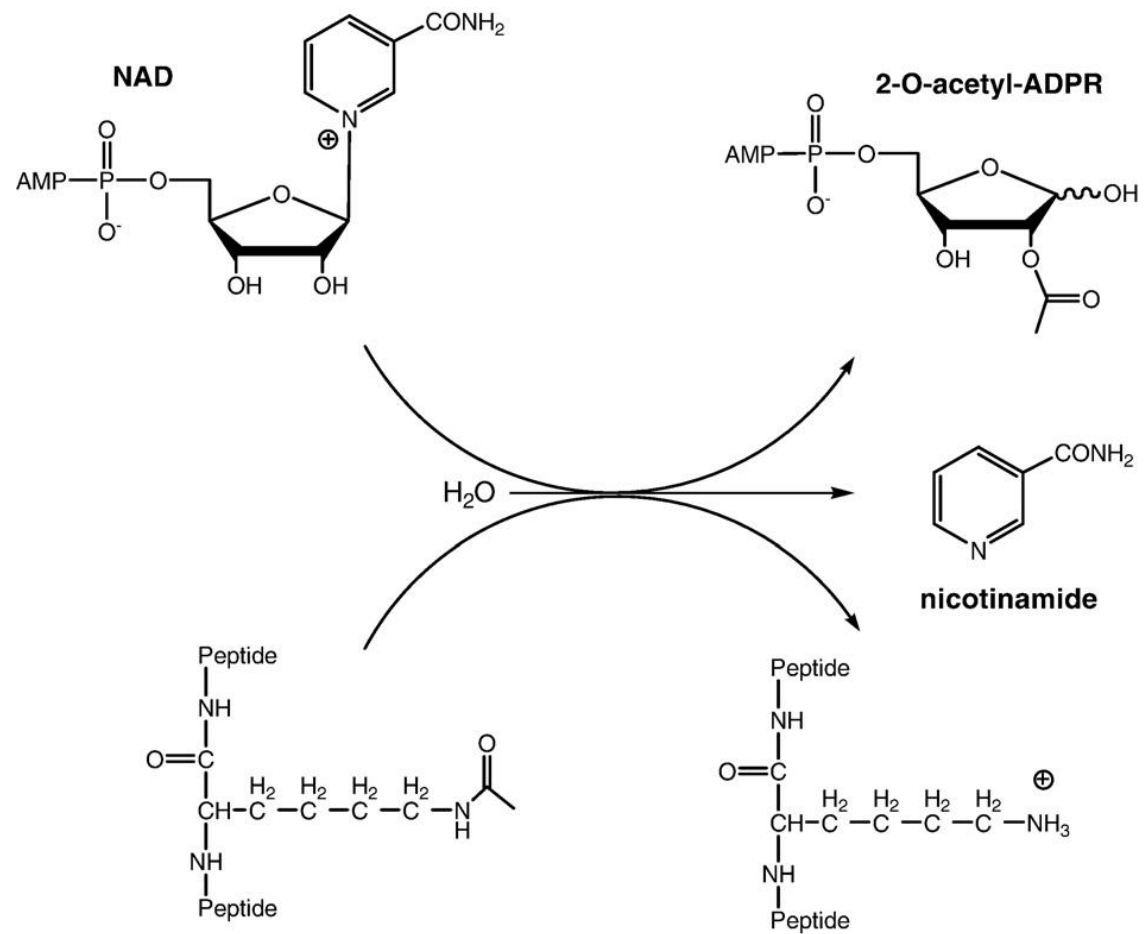

Acetyllysine
Substrate

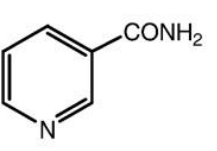

nicotinamide

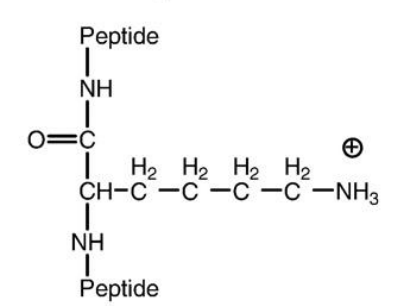

Deacetylated

lysine

Substrate

Figure 1-1: $\mathrm{NAD}^{+}$-dependent protein deacetylation reaction catalyzed by sirtuins.

Deacetylation of an acetyllysine substrate is coupled to hydrolysis of $\mathrm{NAD}^{+}$. The acetyl group is transferred from its substrate to a $\mathrm{NAD}^{+}$cleavage product to form the novel compound O-acetyl-ADP-ribose. Figure taken from [21]. 
A
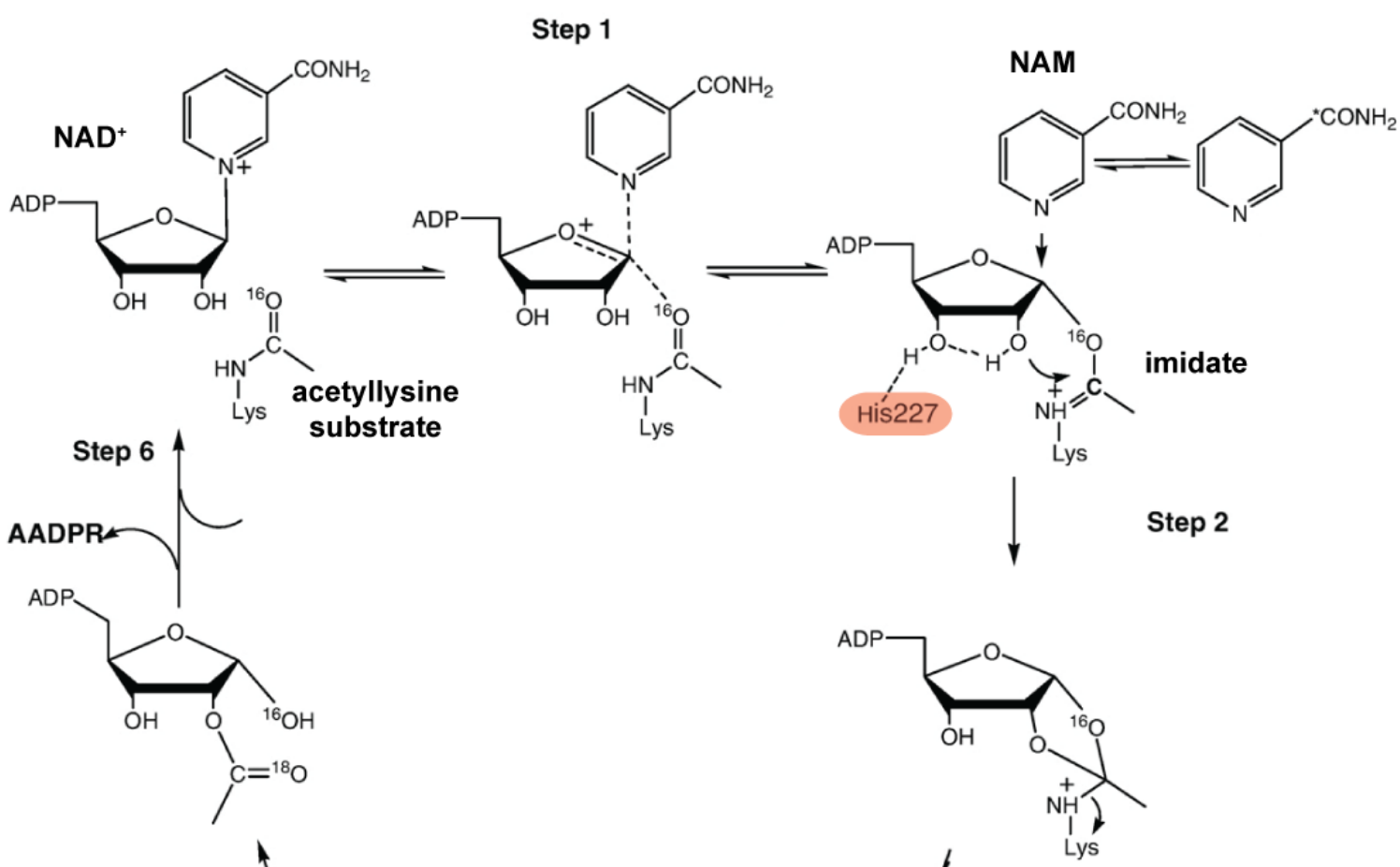

Step 5
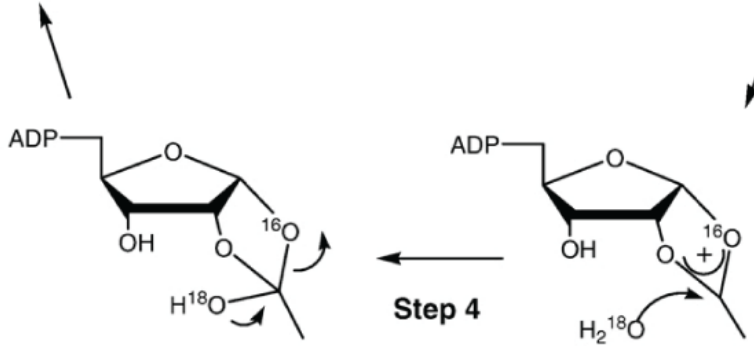

Lys $\mathrm{NH}_{3}+$ Step 3

B

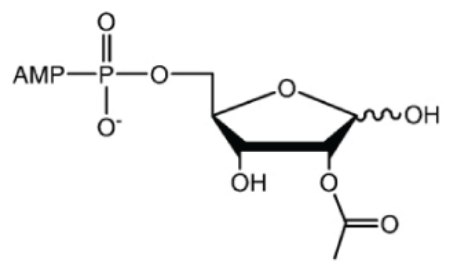

2'-O-acetyl-ADPR

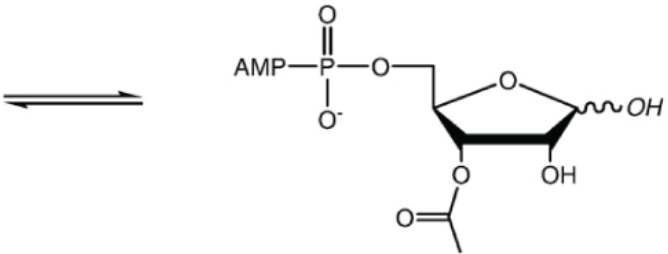

3'-O-acetyl-ADPR

Figure 1-2: Proposed chemical reaction mechanism of $\mathrm{NAD}^{+}$-dependent protein deacetylation catalyzed by sirtuins.

A. The ADPR-peptidyl imidate mechanism proposes that the acetyl oxygen of the bound acetyllysine substrate undergoes a nucleophilic attack of the 1' -carbon of the ADP-ribose moiety of bound $\mathrm{NAD}^{+}$, forming NAM and a peptidyl imidate intermediate (Step 1). In step 2 the activated 2'-hydroxyl of the nicotinamide ribose attacks the imidate carbon generating the 1',2'-cyclic intermediate. Subsequently 2'-O-Acetyl-ADP-ribose (2'-OAADPr) is formed via multiple reaction steps. An active site histidine is shown in red. B. In solution OAADPr interconverts non-enzymatically between 2'-OAADPr and 3'-OAADPr. Figure adapted from [21].

A more detailed mechanism of the proposed deacetylation reaction referred to as ADPRpeptidyl-imidate mechanism is shown in Figure 1-2. After binding of $\mathrm{NAD}^{+}$and the acetyllysine the acetyl oxygen undergoes in the first reaction step a nucleophilic attack of the 1'carbon of the ADP-ribose moiety of $\mathrm{NAD}^{+}$generating NAM and a peptidyl-imidiate, a novel reactive intermediate. Next, the 2'-hydroxyl of the nicotinamide ribose is activated by an active site histidine and attacks the peptidylimidiate carbon generating the 1',2'-cyclic intermediate. Multiple reaction steps including elimination of the deacetylated lysine followed 
by addition of water lead to the formation of 2'-O-Acetyl-ADP-ribose (2'-OAADPr). OAADPr undergoes non-enzymatic interconversions between 2'-OAADPr and 3'-OAADPr after release from the active site [21, 28].

Although $\mathrm{NAD}^{+}$-dependent deacetylation is considered to be the primary enzymatic activity of sirtuins, not all sirtuins exhibit measurable protein deacetylase activity on histone substrates [25, 29]. For SIRT4 [25, 26] and SIRT6 [30] ADP-ribosyltransferase activity, transferring a single ADP-ribosyl group from $\mathrm{NAD}^{+}$to proteins or itself, was reported. Recently SIRT6 proved to be a histone 3 lysine 9 acetyl (H3K9ac)-specific deacetylase [31], implicating that SIRT4 might be as well a true deacetylase with very strict specificity for substrates that have not been identified yet.

Interestingly, some sirtuins such as yeast SIR-2 or the Trypanosoma bruci SIR-2 orthologue TbSIR2rp1 possess both $\mathrm{NAD}^{+}$-dependent protein deacetylase and mono ADPribosyltransferase activity $[4,7,32]$, raising the question whether sirtuins have dual activities. ADP-ribosyltransferase activity was predominantly determined by detecting $\left[{ }^{32} \mathrm{P}\right]$ radiolabeled proteins after incubating them with sirtuins in the presence of $\left[{ }^{32} \mathrm{P}\right]-\mathrm{NAD}^{+}$. As none of the studies provided information on identities of the residues that were specifically ADP-ribosylated and ADP-ribosylation can also occur non-enzymatically [33, 34], the ADPribosyltransferase activity of sirtuins has been doubted. Currently relatively little is known about a potential reaction mechanism, since only few studies have been investigating the exact mechanism in more detail [21, 35-37]. Consistently, all studies reported that sirtuindependent ADP-ribosyltransferase activity is in general very weak compared to the protein deactylase activity $[30,35,36]$. In the case of $T$. brucei SIR-2, it could be shown that to some extend the observed ADP-ribosylation results from non-enzymatic ADP-ribosylation by the deacetylation reaction product O-Acetyl-ADPR or ADPR (generated by hydrolysis of $\mathrm{O}$ Acetyl-ADPR). However, to a larger extend the ADP-ribosylation seemed to be enzymatic via a proposed imidate-dependent reaction mechanism. The nucleophilic attack on the initially formed peptidyl-imidate intermediate (Figure 1-2) is probably intercepted by an exogenous nucleophile, such as the $\varepsilon$-amino of a lysine in the amino acid side chain instead of the acetylated lysine, yielding an ADP-ribosylated protein [35]. As the observed ADPribosylation was five orders of magnitude slower than the deacetylase reaction, it is questionable whether protein ADP-ribosylation by sirtuins is physiologically relevant. Although it is possible that the relative efficiencies not only of $\mathrm{NAD}^{+}$-dependent ADPribosylation but also deacetylation are modulated in vivo by accessory proteins, metabolites or posttranslational modifications in response to changes in cellular energy status or stress [35]. Sirtuin activity is inhibited by its reaction product nicotinamide (NAM) in a non-competitive manner, suggesting that NAM is an endogenous negative regulator of sirtuin activity and prevents intracellular $\mathrm{NAD}^{+}$depletion [5,38]. NAM inhibits the catalytic activity of sirtuins probably via a process termed base exchange. The formed peptidyl-imidate intermediate (Figure 1-2) reacts with NAM reforming $\mathrm{NAD}^{+}$at the expense of deacetylation [39, 40].

$\mathrm{O}-\mathrm{AADPR}$, the reaction product of $\mathrm{NAD}^{+}$-dependent deacetylation, might act as a signaling molecule or serve as a substrate for downstream enzymatic processes [41]. In yeast $\mathrm{O}$ AADPR seems to function in chromatin silencing by binding to SIR-3 and inducing conformational changes that promote the loading of the SIR-2/SIR-3/SIR-4 silencing complex 
onto nucleosomes [42]. In mammals O-AADPR binds to the histone variant macroH2A [43], but apart from that the role of O-AADPR in mammals is still unresolved.

Since sirtuins have been implicated in life span determination, a lot of effort has been put into identifying small molecules and protein interactors modulating sirtuin acitivity. The mechanistic details of sirtuin activation by these factors still need to be resolved [21], but this area of research might provide potent therapeutic agents for treatment of age-associated diseases in the near future.

\subsubsection{Structural properties of sirtuins}

Next to biochemical analyses, determination of the three dimensional structures of several sirtuin proteins has provided important information for understanding the catalytic mechanism, substrate specificity and inhibitory mechanisms of sirtuins [44].

Sirtuin proteins from different organisms all contain a highly conserved catalytic core domain comprising approximately 275 amino acids (shown in multiple sequence alignment in Figure 1-3), but differ highly in length and amino acid composition in their $\mathrm{N}$ - and C-terminal flanking regions $[2,3]$. In agreement, a high degree of structural superposition is found in the crystal structures of the catalytic core domains of different sirtuin proteins (Figure 1-4 A). The catalytic core region folds into two domains, a large domain structurally homologous to a Rossmann-fold domain, and a smaller, zinc-binding domain, which is structurally more diverse. The Rossmann-fold domain, which is commonly found in $\mathrm{NAD}^{+} / \mathrm{NADH}$ binding proteins, features a typical $\mathrm{NAD}^{+}$-binding site comprising a conserved Gly-X-Gly motif for phosphate binding, a pocket for a $\mathrm{NAD}^{+}$molecule, and charged residues for the ribose group binding [45].

The small $\mathrm{Zn}^{2+}$-binding domain is composed of two insertions within the Rossmann-fold domain. One of them contains a conserved $\mathrm{Zn}^{2+}$-binding motif (Cys- $\mathrm{X}_{2-4}-\mathrm{Cys}-\mathrm{X}_{15-40}-\mathrm{Cys}-\mathrm{X}_{2-4}-$ Cys), coordinating a structurally important zinc ion [46]. As the small domain is structurally most diverse among different sirtuins in terms of primary sequence, three dimensional structure and relative position to the large domain, it might have an important function in determination of substrate specificity. In addition, the small $\mathrm{Zn}^{2+}$-binding domain might provide binding sites for small molecules and proteins, modulating the enzymatic activity of sirtuins. It might also influence the subcellular location of sirtuins [44, 45, 47].

The large and the small domain are connected by several loops that form a pronounced, extended cleft. $\mathrm{NAD}^{+}$and the acetyl-lysine containing peptide substrates access the cleft from opposite sides to bind to the enzyme. Deacetylation is catalyzed by conserved amino acid residues and reactive groups of the bound substrate molecules in a hydrophobic tunnel buried in the cleft (Figure 1-4 B). The importance of this region for catalysis is also reflected by the fact that it has the highest sequence conservation within sirtuins (GAGISTSC $\underline{\text { GIPDFR }}$ in Hst2). Indeed, mutation of specific residues in this region disrupts protein deacetylase activity [44]. 


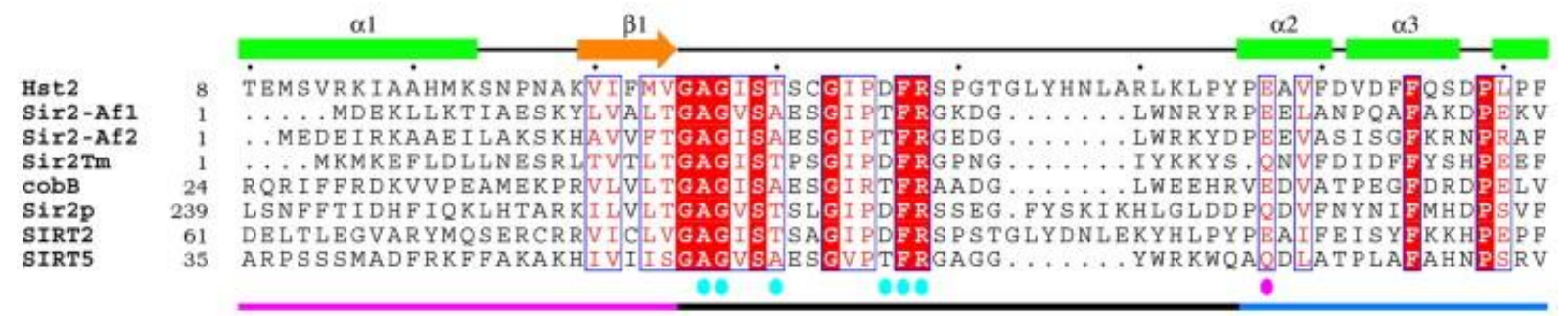

Hat2
Sir2-Af1
Sir2-Af2
Sir2Tm
cobB
Sir2p
SIRT2
SIRT5

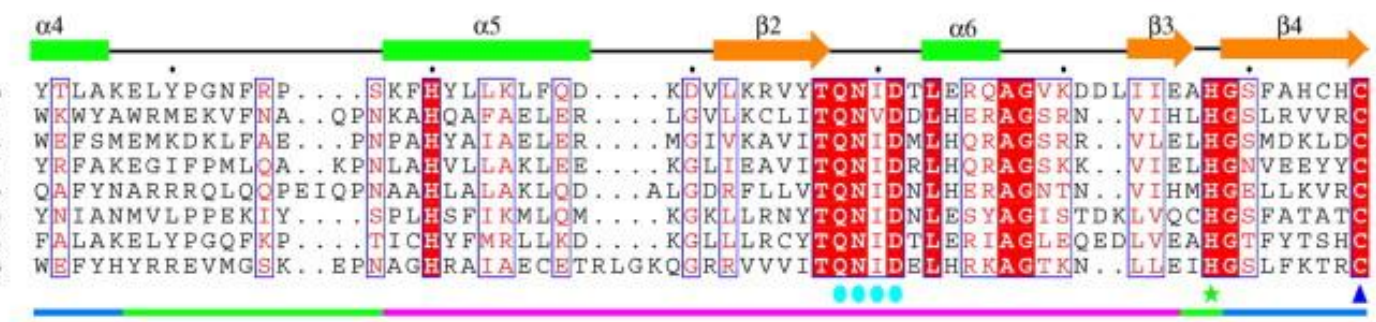

$\begin{array}{ll} & \\ \text { Hst2 } & 144 \\ \text { Sir2-Af1 } & 125 \\ \text { Sir2-Af2 } & 127 \\ \text { Sir2Tm } & 125 \\ \text { cobB } & 156 \\ \text { Sir2p } & 373 \\ \text { SIRT2 } & 197 \\ \text { SIRT5 } & 168\end{array}$
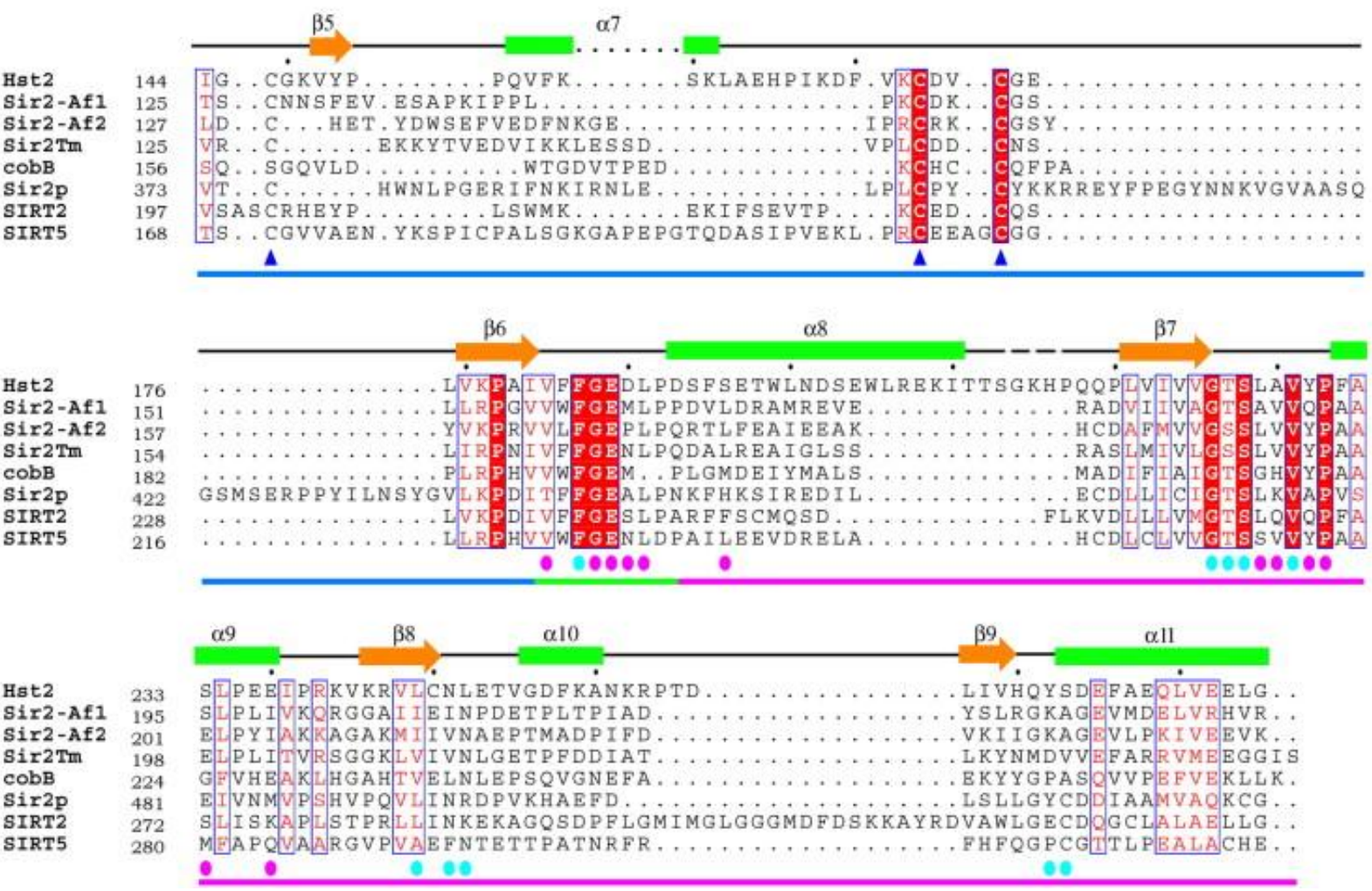

Figure 1-3: Multiple sequence alignment of the catalytic core domain region of sirtuins with known threedimensional structures.

Multiple sequence alignment of S. cerevisiae Hst2 and Sir2p, A. fulgidus Sir2-Af1 and Sir2-Af2, T. maritima Sir2Tm, E. coli CobB, and H. sapiens SIRT2 and SIRT5. Cyan circles mark residues involved in NAD ${ }^{+}$binding, purple circles indicate residues involved in acetyllysine binding, blue triangles label $\mathrm{Zn}^{2+}$-binding residues and a green asterisk marks the highly conserved catalytic histidine residue. Consensus is highlighted by red boxes and white boxes show similarities. Above the sequence alignment secondary structural elements of Hst 2 are shown. Orange arrows: $\beta$ sheets; green rectangles: $\alpha$ helices; black lines: loops; dashed lines: unstructured regions. Beneath the sequence alignment the color of the solid line indicates the Rossmann-fold domain (magenta), cofactor binding loop (black), small domain (blue), and loop regions (green) (also see Figure 1-4). Figure taken from [44]. 
A

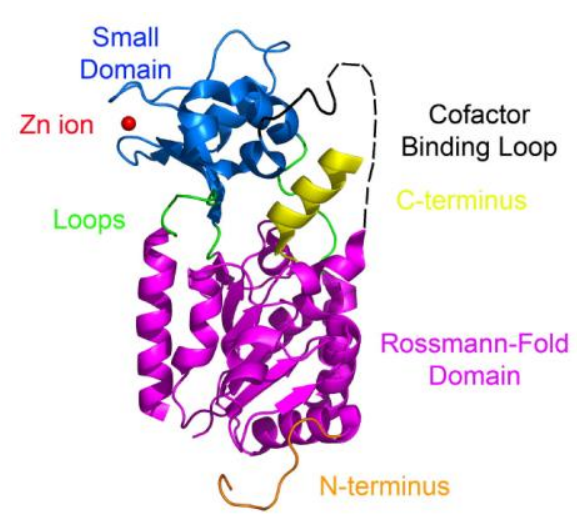

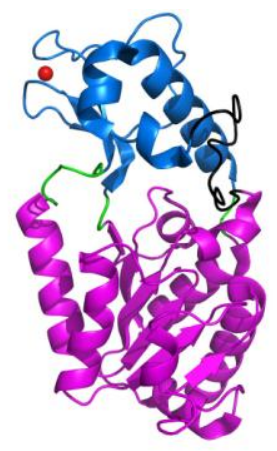

A. fulgidus Sir2-Af1

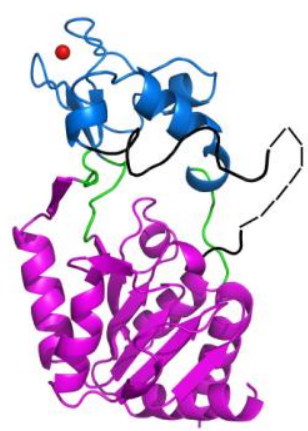

A. fulgidus Sir2-Af2

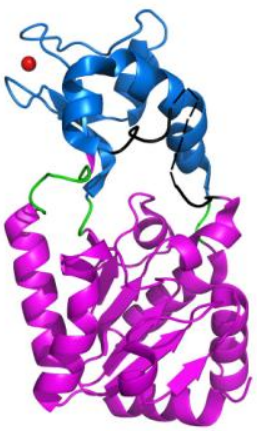

T. maritima Sir2Tm

S. cerevisiae Hst2

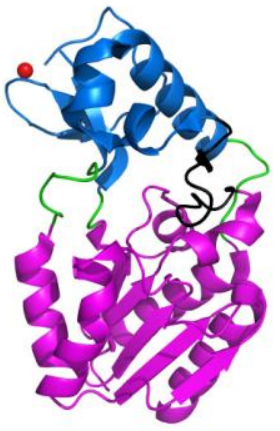

E. coli CobB

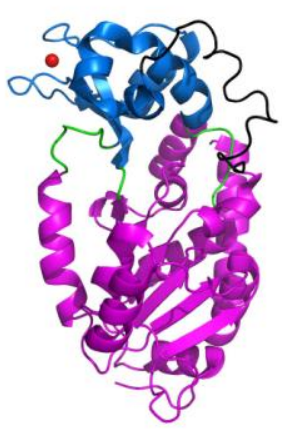

H. sapiens SIRT2

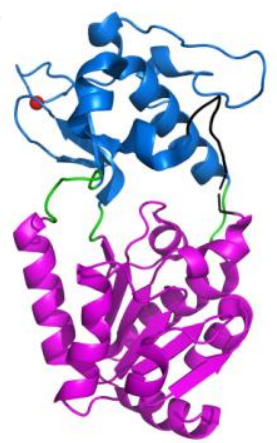

H. sapiens SIRT5

B

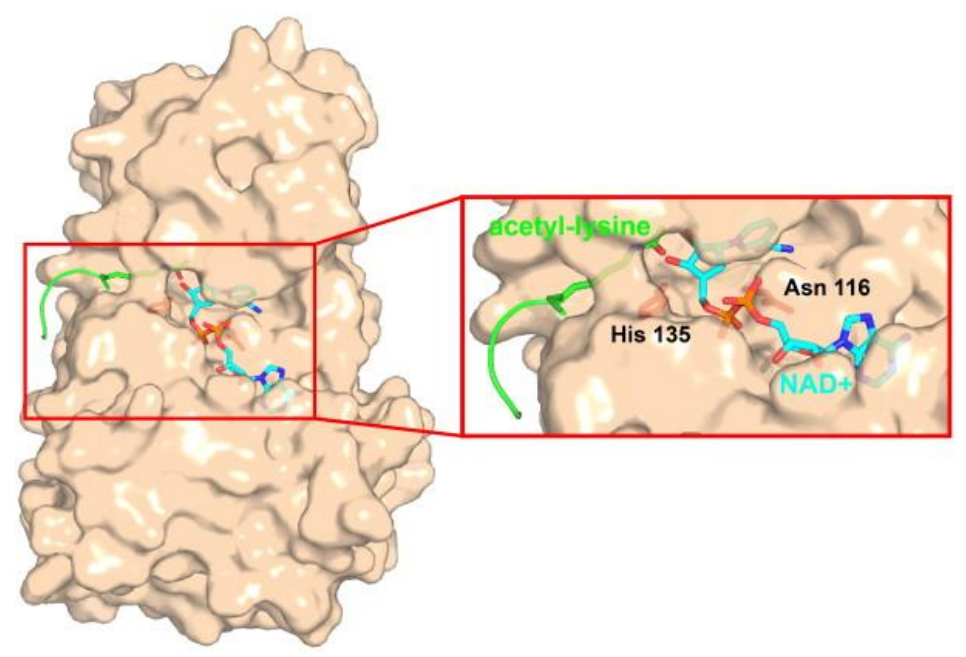

Figure 1-4: Three-dimensional crystal structures of different sirtuins.

A. The three-dimensional structure of each sirtuin is shown in a cartoon representation without bound ligand. The large magenta domain corresponds to the Rossmann-fold domain, the small blue domain to the $\mathrm{Zn}^{2+}$ binding domain, the cofactor binding loop is depicted in black, other loops and the bound $\mathrm{Zn}^{2+}$ ion are shown in green and red, respectively. In the structure of Hst2 the N-terminal (orange) and C-terminal (yellow) regions are also included. B. Active site binding cleft of $S$. cerevisiae Hst 2 shown in tan surface representation. In the close up view the backbone of the peptide substrate is shown in green, the acetyllysine side chain in green cpk stick representation, the conserved $\mathrm{H} 135$ and $\mathrm{N} 116$ in red cpk stick representation, and the bound $\mathrm{NAD}^{+}$in cyan cpk stick representation. Figures taken from [44] 
The catalytic core domain of sirtuins is flanked by $\mathrm{N}$ - and $\mathrm{C}$-terminal regions that are not conserved and vary in length and sequence between different protein family members. Relatively little is known about the function of these regions as they were not included in the majority of determined structures [44]. The structure of full-length yeast Hst 2 showed that the protein forms a homotrimer and the 7 aa long $\mathrm{N}$-terminal region is required for oligomerization. Interestingly, this $\mathrm{N}$-terminal region binds the active side cleft in a similar conformation like an acetyl-lysine containing $\mathrm{H} 4$ peptide substrate. It gets displaced upon addition of acetylated peptide, which also disrupts trimer formation. The C-terminal region of Hst2 (yellow $\alpha$-helical secondary structure in Figure 1-4 A) makes extensive interactions with aa residues within the cleft containing the catalytic core region. It also seems to affect $\mathrm{NAD}^{+}$ binding [48, 49]. As the catalytic core domain is highly conserved among different sirtuins and structures of peptide bound sirtuins provided little information on substrate discrimination, the $\mathrm{N}$-terminal and $\mathrm{C}$-terminal regions might also contribute significantly to substrate specification. However, to fully understand the catalytic mechanism, substrate specificity and inhibition of sirtuins further structural insights need to be complemented with more detailed biochemical analyses.

\subsection{Mammalian sirtuins}

The mammalian SIR-2 gene family named sirtuins (SIRTs) compromises seven members, SIRT1- SIRT7 [3], that all share a conserved sirtuin catalytic core domain. Their variable amino- and carboxyl-terminal extensions mediate diverse subcellular localization and might be also important for regulating their catalytic activity [50] (Table 1-1).

Table 1-1: Diversity of mammalian sirtuins.

\begin{tabular}{|c|c|c|c|c|}
\hline Sirtuin & $\begin{array}{l}\text { Enyzmatic } \\
\text { activity }\end{array}$ & $\begin{array}{l}\text { Subcellular } \\
\text { localization }\end{array}$ & Function & Homologues \\
\hline SIRT1 & Deacetylase & $\begin{array}{l}\text { Nucleus, } \\
\text { (Cytosol) }\end{array}$ & $\begin{array}{l}\text { metabolism (gluconeogenesis, } \\
\text { fatty acid oxidation, cholesterol } \\
\text { regulation, insulin secretion), } \\
\text { differentiation and development, } \\
\text { stress responses and apoptosis }\end{array}$ & $\begin{array}{l}\text { Sir2p }(\text { S. cerevisiae }) \\
\text { Hst1p }(\text { S. cerevisiae }) \\
\text { SIR- } 2.1 \text { (C. elegans }) \\
\text { dSIR2 }(\text { D. melanogaster })\end{array}$ \\
\hline SIRT2 & Deacetylase & $\begin{array}{l}\text { Cytosol } \\
\text { (Nucleus) }\end{array}$ & $\begin{array}{l}\text { tubulin deacetylation } \\
\text { Cell cycle control }\end{array}$ & $\begin{array}{l}\text { Hst2p }(\text { S. cerevisiae }) \\
\text { SIRT2 }(\text { D. melanogaster })\end{array}$ \\
\hline SIRT3 & Deacetylase & Mitochondria & $\begin{array}{c}\text { mitochondrial protein } \\
\text { deacetylation, Acetate } \\
\text { metabolism, ATP production, } \\
\text { fatty-acid oxidation }\end{array}$ & \\
\hline SIRT4 & $\begin{array}{l}\text { ADP- } \\
\text { ribosyltransferase }\end{array}$ & Mitochondria & $\begin{array}{l}\text { insulin secretion } \\
\text { (pancreatic B-cells) }\end{array}$ & $\begin{array}{l}\text { SIR-2.2 }(\text { C. elegans }) \\
\text { SIR-2.3 }(\text { C. elegans }) \\
\text { SIRT4 }(\text { D. melanogaster })\end{array}$ \\
\hline SIRT5 & Deacetylase & Mitochondria & Urea cycle (liver) & \\
\hline SIRT6 & $\begin{array}{l}\text { Deaectylase/ADP- } \\
\text { ribosyltransferase }\end{array}$ & Nucleus & $\begin{array}{c}\text { Genome stability } \\
\text { (Base excision repair), } \\
\text { Telomeric chromatin structure, } \\
\text { NF- } \kappa \mathrm{B} \text { regulation }\end{array}$ & $\begin{array}{l}\text { SIR-2.4 (C. elegans }) \\
\text { SIRT6 (D. melanogaster })\end{array}$ \\
\hline SIRT7 & Deacetylase & $\begin{array}{c}\text { Nucleus } \\
\text { (Nucleolus) }\end{array}$ & rDNA (PolI) transcription & SIRT7 (D. melanogaster) \\
\hline
\end{tabular}


SIRT1, SIRT6 and SIRT7 are predominantly nuclear, SIRT2 is cytoplasmic and SIRT3, SIRT4 and SIRT5 are mitochondrial proteins [51]. In the last ten years most of the sirtuins have been demonstrated to be $\mathrm{NAD}^{+}$-dependent deacetylases and a broad range of different target proteins regulated by sirtuins have been identified.

\subsubsection{The nuclear sirtuins SIRT1, SIRT6, SIRT7}

\subsubsection{SIRT1}

SIRT1 is the best characterized sirtuin as it is evolutionarily closest to the founding member of the sirtuin protein family, yeast SIR-2. Like yeast SIR-2, SIRT1 also functions in epigenetic silencing and chromatin organization by deacetylating acetylated lysine residues of histones (H1K9ac, H1K26ac, H3K9ac, H3K14ac, H4K16ac) [4, 52], but also other chromatin modifying factors such as the histone acetyltransferase p300 [53] or the H3K9me3 methyltransferase Suv39h1 [54]. Moreover, SIRT1 regulates transcription by deacetylating many transcription factors including p53 [55, 56], E2F1 [57], FOXO (Foxo1, Foxo3a, Foxo4) [58-61], NF-кB [62], Hes1 [63], PPAR- $\gamma$ [64], PGC-1 $\alpha$ [65], LXR [66] next to further factors. Based on the broad range of identified substrates, SIRT1 is implicated to function in chromatin organization, cell survival and stress responses, differentiation and development and metabolic regulation.

Most striking is SIRT1's ability to coordinate metabolic pathways in different tissues, facilitating appropriate physiological responses to changes in cellular energy levels and strongly supporting a key role of sirtuins as metabolic sensor (Figure 1-5). Human SIRT1 is expressed in all organs with strong expression in the major metabolic tissues liver, skeletal muscle, adipose tissue, pancreatic $\beta$-cells and brain [51]. In the liver SIRT1 regulates cholesterol flux. During fasting deacetylation of PGC1- $\alpha$ by SIRT1 activates transcription programs promoting fatty acid oxidation and glucose production by enhancing gluconeogenesis and repressing glycolysis in the liver. Mitochondrial fatty acid oxidation is also induced by SIRT1 in skeletal muscle upon fasting. In white adipose tissue, on the other hand, SIRT1 promotes lipolysis and fatty-acid mobilization by binding and repressing the nuclear receptor PPAR- $\gamma$. SIRT1 also modulates the production and secretion of adiponectin, which improves insulin sensitivity. In pancreatic B-cells SIRT1 positively regulates insulin secretion. There is increasing evidence that SIRT1 might have a protective function against type-2 diabetes, as mice overexpressing SIRT1 specifically in the pancreatic B-cells (BESTO) exhibit increased glucose-stimulated insulin secretion and improved glucose tolerance [67]. Interestingly, several SIRT1 activating compounds (including resveratrol and other nonpolyphenolic substances) were shown to improve glucose homeostasis and insulin sensitivity in diet-induced and genetic type-2 diabetes animal models [68-72]. Thus, SIRT1 seems to be a key energy sensor linking $\mathrm{NAD}^{+}$-dependent protein deacetylation to energy metabolism and physiological responses during nutrient deprivation.

Since both resveratrol and SIRT1 orthologs have been shown to extend life span in yeast worms and flies, SIRT1 is also implicated in regulating aging and life-span extending effects of caloric restriction, a dietary regimen of low calorie intake without malnutrition [12, 14-18]. Particularly, SIRT1's potential function in the pathogenesis of age-associated diseases has 
generated a lot of interest in developing sirtuin-targeted therapies to treat these metabolic disorders and to improve life quality.

Whereas the nuclear protein SIRT1 is quite well characterized, relatively little is known about the other mammalian sirtuin homologues.

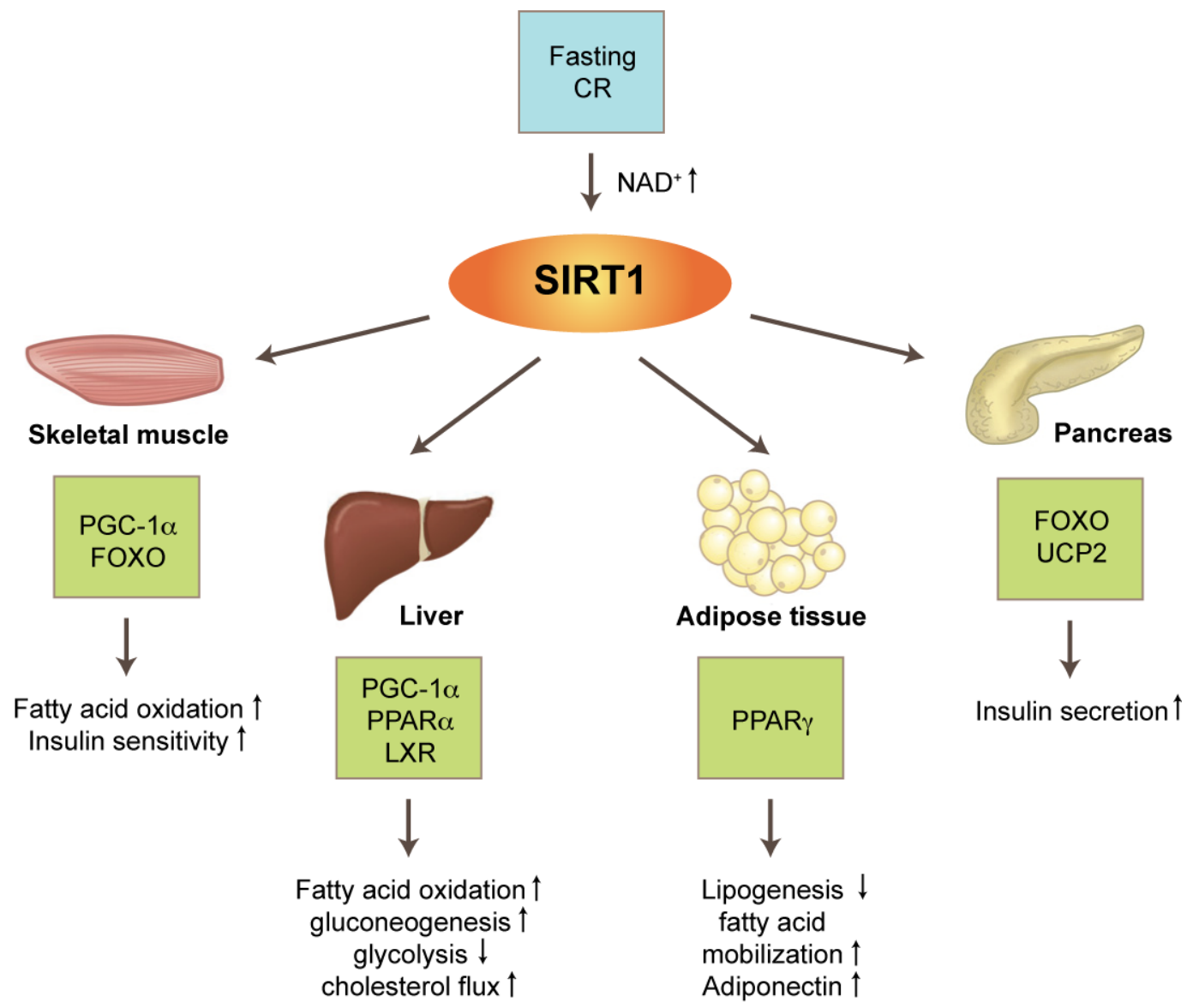

Figure 1-5: Tissue-specific regulation of metabolism by SIRT1.

Fasting or caloric restriction (CR) lead to an increase in intracellular NAD ${ }^{+}$levels activating SIRT1. In the skeletal muscle, SIRT1 promotes fatty acid oxidation and improves insulin sensitivity via PGC-1 $\alpha$ and FOXO. In the liver, SIRT1 upregulates fatty acid oxidation, glucose synthesis, cholesterol flux and downregulates glycolysis through PGC-1 $\alpha$, PPAR $\alpha$ and LXR. In adipose tissue (white adipose tissue), SIRT1 decreases lipogenesis and induces fatty acid mobilization by repressing PPAR $\gamma$ function. In the pancreas (pancreatic $\beta-$ cells) SIRT1 stimulates insulin secretion through FOXO and suppression of UCP2. Tissue icons taken from [25].

\subsubsection{SIRT6 and SIRT7}

SIRT6 and SIRT7 are also nuclear proteins but show different subnuclear localization compared to SIRT1. SIRT6 is highly associated with heterochromatic regions and SIRT7 is enriched in nucleoli.

SIRT6, which was initially described as a mono ADP-ribosyltransferase [30], functions primarily as a histone deacetylase specific for H3K9ac [31] and H3K56ac [73], maintaining telomere integrity and genome stability. Consistently, SIRT6 deficient mice show increased cellular sensitivity to genotoxic stress with defects in base excision repair (BER), a dramatically shortened life span and numerous progeroid and aging-like phenotypes [74]. 
Interaction of SIRT6 with the RelA/p65 component of the NF- $\kappa B$ complex represses NF- $\kappa \mathrm{B}$ target genes. Increased NF- $\kappa B$ transcription seems to contribute to the premature aging-like phenotype and degenerative symptoms observed in SIRT6 knockout mice [75]. Loss of SIRT7 also results in a reduced life span. SIRT7-deficient mice develop progressive cardiac hypertrophy along with inflammation and reduced stress resistance. SIRT7 seems to maintain tissue homeostasis in part by deacetylating p53 [76]. Moreover, SIRT7 interacts with RNA polymerase I and positively regulates rDNA transcription [77]. As SIRT1 also regulates p53 [78] and RNA polymerase I transcription [79], both sirtuins might act together. However, this needs to be further investigated.

\subsubsection{The cytoplasmic sirtuin SIRT2}

SIRT2 is predominantly located in the cytoplasm, but translocates to the nucleus during G2 to M transition [80, 81]. Various findings indicate that SIRT2 functions in controlling cell cycle progression. Overexpression of SIRT2 inhibits cell division in star fish oocytes [82] and SIRT2 expression is downregulated in different cancer types including gliomas, gastric carcinomas and melanomas [83-85]. Deacetylation of $\alpha$-tubulin [29] and H4K16ac prior to mitosis [81] might also contribute to cell cycle regulation. Impaired microtuble stability and cytoskeleton organization due to SIRT2-mediated $\alpha$-tubulin deacetylation has been implicated in promoting neuron degeneration and inhibition of oligodendrocyte differentiation [86-88]. In addition, SIRT2 is upregulated in white adipose tissue during caloric restriction (CR) and inhibits adipocyte differentiation by deacetylating FOXO1 [89, 90]. This further supports a critical role of sirtuins as energy sensors and key regulators of metabolic pathways in response to nutrient deprivation.

\subsubsection{The mitochondrial sirtuins SIRT3, SIRT4, SIRT5}

\subsubsection{SIRT3}

Among the mitochondrial sirtuins SIRT3 is currently the best characterized. SIRT3 is targeted to the mitochondrial matrix and possesses full protein deacetylase activity after proteolytic processing of the mitochondrial targeting sequence [91-93]. Both human and mouse SIRT3 are found in an approximately $44 \mathrm{kD}$ long form (containing $\mathrm{N}$-terminal mitochondrial targeting sequence) and a $28 \mathrm{kD}$ short form. As full-length SIRT3 was also reported to be present in the nucleus and cytoplasm [94-96], controversy has arisen regarding its subcellular localization. It cannot be excluded that a small fraction of SIRT3 might be also present outside mitochondria.

In humans and mice SIRT3 is ubiquitously expressed with highest levels in metabolically active tissues, such as brown adipose tissue, muscle, liver, kidney, heart, and brain [91-93, 97]. Mice lacking SIRT3 are viable and fertile, and do not exhibit any obvious developmental or metabolic phenotype under normal physiological conditions [92]. However, SIRT3 deficient mice display significantly increased lysine acetylation of mitochondrial proteins [92]. There is growing evidence that lysine acetylation is an important posttranslational modification regulating mitochondrial energy metabolism and stress responses [98-100]. Notably, no differences in global protein acetylation levels were detected in SIRT4 and 
SIRT5 null mice, suggesting that SIRT3 is the major protein deacetylase in mitochondria [92]. Nevertheless, only few SIRT3 substrates are known yet.

The first identified substrate of SIRT3 was the mitochondrial matrix protein acetyl-coenzyme A synthetase 2 (AceCS2), which forms acetyl-CoA from acetate, coenzyme A (CoA) and ATP (Figure 1-6) [101, 102]. Deacetylation of AceCS2 by SIRT3 upregulates its enzymatic activity. Increased AceCS2 activity is required during ketogenic conditions such as prolonged fasting or diabetes. AceCS2 is absent in liver, where acetate is released during fasting conditions, and abundant in the energy-expending tissues heart and muscle, where it converts acetate to acetyl-CoA for ATP production through the TCA cycle [103]. SIRT3 also regulates subunits of the electron transport chain and promotes mitochondrial ATP production by deacetylating several subunits of complex I [104], succinate dehydrogenase flavoprotein (SdhA) (subunit of complex II) [105], and ATP synthase alpha and beta subunits [105]. In addition, SIRT3 was shown to deacetylate and regulate the activity of isocitrate dehydrogenase 2 (IDH2), a key regulatory enzyme of the TCA cycle, as well as glutamate dehydrogenase (GDH), which is important for amino acid catabolism and anaplerosis [106]. Consistent with these findings reduced basal ATP levels were observed in heart, kidney, and liver of SIRT3 null mice [104]. However, SIRT3 knockout mice do not show any other obvious metabolic abnormalities under normal physiological conditions. There is growing evidence that SIRT3 function is important during metabolic stress conditions, e.g. fasting and caloric restriction. SIRT3 expression is upregulated during both starvation (liver and brown adipose tissue) [107] and caloric restriction (brown and white adipose tissue) [97]. SIRT3 knockout mice show defects in adaptive thermogenesis during fasting but not under the fed state $[92,107]$. Reduced cold tolerance of starved SIRT3 null mice was recently shown to be caused by defects in B-oxidation of fatty acids. Deacetylation of long-chain acyl coenzyme A dehydrogenase (LCAD) by SIRT3 promotes fatty acid expenditure during fasting [107]. In summary, all these studies emphasize a central role of SIRT3 in regulating mitochondrial energy metabolism.

Besides this, SIRT3 has been implicated to function in mitochondrial stress responses and aging. In response to genotoxic stress both SIRT3 and SIRT4 are required for nicotinamide phosphoribosyltransferase (NAMPT)-mediated protection against cell death. Genotoxic stress or nutrient restriction upregulates the $\mathrm{NAD}^{+}$biosynthetic enzyme NAMPT, boosting mitochondrial $\mathrm{NAD}^{+}$levels and thereby facilitating this protection [108]. Moreover, SIRT3 was recently shown to act as tumor suppressor. In response to genotoxic and metabolic stress significantly increased reactive oxygen species (ROS) levels were observed in SIRT3 deficient mouse embryonic fibroblast (MEF) cells, which provided a tumor permissive environment in mammary gland cells [109].

SIRT3 might also be involved in life span determination. Genetic studies have linked polymorphisms in the SIRT3 gene to extended life span in male humans [110, 111].

\subsubsection{SIRT4}

SIRT4 is a mitochondrial matrix protein that is ubiquitously expressed. In human and in mice highest expression of SIRT4 is observed in major metabolic tissues including pancreatic beta cells, brain, liver, kidney and heart, and moderate expression of SIRT4 is found in skeletal 
muscle $[25,26,51]$. In contrast to SIRT3 no $\mathrm{NAD}^{+}$-dependent protein deacetylase activity could be demonstrated for SIRT4 so far. But SIRT4 seems to exhibit ADP-ribosyltransferase activity $[25,26]$. Only one SIRT4 substrate has been identified until now. SIRT4 interacts and down-regulates the activity of the mitochondrial matrix enzyme glutamate dehydrogenase (GDH) via ADP-ribosylation (Figure 1-6) [25]. GDH, converting glutamate into $\alpha-$ ketoglutarate and ammonia, plays an important role in generating ATP (through the TCA cycle) to promote insulin secretion in pancreatic islet cells [112]. Consistent with these findings, SIRT4 deficient mice show significantly increased blood insulin levels compared to wild type mice fed ad libitum or fasted overnight. Both GDH activity and insulin secretion in response to glucose and amino acids were higher in pancreatic islets isolated from SIRT4 knockout mice [25]. SIRT4 overexpression, on the other hand, suppressed insulin secretion in insulinoma cells [26], further supporting the function of SIRT4 as negative regulator of insulin secretion, which might also protect against diabetes. Furthermore, SIRT4 was reported to interact with insulin-degrading enzyme (IDE) and adenine nucleotide translocator 2 (ANT2/3) [26]. Since no enzymatic activity of SIRT4 on these proteins has been reported, the functional relevance of this interaction still needs to be determined. Interestingly, both IDE and ANT2 are implicated in the pathogenesis of type- 2 diabetes. As loss of SIRT4 might contribute to diabetes, the physiological function of SIRT4 in pancreatic islets but also in other tissues needs to be further analyzed. Moreover, additional SIRT4 substrates need to be identified for a more comprehensive understanding of the physiological role of SIRT4 under normal and pathological conditions. This may also allow to ultimately clarify whether SIRT4 solely acts as ADP-ribosyltransferase or possesses $\mathrm{NAD}^{+}$-dependent protein deacetylase activity with very strict substrate specificity as well.

\subsubsection{SIRT5}

SIRT5 is localized to the mitochondrial matrix and exhibits $\mathrm{NAD}^{+}$-dependent protein deacetylase activity. In contrast to SIRT3, SIRT5 possesses only weak deactylase activity on acetylated histones and BSA [47, 113]. However, robust enzymatic activity could be recently demonstrated on carbamoyl phosphate synthetase 1 (CPS1), the first identified substrate of SIRT5 (Figure 1-6) [114]. CPS1 catalyzes the first and rate-limiting step in the urea cycle $[115,116]$. Deacetylation by SIRT5 increases CPS1 activity and promotes ammonia detoxification, which is important e.g. during fasting when amino acids have to be utilized as energy source generating excess ammonia [116, 117]. Accordingly, fasting leads to an activation of SIRT5 and results in severe hyper-ammonemia in SIRT5 deficient mice, demonstrating an important protective role of SIRT5 in adaption to food limitation [114]. SIRT5 was also reported to interact with cytochrome c, which is localized to the intermembrane space [106]. Although SIRT5 was shown to be targeted to the intermembrane space after overexpression or after mitochondrial import in vitro [96, 106], endogenous SIRT5 was exclusively present in the matrix of liver mitochondria [114]. Therefore, cytochrome c might not be a physiological substrate of SIRT5. Identification of novel SIRT5 substrates will provide more insights into mechanisms and pathways regulated by this sirtuin in order to adapt to food scarcity. 


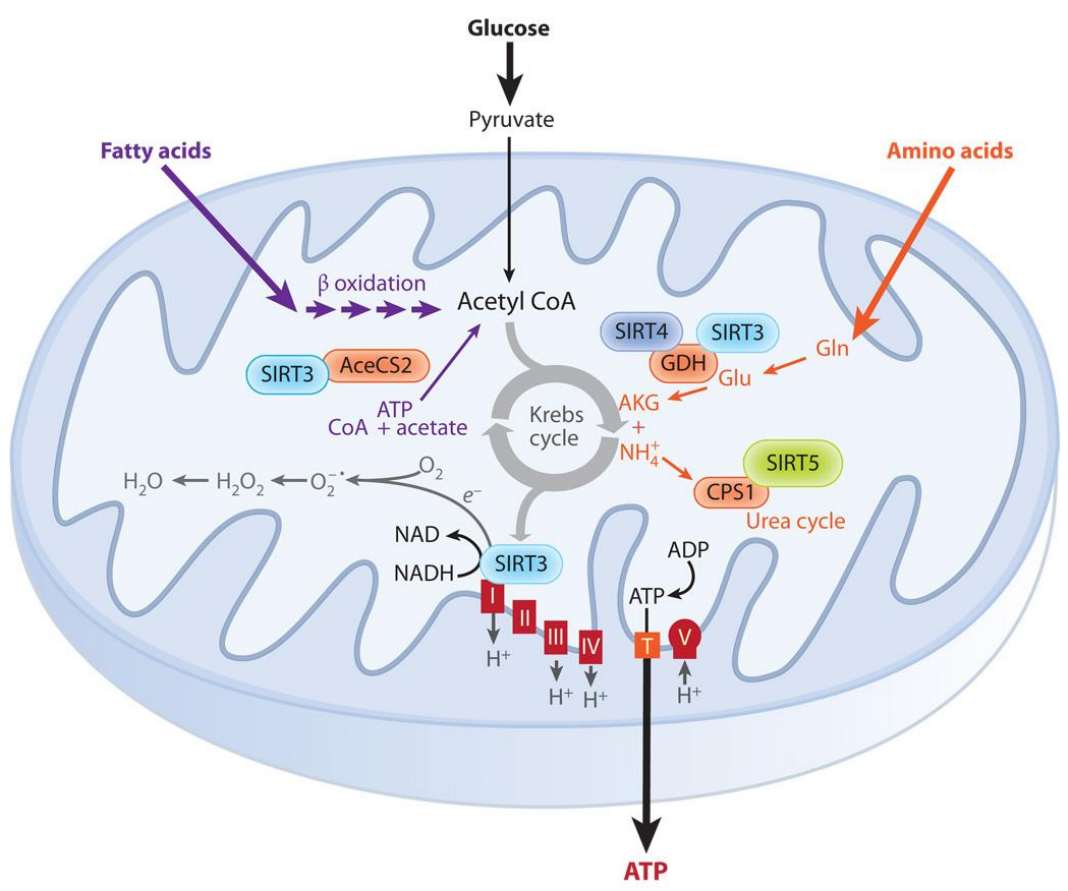

Figure 1-6: Metabolic functions of mitochondrial sirtuins.

Mitochondria are the central organelle for metabolism of fuels such as pyruvate (derived from glucose) fatty acids, and amino acids. SIRT3 regulates mitochondrial ATP production by deacetylating metabolic enzymes such as AceCS2 and complex I subunits. SIRT4 represses GDH activity by ADP-ribosylation and SIRT5 regulates the urea cycle by deacetylating CPS1. Figure taken from [19]

\subsection{Caenorhabditis elegans sirtuins}

Knowledge on SIR-2 protein function in lower eukaryotes such as yeast provided key insights into the biological pathways regulated by mammalian sirtuins. Whereas in lower eukaryotes the biological role of sirtuins is reasonably well understood, their function in simple multicellular organisms such as $C$. elegans has remained elusive.

C. elegans is well suited to study the function of sirtuins and aging-related processes. In contrast to mammals, the genome of $C$. elegans possesses only four sir-2 gene variants, sir2.1 (R11A8.4), sir-2.2 (F46G10.7), sir-2.3 (F46G10.3) and sir-2.4 (C06A5.11). All variants exhibit high sequence similarity to mammalian sirtuins (Table 1-2) [3]. Moreover, C. elegans has a relatively short life span of about two to three weeks and a rapid generation time of approximately 3.5 days $\left(\right.$ at $20^{\circ} \mathrm{C}$ ). The entire cell lineage is relatively invariant and has been traced from single-celled zygote to adult [118]. The ability of generating mutant and transgenic worms as well as the ease of RNAi have made $C$. elegans a powerful system to analyze gene functions [119].

So far, relatively little is known about the functions of $C$. elegans sirtuins. The vast majority of the studies have focused on the role of SIR-2.1 in life span determination, after sir-2.1 was identified as longevity factor in a genetic $C$. elegans screen [15].

SIR-2.1 is evolutionarily closest to yeast SIR-2 and mammalian SIRT1. Extra copies of the sir-2.1 gene lead to an increase in C. elegans life span by up to 50\% [15]. SIR-2.1 seems to extend life span by multiple pathways. One pathway depends on DAF-16, a forkhead 
transcription factor of the FOXO family, which is negatively regulated by the conserved insulin/IGF-1 pathway [15]. Instead of a direct function in the insulin/IGF-1 pathway, recent studies indicate that SIR-2.1 acts in a parallel pathway, which converges on the level of DAF16 regulation. 14-3-3 proteins (C. elegans PAR-5 and FTT-2), which are known to bind FOXO transcription factors in mammals, were identified as interaction partners of SIR-2.1. These seem to be required for SIR-2.1-induced activation of DAF-16 and stress resistance [120, 121]. Recently, SIR-2.1 was also reported to be required for life span extension by calorie restriction $(\mathrm{CR})$ that does not depend on DAF-16, but the exact mechanism has not been determined yet [122].

SIR-2.1 localizes predominantly to the cell nucleus [122] and was shown to exhibit histone deacetylase activity [18]. Like its yeast and mammalian counterparts, SIR-2.1 functions in chromatin regulation and is involved in chromatin silencing of repetitive transgenes in the germline of $C$. elegans by a mechanism similar to SIR-2-dependent silencing of telomeres in yeast [123]. In addition, SIR-2.1 induces (next to the chromatin modifying C. elegans Polycomb group proteins (Mes-2, Mes-3, Mes-4, and Mes-6)) a partial cytoplasmatic localization of the linker histone HIS-24 (H1.1) in the germline [124]. Moreover, both SIR2.1 and HIS-24 associate with subtelomeric regions, promote the modification of H3K27me3 and $\mathrm{H} 3 \mathrm{~K} 9 \mathrm{me} 3$ and have synthetic effects on brood size, embryogenesis and fertility in $C$. elegans [125].

SIR-2.1 also functions in stress responses and was shown to be essential in DNA damage and repair signaling in the $C$. elegans germline. Translocation of SIR-2.1 from the nucleus to the cytoplasm and colocalization with the $C$. elegans Apaf-1 homologue CED-4 seems to induce a novel proapoptotic pathway of DNA-damage-induced apoptosis, which is independent of CEP-1 (C. elegans P53-like protein) and DAF-16 [126]. In neurons SIR-2.1 overexpression was shown to promote cell survival and protect against huntingtin polyglutamine [127] and prion neurotoxicity [128]. These studies further demonstrate a neuroprotective function of sirtuins and implicate a promising therapeutic potential of sirtuin activity modulators for treatment of neurodegenerative diseases.

Currently the analysis of $C$. elegans sirtuins has been focused on SIR-2.1, whereas the other three variants have been neglected and still need to be characterized.

SIR-2.2 and SIR-2.3 are most homologous to mammalian SIRT4 [3] and might be also mitochondrial proteins. A genome wide RNAi screen identified SIR-2.2 together with many chromatin related factors, DNA repair/replication proteins, and cell cycle/checkpoint proteins, to be required for genome stability in somatic and germline cells [129]. Next to SIR-2.1, SIR2.2 was also able to protect $C$. elegans from neurodegeneration [127], suggesting that SIR-2.2 might function in the nucleus or cytoplasm. However, both SIR-2.2 and SIR-2.3 do not seem to function in life span extension $[15,130]$. Moreover, no changes in life span were observed in worms overexpressing SIR-2.4, which is evolutionarily closest to mammalian SIRT6 [15]. As in the case of SIR-2.2 and SIR-2.3 the biological function of SIR-2.4 remains elusive. 
Table 1-2: Diversity of $C$. elegans SIR-2 proteins.

\begin{tabular}{lccc}
\hline SIR-2 variant & Function & Substrates & Homology \\
\hline SIR-2.1 & $\begin{array}{c}\text { Life span determination, } \\
\text { Chromatin silencing/regulation, } \\
\text { DNA-damage induced apoptosis, } \\
\text { protection against neurodegeneration }\end{array}$ & Histones, 14-3-3 & SIRT1 \\
SIR-2.2 & $\begin{array}{c}\text { Genome stability, } \\
\text { protection against neurodegeneration }\end{array}$ & $?$ & SIRT4 \\
SIR-2.3 & $?$ & $?$ & SIRT4 \\
SIR-2.4 & $?$ & $?$ & SIRT6 \\
\hline
\end{tabular}

\subsection{Modulation of sirtuin activity by $\mathrm{NAD}^{+}$metabolism}

Sirtuins were classified into a new class of HDACs (class III) because of their unique requirement of $\mathrm{NAD}^{+}$as cofactor for protein deacetylation. $\mathrm{NAD}^{+}$and its reduced form $\mathrm{NADH}$ are essential redox carriers, coupling the metabolism of biomolecules to ATP synthesis though the respiratory chain [131]. Therefore, the $\mathrm{NAD}^{+} / \mathrm{NADH}$ ratio is a key indicator of the cellular energy status and sirtuins, that are absolutely depending on $\mathrm{NAD}^{+}$as cofactors for enzymatic activity, have become important sensors of the cellular metabolic state [132].

There is growing evidence that $\mathrm{NAD}^{+}$biosynthetic pathways are critical regulators of sirtuin activity. Genetic studies in yeast have linked changes in $\mathrm{NAD}^{+}$metabolism to sirtuin activity, as deficiencies in the $\mathrm{NAD}^{+}$synthesis salvage pathway decrease SIR-2-mediated chromatin silencing $[6,133,134]$, and increased $\mathrm{NAD}^{+}$synthesis enhances silencing of SIR-2-regulated gene loci and life span extension [134].

In addition, there is growing evidence that metabolic stress such as prolonged fasting or caloric restriction $(\mathrm{CR})$ induces $\mathrm{NAD}^{+}$biosynthetic pathways increasing intracellular $\mathrm{NAD}^{+}$ levels $[108,114]$ and thereby upregulates sirtuin activity. In C. elegans overexpression of the nicotinamidase PNC-1, the first enzyme in the $\mathrm{NAD}^{+}$salvage pathway of invertebrates, increases survival of $C$. elegans during oxidative stress in a SIR-2.1 dependent manner [135]. In mammals genotoxic stress and nutrient restriction upregulates NAMPT (catalyzing the first and rate-limiting step in $\mathrm{NAD}^{+}$biosynthesis in vertebrates) and boosts mitochondrial $\mathrm{NAD}^{+}$ levels. Increased mitochondrial $\mathrm{NAD}^{+}$promotes cell survival and requires not only an intact mitochondrial $\mathrm{NAD}^{+}$salvage pathway but also SIRT3 and SIRT4 [108]. Interestingly, this protective function depends only on physiological $\mathrm{NAD}^{+}$levels in mitochondria, but not in the cytoplasm and nucleus, suggesting that mitochondria dictate cell survival. Sirtuins and functional homologs of NAMPT are also present in prokaryotes [6]. The protective function of $\mathrm{NAD}^{+}$for cell survival seems to be evolutionarily conserved and to induce ancient survival responses, as increased $\mathrm{NAD}^{+}$levels also provide bacterial survival to heat, salt stress, and glucose restriction [136].

Sirtuin activity is inhibited by its reaction product NAM in a non-competitive manner, indicating that the catalytic activity of sirtuins is negatively regulated by intracellular NAM concentrations [38, 137, 138]. Notably, NAM is an agent with therapeutic potential as it was 
shown to prevent type I diabetes, neurotoxicity and tissue damage in ischemia [132, 139, 140]. Nicotinamide (at high dose) seems to function by enhancing $\mathrm{NAD}^{+}$biosynthesis and increasing $\mathrm{NAD}^{+}$pools $[141,142]$.

$\mathrm{NAD}^{+}$biosynthesis pathways and sirtuins are intimately connected and critical components in a regulatory network that contributes to metabolic robustness in response to nutritional and environmental cues that affect cell survival, tissue functionality, and ultimately life span. Therefore, next to drugs targeting sirtuins, $\mathrm{NAD}^{+}$intermediates (nutriceuticals) promoting $\mathrm{NAD}^{+}$biosynthesis and indirectly affecting sirtuin activity may be beneficial for treatment of age-associated diseases such as diabetes and neurodegenerative diseases [143].

\subsection{Reversible mitochondrial protein acetylation}

Mitochondria are the central organelle for important physiological processes including cellular energy (ATP) production, fatty acid and amino acid metabolism, biosynthesis of heme, pyrimidines and steroids, ion homeostasis, and apoptosis [144]. Mitochondria are also the major site for generation of reactive oxygen species (ROS) as a byproduct of oxidative phosporylation, which damage macromolecules and can cause mitochondrial defects and dysfunction. Mitochondrial function must therefore be tightly linked to nutrient availability and be able to adapt to oxidative stress in order to avoid imbalances in metabolic homeostasis. Notably, defects in mitochondrial functions have been implicated in aging and age-associated diseases such as diabetes, neurodegenerative disorders, cardiovascular diseases and cancer [145].

Protein lysine acetylation is emerging to be a key posttranslational modification in regulating metabolic enzymes [98, 99, 146, 147]. Global proteomic approaches employing immunoaffinity purification of lysine-acetylated, tryptic peptides with anti-acetyllysine-specific antibodies and subsequent mass spectrometric analyses have shown that at least $20 \%$ of mitochondrial proteins are acetylated. Acetylation sites were identified in mitochondrial proteins of all major pathways of intermediate metabolism, including the tricarboxylic acid (TCA) cycle, oxidative phosphorylation, $\beta$-oxidation and the urea cycle. In addition, mitochondrial channel proteins, proteins acting in amino acid, carbohydrate and nucleotide metabolic pathways and antioxidant defense pathways are acetylated [98, 99, 146]. There is growing evidence that mitochondrial protein acetylation is dynamic, as it changes during fasting and calorie restriction and is an important posttranslational modification to regulate the catalytic activity of metabolic enzymes [98, 146, 148].

Mitochondria are double-membrane organelles that are derived from a eubacterial endosymbiont and still share many features with their prokaryotic ancestors [149]. Recent studies showed that lysine acetylation is also an abundant posttranslational modification in prokaryotic cells (E. coli) $[100,147,150]$. In these studies, more than $50 \%$ of the identified acetylated proteins are metabolic enzymes. A large number of proteins were lysine-acetylated orthologs between E. coli and mammals, suggesting an evolutionarily conserved function of lysine acetylation in energy metabolism, but also translation and stress responses from bacteria to mammals. Exposure to hypoxia (but not starvation) led to changes in acetylation 
levels intimately linking reversible protein acetylation to regulatory mechanisms that allow cells to adjust to changes in cellular environment [50, 100].

The identification of lysine-acetylation as an abundant post-translational modification in mitochondria and sirtuins as mitochondrial deacetylases raises an interesting question. Are there mitochondrial lysine acetyltransferases? Up to now this question remains unresolved, as no mitochondrial protein acetyltransferase has so far been identified in mammals.

In Salmonella enterica the enzymatic activity of actyl-CoA synthetase is regulated by acetylation through Pat [151], the only known bacterial acetyltransferase, and deacetylation through CobB, a bacterial SIR-2 homolog [152]. Interestingly, both human SIRT2 and yeast SIR-2 can substitute CobB function in CobB-deficient $S$. enterica strains, suggesting an evolutionarily conserved function of sirtuins in regulating cellular metabolism [153]. No orthologs of Pat have been found in mammalian cells and it is also not known whether there are other mitochondrial acetyltransferases existing in mammals [50]. However, the observation that proteins encoded by mitochondrial DNA, e.g. the ATP synthase $\mathrm{F}_{0}$ subunit 8 , are acetylated, argues against the possibility that lysine acetylation of mitochondrial proteins occurs in the cytoplasm prior to import, but not within mitochondria. It is therefore anticipated that there are also acetyltransferases existing in the mammalian mitochondrion [50]. Since it cannot be excluded that mitochondrial proteins also become acetylated in a nonenzymatic manner [154, 155], some acetylation sites of mitochondrial proteins might not have regulatory functions.

Taken together, these findings show that lysine acetylation is intimately linked to energy metabolism and stress responses in mitochondria. The mitochondrial sirtuins SIRT3, SIRT4 and SIRT5, requiring $\mathrm{NAD}^{+}$for deacetylation, are potential energy and stress sensors and seem to contribute to coordination and regulation of mitochondrial energy homeostasis. Thus, identification of further sirtuin substrates as well as mitochondrial acetyltransferase will be crucial for a comprehensive understanding of the functional importance of protein lysine acetylation in mitochondria.

\subsection{Open questions and objective of this PhD thesis}

Sirtuin research has created an exciting field and revealed intriguing connections between protein acetylation and regulation of metabolic pathways, stress responses and life span [20]. The mammalian sirtuin protein family comprises seven members and is very complex. Three sirtuins, SIRT3, SIRT4 and SIRT5 are localized to mitochondria and are highly expressed in major metabolic tissues [51]. Although these proteins might function as important energy sensors, which couple metabolic pathways to nutrient availability, only few studies have investigated their biological functions so far.

The mitochondrion is the major organelle for ATP production, generation of ROS and apoptotic signaling events [144]. Dysfunction of mitochondrial metabolism has been associated to many age-related diseases such as diabetes, neurodegenerative disorders, cardiovascular diseases and cancer [145]. Interestingly, SIRT4 has been shown to negatively regulate insulin secretion and might be associated to the pathogenesis of diabetes $[25,26]$. 
Therefore, SIRT4 itself, but also factors regulated by SIRT4, might be novel therapeutic targets in treatment of diabetes.

Only one SIRT4 substrate, glutamate dehydrogenase (GDH), has been identified so far. Many important questions regarding its biological function still need to be answered: Which other factors are substrates of SIRT4? Does SIRT4 regulate their activity in response to nutrient deprivation or stress? Is SIRT4 a regulator of energy homeostasis, which coordinates mitochondrial metabolism and adaption to metabolic stress in different tissues?

Reversible mitochondrial protein acetylation might switch metabolic pathways in response to changing nutrient levels. Until now, SIRT4 is the only mammalian sirtuin where no other activity than ADP-ribosylation has been detected, raising the question whether SIRT4 has protein deacetylase activity. Because of its high sequence conservation to the other mammalian sirtuins, it is very likely that SIRT4 also possesses $\mathrm{NAD}^{+}$-dependent protein deacetylase activity. However, the proof of this might be challenging, as SIRT4 seems to exhibit very strict substrate specificity.

Although analysis of SIR-2 proteins in lower eukaryotes has provided key insights into the biological function of mammalian sirtuins, the knowledge of sirtuins in the simple multicellular organism $C$. elegans is very limited and has been focused primarily on the variant sir-2.1, neglecting the other three variants (sir-2.2 to sir-2.3). As discussed in section 1.4 , C. elegans provides a less complex and powerful model system to analyze the biology of sirtuins on an organismal level. Interestingly, $C$. elegans SIR-2.2 and SIR-2.3 are most homologous to SIRT4 and there are no other SIR-2 proteins that share highest sequence homology to SIRT3 or SIRT5. Currently, it is not known whether SIR-2.2 and SIR-2.3 are mitochondrial proteins and several additional questions remain: Are SIR-2.2 and SIR-2.3 $\mathrm{NAD}^{+}$-dependent protein deacetylases? Do they function in regulation of energy metabolism and stress responses? Are these functions conserved for mammalian SIRT4?

Based on these questions the aim of my $\mathrm{PhD}$ thesis was to characterize the expression and localization of $C$. elegans SIR-2.2 and SIR-2.3. A further goal was to elucidate their role in regulation of metabolism and stress responses. This included the identification of novel interaction partners, which were also relevant for the analysis of the enzymatic activities of SIR-2.2 and SIR-2.3. Moreover, I investigated whether my findings are conserved from $C$. elegans to human in order to contribute to a better understanding of the biological function and enzymatic activity of mammalian SIRT4. 


\section{Material and Methods}

\subsection{Material and Reagents}

\subsubsection{Laboratory equipment}

Generally used laboratory equipment is summarized in Table 2-1.

Table 2-1: Generally used laboratory equipment.

\begin{tabular}{|c|c|c|c|}
\hline Equipment & Manufacturer & Equipment & Manufacturer \\
\hline 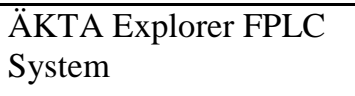 & $\begin{array}{l}\text { GE Healthcare, } \\
\text { Buckinghamshire (UK) }\end{array}$ & Multitron shaker & $\begin{array}{l}\text { HT Infors, } \\
\text { Braunschweig }\end{array}$ \\
\hline Balances & Mettler-Toledo, Giessen & Nanodrop® ND-1000 & Peqlab, Erlangen \\
\hline Bioruptor $^{\mathrm{TM}}$ & $\begin{array}{l}\text { Diogenode, Liege } \\
\text { (Belgium) }\end{array}$ & $\begin{array}{l}\text { NuPAGE® Pre-cast } \\
\text { system }\end{array}$ & Invitrogen, Karlsruhe \\
\hline Branson Digital Sonifier & $\begin{array}{l}\text { Heinemann Ultraschall- } \\
\text { und Labortechnik, } \\
\text { Schwaebisch Gmuend }\end{array}$ & Olympus IX70 & Olympus, Hamburg \\
\hline $\begin{array}{l}\text { Cary } 100 \mathrm{UV}-\mathrm{Vis} \\
\text { Spectrophotometer }\end{array}$ & Varian, Palo Alto (USA) & Olympus SZX10 & Olympus, Hamburg \\
\hline $\begin{array}{l}\text { Centrifuges } \\
5415 \mathrm{R} / 5810 \mathrm{R}\end{array}$ & Eppendorf, Hamburg & $\begin{array}{l}\text { PCR machine Eppendorf } \\
\text { Mastercycler } \\
\text { epgradientS }\end{array}$ & Eppendorf, Hamburg \\
\hline $\begin{array}{l}\text { ECLIPSE Ti-E, inverted } \\
\text { research microscope }\end{array}$ & Nikon, Kingston (UK) & $\mathrm{pH}$ meter & Mettler-Toledo, Giessen \\
\hline $\begin{array}{l}\text { EmulsiFlex-C5 High } \\
\text { Pressure Homogenizer }\end{array}$ & $\begin{array}{l}\text { Avestin, Ottawa } \\
\text { (Canada) }\end{array}$ & PlateChameleon & Hidex, Turku (Finland) \\
\hline $\begin{array}{l}\text { Eppendorf Transjector } \\
5246\end{array}$ & Eppendorf, Hamburg & Potter S & $\begin{array}{l}\text { B. Braun Biotech } \\
\text { International GmbH, } \\
\text { Melsungen }\end{array}$ \\
\hline $\begin{array}{l}\text { Eppendorf TransferMan } \\
\text { NK2 }\end{array}$ & Eppendorf, Hamburg & $\begin{array}{l}\text { Power Supply } \\
\text { Power Pac Universal }\end{array}$ & Biorad, München \\
\hline Freezer $-20^{\circ} \mathrm{C}$ & $\begin{array}{l}\text { Liebherr, Bulle } \\
\text { (Switzerland) }\end{array}$ & $\begin{array}{l}\text { Scanner } \\
\text { Perfection V750 PRO }\end{array}$ & Epson \\
\hline Freezer $-80^{\circ} \mathrm{C}$ & $\begin{array}{l}\text { Thermo Scientific, } \\
\text { Braunschweig }\end{array}$ & Sorvall Evolution RC & $\begin{array}{l}\text { Thermo Scientific, } \\
\text { Braunschweig }\end{array}$ \\
\hline Here Safe sterile hood & Heraeus, Hanau & $\begin{array}{l}\text { Stratalinker }{ }^{\circledR} \mathrm{UV} \\
\text { crosslinker } 2400\end{array}$ & $\begin{array}{l}\text { Stratagene, La Jolla } \\
\text { (USA) }\end{array}$ \\
\hline $\begin{array}{l}\text { Hereaus Kelvitron } \\
\text { Incubator }\end{array}$ & $\begin{array}{l}\text { Thermo Scientific, } \\
\text { Braunschweig }\end{array}$ & Stuart Gyrorocker SSL3 & Sigma, Steinheim \\
\hline $\begin{array}{l}\text { Kodak X OMAT } 2000 \\
\text { processor }\end{array}$ & $\begin{array}{l}\text { Caresream Health, New } \\
\text { York }\end{array}$ & $\begin{array}{l}\text { Sub-Cell-GT Agarose } \\
\text { gel electrophoresis }\end{array}$ & Biorad, München \\
\hline Leica TCS SP5 & Leica, Wetzlar & Thermomixer comfort & Eppendorf, Hamburg \\
\hline $\begin{array}{l}\text { Liquid Scintillation } \\
\text { Analyzer Tri-Carb } \\
\text { 3110TR }\end{array}$ & $\begin{array}{l}\text { PerkinElmer, Waltham } \\
\text { (USA) }\end{array}$ & UV Transilluminator & Biorad, München \\
\hline Mini-Protean 3 Cells & Biorad, München & Vortex Genie 2 & $\begin{array}{l}\text { Scientific Industries, } \\
\text { New York (USA) }\end{array}$ \\
\hline MiniTrans-Blot & Biorad, München & Waterbath TW12 & Julabo, Seelbach \\
\hline
\end{tabular}




\subsubsection{Chemicals}

Chemicals generally used for buffers and media are listed in Table 2-2.

Table 2-2: Generally used chemicals.

\begin{tabular}{|c|c|c|c|}
\hline Chemical & Manufacturer & Chemical & Manufacturer \\
\hline Acetic acid & Merck, Mannheim & D-Mannitol & Sigma, Steinheim \\
\hline $\begin{array}{l}\text { Adenosine 5'-triphosphate } \\
\text { (ATP) }\end{array}$ & Sigma, Steinheim & 2-Mercaptoethanol & Sigma, Steinheim \\
\hline Acetyl Coenzyme A & Roche, Mannheim & Methanol & Sigma, Steinheim \\
\hline $\begin{array}{l}\text { Acrylamide / Bisacrylamide } \\
(37.5: 1)\end{array}$ & Merck, Mannheim & D/L-Methionine & Sigma, Steinheim \\
\hline Agar & Roth, Karlsruhe & Milk powder & $\begin{array}{l}\text { Regilait, Saint-Martin- } \\
\text { Belle-Roche (France) }\end{array}$ \\
\hline Agarose & Serva, Heidelberg & $\begin{array}{l}\beta \text {-Nicotinamide Adenine } \\
\text { Dinucleotide, }\left(\beta-\mathrm{NAD}^{+}\right)\end{array}$ & Sigma, Steinheim \\
\hline Albumin, bovine (BSA) & $\begin{array}{l}\text { New England Biolabs, } \\
\text { Ibswich }\end{array}$ & $\begin{array}{l}\beta \text {-Nicotinamide Adenine } \\
\text { Dinucleotide, reduced } \\
\text { form }(\beta-N A D H)\end{array}$ & Sigma, Steinheim \\
\hline $\begin{array}{l}\text { Ammonium chloride } \\
\left(\mathrm{NH}_{4} \mathrm{Cl}\right)\end{array}$ & Merck, Mannheim & Nickel chloride $\left(\mathrm{NiCl}_{2}\right)$ & Riedel-de Haën, Seelze \\
\hline $\begin{array}{l}\text { Ammonium persulfate } \\
\text { (APS) }\end{array}$ & $\begin{array}{l}\text { AppliChem GmbH, } \\
\text { Darmstadt }\end{array}$ & Nonidet P-40 (NP-40) & Roche, Mannheim \\
\hline Ampicillin & $\begin{array}{l}\text { AppliChem GmbH, } \\
\text { Darmstadt }\end{array}$ & $\begin{array}{l}\text { Paraquat } \\
\text { (Methylviologen- } \\
\text { dichloride hydrat) }\end{array}$ & Sigma, Steinheim \\
\hline Bovine growth serum (BGS) & Sigma, Steinheim & $\begin{array}{l}\text { Penicillin Streptomycin } \\
\text { 100x }\end{array}$ & Gibco, München \\
\hline $\begin{array}{l}\text { Bovine Serum Albumin } \\
\text { (BSA) }\end{array}$ & Sigma, Steinheim & Peptone & Roth, Karlsruhe \\
\hline Bromophenol blue & Serva, Heidelberg & $\begin{array}{l}\text { Phenol/Chloroform/ } \\
\text { Isoamylalcohol }\end{array}$ & Roth, Karlsruhe \\
\hline Calcium chloride $\left(\mathrm{CaCl}_{2}\right)$ & Roth, Karlsruhe & $\begin{array}{l}\text { Phenymethylsulfonyl } \\
\text { fluorid (PMSF) }\end{array}$ & Serva, Heidelberg \\
\hline Chloramphenicol & Amresco, Solon (USA) & Ponceau S & Sigma, Steinheim \\
\hline Chloroform & Merck, Mannheim & Potassium bicarbonate & Sigma, Steinheim \\
\hline Cobalt chloride $\left(\mathrm{CoCl}_{2}\right)$ & Riedel-de Haën, Seelze & Potassium chloride $(\mathrm{KCl})$ & Roth, Karlsruhe \\
\hline Coomassie brilliant blue & BIO-RAD, München & $\begin{array}{l}\text { Potassium dihydrogen } \\
\text { phosphate }\left(\mathrm{KH}_{2} \mathrm{PO}_{4}\right)\end{array}$ & Roth, Karlsruhe \\
\hline Copper chloride $\left(\mathrm{CuCl}_{2}\right)$ & Merck, Mannheim & $\begin{array}{l}\text { Potassium } \\
\text { monohydrogen } \\
\text { phosphate }\left(\mathrm{K}_{2} \mathrm{HPO}_{4}\right)\end{array}$ & Merck, Mannheim \\
\hline Dimethylsulfoxid (DMSO) & Sigma, Steinheim & $\begin{array}{l}\text { Protease inhibitor } \\
\text { (Complete EDTA-free) }\end{array}$ & Roche, Mannheim \\
\hline $\begin{array}{l}\text { 1,1'-dioctadecyl-3,3,3',3'- } \\
\text { tetramethylindocarbocyanine } \\
\text { perchlorate }\left(\mathrm{DiI} ; \operatorname{DiIC}_{18}(3)\right)\end{array}$ & $\begin{array}{l}\text { Molecular Probes }{ }^{\circledR}, \\
\text { Invitrogen, Karlsruhe }\end{array}$ & Sodium acetate & Roth, Karlsruhe \\
\hline $\begin{array}{l}\text { DL-Dithiothreitol (DTT) } \\
\text { dNTPs }\end{array}$ & $\begin{array}{l}\text { Alexis Biochemicals } \\
\text { Invitrogen, Karlsruhe }\end{array}$ & $\begin{array}{l}\text { Sodium azide }\left(\mathrm{NaN}_{3}\right) \\
{\left[{ }^{14} \mathrm{C}\right] \text { Sodium }} \\
\text { Bicarbonate }(\text { specific } \\
\text { activity of } 52 \mathrm{mCi} / \mathrm{mmol} \text {, } \\
1 \mathrm{mCi})\end{array}$ & $\begin{array}{l}\text { Alfar Aesar, Karlsruhe } \\
\text { PerkinElmer, Waltham } \\
\text { (USA) }\end{array}$ \\
\hline
\end{tabular}




\begin{tabular}{|c|c|c|c|}
\hline Ethanol & Merck, Mannheim & Sodium chloride $(\mathrm{NaCl})$ & Merck, Mannheim, \\
\hline Ethidium bromide & Roth, Karlsruhe & $\begin{array}{l}\text { Sodium dihydrogen } \\
\text { phosphate }\left(\mathrm{NaH}_{2} \mathrm{PO} 4\right)\end{array}$ & Merck, Mannheim \\
\hline $\begin{array}{l}\text { Ethylenediaminetetraacetate } \\
\text { (EDTA) }\end{array}$ & Roth, Karlsruhe & $\begin{array}{l}\text { Sodium dodecyl sulfate } \\
\text { (SDS) }\end{array}$ & VWR, Poole \\
\hline $\begin{array}{l}\text { Ethylene glycol tetraacetic } \\
\text { acid (EGTA) }\end{array}$ & Roth, Karlsruhe & Sodium hydroxide & Merck, Mannheim \\
\hline Glucose & Merck, Mannheim & $\begin{array}{l}\text { Sodium monohydrogen } \\
\text { phosphate }\left(\mathrm{Na}_{2} \mathrm{HPO}_{4}\right)\end{array}$ & Merck, Mannheim \\
\hline Glycerol & Merck, Mannheim & Sodium pyruvic acid & Sigma, Steinheim \\
\hline Glycine & Merck, Mannheim & & \\
\hline Halocarbon oil 700 & Sigma, Steinheim & Sodium sulfate $\left(\mathrm{Na}_{2} \mathrm{SO}_{4}\right)$ & Merck, Mannheim \\
\hline Hydrochloric acid $(\mathrm{HCl})$ & Merck, Mannheim & Sucrose & Serva, Heidelberg \\
\hline $\begin{array}{l}\text { 4-(2-Hydroxyethyl)-1- } \\
\text { piperazineethanesulfonic } \\
\text { acid (HEPES) }\end{array}$ & VWR, Poole & $\begin{array}{l}\text { Tetramethyl } \\
\text { ethylendiamine } \\
\text { (TEMED) }\end{array}$ & Sigma, Steinheim \\
\hline Iron chloride $\left(\mathrm{FeCl}_{3}\right)$ & Roth, Karlsruhe & Trichostatin A & $\begin{array}{l}\text { Cell Signaling (NEB, } \\
\text { Ibswich, USA) }\end{array}$ \\
\hline $\begin{array}{l}\text { Isopropyl } \beta \text {-D- } \\
\text { thiogalactopyranoside } \\
\text { (IPTG) }\end{array}$ & $\begin{array}{l}\text { AppliChem GmbH, } \\
\text { Darmstadt }\end{array}$ & Triethanolamine & VWR, Poole \\
\hline L-Glutamine $100 \mathrm{x}$ & Gibco, München & $\begin{array}{l}\text { Tris (hydroxymethyl) } \\
\text { amino ethane (Tris) }\end{array}$ & Roth, Karlsruhe \\
\hline Lumasafe $^{\mathrm{TM}}$ Plus & $\begin{array}{l}\text { Lumac, Groningen } \\
\text { (Netherlands) }\end{array}$ & Triton X-100 & Merck, Mannheim \\
\hline Isoamylalcohol & Sigma, Steinheim & Trypsin solution & Gibco, München \\
\hline$\alpha$-Lactose & Roth, Karlsruhe & Tween 20 & Sigma, Steinheim \\
\hline $\begin{array}{l}\text { Magnesium chloride } \\
\left(\mathrm{MgCl}_{2}\right)\end{array}$ & Merck, Mannheim & Urea & Merck, Mannheim \\
\hline Magnesium sulfate $\left(\mathrm{MgSO}_{4}\right)$ & Roth, Karlsruhe & Yeast extract & MOBIO, Hamburg \\
\hline Manganese chloride $\left(\mathrm{MnCl}_{2}\right)$ & Roth, Karlsruhe & Zinc sulfate $\left(\mathrm{ZnSO}_{4}\right)$ & $\begin{array}{l}\text { AppliChem GmbH, } \\
\text { Darmstadt }\end{array}$ \\
\hline
\end{tabular}

\subsubsection{Kits}

Generally used kits are listed in Table 2-3.

Table 2-3: Generally used kits.

\begin{tabular}{ll}
\hline Kits & Supplier \\
\hline Coomassie Plus (Bradford) Protein Assay $^{\mathrm{TM}}$ Mammalian Transfection Kit & Thermo Fisher Scientific, Rockford (USA) \\
CalPhos $^{\mathrm{TM}}$ Mamin $^{\circledR}$ Clontech, Mountain View (USA) \\
MEGAscript $^{\circledR}$ T7 Kit & Ambion, Wiesbaden \\
Micro BSA Protein Assay Kit $^{\text {NucleoBond }}{ }^{\circledR}$ Xtra Midi & Thermo Fisher Scientific, Rockford (USA) \\
NucleoBond $^{\circledR}$ Plasmid & Macherey \& Nagel, Dueren \\
SuperScript $^{\mathrm{TM}}$ III First-Strand Synthesis System for & Invitrogen, Karlsruhe \\
RT-PCR & \\
Zymoclean $^{\mathrm{TM}}$ DNA Clean \& Concentrator & \\
Zymoclean $^{\mathrm{TM}}$ Gel DNA Recovery Kit & Zymo Research, Orange (USA) \\
\hline
\end{tabular}




\subsubsection{Consumables and reagents}

Generally used consumables and reagents are listed in Table 2-4.

Table 2-4: Generally used consumables and reagents.

\begin{tabular}{|c|c|}
\hline Consumables / Others & Supplier \\
\hline $9 \mathrm{~cm}, 6 \mathrm{~cm}, 3.5 \mathrm{~cm}$ Petri dish & Greiner, Solingen \\
\hline $1 \mathrm{~kb}$ Plus DNA Ladder & Invitrogen, Karlsruhe \\
\hline Amersham Hyperfilm ECL (18 x 24 cm) & GE Healthcare, Buckinghamshire (UK) \\
\hline Amicon Ultra-15 Centrifugal Filter Units & Millipore, Billerica (USA) \\
\hline Amylose Resin & New England Biolabs, Ibswich (USA) \\
\hline Anti-FLAG ${ }^{\circledR} \mathrm{M} 2$ affinity gel & Sigma, Steinheim \\
\hline Cryotubes & Greiner, Solingen \\
\hline $\begin{array}{l}\text { DMEM GlutaMAXII [-Pyruvate] } \\
\text { Dynabeads }{ }^{\circledR} \text { M280 sheep anti mouse IgG }\end{array}$ & $\begin{array}{l}\text { Gibco, München } \\
\text { Invitrogen, Karlsruhe }\end{array}$ \\
\hline $\begin{array}{l}\text { ECL plus }{ }^{\mathrm{TM}} \text { Western Blotting Detection Reagent } \\
\text { Femtotip }{ }^{\circledR} \mathrm{II}\end{array}$ & $\begin{array}{l}\text { GE Healthcare, Buckinghamshire (UK) } \\
\text { Eppendorf, Hamburg }\end{array}$ \\
\hline GFP-Trap $^{\circledR}-\mathrm{A}$ & Chromotek, Planegg-Martinsried \\
\hline jetPEI ${ }^{\mathrm{TM}}$ Transfection Reagent & Polyplus-transfection SA, Illkirch (France) \\
\hline Microloader & Eppendorf, Hamburg \\
\hline Mono $\mathrm{Q}^{\mathrm{TM}} 5 / 50 \mathrm{GL}$ & GE Healthcare, Buckinghamshire (UK) \\
\hline Ni-NTA resin & Qiagen, Hilden \\
\hline Nitrocellulose membrane & GE Healthcare, Buckinghamshire (UK) \\
\hline Phase Lock Gel ${ }^{\mathrm{TM}}$ ( $2 \mathrm{ml}$, heavy) & Eppendorf, Hamburg \\
\hline Pierce $^{\circledR}$ Avidin Agarose Resin & Thermo Fisher Scientific, Rockford (USA) \\
\hline Protein G Sepharose $^{\mathrm{TM}} 4$ Fast Flow & GE Healthcare, Buckinghamshire \\
\hline $\begin{array}{l}\text { Complete, EDTA-free, Protease Inhibitor Cocktail } \\
\text { tablets }\end{array}$ & Roche, Mannheim \\
\hline SeeBlue ${ }^{\circledR}$ Plus2 Pre-Stained protein standard & Invitrogen, Karlsruhe \\
\hline Superdex 200 10/30 GL & GE Healthcare, Buckinghamshire (UK) \\
\hline TRIzol ${ }^{\circledR}$ Reagent & Invitrogen, Karlsruhe \\
\hline
\end{tabular}

\subsubsection{Enzymes}

Generally used enzymes are listed in Table 2-5.

Table 2-5: Generally used enzymes.

\begin{tabular}{ll}
\hline Enzyme & Supplier \\
\hline Antarctic phosphatase & New England Biolabs (NEB), Ibswich (USA) \\
BamHI, BglII, EcoRI, KpnI, MluI, NdeI, NotI, PstI, XhoI & New England Biolabs (NEB), Ibswich (USA) \\
DNaseI & New England Biolabs (NEB), Ibswich (USA) \\
DpnI & New England Biolabs (NEB), Ibswich (USA) \\
Expand High Fidelity DNA polymerase mix & Roche, Mannheim \\
Malate Dehydrogenase (EC 1.1.1.37), porcine heart mitochondria & Serva, Heidelberg \\
Micrococcal nuclease (MNase) & Calbiochem ${ }^{\circledR}$, Merck, Darmstadt \\
PfuUltra ${ }^{\text {TM }}$ II Fusion HS DNA Polymerase & Stratagene, La Jolla (USA) \\
Pfu DNA polymerase & Fermentas, St. Leon-Rot \\
Proteinase K & Invitrogen, Karlsruhe \\
Pyruvate Carboxylase (EC 6.4.1.1), bovine liver & Sigma, Steinheim \\
T4 DNA Ligase & New England Biolabs (NEB), Ibswich (USA) \\
Taq DNA Polymerase (recombinant), LC & Fermentas, St. Leon-Rot \\
\hline
\end{tabular}




\subsubsection{Antibodies}

Used antibodies for Western blotting and immunoprecipitation are listed in Table 2-6.

Table 2-6: Generally used antibodies.

\begin{tabular}{|c|c|c|c|c|}
\hline Name & Host & $\begin{array}{c}\text { Manufacturer, catalog } \\
\text { number }\end{array}$ & Application & $\begin{array}{c}\text { Dilution for } \\
\text { WB }\end{array}$ \\
\hline \multicolumn{5}{|l|}{ Primary antibodies: } \\
\hline anti-acetylated-Lysine & rabbit, polyclonal & Cell signaling, \#9441 & WB & $1: 1000$ \\
\hline anti-acetylated-Lysine & mouse, monoclonal & Cell signaling, \#9681 & & $1: 1000$ \\
\hline & & & WB & \\
\hline $\begin{array}{l}\text { anti-ATP synthase } \\
\text { (Complex V) subunit } \\
\text { alpha }\end{array}$ & mouse, monoclonal & Mitosciences, MS507 & & \\
\hline $\begin{array}{l}\text { anti-Complex I subunit } \\
\text { NDUFS3 (C. elegans } \\
\text { NUO-2) }\end{array}$ & mouse monoclonal & Mitosciences, MS112 & WB & $1: 1000$ \\
\hline anti-cytochrome c & mouse, monoclonal & Mitosciences, MSA06 & WB & $1: 1000$ \\
\hline anti-Flag M2 & mouse, monoclonal & Sigma, F3165 & WB, IP & $1: 1000$ \\
\hline anti-GFP & $\begin{array}{l}\text { mouse monoclonal } \\
\text { (clones } 7.1 \text { and 13.1) }\end{array}$ & Roche, 11814460001 & WB, IP & $1: 1000$ \\
\hline anti-H3 & rabbit, polyclonal & Abcam, ab1791 & WB & $1: 30000$ \\
\hline anti-Myc & $\begin{array}{l}\text { mouse monoclonal } \\
\quad(\text { clone 4A6) }\end{array}$ & $\begin{array}{c}\text { Millipore, Temecula } \\
\text { (USA) }\end{array}$ & WB, IP & $1: 1000$ \\
\hline anti-SIR-2.2 & & & $\mathrm{WB}, \mathrm{IP}$ & \\
\hline \multicolumn{5}{|l|}{ Secondary antibodies: } \\
\hline anti-mouse-HRP & goat, polyclonal & DakoCytomation, P0447 & WB & $1: 5000$ \\
\hline anti-rabbit-HRP & swine, polyclonal & DakoCytomation, P0399 & WB & $1: 5000$ \\
\hline
\end{tabular}

WB: Western blotting; IP: immunoprecipitation

\subsubsection{Peptides}

Peptides used as substrates for deacetylase activity assays are listed in Table 2-7.

Table 2-7: Peptides used for deacetylase activity assays.

\begin{tabular}{|c|c|c|c|c|}
\hline Name & Peptide & Amino acid sequence & $\begin{array}{l}\text { Acetylated } \\
\text { lysine }\end{array}$ & Supplier \\
\hline MPIG-47 & $\begin{array}{c}\text { Human PC } \\
(265-280)\end{array}$ & $\mathrm{CSIQRRHQK}_{273}(\mathrm{ac}) \mathrm{VVEIAPA}-\mathrm{CONH} 2$ & $\mathrm{~K}_{273} \mathrm{ac}$ & $\begin{array}{l}\text { Charite-Universitäts } \\
\text { medizin Berlin }\end{array}$ \\
\hline MPIG-48 & $\begin{array}{l}\text { Human PC } \\
(733-749)\end{array}$ & AGTHILCIK $_{741}(\mathrm{ac})$ DMAGLLKP-CONH2 & $\mathrm{K}_{741} \mathrm{ac}$ & $\begin{array}{l}\text { Charite-Universitäts- } \\
\text { medizin Berlin }\end{array}$ \\
\hline H3K9ac & H3 (1-20C) & ARTKQTARK $_{9}($ ac)STGGKAPRKQLC & $\mathrm{K}_{9} \mathrm{ac}$ & Baylor \\
\hline $\mathrm{H} 3 \mathrm{~K} 14 \mathrm{ac}$ & H3 (1-20C) & ARTKQTARKSTGGK $_{14}(\mathrm{ac})$ APRKQLC & $\mathrm{K}_{14} \mathrm{ac}$ & Baylor \\
\hline
\end{tabular}

\subsubsection{Oligonucleotides}

Primer sequences were designed using the DNASTAR Lasergene 7 program and purchased from Invitrogen (Karlsruhe) or MWG (Ebersberg). The oligonucleotide sequences are described in the corresponding method sections $(2.2 .8,2.4 .5,2.4 .12)$ (underlined sequences indicate restriction sites, mutated nucleotides are lowercased). 


\subsubsection{Plasmids}

Vectors used for cloning are listed in Table 2-8.

Table 2-8: Generally used plasmids.

\begin{tabular}{|c|c|c|c|c|c|}
\hline Name & Type & Promoter & Selection & Tags & Source \\
\hline $\begin{array}{l}\text { pCDNA3.1(+)- } \\
\text { FLFL-HAHA-C }\end{array}$ & $\begin{array}{l}\text { mammalian } \\
\text { expression } \\
\text { vector }\end{array}$ & T7/CMV & Ampicillin & $\begin{array}{l}\text { Double FLAG } \\
\text { and double HA- } \\
\text { tag N-terminal }\end{array}$ & $\begin{array}{l}\text { [156], Chromatin } \\
\text { Biochemistry group, Dr. } \\
\text { W. Fischle, Max Planck } \\
\text { Institute for Biophysical } \\
\text { Chemistry, Göttingen }\end{array}$ \\
\hline $\begin{array}{l}\text { pCDNA3.1(+)- } \\
\text { FLFL-HAHA-C }\end{array}$ & $\begin{array}{l}\text { mammalian } \\
\text { expression } \\
\text { vector }\end{array}$ & T7/CMV & Ampicillin & $\begin{array}{l}\text { Double FLAG } \\
\text { and double HA- } \\
\text { tag C-terminal }\end{array}$ & [156] \\
\hline pET11a & $\begin{array}{l}\text { bacterial } \\
\text { expression } \\
\text { vector }\end{array}$ & $\mathrm{T} 7$ & Ampicillin & - & $\begin{array}{l}\text { New England Biolabs } \\
\text { (NEB), Ibswich (USA) }\end{array}$ \\
\hline $\begin{array}{l}\text { pEU3-NII- } \\
\text { StrepII }\end{array}$ & $\begin{array}{l}\text { Cell-free protein } \\
\text { synthesis }\end{array}$ & $\mathrm{T} 7$ & Ampicillin & $\begin{array}{l}\text { C-terminal } \\
\text { StrepII-tag }\end{array}$ & $\begin{array}{l}\text { Department of Cellular } \\
\text { Biochemistry, Prof. R. } \\
\text { Luehrmann, Max Planck } \\
\text { Institute for Biophysical } \\
\text { Chemistry, Göttingen }\end{array}$ \\
\hline pEGFP-N1 & $\begin{array}{l}\text { Mammalian } \\
\text { expression } \\
\text { vector }\end{array}$ & CMV & Kanamycin & $\begin{array}{l}\text { C-terminal } \\
\text { EGFP-tag }\end{array}$ & $\begin{array}{l}\text { Clontech, Mountain } \\
\text { View (USA) }\end{array}$ \\
\hline $\begin{array}{l}\text { pPD115.62 } \\
(\mathrm{L} 3570)\end{array}$ & $\begin{array}{l}\text { worm } \\
\text { expression }\end{array}$ & myo-3 & Ampicillin & $\begin{array}{l}\text { C-terminal } \\
\text { GFP-tag, } \\
\text { (unc-54 3'UTR) }\end{array}$ & $\begin{array}{l}\text { Andrew Fire, Stanford } \\
\text { School of Medicine } \\
\text { (USA) }\end{array}$ \\
\hline $\begin{array}{l}\text { L4440 } \\
\text { (pPD129.36) }\end{array}$ & $\begin{array}{l}\text { Worm } \\
\text { expression, } \\
\text { RNAi }\end{array}$ & $\mathrm{T} 7$ & Ampicillin & - & $\begin{array}{l}\text { Andrew Fire, Stanford } \\
\text { School of Medicine } \\
\text { (USA) }\end{array}$ \\
\hline
\end{tabular}

The following plasmids were provided by other group members or collaborators:

The plasmid pRF4 [157] used as selection marker for microinjection of C. elegans as well as the cosmid F46G10 (F46G10.7 and F46G10.3), originally generated by the Wellcome Trust Sanger Institute (Cambridge, UK), were kindly provided by Dr. Monika Jedrusik-Bode (Max Planck Institute for Biophysical Chemistry, Göttingen). Szabolcs Soeroes and Nora KösterEiserfunke (Max Planck Institute for Biophysical Chemistry, Göttingen) kindly provided the plasmids pEU3-NII-Strep and pcDNA3.1(+)-FLFL-HAHA, respectively, containing both the cDNA of HP1ß. Mammalian expression plasmids pcDNA3.1 encoding human SIRT3, SIRT4, SIRT5, and CDYL1c with a C-terminal Myc-HIS-tag were kindly provided by the laboratory of Prof. Eric Verdin (Gladstone Institute of Virology and Immunology, University of California, San Francisco, USA) and Henriette Franz (Max Planck Institute for Biophysical Chemistry, Göttingen). 


\subsubsection{Bacterial Strains}

Table 2-9 summarizes all bacterial strains used for cloning, expression of recombinant protein or as food source for C. elegans.

Table 2-9: Generally used bacterial strains.

\begin{tabular}{|c|c|c|c|}
\hline Strain & Genotype/description & Application & Source \\
\hline DH5a & 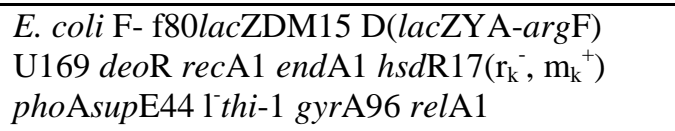 & $\begin{array}{l}\text { plasmid } \\
\text { amplification; } \\
\text { cloning }\end{array}$ & $\begin{array}{l}\text { Invitrogen, } \\
\text { Karlsruhe }\end{array}$ \\
\hline $\begin{array}{l}\text { BL21-CodonPlus } \\
\text { (DE3)-RIL }\end{array}$ & $\begin{array}{l}\text { E. coli } \mathrm{B} \mathrm{F}-\text { ompT hsdS }\left(\mathrm{r}_{\mathrm{B}}{ }^{-} \mathrm{m}_{\mathrm{B}}{ }^{-}\right) d c m+\mathrm{Tet}^{\mathrm{r}} \\
\left.\text { gal } l(\mathrm{DE} 3) \text { endA Hte [argU ileY leuW } \mathrm{Cam}^{\mathrm{r}}\right]\end{array}$ & protein expression & $\begin{array}{l}\text { Stratagene, La } \\
\text { Jolla (USA) }\end{array}$ \\
\hline OP50-1 & $\begin{array}{l}\text { Uracil auxotroph. E. coli B, streptomycin } \\
\text { resistant, useful for growing C. elegans in } \\
\text { bulk }\end{array}$ & C. elegans food & $\begin{array}{l}\text { CGC } \\
\text { (Caenorhabditis } \\
\text { Genetics Center, } \\
\text { University of } \\
\text { Minnesota, USA) }\end{array}$ \\
\hline HB101 & $\begin{array}{l}\text { E. coli [supE44 hsdS20(rB-mB-) recA13 ara- } \\
14 \text { proA2 lacY1 galK2 rpsL20 xyl-5 mtl-1]. } \\
\text { Contains a mutation (rpsL20) in a ribosomal } \\
\text { subunit gene that confers streptomycin } \\
\text { resistance }\end{array}$ & C. elegans food & $\begin{array}{l}\text { CGC } \\
\text { (Caenorhabditis } \\
\text { Genetics Center, } \\
\text { University of } \\
\text { Minnesota, USA) }\end{array}$ \\
\hline HT115(DE3) & $\begin{array}{l}\text { E. coli } \mathrm{F}-\text {, mcrA, mcrB, IN(rrnD-rrnE)1, } \\
\text { rnc14::Tn10(DE3 lysogen: lavUV5 promoter - } \\
\text { T7 polymerase) (IPTG-inducible T7 } \\
\text { polymerase) (RNAse III minus), tetracycline } \\
\text { resistant }\end{array}$ & RNAi feeding & $\begin{array}{l}\text { CGC } \\
\text { (Caenorhabditis } \\
\text { Genetics Center, } \\
\text { University of } \\
\text { Minnesota, USA) }\end{array}$ \\
\hline
\end{tabular}

\subsubsection{C. elegans strains}

C. elegans strains I generated in this study (MAJ13 to MAJ16) or obtained from different sources are listed in Table 2-10.

Table 2-10: C. elegans strains used in this study.

\begin{tabular}{|c|c|c|c|}
\hline Strain & Genotype & Source/CGC lab designation & Reference \\
\hline $\mathrm{N} 2$ & wild-type & $\begin{array}{l}\text { Hodkin J, Oxford University, Oxford (UK); } \\
\text { distributed by the CGC }\end{array}$ & [158] \\
\hline VC199 & sir-2.1(ok434)IV & $\begin{array}{l}\text { C. elegans Gene Knockout Project (OMRF), } \\
\text { Robert Barstead (RB), Oklahoma Medical } \\
\text { Research Foundation, Oklahoma City, USA) }\end{array}$ & \\
\hline MAJ11 & $\operatorname{sir}-2.2(\operatorname{tm} 2648) \mathrm{X}$ & National BioResource Project NBRP, Mitani & \\
\hline MAJ12 & $\operatorname{sir}-2.2(\operatorname{tm} 2673) \mathrm{X}$ & National BioResource Project NBRP, Mitani & \\
\hline RB654 & sir-2.3(ok444)X & $\begin{array}{l}\text { C. elegans Gene Knockout Project (OMRF), } \\
\text { Robert Barstead (RB), Oklahoma Medical } \\
\text { Research Foundation, Oklahoma City, USA) }\end{array}$ & \\
\hline BC14289 & $\begin{array}{l}s E X 14289\left[\text { sir }-2.2_{p r}: \because g f p\right] \\
\text { transcriptional fusion }\end{array}$ & $\begin{array}{l}\text { David Baillie (BC), Simon Fraser University, } \\
\text { Vancouver, Canada }\end{array}$ & {$[159,160]$} \\
\hline BC15074 & $\begin{array}{l}s E X 15074\left[\text { sir- } 2.2_{p r}: \because g f p\right] \\
\text { transcriptional fusion }\end{array}$ & $\begin{array}{l}\text { David Baillie (BC), Simon Fraser University, } \\
\text { Vancouver, Canada }\end{array}$ & [159-161] \\
\hline HT822 & $\begin{array}{l}\text { lpIs }\left[\text { sir-2.1 } 1_{p}: \text { sir- } 2.1: \because g f p\right. \\
\text { rol-6(su1006)], translational fusion }\end{array}$ & $\begin{array}{l}\text { Heidi Tissenbaum (HT), Univ. of Massa- } \\
\text { chusetts Medical School, Worcester, USA }\end{array}$ & {$[122]$} \\
\hline MAJ13 & $\begin{array}{l}\text { mpgIs 13[sir-2.2 }{ }_{p r}: \text { sir-2.2::strep }:: g f p \\
\text { rol-6(su1006)], translational fusion }\end{array}$ & $\begin{array}{l}\text { Monika Jedrusik-Bode (MAJ), MPI for } \\
\text { Biophysical Chemistry, Göttingen }\end{array}$ & \\
\hline
\end{tabular}




\begin{tabular}{|c|c|c|c|}
\hline Strain & Genotype & Source & Reference \\
\hline MAJ14 & $\begin{array}{l}\text { mpgIs14[sir-2.3 } 3_{p r}: \text { sir-2.3::ha::gfp } \\
\text { rol-6(su1006)], translational fusion }\end{array}$ & $\begin{array}{l}\text { Monika Jedrusik-Bode (MAJ), MPI for } \\
\text { Biophysical Chemistry, Göttingen }\end{array}$ & \\
\hline MAJ15 & $\begin{array}{l}\text { mpgEx15[sir-2.4 }{ }_{p r}:: \text { sir- } 2.3:: h a:: g f p \\
\text { rol-6(su1006)], translational fusion }\end{array}$ & $\begin{array}{l}\text { Monika Jedrusik-Bode (MAJ), MPI for } \\
\text { Biophysical Chemistry, Göttingen }\end{array}$ & \\
\hline MAJ16 & $\begin{array}{l}\text { mpgIs } 13\left[\text { sir- } 2.2_{p r}: \text { sir- } 2.2:: \text { strep }: \because g f p\right. \\
\text { rol-6(su1006)]; mpgEx16 } \\
{\left[\text { sir- } 2.3_{p r}: \because \text { sir- } 2.3: \because \text { ha }:: m c h e r r y\right]} \\
\text { translational fusion }\end{array}$ & $\begin{array}{l}\text { Monika Jedrusik-Bode (MAJ), MPI for } \\
\text { Biophysical Chemistry, Göttingen }\end{array}$ & \\
\hline SJ4103 & $\begin{array}{l}z c l s 14\left[m y o-3_{p r}: g f p(m i t)\right], \\
\text { transcriptional fusion, mitochondrial } \\
\text { GFP expression }\end{array}$ & $\begin{array}{l}\text { David Ron (SJ), Skirball Institute, New York, } \\
\text { USA }\end{array}$ & [162] \\
\hline SJ4143 & $\begin{array}{l}z c l s 17\left[\text { ges }-1_{p r}:: g f p(m i t)\right], \\
\text { transcriptional fusion, mitochondrial } \\
\text { GFP expression }\end{array}$ & $\begin{array}{l}\text { David Ron (SJ), Skirball Institute, New York, } \\
\text { USA }\end{array}$ & [162] \\
\hline
\end{tabular}

Sequence context specifying the localization of the different deletion mutations is summarized in Table 2-11. Flanking sequences are reported on the plus strand.

Table 2-11: Molecular details for genotyping.

\begin{tabular}{|c|c|}
\hline Genotype & Molecular details (taken from wormbase) \\
\hline sir-2.1(ok434)IV & $\begin{array}{l}\text {...gcagaaatctgaagaaaaaa --[768 bp deletion] ttttgtccacaacgtgtac... - wild type } \\
\text {...gcagaaatctgaagaaaaaaTT--- }\end{array}$ \\
\hline $\operatorname{sir}-2.2(\operatorname{tm} 2648) \mathrm{X}$ & $\begin{array}{l}\text {...atataaaatttcaaaacaata [419 bp deletion] catattggatttaaaaaaaa... - wild type } \\
\text {...atataaaatttcaaaacaata --..- catattggatttaaaaaaaa... }- \text { tm } 2648\end{array}$ \\
\hline $\operatorname{sir}-2.2(\operatorname{tm} 2673) \mathrm{X}$ & $\begin{array}{l}\text {...ctagctgagccttcaaaaaat }[548 \text { bp deletion] tcttcctaattgataatgttt... - wild type } \\
\text {...ctagctgagccttcaaaaaat - }\end{array}$ \\
\hline sir-2.3(ok444)X & $\begin{array}{l}\text {...taaaatgcacatcatgtgaat }[839 \text { bp deletion] gcaaaacaaaccaattttcat... - wild type } \\
\text {...taaaatgcacatcatgtgaat --.- gcaaaacaaaccaattttcat... - ok444 }\end{array}$ \\
\hline
\end{tabular}

\subsubsection{Cell lines}

Cell lines used for protein expression are listed in Table 2-12.

Table 2-12: Cell lines used in this study.

\begin{tabular}{ccccc}
\hline Cell line & Origin & Organism & Medium & Source \\
\hline HEK293 & Embryonic Kidney & human & DMEM & ATCC \\
HEK293T & Embryonic Kidney & human & DMEM & ATCC \\
\hline
\end{tabular}

\subsection{Molecular biological methods}

\subsubsection{Plasmid DNA preparation}

DH5 $\alpha$ bacteria transformed with the plasmid of interest were grown in $5 \mathrm{ml}$ or $100 \mathrm{ml} \mathrm{LB}$ medium $(1 \%(\mathrm{w} / \mathrm{v})$ peptone, $0.5 \%(\mathrm{w} / \mathrm{v})$ yeast extract, $0.5 \%(\mathrm{w} / \mathrm{v}) \mathrm{NaCl})$ at $37^{\circ} \mathrm{C}$ overnight. Plasmid DNA was isolated using either the NucleoBond® Plasmid or NucleoBond ${ }^{\circledR}$ Xtra Midi (Macherey \& Nagel, Dueren) according to manufacturer's description. The plasmid DNA concentration was determined photometrically with the NanoDrop ${ }^{\circledR}$ ND-1000 at 260 nm. 


\subsubsection{DNA digestion with restriction endonucleases}

PCR products and plasmids were digested with restriction endonucleases (New England Biolabs (NEB), Frankfurt am Main) according to NEB protocols [163].

\subsubsection{Polymerase chain reaction (PCR)}

Specific DNA sequences were amplified by PCR based on standard protocols [164]. A $50 \mu 1$ reaction mix contained $50 \mathrm{ng}$ of template DNA, $500 \mathrm{nM}$ of each primer, $300 \mu \mathrm{M}$ of each dNTP (Roche, Mannheim), 1 unit PfuUltra ${ }^{\mathrm{TM}}$ II Fusion HS DNA Polymerase (Stratagene, Agilent Technologies, Waldbronn), 1x reaction buffer (provided by the manufacturer) and 2 $\mu 1$ DMSO. PCR reactions were performed in the Mastercycler ep gradient $\mathrm{S}$ (Eppendorf) using the following program: $5 \mathrm{~min}$ at $94^{\circ} \mathrm{C}$; $\left[1 \mathrm{~min}\right.$ at $94^{\circ} \mathrm{C}, 1 \mathrm{~min}$ at $55^{\circ} \mathrm{C}, 1 \mathrm{~min} / \mathrm{kb}$ at $72^{\circ} \mathrm{C}$ ] $8 \mathrm{x}$; [30 sec at $94^{\circ} \mathrm{C}, 30 \mathrm{sec}$ at $60^{\circ} \mathrm{C}, 1 \mathrm{~min} / \mathrm{kb}$ at $72^{\circ} \mathrm{C}$ ] $22 \mathrm{x} ; 10 \mathrm{~min}$ at $72^{\circ} \mathrm{C}$.

\subsubsection{Site-directed mutagenesis}

For site-directed mutagenesis the primers were designed according to the "Quick Change Site-directed mutagenesis" protocol (Stratagene). Briefly, the length of the two complementary primers was 25-45 bp and the mutated nucleotides were located in the middle of the primers with 10-15 bp of correct sequence on both sides. The template plasmid was amplified with PfuUltra ${ }^{\mathrm{TM}}$ II Fusion HS DNA Polymerase (Stratagene) as described in (2.2.3) or with Pfu DNA Polymerase (Fermentas), using the following reaction conditions and thermocycler program: $1 \mathrm{x}$ buffer w/o $\mathrm{MgSO}_{4}$ (provided by the manufacturer), $3 \mathrm{mM} \mathrm{MgSO}$, $200 \mathrm{nM}$ of each primer, $300 \mu \mathrm{M}$ of each dNTP (Roche, Mannheim), $200 \mathrm{ng}$ template DNA, 1 $\mu 1 \mathrm{Pfu}$ DNA Polymerase in a total volume of $50 \mu 1.3 \mathrm{~min}$ at $95^{\circ} \mathrm{C}$; $\left[30 \mathrm{sec}\right.$ at $95^{\circ} \mathrm{C}, 45 \mathrm{sec}$ at $65^{\circ} \mathrm{C}, 2 \mathrm{~min} / \mathrm{kb}$ at $\left.72^{\circ} \mathrm{C}\right] 19 \mathrm{x} ; 20 \mathrm{~min}$ at $72^{\circ} \mathrm{C}$. If two sites were mutated, both primer pairs were included in the PCR reaction.

The obtained PCR product was separated by agarose gel electrophoresis, purified from the gel (2.2.5) and digested with DpnI (NEB) according to manufacturer's instructions [163]. After transformation into DH5 $\alpha$ the DNA was isolated (2.2.1) and sequenced by MWG (Ebersberg) or Seqlab (Göttingen).

\subsubsection{Separation and isolation of DNA fragments}

Agarose gel electrophoresis was used to separate DNA fragments according to their size [164]. To load the DNA solution into the gel pockets, 10x loading dye (10 mM EDTA, 30\% (w/v) glycerol, $100 \mu \mathrm{g} / \mathrm{ml}$ bromphenol blue) was added and the DNA samples were separated in $0.7 \%$ to $2 \%$ agarose gels $(0.7 \%(\mathrm{w} / \mathrm{v})$ agarose, $89 \mathrm{mM}$ Tris, $89 \mathrm{mM}$ boric acid, $2 \mathrm{mM}$ EDTA, $0.01 \%$ (v/v) ethidium bromide, $\mathrm{pH}$ 8.0) and TBE buffer ( $89 \mathrm{mM}$ Tris, $89 \mathrm{mM}$ boric acid, $2 \mathrm{mM}$ EDTA), using the Sub-Cell-GT Agarose gel electrophoresis system (Biorad, München) at a setting of $120 \mathrm{~V}$ for $30 \mathrm{~min}$. The DNA was visualized with UV light (320 nm) and the sizes of the DNA fragments were determined by comparing with the bands of the $1 \mathrm{~kb}$ Plus DNA ladder (Invitrogen). DNA bands of interest were cut out of the gel and purified from the agarose gel with the Zymoclean ${ }^{\mathrm{TM}}$ Gel DNA Recovery Kit (Zymo Research) according to the manufacturer's protocol.

The DNA Clean \& Concentrator ${ }^{\mathrm{TM}}-5$ Kit (Zymo Research) or phenol/chloroform extraction was used as well to isolate and purify DNA samples. Phenol/chloroform extraction was 
performed in Phase Lock Gel ${ }^{\mathrm{TM}}$ ( $2 \mathrm{ml}$, heavy) tubes (Eppendorf, Hamburg). Briefly, samples were mixed with an equal volume of phenol:chloroform:isoamyl alcohol (25:24:1) and centrifuged at $14000 \mathrm{rpm}$ for $5 \mathrm{~min}$. The upper aqueous phase containing the DNA was then mixed with an equal volume of chloroform:isoamyl alcohol $(24: 1)$, centrifuged again and then transferred to new tube.

If necessary, DNA was further purified or concentrated by ethanol precipitation. 1/10 volume of $3 \mathrm{M}$ sodium acetate $\mathrm{pH} 5.2$ and a 2.5 -fold volume of ethanol were mixed with the DNA sample and incubated for $1 \mathrm{~h}$ to overnight at $-20^{\circ} \mathrm{C}$. After centrifugation at $16000 \mathrm{x} \mathrm{g}, 30 \mathrm{~min}$ at $4{ }^{\circ} \mathrm{C}$ ) the DNA pellet was washed once with $75 \%$ ethanol, air dried and then resolved in 20$50 \mu \mathrm{l}$ of sterile $\mathrm{H}_{2} \mathrm{O}$.

\subsubsection{Transformation of plasmids into chemically competent bacteria}

Plasmid DNA was transformed into chemically competent DH5 $\alpha$ or BL21CodonPlus $®(D e 3)-(R I L)$ bacteria via heat shock treatment [164]. A $50 \mu$ laliquot of bacteria was thawed on ice, DNA was added and the sample was incubated on ice for further $20 \mathrm{~min}$. After heat shock treatment at $42^{\circ} \mathrm{C}$ for 1 min the sample was put immediately on ice for 2 min. Next, $500 \mu \mathrm{l}$ of SOC medium $(2 \%(\mathrm{w} / \mathrm{v})$ tryptone, $0.5 \%(\mathrm{w} / \mathrm{v})$ yeast extract, $10 \mathrm{mM}$ $\mathrm{NaCl}, 2.5 \mathrm{mM} \mathrm{KCl}, 10 \mathrm{mM} \mathrm{MgCl}, 20 \mathrm{mM}$ glucose) was added and the mixture was incubated at $37^{\circ} \mathrm{C}$ for 60 min with shaking. Bacteria were pellet by centrifugation at $1500 \mathrm{x} \mathrm{g}$ for $2 \mathrm{~min}$ and then spread on a LB-agar plate $(1 \%(\mathrm{w} / \mathrm{v})$ tryptone, $0.5 \%(\mathrm{w} / \mathrm{v})$ yeast extract, $1 \%(\mathrm{w} / \mathrm{v}) \mathrm{NaCl}, 1 \%(\mathrm{w} / \mathrm{v})$ agar), containing the required antibiotic $(100 \mu \mathrm{g} / \mathrm{ml}$ ampicillin or $50 \mu \mathrm{g} / \mathrm{ml}$ kanamycin). The bacterial growth plate was incubated at $37^{\circ} \mathrm{C}$ overnight. A single colony was picked to inoculate growth media.

\subsubsection{General cloning procedure}

For cloning of cDNA or genomic DNA fragments into target vectors [164] the DNA sequence was amplified by PCR (2.2.3) with primers described in Section 2.2.8. The amplified DNA was purified from an agarose gel (2.2.4) and digested with the same restriction endonucleases used for the target vector. After restriction digest the DNA fragments were separated by agarose gel electrophoresis and purified by gel extraction (2.2.4). The vector sequence was dephosphorylated with Antarctic phosphatase [163]. Ligation was performed in a total reaction volume of $20 \mu \mathrm{l}$ containing $100 \mathrm{ng}$ vector, 3 - to 8-fold molar excess of insert DNA, 1 $\mu 1$ of T4 DNA ligase (NEB) and 1x reaction buffer (provided by the manufacturer). After incubation at RT for $2 \mathrm{~h}$ or $15^{\circ} \mathrm{C}$ overnight $10 \mu \mathrm{l}$ of the reaction were transformed into DH5 $\alpha$ (2.2.6), plated on agar plates with the corresponding antibiotic and incubated at $37^{\circ} \mathrm{C}$ overnight. Single colonies were picked and grown in $5 \mathrm{ml}$ LB medium (containing the antibiotic corresponding to the used cloning vector) at $37^{\circ} \mathrm{C}$ overnight. $500 \mathrm{ng}$ of plasmid DNA purified from these cultures (2.2.1) was digested with the restriction enzymes used for cloning and separated by agarose gel electrophoresis. Plasmids exhibiting the correct insert sizes were sequenced by MWG (Ebersberg) or Seqlab (Göttingen). 


\subsubsection{Summary of cloned plasmid constructs}

\subsubsection{1 pET11a based expression vector construct}

To generate a SIR-2.2-specific antibody directed against the whole protein, the cDNA sequence of SIR-2.2 was cloned into the bacterial expression vector pET11a using NdeI and BamHI restriction sites. The sequence of SIR-2.2 was amplified by PCR (2.2.3) using cDNA isolated from wild type N2 worms (2.4.9) as template.

The following primers were used:

$\begin{array}{ll}\text { MJ75_sir-2.2cDNA_pet11a_for_NdeI: } & \text { GGAATTCCATATGATGGCTCAAAAGTTTGTACCGG } \\ \text { MJ76_sir-2.2cDNA_pet11a_rev_BamHI: } & \text { CGGGATCCCTACATTTCTTTTAAAACGTCAGAG }\end{array}$

\subsubsection{2 pEU3-NII-StrepII based expression vector constructs}

The cDNA of SIR-2.1, SIR-2.2, SIR-2.3 and SIR-2.4 was cloned into the pEU3-NII-StrepII vector for recombinant protein expression using wheat germ extract, a cell-free in vitro transcription and translation system [165]. The construct containing the cDNA of HP1 $\beta$ was kindly provided by Szabolcs Sörös (Max Planck Institute for Biophysical Chemistry, Göttingen).

The following primers were used:

$\begin{array}{ll}\text { MW09_sir-2.1cDNA_for_XhoI: } & \text { CCGCTCGAGATGTCACGTGATAGTGGCAACG } \\ \text { MW10_sir-2.1cDNA_rev_NotI: } & \text { ATAAGAATGCGGCCGCGATACGCATTTCTTCACACAAATGC } \\ \text { MJ130_sir-2.2cDNA_for_XhoI: } & \text { CCGCTCGAGATGGCTCAAAAGTTTGTACCG } \\ \text { MJ131_sir-2.2cDNA_rev_NotI: } & \text { ATAAGAATGCGGCCGCCATTTCTTTTAAAACGTCAGAG } \\ \text { MW13_sir2.3cDNA_for_XhoI: } & \text { CCGCTCGAGATGGCACGAAAGTATGTACC } \\ \text { MW14_sir2.3cDNA_rev_NotI: } & \text { ATAAGAATGCGGCCGCCATTTCTTTCAAAACATCCG } \\ & \\ \text { MW11_sir2.4cDNA_for_XhoI: } & \text { CCGCTCGAGATGAAATCTGCAAAATACAAAACCG } \\ \text { MW12_sir2.4cDNA_rev_NotI: } & \text { ATAAGAATGCGGCCGCGCTAATTTTCAATGGAATAGGCAC }\end{array}$

\subsection{9 pCDNA3.1(+)-FLFL-HAHA-N mammalian expression vector based constructs}

To express $C$. elegans and mammalian proteins with an N-terminal FLAG-tag in mammalian cells cDNA sequences were cloned into the mammalian expression vector pCDNA3.1(+)FLFL-HAHA-N, kindly provided by Nora Köster-Eiserfunke (Max Planck Institute for Biophysical Chemistry, Göttingen) [156].

The sequences of $C$. elegans proteins were amplified by PCR (2.2.3) using cDNA isolated from wild type $\mathrm{N} 2$ worms (2.4.9) as template. The DNA sequences of the mammalian proteins were obtained by PCR from cDNA of NIH3T3 cells, kindly provided by Nils Kost (Max Planck Institute for Biophysical Chemistry, Göttingen). Mouse SIRT5 cDNA was amplified from the plasmid pCAGGS-SIRT5 kindly provided by the laboratory of Leonard Guarente (Massachusetts Institute of Technology, Cambridge, USA). 
The following primers were used:

C. elegans SIR-2 proteins:

MW24_sir-2.1cDNA_for_NotI:

MW10_sir-2.1cDNA_rev_NotI:

ATAAGAATGCGGCCGCATGTCACGTGATAGTGGCAACG

ATAAGAATGCGGCCGCGATACGCATTTCTTCACACAAATGC

MJ94_sir_2.2_cDNA_for_BamHI:CGCGGATCCATGGCTCAAAAGTTTGTACCGG

MJ131_sir-2.2cDNA_rev_NotI: ATAAGAATGCGGCCGCCATTTCTTTTAAAACGTCAGAG

MW25_sir2.3cDNA_for_NotI: ATAAGAATGCGGCCGCATGGCACGAAAGTATGTACC

MW14_sir2.3cDNA_rev_NotI: ATAAGAATGCGGCCGCCATTTCTTTCAAAACATCCG

C. elegans ACDH-3:

MW79_acdh-3cDNA_for_NotI: ATAAGAATGCGGCCGCATGTCTTCCTTGTCTCGGTCTC

MW80_acdh-3cDNA_rev_NotI: ATAAGAATGCGGCCGCAGCCTTTTGTTGATATTCGATGTC

C. elegans CYC-1:

MW62_cyc-2.1cDNA_for_NotI: ATAAGAATGCGGCCGCATGTCCGATATCCCAGCTGGAG

MW63_cyc-2.1cDNA_rev_NotI: ATAAGAATGCGGCCGCGAGGGACTTGGCGGATTCAACC

C. elegans biotin carboxylases:

MW75_mecc-1cDNA_for_NotI: ATAAGAATGCGGCCGCATGCTTGGTGTATTCCAAAAACGATGTGC

MW76_mccc-1cDNA_rev_NotI: ATAAGAATGCGGCCGCTGCGAATTGAACCAAAACTGC

MW83_pcca-1cDNA_for_NotI: ATAAGAATGCGGCCGCATGCTCCGTGCTGCATCCAG

MW84_pcca-1cDNA_rev_NotI: ATAAGAATGCGGCCGCCTCGAGCTCAACGAGCACCTC

MW121_pyc-1cDNA_for_NotI: ATAAGAATGCGGCCGCATGCGGTTCTCCCGCATCCCACC

MW122_pyc-1cDNA_rev_NotI: ATAAGAATGCGGCCGCTGGTTCAACTTCAACTACCAAGTCTCCGG C

Mouse biotin carboxylases:

MW106_mMCCC1cDNA_for_NotI:

MW107_mMCCC1cDNA_rev_NotI:

ATAAGAATGCGGCCGCATGGCGGCGGCGGCGTTG

ATAAGAATGCGGCCGCTTTGTCAGACTCCTCCTCCTCAAA TTCC

MW103_mPCCA1cDNA_for_NotI:

ATAAGAATGCGGCCGCATGGCGGGGCAGTGGGTCAGG

MW104_mPCCA1cDNA_rev_NotI

ATAAGAATGCGGCCGCTTCCAGCTCCACAAGCAGGTCTCC

MW132_mPCcDNA_for_NotI:

ATAAGAATGCGGCCGCATGCTGAAGTTCCAAACAGTTCGA GG

MW133_mPCcDNA_rev_NotI:

ATAAGAATGCGGCCGCCTCAATCTCTAGGATGAGGTCGTC GC

Site-directed mutagenesis PCR (2.2.4) was performed to generate a SIR-2.2 construct that contains two point mutations in amino acid residues that are important for the enzymatic activity of sirtuins. The histidine $(\mathrm{H})$ residue 134 and the asparagine $(\mathrm{N})$ residue 117 were mutated to a tryrosine $(\mathrm{Y})$ and alanine $(\mathrm{A})$ residue, respectively, using the following primers:

MW181_sir-2.2cDNA_H134Y_for:

MW182_sir-2.2cDNA_H134Y_rev:

MW183_sir-2.2cDNA_N117A_for:

MW184_sir-2.2cDNA_N117A_rev:
GGTAACGGAACTTtATGGCAGTGCTCTTCAAGTAAAATGT ACAACATG

CATTTTACTTGAAGAGCACTGCCATaAAGTTCCGTTACCAT TTTTGAGC CCAATGGTTAATCACACAAgcCGTGGATGGGCTTCACTTA AAAGCGG GTGAAGCCCATCCACGgcTTGTGTGATTAACCATTGGAAT CTATCGG 


\subsubsection{0 pCDNA3.1(+)-FLFL-HAHA-C mammalian expression vector based constructs}

To map the domain mediating the interaction with mouse SIRT4 the sequences of the different biotin carboxylase domains were cloned with an C-terminal FLAG-tag into the mammalian expression vector pCDNA3.1(+)-FLFL-HAHA-C kindly provided by Nora Koester-Eiserfunke (Max Planck Institute for Biophysical Chemistry, Göttingen) [156].

The following primers were used:

Mouse pyruvate carboxylase:

MW132_mPCcDNA_for_NotI:

MW134_mPCcDNA_rev_XhoI:

ATAAGAATGCGGCCGCATGCTGAAGTTCCAAACAGTTCGA

GG

GGCCGCTCGAGTCACTCAATCTCTAGGATGAGGTCGTCG

MW132_mPC_BC_for_NotI:

ATAAGAATGCGGCCGCATGCTGAAGTTCCAAACAGTTCGA

GG

MW141_mPC_BC_rev_XhoI:

GGCCGCTCGAGTTAAACAGCAGGATCCACAGGACTGG

MW142_mPC_ATP_for_NotI:

ATAAGAATGCGGCCGCGGTCCAAGCCCAGAGGTGGTCCG

C

MW143_mPC_ATP_rev_XhoI:

GGCCGCTCGAGTTAGTTCTCCTGCCGCAGGCCCAGG

MW144_mPC-PCT_for_NotI:

ATAAGAATGCGGCCGCCCTGTGGTGCCCATAGGCCC

MW145_mPC-PCT_rev_XhoI:

GGCCGCTCGAGTTAGTTGCCAGACTTCATGGTAGCCG

MW146_mPC_BCCPL_for_NotI:

ATAAGAATGCGGCCGCTCCGACGTGTATGAGAATGAGATT $\mathrm{CC}$

MW134_mPCcDNA_rev_XhoI:

GGCCGCTCGAGTCACTCAATCTCTAGGATGAGGTCGTCG

MW147_mPC_BCCP_for_NotI:

ATAAGAATGCGGCCGCAAGGCTTTGAAGGATGTGAAGGG CC

MW134_mPCcDNA_rev_XhoI:

GGCCGCTCGAGTCACTCAATCTCTAGGATGAGGTCGTCG

Mouse propionyl carboxylase $\alpha$-subunit:

MW103_mPCCA1cDNA_for_NotI:

MW105_mPCCA1cDNA_rev_XhoI:

MW103_mPCCA1_BC_for_NotI:

MW174_mPCCA1_BC_rev_XhoI:

MW175_mPCCA1_Cterm_for_NotI:

MW105_mPCCA1_Cterm_rev_XhoI:
ATAAGAATGCGGCCGCATGGCGGGGCAGTGGGTCAGG GGCCGCTCGAGTCATTCCAGCTCCACAAGCAGGTCTCC

ATAAGAATGCGGCCGCATGGCGGGGCAGTGGGTCAGG GGCCGCTCGAGTCACACATCAGGCCTAATAACTGGTACTC

ATAAGAATGCGGCCGCGCTAAGTGGGAGCTCTCGGTAAA GTTAC

GGCCGCTCGAGTCATTCCAGCTCCACAAGCAGGTCTCC

Mouse methylcrotonyl-CoA carboxylase $\alpha$-subunit:

MW106_mMCCC1cDNA_for_NotI: MW108_mMCCC1cDNA_rev_XhoI:

MW106_mMCCC1_BC_for_NotI: MW176_mMCCC1_BC_rev_XhoI:

MW177_mMCCC1_Cterm_for_NotI:

MW108_mMCCC1_Cterm_rev_XhoI:
ATAAGAATGCGGCCGCATGGCGGCGGCGGCGTTG GGCCGCTCGAGTCATTTGTCAGACTCCTCCTCCTCAAATTC $\mathrm{C}$

ATAAGAATGCGGCCGCATGGCGGCGGCGGCGTTG GGCCGCTCGAGTCAACTGCTGAATGAAAACGGAGAGAAT TGATC

ATAAGAATGCGGCCGCGGGAGAAGACTGAATATCTCTTAC ACCAGG GGCCGCTCGAGTCATTTGTCAGACTCCTCCTCCTCAAATTC $\mathrm{C}$ 


\subsubsection{1 pEGFP-N1 mammalian expression vector based constructs}

To express $C$. elegans and mouse sirtuins with an N-terminal GFP-tag in HEK293 cells, the sequences were cloned into the mammalian expression vector pEGFP-N1 using the following primers:

C. elegans SIR-2 proteins:

MW09_sir-2.1cDNA_for_XhoI: MW131_sir-2.1cDNA_rev_KpnI:

MJ130_sir-2.2cDNA_for_XhoI: MW17_sir-2.2cDNA_rev_BamHI:

MJ88_sir-2.3cDNA_for_XhoI: MW130_sir-2.3cDNA_rev_BamHI:

Mitochondrial mouse sirtuins:

MW137 mSIRT3cDNA for XhoI: MW156_mSIRT3cDNA_rev_KpnI:

MW101_mSIRT4cDNA_for_XhoI: MW102_mSIRT4cDNA_rev_BamHI:

MW139_mSIRT5cDNA_for_XhoI: MW157_mSIRT5cDNA_rev_KpnI:
CCGCTCGAGATGTCACGTGATAGTGGCAACG CGGGGGTACCCCGATACGCATTTCTTCACACAAATGCG

CCGCTCGAGATGGCTCAAAAGTTTGTACCG GGGATCCGCGCGCATTTCTTTTAAAACGTCAGAG

CCGCTCGAGTGTATGGCACGAAAGTATGTACC GGGATCCGCGCGCGATGAAAATTGGTTTGTTTTGC

\author{
GGCCGCTCGAGATGGCGCTTGACCCTCTAGGCG \\ CGGGGGTACCCCTCTGTCCTGTCCATCCAGCTTGCC \\ CCGCTCGAGATGAGCGGATTGACTTTCAGGCCG \\ GGGATCCGCGCGGGGATCTTGAGCAGCGGAACTCAG \\ GGCCGCTCGAGATGCGACCTCTCCTGATTGCTCC \\ CGGGGGTACCCCAGAAGTCCTTTCAGTTTCATGAGGAGC
}

\subsubsection{L4440 based constructs}

For knockdown of SIR-2.2 and SIR-2.3 by RNAi feeding the cDNA sequences were cloned into the vector L4440 using the following primers:

\begin{tabular}{|c|c|}
\hline MJ39_sir-2.2cDNA_for_KpnI: & GGGGTACCCCGCCGAGCTCTGTGAAAATTCC \\
\hline MJ40_sir-2.2cDNA_rev_BglII: & GAAGATCTTTTATTAACTTCATCGTCGCCATGT \\
\hline MJ88_sir- & CCGCTCGAGTGTATGGCACGAAAGTATG \\
\hline MJ89_sir-2.3cDNA_rev_XhoI: & CCGCTCGAGCTTCATTGTTGCCATCTG \\
\hline
\end{tabular}

\subsubsection{2 pPD115.62 based constructs}

To generate transgenic C. elegans strains that express GFP-tagged (C-terminal) SIR-2.2 under control of the endogenous promoter, the genomic sequence of SIR-2.2 was cloned into the vector pPD115.62 (Andrew Fire, Stanford University, Stanford, USA) using PstI and MluI restriction sites. The myo-3 promoter was removed and at the C-terminus a Strep-tag and a TEV protease cleavage site were introduced. The promoter and genomic sequence of SIR-2.2 was amplified by PCR from the cosmid F46G10 using the following primers:

MW18_sir-2.2promoter\&genomic_for_PstI:

MW19_sir-2.2promoter\&genomic_rev_MluI: 
To generate mCherry-tagged transgenic worm strains the sequence of gfp was replace by the sequence of mcherry using the following primer pair:

MW53_mCherry_for_MluI:

MW54_mCherry_rev_EcoRI:
CGGGACGCGTGGCATGGTGAGCAAGGGCGAGGAGG GCGCGGAATTCTTACTTGTACAGCTCGTCCATGCCG

\subsection{Protein biochemical methods}

\subsubsection{SDS polyacrylamide gel electrophoresis (SDS-PAGE)}

Separation of proteins according to their molecular weight was performed by SDS polyacrylamide gel electrophoresis [166] based on standard protocols [167]. Tris-glycine gels with a $10 \%, 12 \%$ or $15 \%$ separating gel (10-15\% acrylamide/bisacrylamide (37.1:1), $0.4 \mathrm{M}$ Tris, $0.1 \%(\mathrm{w} / \mathrm{v})$ SDS, $5 \%$ (v/v) glycerol, $0.1 \%$ (w/v) APS, $0.04 \%$ (v/v) TEMED, pH 8.8) and a $4 \%$ stacking gel (4\% acrylamide/bisacrylamide (37.1:1), $0.68 \mathrm{M}$ Tris, $0.1 \%$ (w/v) SDS, $0.1 \%(\mathrm{w} / \mathrm{v})$ APS, $0.1 \%(\mathrm{v} / \mathrm{v})$ TEMED, $\mathrm{pH}$ 6.8) were poured and run using the Mini-Protean electrophoresis system (Bio-Rad, München). After boiling for $5 \mathrm{~min}$ in protein sample buffer (62.5 mM Tris, 8.5\% (v/v) glycerol, 2\% (w/v) SDS, $100 \mu \mathrm{g} / \mathrm{ml}$ bromphenol blue, $150 \mathrm{mM} 2-$ mercaptoethanol) the samples were loaded onto the gels and separated at a constant voltage of 150-200 V in SDS-PAGE running buffer (25 mM Tris, $200 \mathrm{mM}$ glycine, $0.1 \%(\mathrm{w} / \mathrm{v})$ SDS) until the tracking dye reached the bottom of the gel. SeeBlue ${ }^{\circledR}$ Plus2 Pre-Stained protein standard (Invitrogen, Karlsruhe) was used as size reference.

For mass spectrometric analysis of protein samples the NuPAGE ${ }^{\circledR}$ Pre-cast system (Invitrogen, Karlsruhe) was used according to manufacturer's instructions.

\subsubsection{Protein detection techniques}

\subsubsection{Coomassie Blue staining}

Coomassie Blue staining was used to stain proteins in SDS-PAGE gels. The gel was incubated in Coomassie staining solution $(0.05 \%(\mathrm{w} / \mathrm{v})$ Coomassie brilliant blue, $10 \%(\mathrm{v} / \mathrm{v})$ acetic acid, $50 \%(\mathrm{v} / \mathrm{v})$ methanol) for 20-30 min at RT and then destained in destaining solution $(10 \%(\mathrm{v} / \mathrm{v})$ acetic acid, $7.5 \%(\mathrm{v} / \mathrm{v})$ methanol) for at least $60 \mathrm{~min}$ at RT.

\subsubsection{Western blotting}

For antibody-specific detection of proteins samples were separated by SDS-PAGE and transferred to a nitrocellulose membrane in transfer buffer $(25 \mathrm{mM}$ Tris, $200 \mathrm{mM}$ glycine, $20 \%(\mathrm{v} / \mathrm{v})$ methanol, $0.1 \%(\mathrm{w} / \mathrm{v}) \mathrm{SDS}$ ) for $60 \mathrm{~min}$ at $4{ }^{\circ} \mathrm{C}$ and constant voltage of $100 \mathrm{~V}$ with the Mini-Trans-Blot blotting system (Bio-Rad, München). After transfer the membrane was

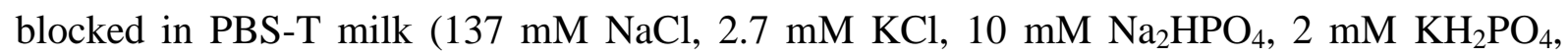
$0.1 \%(\mathrm{v} / \mathrm{v})$ Tween $^{\circledR}-20,5 \%(\mathrm{w} / \mathrm{v})$ low-fat dry milk, $\mathrm{pH} 7.4$ ) for $30-60$ min with gentle rocking. To detect the protein of interest the membrane was incubated with the primary antibody diluted in PBS-T milk (for dilutions see 2.1.6) for $60 \mathrm{~min}$ at RT or overnight at $4{ }^{\circ} \mathrm{C}$. The membrane was washed four times with PBS-T $(137 \mathrm{mM} \mathrm{NaCl}, 2.7 \mathrm{mM} \mathrm{KCl}, 10 \mathrm{mM}$ $\mathrm{Na}_{2} \mathrm{HPO}_{4}, 2 \mathrm{mM} \mathrm{KH} \mathrm{PO}_{4}, 0.1 \%$ (v/v) Tween $\left.{ }^{\circledR}-20,5 \%(\mathrm{w} / \mathrm{v}), \mathrm{pH} 7.4\right)$ for 15 min each and then incubated with the respective horseradish peroxidase (HRP) conjugated secondary antibodies (1:5000 dilution) in PBS-T milk for $60 \mathrm{~min}$ at RT. The membrane was washed 
again with PBS-T four times for $15 \mathrm{~min}$ each. To detect the protein of interest chemiluminescently ECL or ECL Plus Western Blotting Detection Reagents (GE Healthcare) and Amersham Hyper ECL films (GE Healthcare) were used according to manufacturer's instructions. Films were developed with the Kodak X OMAT 2000 processor.

\subsubsection{Mass spectrometry and data analysis}

Protein samples were analyzed by mass spectrometry (MS) in the group of Dr. Henning Urlaub at the Max Planck Institute for Biophysical Chemistry (Göttingen). Proteins were separated on NuPAGE ${ }^{\circledR}$ gels (2.3.1) and stained with Coomassie (2.3.2.1). Entire individual lanes were cut into 23 slices of equal size and digested according to Shevchenko et al. [168]. After extraction peptides were analyzed by LC-coupled tandem MS on an Orbitrap XI mass spectrometer (Thermo Fisher Scientific). The MASCOT search engine (with the taxonomy filter C. elegans) was used to search CID fragment spectra against the NCBInr database. The statistical program $\mathrm{R}$ was used to analyze output files and substract output files from each through their gi-numbers (NCBI).

\subsubsection{Generation of SIR-2.2-specific antibodies using recombinant protein for immunization}

\subsubsection{Expression of recombinant SIR-2.2 in E. coli}

To express non-tagged SIR-2.2 protein the plasmid pET11a containing the cDNA sequence of SIR-2.2 (2.2.8) was transformed into E. coli BL21 (DE3) RIL cells (2.2.6) and a single colony was picked to inoculate $100 \mathrm{ml}$ pre-culture (LB medium) and finally 61 of ZYM-5052 autoinducing medium $(1 \%(\mathrm{w} / \mathrm{v}) \mathrm{N}-\mathrm{Z}$-amine (enzymatic digested casein from bovine milk), $0.5 \%$ $(\mathrm{w} / \mathrm{v})$ yeast extract, $0.5 \%(\mathrm{w} / \mathrm{v})$ glycerol, $0.05 \%(\mathrm{w} / \mathrm{v})$ glucose, $0.2 \%(\mathrm{w} / \mathrm{v}) \alpha$-lactose, $25 \mathrm{mM}$ $\mathrm{Na}_{2} \mathrm{HPO}_{4}, 25 \mathrm{mM} \mathrm{KH}_{2} \mathrm{PO}_{4}, 50 \mathrm{mM} \mathrm{NH} 4 \mathrm{Cl}, 5 \mathrm{mM} \mathrm{Na} \mathrm{SO}_{4}, 2 \mathrm{mM} \mathrm{MgCl} 2,50 \mu \mathrm{M} \mathrm{FeCl}_{3}, 20$ $\mu \mathrm{M} \mathrm{CaCl}_{2}, 10 \mu \mathrm{M} \mathrm{MnCl}_{2}, 10 \mu \mathrm{M} \mathrm{ZnSO}_{4}, 2 \mu \mathrm{M} \mathrm{CoCl}_{2}, 2 \mu \mathrm{M} \mathrm{CuCl}_{2}, 2 \mu \mathrm{M} \mathrm{NiCl}, 2 \mu \mathrm{M}$ $\mathrm{Na}_{2} \mathrm{MoO}_{2}, 2 \mu \mathrm{M} \mathrm{Na}_{2} \mathrm{SeO}_{3}, 2 \mu \mathrm{M} \mathrm{H}_{3} \mathrm{BO}_{3}$ ) both containing $100 \mu \mathrm{g} / \mathrm{ml}$ ampicillin [169]. After shaking $24 \mathrm{~h}$ at $25^{\circ} \mathrm{C}$ bacteria were harvested by centrifugation at $6000 \mathrm{x} \mathrm{g}$ for $15 \mathrm{~min}$ at $4{ }^{\circ} \mathrm{C}$. Expression of protein was checked by analyzing an aliquot of bacteria by SDS-PAGE (2.3.1) and Coomassie Blue staining (2.3.2.1).

\subsubsection{Purification of recombinant SIR-2.2 from inclusion bodies}

Since full-length non-tagged SIR-2.2 was not soluble when expressed in E. coli, it was purified from inclusion bodies analog to Luger et al. [170] with some modifications. The bacterial pellet from 2.3.4.1 was resuspended in $30 \mathrm{ml}$ washing buffer $(50 \mathrm{mM}$ Tris, $100 \mathrm{mM}$ $\mathrm{NaCl}, 1 \mathrm{mM}$ EDTA, $1 \mathrm{mM}$ PMSF, $1 \mathrm{mM}$ benzamidine, $1 \mathrm{mM}$ DTT, pH 7.5) and lyzed with the EmulsiFlex-C5 cell disruptor (Avestin) at $4^{\circ} \mathrm{C}$ until homogeneity was reached. After centrifugation at $23000 \mathrm{x} \mathrm{g}$ and $4{ }^{\circ} \mathrm{C}$ for 20 min the pellet containing the SIR-2.2 inclusion bodies was resuspended and washed twice with $150 \mathrm{ml}$ TW buffer $(50 \mathrm{mM}$ Tris, $100 \mathrm{mM}$ $\mathrm{NaCl}, 1 \mathrm{mM}$ EDTA, $1 \mathrm{mM}$ PMSF, 1mM benzamidine, $1 \mathrm{mM}$ DTT, $1 \%$ (v/v) Triton X-100, $\mathrm{pH}$ 7.5) followed by two washes with $150 \mathrm{ml}$ wash buffer. To extract the inclusion bodies 1 $\mathrm{ml}$ DMSO was added and the pellet was incubated at RT for at least $30 \mathrm{~min} .10 \mathrm{ml}$ unfolding buffer (7 M guanidinium-HCl, $20 \mathrm{mM}$ Tris- $\mathrm{HCl}, 10 \mathrm{mM}$ DTT, $\mathrm{pH}$ 8.0) were added and the 
pellet was shaken gently for $1 \mathrm{~h}$ at RT. To remove non-dissolved material the suspension was centrifuged for $20 \mathrm{~min}$ at $23000 \mathrm{x} \mathrm{g}$ and $4^{\circ} \mathrm{C}$. The supernatant was saved and subjected to further purification by gel-filtration.

\subsubsection{Gelfiltration and ion exchange chromatography}

Gelfiltration and ion exchange chromatography were performed on the ÄKTA Explorer FPLC instrument (GE Healthcare). The protein extract was first purified using an XK50/100 Sephacryl S-200 high-resolution gel-filtration column (GE Healthcare) that had been equilibrated with SAU1000 buffer (7 mM deionized urea (passed over Amberlite MB3 ion exchange resin prior to use), $20 \mathrm{mM}$ Tris-HCl, $1 \mathrm{mM}$ EDTA, $1 \mathrm{M} \mathrm{NaCl}, 2 \mathrm{mM}$ DTT, $\mathrm{pH}$ 8.0). Eluted peak fractions that contained SIR-2.2 were combined, diluted 1:20 in SAU-0 buffer (7 $\mathrm{mM}$ deionized urea, $20 \mathrm{mM}$ Tris-HCl, $1 \mathrm{mM}$ EDTA, $2 \mathrm{mM}$ DTT, $\mathrm{pH}$ 10.5) and applied to a MonoQ $^{\mathrm{TM}}$ 5/50 GL Anion exchange column (GE Healthcare) equilibrated in SAU-0 buffer. SIR-2.2 was eluted with a linear gradient from $50 \mathrm{mM}$ to $1 \mathrm{M} \mathrm{NaCl}$ in 20 column volumes. Fractions containing SIR-2.2 were pooled and analyzed for purity by SDS-PAGE (2.3.1) and Coomassie Blue staining (2.3.2.1).

\subsubsection{High-performance liquid chromatography (HPLC)}

To further improve the purity of the SIR-2.2 sample (2.3.4.3) HPLC was performed using the HPLC Prominence system (Shimadzu) and a VYDAC ${ }^{\circledR}$ 208TP C8 reverse phase column (Grace, Deerfield, USA). Peak fractions containing highly pure SIR-2.2 were pooled and lyophilized in the SpeedVac Savant SPD131DDA (Thermo Scientific, Braunschweig).

\subsubsection{Immunization, purification and characterization of SIR-2.2-specific antibodies from antiserum}

Two rabbits were immunized with recombinant SIR-2.2 protein by the Charles River Laboratory according to their proprietary protocol. For immunization of each rabbit $1.6 \mathrm{mg}$ protein at a concentration of $1 \mathrm{mg} / \mathrm{ml}$ in $3 \mathrm{M}$ urea and $50 \mathrm{mM} \mathrm{NaPhosphate} \mathrm{buffer} \mathrm{pH} 6.8$ were forwarded to the company.

The serum of both rabbits was tested on crude $C$. elegans lysates (2.4.7.3) of N2 and sir2.2(tm2648)X and sir-2.2(tm2673)X mutant worms by Western blot analysis (2.3.2.2). Sir2.2-specific antibodies present in the serum of one rabbit were affinity purified using SIR-2.2 protein bound to nitrocellulose membranes $[171,172]$. Briefly, $1 \mathrm{mg}$ of recombinant SIR-2.2 (protein also used for immunization) was loaded onto 4 SDS-PAGE gels and transferred onto nitrocellulose membranes (GE Healthcare) by Western blotting. After staining the membranes with Ponceau-S solution (5\% (v/v) acetic acid, 0.1\% (w/v) Ponceau-S), the bands of SIR-2.2 were cut out, destained by washing with PBS-T and dried. The membrane stripes containing SIR-2.2 protein were blocked with PBS-T milk for $1 \mathrm{~h}$ at RT and then washed three times with PBS-T. $2 \mathrm{ml}$ serum were diluted with $8 \mathrm{ml}$ PBS (1:5) and incubated with the membrane stripes for 2-3 $\mathrm{h}$ at RT or overnight at $4^{\circ} \mathrm{C}$. After washing four times $10 \mathrm{~min}$ each with PBS-T SIR-2.2-specific antibodies were eluted from the membrane stripes with glycine elution buffer (5 mM glycine, $0.01 \%$ BSA, $0.05 \%$ Tween, $500 \mathrm{mM} \mathrm{NaCl}, \mathrm{pH} 2.6$ ). One membrane stripe at a time was swirled for $30 \mathrm{sec}$ with $2 \mathrm{ml}$ glycine elution buffer. The buffer was then immediately transferred to a $15 \mathrm{ml}$ tube with $600 \mu \mathrm{l} 1 \mathrm{M}$ Tris $\mathrm{pH} 8.0$. The glycine elution step 
was repeated twice and the eluates were all pooled in the same tube. The $\mathrm{pH}$ of the eluate was checked with $\mathrm{pH}$ stripes and was between $\mathrm{pH}$ 7-8. The eluates of all four membrane stripes were pooled, dialyzed against $\mathrm{PBS}$ at $4{ }^{\circ} \mathrm{C}$ overnight and concentrated to a volume of approximately $1 \mathrm{ml}$ with an Amicon Ultra centrifugal filter (Millipore). For long-term storage of the SIR-2.2-specific antibodies sodium azide was added to a final concentration of $0.05 \%$ $(\mathrm{w} / \mathrm{v})$ and the aliqots were stored at $4{ }^{\circ} \mathrm{C}$ for further use.

The specificity of the SIR-2.2 antibodies was analyzed on crude C. elegans lysate (2.4.7.3) of wild type $\mathrm{N} 2$ and sir-2.2 deletion mutant worm strains (sir-2.2(tm2648) and sir-2.2(tm2673)) by Western blotting (2.3.2.2). The antibodies of one rabbit specifically detected SIR-2.2 and are referred to as anti-SIR-2.2 antibodies in this study. These antibodies were used for Western blot and immunoprecipitation experiments (2.4.8).

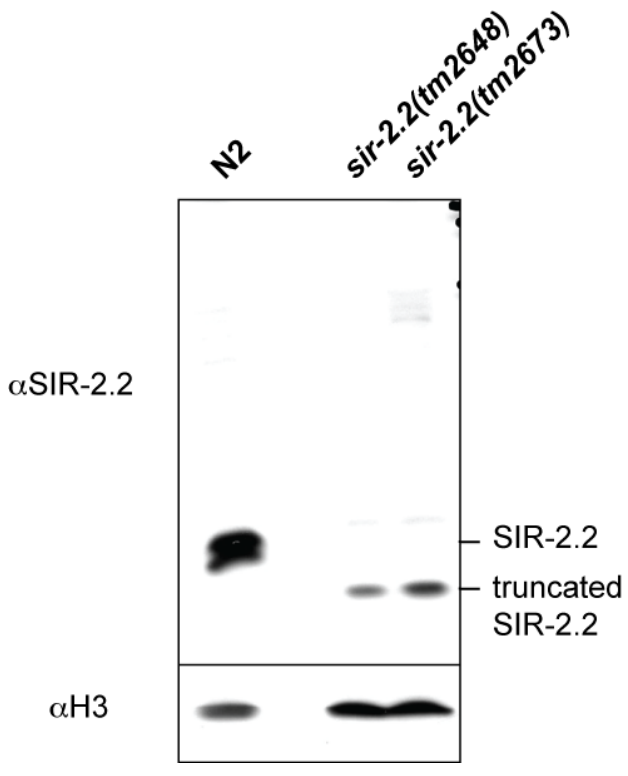

Figure 2-1: Western blot analysis of generated SIR-2.2-specific antibodies.

Crude extracts of wild type N2, sir2.2(tm2648) and sir-2.2(tm2673) mutant worms were separated by SDS PAGE and analyzed by Western blotting using the antiSIR-2.2 antibodies in a dilution of 1:1000. Western blot analysis with anti-H3 antibodies was used to confirm equal loading. Running positions of the full-length and truncated SIR-2.2 protein are indicated on the right.

\subsection{C. elegans based methods}

\subsubsection{Culturing $C$. elegans on agar plates}

C. elegans strains were maintained on Nematode Growth Medium (NGM) agar plates $(0.3 \%$ (w/v) $\mathrm{NaCl}, 0.25 \%(\mathrm{w} / \mathrm{v})$ peptone, $1.7 \%$ (w/v) agar, $5 \mathrm{mg} / \mathrm{l}$ cholesterol, $1 \mathrm{mM} \mathrm{CaCl} 2,1 \mathrm{mM}$ $\mathrm{MgSO}_{4}, 25 \mathrm{mM}$ K-phosphate buffer, $\mathrm{pH}$ 6.0, $100 \mu \mathrm{g} / \mathrm{ml}$ streptomycin, $10 \mu \mathrm{g} / \mathrm{ml}$ nystatin) seeded with $E$. coli $\mathrm{OP} 50-1$ at $15^{\circ} \mathrm{C}, 20^{\circ} \mathrm{C}$ or $24.5^{\circ} \mathrm{C}[158,173]$. Larger quantities of worms were obtained on Super NGM plates $(0.3 \%(\mathrm{w} / \mathrm{v}) \mathrm{NaCl}, 2 \%(\mathrm{w} / \mathrm{v})$ peptone, $1.7 \%(\mathrm{w} / \mathrm{v})$ agar,

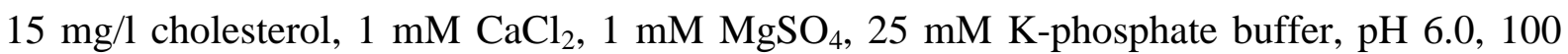
$\mu \mathrm{g} / \mathrm{ml}$ streptomycin, $10 \mu \mathrm{g} / \mathrm{ml}$ nystatin) which produced a much thicker bacterial lawn and allowed the worms to grow to higher densities [174].

Worms were transferred form an old plate to a new plate either by cutting out a chunk of agar with a spatula and putting it on a new plate, or by picking individual worms with a platinum wire mounted to a pasteur pipette. 


\subsubsection{Liquid culture of $C$. elegans}

For biochemical analyses large quantities of $C$. elegans were generated by growing worms in liquid culture [175]. Worms of approximately $5(9 \mathrm{~mm})$ NGM plates were washed off with $\mathrm{dH}_{2} \mathrm{O}$. After washing three times with $\mathrm{dH}_{2} \mathrm{O}$ the worms or axenic eggs (obtained from hypochloride treatment (2.4.3)) were used to inoculate $200 \mathrm{ml} \mathrm{S}$ basal Medium $(0.1 \mathrm{M} \mathrm{NaCl}$, $50 \mathrm{mM}$ K-phosphate buffer $\mathrm{pH} 6.0,5 \mathrm{mg} / \mathrm{ml}(\mathrm{w} / \mathrm{v})$ cholesterol, $10 \mathrm{mM} \mathrm{K}$-citrate $\mathrm{pH}$ 6.0, 6.4

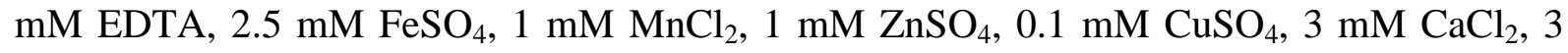
$\mathrm{mM} \mathrm{MgSO}_{4}, 1 \mathrm{x}$ Penicillin/Streptomycin/Neomycin (PNS, Gibco), 1x Steptomycin (Sigma)) supplemented with $2 \mathrm{ml}$ concentrated $\mathrm{HB} 101$ bacterial solution. The worm cultures were incubated at $15^{\circ} \mathrm{C}, 20^{\circ} \mathrm{C}$ or $25^{\circ} \mathrm{C}$ while shaking $(120 \mathrm{rpm})$ for 3 to 6 days until a high worm density had been reached with the majority of worms being adults. The growth of the worms was monitored daily by inspecting small aliquots of worm culture with a dissecting microscope. More bacterial solution was added to the culture if required. For harvesting, the worm suspension was transferred to $50 \mathrm{ml}$ falcon tubes and centrifuged at $1500 \mathrm{x} \mathrm{g}$ and $4{ }^{\circ} \mathrm{C}$ for $3 \mathrm{~min}$. The worm pellet was washed several times with $\mathrm{dH}_{2} \mathrm{O}$ until the supernatant was clear. Depending on further experiments the worm pellet was either flash frozen in liquid $\mathrm{N}_{2}$ and stored at $-80^{\circ} \mathrm{C}$ or directly lyzed for preparation of mitochondria (2.4.7.2).

\subsubsection{Axenization to synchronize or decontaminate C. elegans}

Worms were harvested when the plates contained many gravid hermaphrodites and washed several times with $\mathrm{dH}_{2} \mathrm{O}$. Worms were resolved by treatment with bleach solution $(0.5 \mathrm{M}$ $\mathrm{NaOH}, 1.2 \% \mathrm{NClO}$ ) for $10 \mathrm{~min}$ with frequent vortexing in between. The released axenized eggs were collected by centrifugation at $1500 \mathrm{x} \mathrm{g}, 4^{\circ} \mathrm{C}$ for $3 \mathrm{~min}$ and washed three times with $\mathrm{dH}_{2} \mathrm{O}$. The eggs were either directly transferred to fresh NGM plates or further staged by incubation in $\mathrm{M} 9$ buffer overnight at $20^{\circ} \mathrm{C}$. In the absence of food hatched larvae arrested in L1 stage and resumed growth after transferring them onto fresh NGM plates the next day. If worms were severely contaminated gentamycin $(10 \mathrm{mg} / \mathrm{l})$ was added to the M9 buffer for overnight incubation [173].

\subsubsection{Freezing and recovery of C. elegans stocks}

For indefinite storage C. elegans strains were frozen and kept at $-80^{\circ} \mathrm{C}$. Worms of $2-3$ freshly starved $90 \mathrm{~mm}$ plates (containing many L1-L2 stage larvae) were washed off plates with $\mathrm{dH}_{2} \mathrm{O}$ and collected in a $15 \mathrm{ml}$ falcon tube. The tube was incubated on ice until worms had settled to the bottom of the tube. The supernatant was removed and the volume of the worm suspension was adjusted to 3-4 $\mathrm{ml}$ with $\mathrm{dH}_{2} \mathrm{O}$. After adding an equal volume of freezing solution $\left(0.3 \%\right.$ (w/v) $\mathrm{KH}_{2} \mathrm{PO}_{4}, 0.6 \%$ (w/v) $\mathrm{Na}_{2} \mathrm{HPO}_{4}, 0.5 \%$ (w/v) $\mathrm{NaCl}, 1 \mathrm{mM} \mathrm{MgSO}$, $30 \%$ glycerin (v/v)), the worm suspension was mixed and aliquoted into cryotubes $(1 \mathrm{ml} /$ tube). The cryotubes were packed in a styrofoam box and frozen at $-80^{\circ} \mathrm{C}$. For recovery of a C. elegans stock, a frozen aliquot was thawed at RT and transferred onto a fresh NGM plate [158, 173].

\subsubsection{Single worm PCR}

To determine whether a worm is homozygous or heterozygous for a particular deletion allele, single worm duplex PCR genotyping was performed [119]. A single hermaphrodite was picked into $2.5 \mu \mathrm{l}$ single worm PCR lysis buffer (10 mM Tris, $50 \mathrm{mM} \mathrm{KCl,} 2.5 \mathrm{mM} \mathrm{MgCl}{ }_{2}$, 
$0.45 \%$ (v/v) NP-40, $0.45 \%$ (v/v) Tween 20, 0.01\% (w/v) gelatin, $100 \mu \mathrm{g} / \mathrm{ml}$ Proteinase K, $\mathrm{pH}$ 8.3) of a PCR tube. The tube was frozen at $-80^{\circ} \mathrm{C}$ for $30 \mathrm{~min}$. Worms were lyzed in the PCR machine by incubating them at $60^{\circ} \mathrm{C}$ for $60 \mathrm{~min}$ followed by $15 \mathrm{~min}$ at $95^{\circ} \mathrm{C}$ to inactivate the Proteinase K. The PCR reaction was then performed with three primers that can amplify two different-sized PCR products, each arising only from the wild type or deletion allele, respectively. Primer F1 (forward primer) and primer R1 (reverse primer) were placed outside and primer F2 (forward primer) within the deletion mutation. Due to a relatively short elongation time primers F2 and R1 produced a $\sim 250-400$ bp long wild type amplicon and primers $\mathrm{F} 1$ and $\mathrm{R} 1 \mathrm{a} \sim 100 \mathrm{bp}$ larger deletion allele amplicon.

To each lyzed worm $22.5 \mu \mathrm{l}$ PCR reaction buffer $(2.2 \mathrm{mM} \mathrm{MgCl} 2,250 \mu \mathrm{M}$ of each dNTP (Roche), $0.7 \mu \mathrm{M}$ of each primer, 0.5 unit Taq DNA polymerase (Fermentas), 1x reaction buffer (provided by the manufacturer)) and the PCR was performed using the following protocol: $3 \mathrm{~min}$ at $94^{\circ} \mathrm{C}$; [ $40 \mathrm{sec}$ at $94^{\circ} \mathrm{C}, 40 \mathrm{sec}$ at $55^{\circ} \mathrm{C}, 40 \mathrm{sec}$ at $72^{\circ} \mathrm{C}$ ] $8 \mathrm{x}$; [40 sec at $94^{\circ} \mathrm{C}$, $40 \mathrm{sec}$ at $56^{\circ} \mathrm{C}, 40 \mathrm{sec}$ at $\left.72^{\circ} \mathrm{C}\right] 22 \mathrm{x} ; 5 \mathrm{~min}$ at $72^{\circ} \mathrm{C}$.

The following primers were used to genotype sir-2.2(tm2648) and sir-2.2(tm2673) deletion mutant worms:

MW27_sir-2.2_F1

MW28_sir-2.2_R1

MW29_sir-2.2_F2
GCAGGAATATCTACAGAATCTGG

AGAGGCGTCCATACTCTCTTAG

GGTACATTGGACTGAATCAACTC

The following primers were used to analyze sir-2.3(ok444) deletion mutant worms:

MW34_sir-2.3_R1

MW35_sir-2.3_F2

MW36_sir-2.3 F1
CTGATCAGCTCTAGTAGGTCCA

CCGACTTACTTAATCATACCAC

GGCTCATAACTGCTCTCACG

\subsubsection{Isolation of Mitochondria for cellular subfractionation}

Mitochondria were isolated based on the protocol of Li et. al. [176] with minor modifications. Synchronized worms were obtained from axenic eggs by treatment with hypochloride (2.4.3) and harvested when grown to adult stage on Super NGM plates.

Worms were washed of plates with $\mathrm{dH}_{2} \mathrm{O}$ and collected by centrifugation at $3000 \mathrm{rpm}$ at $4{ }^{\circ} \mathrm{C}$ for $3 \mathrm{~min}$. After washing three to four times worms were resuspended in M9 buffer $(0.3 \%$ $\mathrm{KH}_{2} \mathrm{PO}_{4}, 0.6 \% \mathrm{Na}_{2} \mathrm{HPO}_{4}, 0.5 \% \mathrm{NaCl}, 1 \mathrm{mM} \mathrm{MgSO}$ ) and incubated $30 \mathrm{~min}$ at $\mathrm{RT}$ to allow them to digest remaining bacteria in the gut. The isolation of mitochondria was performed in the cold room and throughout the purification procedure all samples were kept on ice. For isolation of mitochondria five to $10 \mathrm{~g}$ of worms were resuspended in $20 \mathrm{ml}$ lysis buffer (250 mM sucrose, $10 \mathrm{mM}$ HEPES $\mathrm{pH} 7.5,1 \mathrm{mM}$ EGTA) containing protease inhibitor cocktail (complete EDTA-free, Roche, Mannheim) and homogenized in a glass tissue grinder using 20 strokes. The homogenate was centrifuged at $800 \mathrm{x} \mathrm{g}$ for $10 \mathrm{~min}$ at $4^{\circ} \mathrm{C}$. The supernatant was saved and the pellet was resuspended in another $20 \mathrm{ml}$ of lysis buffer. To achieve disruption of more than $90 \%$ of the worms the homogenization procedure and $800 \mathrm{x} \mathrm{g}$ centrifugation step were repeated four times. Afterwards, supernatants were pooled (corresponding to the postnuclear supernatant) and centrifuged at $12000 \mathrm{x} \mathrm{g}$ for $10 \mathrm{~min}$ at $4^{\circ} \mathrm{C}$. The resulting supernatant, which is referred to the postmitochondrial supernatant, was 
saved. To increase the purity of the crude mitochondria, the pellet was gently resuspended in $10 \mathrm{ml}$ lysis buffer and subsequently centrifuged at $800 \mathrm{x} \mathrm{g}$. The pellet was discarded and the collected supernatant was centrifuged at $12000 \mathrm{x} \mathrm{g}$ for $10 \mathrm{~min}$ at $4^{\circ} \mathrm{C}$. The final crude mitochondrial pellet was resuspended in LB buffer. After adjusting the protein concentration to $5-10 \mathrm{mg} / \mathrm{ml}$ with $\mathrm{LB}$, aliquots were flash frozen in liquid $\mathrm{N}_{2}$ and stored at $-80^{\circ} \mathrm{C}$.

During the purification procedure aliquots of the postnuclear supernatant, postmitochondrial supernatant and final crude mitochondrial pellet were taken and analyzed by SDS-PAGE and Western blotting (2.3.2.2).

\subsubsection{Preparation of C. elegans protein extracts}

\subsubsection{Preparation of total worm protein extracts}

Total worm protein extract was prepared according to Cheeseman et al. [177] with some modifications. Sufficient amounts of worms were obtained by liquid culture (2.4.2). Approximately $5 \mathrm{~g}$ of frozen worm pellet was grounded in liquid $\mathrm{N}_{2}$ with a pre-chilled mortar and pestle. An equal volume of 2x Cheeseman buffer (50 mM Hepes, 2 mM EGTA, $2 \mathrm{mM}$ $\mathrm{MgCl} 2,200 \mathrm{mM} \mathrm{KCl}, 20 \%$ (v/v) glycerol, 0.1\% (v/v) NP-40, $\mathrm{pH}$ 7.4) containing 2x protease inhibitor cocktail (Complete EDTA-free Protease inhibitor, Roche) was added to the grounded worms, thawed on ice and then sonicated with a Branson Digital Sonifier using the following settings: $30 \%$ amplitude for $3 \mathrm{~min}$ total (15 sec on, $59 \mathrm{sec}$ off), $40 \%$ amplitude for $30 \mathrm{sec}$ total (15 sec on, $59 \mathrm{sec}$ off). After centrifugation at $22000 \mathrm{x} \mathrm{g}$ and $4{ }^{\circ} \mathrm{C}$ for $10 \mathrm{~min}$ the supernatant was transferred to a fresh ultracentrifuge tube and further clarified by centrifugation at $\sim 105000 \mathrm{~g}$ and $4^{\circ} \mathrm{C}$ for $20 \mathrm{~min}$. The supernatant was collected in a fresh tube and protein concentration of the extract was determined using the Coomassie Plus (Bradford) Protein Assay (Thermo Scientific) according to manufacturer's instructions.

\subsubsection{Preparation of mitochondrial protein extracts}

For mitochondrial protein extract preparation mitochondria were isolated according to the protocol described by Gandre and van der Bliek [178] with some modifications. $5 \mathrm{~g}$ of worms grown in liquid culture (2.4.2) were resuspended in $10 \mathrm{ml}$ ice-cold isolation buffer (IB) (210 mM mannitol, $70 \mathrm{mM}$ sucrose, $10 \mathrm{mM}$ Hepes, $0.1 \mathrm{mM}$ EDTA, 0,4\% (w/v) BSA, 1x Complete EDTA-free protease inhibitor (Roche), $\mathrm{pH}$ 7.6) and homogenized in a chilled Glass-Teflon Potter (Size S) attached to a Potter homogenizer (Potter S, B. Braun Biotech) with 15 strokes at $1200 \mathrm{rpm}$. The homogenate was transferred to a $50 \mathrm{ml}$ falcon tube and centrifuged at $750 \mathrm{x}$ $\mathrm{g}$ and $4^{\circ} \mathrm{C}$ for $10 \mathrm{~min}$. The supernatant (corresponding to the postnuclear supernatant (PNS)) was collected in a fresh tube and the pellet was resuspended in $10 \mathrm{ml}$ IB. To disrupt the majority of worms, the homogenization procedure and $750 \mathrm{x}$ g centrifugation step were repeated four times. All postnuclear supernatants were pooled and then centrifuged at $12000 \mathrm{x}$ $\mathrm{g}, 4^{\circ} \mathrm{C}$ for $10 \mathrm{~min}$. The resulting supernatant referred to as postmitochondrial supernatant (PMS) was discarded, the mitochondrial pellet was resuspended carefully in $12 \mathrm{ml} \mathrm{IB}$ and centrifuged at $12000 \mathrm{x} \mathrm{g}, 4^{\circ} \mathrm{C}$ for $10 \mathrm{~min}$. The supernatant was discarded and the crude mitochondrial pellet was resuspended in IB buffer. After adjusting the protein concentration to $5-10 \mathrm{mg} / \mathrm{ml}$ with $\mathrm{IB}$, the sample was aliquoted, flash frozen in liquid $\mathrm{N}_{2}$ and stored at $80^{\circ} \mathrm{C}$. 
$1 \mathrm{ml}$ crude mitochondria were thawed on ice and centrifuged at $12000 \mathrm{x} \mathrm{g}$ and $4^{\circ} \mathrm{C}$ for 10 min. The mitochondrial pellet was resuspended in $750 \mu$ lysis buffer $(25 \mathrm{mM}$ Hepes, $1 \mathrm{mM}$ EGTA, $1 \mathrm{mM} \mathrm{MgCl} 2,500 \mathrm{mM} \mathrm{KCl,} \mathrm{10 \%} \mathrm{(v/v)} \mathrm{glycerol,} \mathrm{0.5 \%} \mathrm{(v/v)} \mathrm{NP-40,} \mathrm{pH} \mathrm{7.6)}$ containing Complete EDTA-free protease inhibitor (Roche) and incubated on a rotating platform for $\sim 1 \mathrm{~h}$ in the cold room. The sample was centrifuged at $16000 \mathrm{x} \mathrm{g}$ and $4^{\circ} \mathrm{C}$ for 30 min and the supernatant was transferred to a fresh tube. The pellet was resuspended in $1 \mathrm{ml}$ lysis buffer, rotated again for $\sim 1 \mathrm{~h}$ in the cold room before recentrifugation. Supernatants were combined and subjected to immunoprecipitation experiments.

\subsubsection{Preparation of crude $\boldsymbol{C}$. elegans lysate for Western blot analysis}

Worms were washed off NGM plates with $\mathrm{dH}_{2} \mathrm{O}$ and transferred to a $1.5 \mathrm{ml}$ tube. After centrifugation at $1500 \mathrm{x}$ g for 3 min the worm pellet was washed with $\mathrm{dH}_{2} \mathrm{O}$ several times until the supernatant was clear. The worm pellet was weighed and an equal volume of nematode solubilization buffer $(0.3 \%$ (v/v) ethanolamine, $2 \mathrm{mM}$ EDTA, $1 \mathrm{mM}$ PMSF, $5 \mathrm{mM}$ DTT) [179] and 2x SDS sample buffer were added. The sample was boiled for $10 \mathrm{~min}$, sonicated for $20 \mathrm{~min}$ (at $30 \mathrm{sec}$ on, $30 \mathrm{sec}$ off intervals) in the Bioruptor ${ }^{\mathrm{TM}}$ (Diogenode, Belgium) and boiled again for another $5 \mathrm{~min}$. After centrifugation at $16000 \mathrm{x} \mathrm{g}$ and $4^{\circ} \mathrm{C}$ for 10 min 15-20 $\mu 1$ of the supernatant were loaded onto a SDS-PAGE gel (2.3.1) for Western blot analysis (2.3.2.2).

\subsubsection{Immunoprecipitation of proteins from C. elegans extract}

Immunoprecipitation experiments were performed with total worm protein extracts (2.4.7.1) or mitochondrial protein extracts (2.4.7.2) obtained from sir-2.2::gfp (MAJ13), sir-2.3::gfp (MAJ14), BC14289/BC15074 (negative control for total worm extracts) or SJ4103/SJ4143 (negative control for mitochondrial worm extracts) transgenic worms.

$60 \mu$ l ProteinG-Sepharose beads (50\% slurry) or $40 \mu 1$ GFP-Trap ${ }^{\circledR}$-A beads were equilibrated by washing three times each with $1 \mathrm{ml}$ ice-cold PBS and centrifugation at $500 \mathrm{x} \mathrm{g}$ and $4^{\circ} \mathrm{C}$ for $5 \mathrm{~min}$. $7.5 \mu \mathrm{l}$ anti-GFP (Roche) or $25 \mu \mathrm{l}$ of the anti-SIR-2.2 antibody were bound to the ProteinG-Sepharose beads for at least $1 \mathrm{~h}$ at $4^{\circ} \mathrm{C}$ with rotation. Beads were blocked with $0.1 \%$ $(\mathrm{w} / \mathrm{v}) \mathrm{BSA}$ for $1 \mathrm{~h}$ at $4^{\circ} \mathrm{C}$ with rotation and then washed three times each with $1 \mathrm{ml} 1 \mathrm{x}$ Cheeseman buffer (2.4.7.1) before adding $1 \mathrm{ml}$ Cheesemann extract or $0.7 \mathrm{ml}$ mitochondrial extract to the beads.

For immunoprecipitation the beads were incubated at $4{ }^{\circ} \mathrm{C}$ over night with constant rotation and washed three times each with $1 \mathrm{ml}$ 1x Cheeseman buffer containing 1x Complete EDTAfree protease inhibitor (Roche). After the last wash beads were drained using a gel loading tip and boiled in $40 \mu 1$ SDS sample buffer.

\subsubsection{Crossing of C. elegans}

The sir-2.2(tm2648) and sir-2.2(tm2673) deletion mutant worms as well as the stable integrated sir-2.2::gfp and sir-2.3::gfp transgenic worms (2.4.14) were crossed back to wild type N2 worms to eliminate any potential background mutation. Crosses were set up by placing 1-4 hermaphrodites of the corresponding strain together with 10-15 N2 males on the same NGM plate for 2 days at $20^{\circ} \mathrm{C}$. Due to their roller phenotype the sir-2.2::gfp and sir2.3::gfp transgenic worms were crossed with 20-30 N2 males. If mating was successful 
( $50 \%$ occurrence of male progeny), L4 stage hermaphrodites of the F1 generation were singled on new NGM plates and allowed to lay eggs. In the case of the sir-2.2(tm2648) and sir-2.2(tm2673) mutant worms the F1 hermaphrodites were picked and analyzed by single worm PCR (2.4.5) to confirm the heterozygosity of the particular deletion alleles. F2 L4 hermaphrodites of heterozygous animals were again singled on NGM plates to lay eggs and analyzed by single worm PCR. The progeny of homozygous F2 hermaphrodites were used to set up the next backcross with $\mathrm{N} 2$ males. In the case of the sir-2.2::gfp and sir-2.3::gfp transgenic worm strains single worm PCR could not be applied and homozygosity of the F2 generation hermaphrodites was determined by $100 \%$ propagation of the GFP expression signal. The sir-2.2(tm2648) and sir-2.2(tm2673) deletion strains were crossed back to N2 worms six times and five times, respectively, the sir-2.2::gfp and sir-2.3::gfp transgenic worms were backcrossed three times. The sir-2.3(ok444) deletion mutant strain was crossed back to wild type twice by Dr. Monika Jedrusik-Bode (Max Planck Institute for Biophysical Chemistry, Göttingen).

\subsubsection{Isolation of RNA from $C$. elegans and reverse transcription}

RNA was isolated from C. elegans with TRIzol ${ }^{\circledR}$ Reagent (Invitrogen) extraction. To $0.25 \mathrm{~g}$ worms $1 \mathrm{ml}$ TRIzol ${ }^{\circledR}$ Reagent and $12.5 \mu \mathrm{l} \beta$-mercaptoethanol were added. The sample was vortexed for several minutes, frozen in liquid $\mathrm{N}_{2}$, and thawed again with intensive vortexing. After repeating twice the freeze-thaw procedure the tube was incubated at RT for 5 min and then centrifuged at $16000 \mathrm{x}$ g for $10 \mathrm{~min}$ at $4^{\circ} \mathrm{C}$ to pellet insoluble material. The supernatant was transferred into a Phase Lock $\mathrm{Gel}^{\mathrm{TM}}(2 \mathrm{ml}$, heavy) tube, $200 \mu \mathrm{l}$ chloroform/isoamylalcohol (49:1, (v/v)) were added and mixed well. The sample was incubated at RT for $3 \mathrm{~min}$, followed by centrifugation at $16000 \mathrm{x} \mathrm{g}$ for $10 \mathrm{~min}$ at $4{ }^{\circ} \mathrm{C}$ to separate phases. The upper aqueous phase was transferred to a fresh tube and mixed with 500 $\mu 1$ isopropanol. To precipitate the RNA the sample was incubated at RT for at least $10 \mathrm{~min}$ and then centrifuged at $16000 \mathrm{x}$ g for $10 \mathrm{~min}$ at $4^{\circ} \mathrm{C}$. The RNA pellet was washed once with 1 $\mathrm{ml} 75 \% \mathrm{EtOH}$, dried at $37^{\circ} \mathrm{C}$ for 5-10 min and finally dissolved in RNase-free $\mathrm{H}_{2} \mathrm{O}$. The RNA concentration was determined using the Nanodrop ${ }^{\circledR}$ ND-1000.

To remove contaminating genomic DNA, $3 \mu \mathrm{g}$ of RNA was digested with DNaseI at $37^{\circ} \mathrm{C}$ for 30 min using the following DNaseI reaction mix: $0.8 \mu 1$ DNaseI buffer $(100 \mathrm{mM}$ Tris, $25 \mathrm{mM}$ $\mathrm{MgCl}_{2}, 5 \mathrm{mM} \mathrm{CaCl}$, pH 7.6), $1 \mu \mathrm{R}$ Rase-out, and $0.8 \mu \mathrm{l}$ DNaseI in a total volume of $8 \mu \mathrm{l}$. The reaction was stopped by adding $0.4 \mu 1100 \mathrm{mM}$ EDTA and DNaseI was inactivated by incubation at $75^{\circ} \mathrm{C}$ for $10 \mathrm{~min}$. The $8 \mu \mathrm{RNA}$ solution was then used for the synthesis of firststrand cDNA, which was performed using the Superscript II Kit (Invitrogen) and provided Oligo(dT) primers according to manufacturer's instructions. After digesting RNA with $1 \mu 1$ RNase $\mathrm{H}$ at $37^{\circ} \mathrm{C}$ for $30 \mathrm{~min}$, the cDNA was stored at $-80^{\circ} \mathrm{C}$ for further use.

\subsubsection{Microinjection of C. elegans}

Transgenic C. elegans strains were generated by microinjection of DNA mixtures into the distal gonad arms of young adult hermaphrodites [157, 180, 181]. As a marker for successful transformation the plasmid pRF4, carrying the dominant mutant rol-6(su1006) allele of the collagen gene rol-6, was co-injected. Expression of rol-6(sul006) causes worms to move in circles and rotate around their body axis (roller phenotype) allowing an easy identification of 
transgenic animals $[182,183]$. To generate sir-2.2::gfp transgenic worms, $25 \mathrm{ng} / \mu \mathrm{l}$ of the plasmid pPD115.62 encoding the promoter and genomic sequence of sir-2.2 fused to a Cterminal Strep-GFP-tag (2.2.11.2) were injected together with $100 \mathrm{ng} / \mu 1 \mathrm{pRF} 4$ into N2 worms according to Mello and Fire [181] with some modifications. The $g f p$ reporter gene construct of sir-2.3 was created by a PCR fusion-based approach and is described in section (2.4.12).

For injection worms were mounted in a drop of halocarbon oil on a $2 \%$ agarose pad. 2-5 $\mu$ l of DNA solution was loaded into a Femtotip ${ }^{\circledR}$ II microinjection needle using a Microloader tip. The needle was connected to a pressurized Eppendorf transjector 5246 (Eppendorf, Hamburg) controlled by a micromanipulator (TransferMan NK2, Eppendorf) and the agar pad with the worm was placed on the inverted Olympus IX70 microscope (Olympus, Hamburg). A 40x magnification was used to focus and inject the needle into the syncytial region of one gonad arm. Pressure was applied until a flow of DNA solution could be seen and the gonad swelled considerably. After retracting the needle the second gonad arm was injected or the worm was immediately recovered by putting a drop of M9 buffer on top of it. The worm was allowed to rehydrate for $5 \mathrm{~min}$ and was then transferred to a new NGM plate. Surviving worms were singled on NGM plates and their progeny were screened for a roller phenotype. Transgenic animals displaying a roller phenotype were analyzed for GFP-expression on a dissecting microscope (Olympus SZX10, Olympus, Hamburg) equipped with a GFP filter. Worms exhibiting GFP-expression were again singled to obtain individual transgenic lines with a good transmission rate of the extrachromosomal array.

\subsubsection{Generation of GFP/mCherry reporters using a PCR fusion-based approach}

The reporter gene constructs sir-2.3pr::sir-2.3::ha::gfp, sir-2.3pr::sir-2.3::ha::mcherry and sir-2.4pr::sir-2.4::ha::gfp were generated by a PCR fusion-based approach according to the protocol described by Hobert [184] and as outlined in Figure 2-2. In PCR \#1 the promoter and genomic sequence of sir-2.3 was amplified from the cosmid F46G10 using the following reaction conditions and the following thermocycler protocol: $50 \mathrm{ng}$ of template DNA, $500 \mathrm{nM}$ of each primer, $300 \mu \mathrm{M}$ of each dNTP (Roche, Mannheim), $0.5 \mu$ l Expand High Fidelity DNA polymerase mix (Roche, Mannheim), $1 \mathrm{x}$ reaction buffer (provided by the manufacturer), $3 \mathrm{mM} \mathrm{MgCl} 2 ; 5 \mathrm{~min}$ at $94^{\circ} \mathrm{C}$; $\left[1 \mathrm{~min}\right.$ at $94^{\circ} \mathrm{C}, 1 \mathrm{~min}$ at $48^{\circ} \mathrm{C}, 3 \mathrm{~min} 30 \mathrm{sec}$ at $68^{\circ} \mathrm{C}$ ] 8x; [30 sec at $94^{\circ} \mathrm{C}, 30 \mathrm{sec}$ at $55^{\circ} \mathrm{C}, 3 \mathrm{~min} 30 \mathrm{sec}$ at $72^{\circ} \mathrm{C}$ ] $22 \mathrm{x} ; 10 \mathrm{~min}$ at $72^{\circ} \mathrm{C}$. In parallel, the $g f p$ or mcherry coding sequence and the 3 ' untranslated region (UTR) of the unc54 gene were amplified by PCR \#2 using the same reaction conditions (except for pPD115.62-sir-2.2 pr: sir-2.2::strep ::gfp being the template for the $g f p$ coding sequence and pPD115.62-mCherry (2.2.11.2) for the mcherry coding sequence) and the following thermocycler protocol: $5 \mathrm{~min}$ at $94^{\circ} \mathrm{C}$; [ $1 \mathrm{~min}$ at $94^{\circ} \mathrm{C}, 1 \mathrm{~min}$ at $50^{\circ} \mathrm{C}, 4 \mathrm{~min}$ at $68^{\circ} \mathrm{C}$ ] $8 \mathrm{x}$; [30 sec at $94^{\circ} \mathrm{C}, 30 \mathrm{sec}$ at $55^{\circ} \mathrm{C}, 4 \mathrm{~min}$ at $72^{\circ} \mathrm{C}$ ] $22 \mathrm{x} ; 10 \mathrm{~min}$ at $72^{\circ} \mathrm{C}$. Primer B (reverse primer of PCR \#1) introduced a C-terminal HA-tag and TEV-protease cleavage site. The sequence of the TEV-protease cleavage site was also present in primer $\mathrm{C}$ (forward primer of PCR \#2) producing an overlap of more than 24 nucleotides between amplicon \#1 and amplicon \#2. The DNA concentration of each PCR product was roughly estimated by agarose gel electrophoresis and an aliquot of each reaction was diluted to a concentration of $\sim 10-50 \mathrm{ng} / \mu \mathrm{l}$ with $\mathrm{dH}_{2} \mathrm{O}$. In the fusion PCR reaction both products are fused with nested primers (Primer 
$\mathrm{A}^{*}$ and Primer $\mathrm{D}^{*}$ ). The same PCR reaction conditions and thermocycler protocol were used as described above except for using $1 \mu \mathrm{l}$ of each PCR product as template, $55^{\circ} \mathrm{C}$ and $60^{\circ} \mathrm{C}$ as annealing temperatures and $4 \mathrm{~min} 30 \mathrm{sec}$ as elongation time. The DNA concentration of the fusion PCR product was again estimated by agarose gel electrophoresis. Without any further purification the reaction was diluted with $\mathrm{dH}_{2} \mathrm{O}$ to a final concentration of $\sim 50 \mathrm{ng} / \mu \mathrm{l}$ and microinjected into worms together with the marker plasmid pRF4 (100 ng/ $\mu \mathrm{l})(2.4 .11)$.
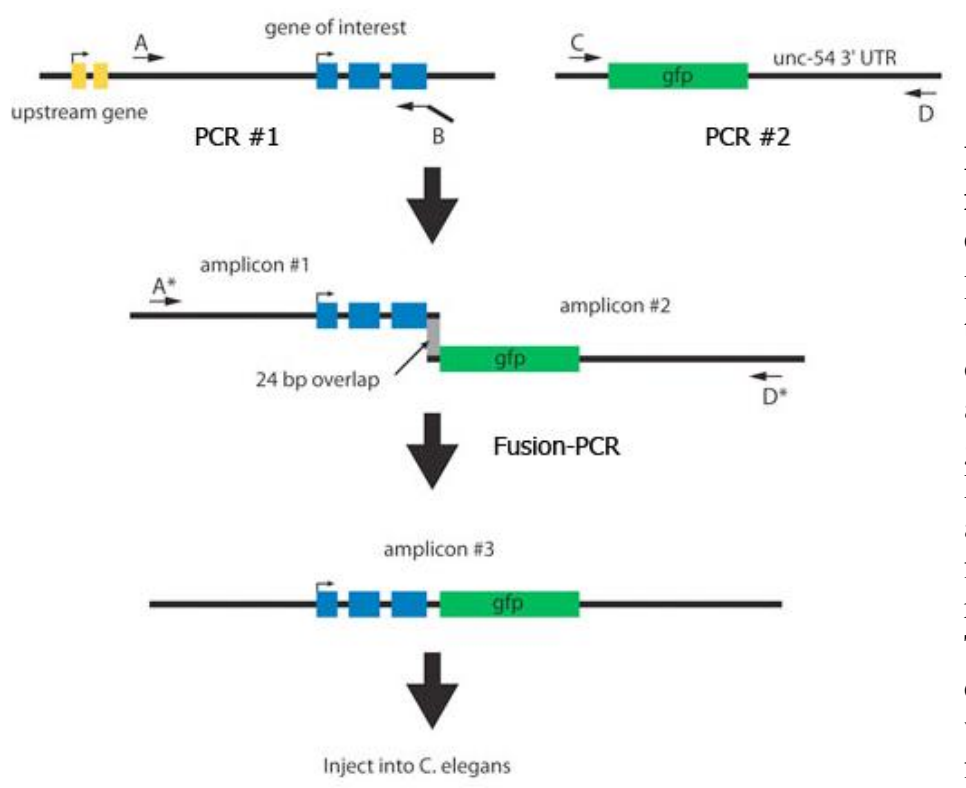

Figure 2-2: PCR-fusion based approach for generating a C-terminal $g f p$ reporter construct.

In PCR reaction \#1 primer A and B amplify the promoter and genomic region of a gene of interest. In parallel, primer $\mathrm{C}$ and $\mathrm{D}$ amplify in PCR reaction \#2 the $g f p$ reporter gene sequence and 3'UTR of unc-54. Primer $\mathrm{B}$ and $\mathrm{C}$ introduce a $24 \mathrm{bp}$ overlap into amplicon \#1 and amplicon \#2 allowing fusion of both fragments in the fusion-PCR reaction using the nested primer $\mathrm{A}^{*}$ and $\mathrm{D}^{*}$. The resulting PCR product (amplicon \#3) can be directly microinjected into $C$. elegans without further purification. Figure taken from Boulin et al. [185].

The following primer sequences were used:

SIR-2.3:

MW50_sir-2.3_PrimerA:

CGTGTAGTTTTGGAATTTGATAATATTGTG

MW51_sir-2.3_PrimerA*:

GCGGGCTGCAGGGAATTTGATAATATTGTGTTGACGACAG

MW52_sir-2.3_gfp_PrimerB:

GCGTAGTCTGGGACGTCGTATGGGTACGCGGCCGCCATTTCTTTCA

MW41_sir-2.3_gfp_PrimerC:

AAACATCCGAAATTCTG

CGTACCCATACGACGTCCCAGACTACGCTGAAAACCTGTATTTTCA GGGCGCCACGCG

MW42_sir-2.3_unc-54_PrimerD: AAGGGCCCGTACGGCCGACTAGTAGG

MW43_sir-2.3_unc-54_PrimerD*: CGACTAGTAGGAAACAGTTATGTTTGGTATATTGGG

MW58_sir23_mCherry_PrimerB: GCCCTGAAAATACAGGTTTTCAGCGTAGTCTGGGACGTCGTATGG GTACGCGGCC

MW59_sir23_mCherry_PrimerC: CCAGACTACGCTGAAAACCTGTATTTTCAGGGCGCCACGCGTGGC ATGGTGAGCAAGGGCGAGGAGG

SIR-2.4:

MW47_sir-2.4_gfp_PrimerA:

GCAGCTAAAAATGCTAAAAAAAGGTGC

MW48_sir-2.4_gfp_PrimerA*:

GCGGGCTGCAGGGTGCTAAATATTGAAAATCCTTCGACC

MW49_sir-2.4_gfp_PrimerB:

GCGTAGTCTGGGACGTCGTATGGGTACGCGGCCGCGCTAATTTTC AATGGAATAGGCAC 


\subsubsection{RNA interference (RNAi) by microinjection and feeding}

RNAi was induced by microinjecting dsRNA into the gonad of $C$. elegans and further enhanced by feeding injected worms with E. coli HT115 (DE3) expressing the specific dsRNA [186].

\section{In vitro synthesis and microinjection of dsRNA}

To generate dsRNA, the cDNA sequences of sir-2.2 and sir- 2.3 were cloned into the feeding vector L4440 (2.2.11.1), which contains two convergent T7 polymerase promoters in opposite orientations separated by a multicloning site [187]. Subsequently, the cDNA sequence of sir2.2 was PCR amplified with a primer specific for the flanking $\mathrm{T} 7$ promoter sequences $\left(5^{\prime}-\right.$ GTAATACGACTCACTATAGGG-3'). The following $50 \mu 1$ reaction mix and PCR protocol were used: 50 ng plasmid DNA, $1 \mu \mathrm{M}$ T7 primer, $300 \mu \mathrm{M}$ of each dNTP (Roche, Mannheim), $0.5 \mu 1$ Expand High Fidelity DNA polymerase mix (Roche, Mannheim), 1 x reaction buffer (provided by the manufacturer), $3 \mathrm{mM} \mathrm{MgCl}_{2} ; 3 \mathrm{~min}$ at $94^{\circ} \mathrm{C},\left[1 \mathrm{~min}\right.$ at $94^{\circ} \mathrm{C}, 40 \mathrm{sec}$ at $55^{\circ} \mathrm{C}$, $1 \mathrm{~min}$ at $\left.72^{\circ} \mathrm{C}\right] 5 \mathrm{x}$; [40 sec at $94^{\circ} \mathrm{C}, 40 \mathrm{sec}$ at $60^{\circ} \mathrm{C}, 1 \mathrm{~min}$ at $\left.72^{\circ} \mathrm{C}\right] 25 \mathrm{x}, 10 \mathrm{~min}$ at $72^{\circ} \mathrm{C}$. The PCR product was extracted with chloroform:isoamylalcohol (24:1) and ethanol precipitated (2.2.1). The DNA pellet was resuspended in RNase-free $\mathrm{H}_{2} \mathrm{O}$ and DNA concentration was measured using the Nanodrop ${ }^{\circledR}$ ND-1000 (Peqlab).

The DNA was in vitro transcribed by T7 RNA polymerase using the MEGAscript ${ }^{\circledR}$ T7 kit (Ambion) according to manufacturer's instructions. The generated dsRNA was isolated by phenol/chloroform extraction and ethanol precipitation. The RNA pellet was resuspended in RNase-free $\mathrm{H}_{2} \mathrm{O}$ and the concentration was determined by Nanodrop ${ }^{\circledR}$ ND-1000 (Peqlab). In addition the integrity of the dsRNA was checked on a $1 \%$ agarose gel. The sir-2.2 dsRNA was microinjected (2.4.11) into sir-2.3(ok444) mutant worms at a concentration of $2 \mu \mathrm{g} / \mu \mathrm{l}$. As control M9 buffer was injected into wild type N2 worms.

\section{RNAi mediated by feeding}

The feeding construct L4440-sir-2.2(cDNA) was transformed into the E. coli strain HT115 (DE3), a RNaseIII-deficient strain of $E$. coli with an isopropyl-ß-D-thiogalactoprynoside (IPTG) inducible T7 polymerase [188]. $5 \mathrm{ml} \mathrm{LB}$ medium containing ampicillin $(100 \mu \mathrm{g} / \mathrm{ml})$ was inoculated with a single bacterial colony and incubated at $37^{\circ} \mathrm{C}$ for $8 \mathrm{~h}$ with constant shaking. $100 \mu \mathrm{l}$ of the bacterial culture were spread on $50 \mathrm{~mm}$ NGM feeding plates (NGM plates with $100 \mu \mathrm{g} / \mathrm{ml}$ ampicillin, $12.5 \mu \mathrm{g} / \mathrm{ml}$ tetracycline, $1 \mathrm{mM}$ IPTG and without streptomycin) and incubated overnight at RT to grow bacterial lawn and induce dsRNA expression.

After microinjection of sir-2.2 dsRNA, sir-2.3( ok444) mutant worms were singled to sir-2.2 feeding plates and incubated at $25^{\circ} \mathrm{C}$. Every $12 \mathrm{~h}, 24 \mathrm{~h}, 36 \mathrm{~h}$ and $48 \mathrm{~h}$ the hermaphrodites were transferred to fresh feeding plates. Control worms injected with M9 buffer were transferred to feeding plates seeded with E. coli HT115 (DE3) carrying the empty L4440 vector. The F1 generation was screened for phenotypic alterations with a dissecting microscope and differential interference contrast (DIC), using the confocal laser scanning microscope Leica TCS SP5 (Leica, Wetzlar). 


\subsubsection{Integration of extrachromosomal arrays by $U V$ radiation}

Extrachromosomal arrays were integrated into chromosomal DNA of sir-2.2::gfp and sir2.3::gfp transgenic worms by treatment with UV radiation [174]. L4 hermaphrodites of the sir-2.2::gfp and sir-2.3::gfp extrachromosomal transgenic lines that expressed the corresponding $g f p$ construct were picked on 5-9 $50 \mathrm{~mm}$ NGM plates ( 40 worms/plate) that were not seeded with bacteria. The worms were UV radiated in a Stratlinker ${ }^{\circledR}$ UV crosslinker 2400 using an energy setting of $30,000 \mu \mathrm{J} / \mathrm{cm}^{2}$ and a wavelength of $254 \mathrm{~nm}$. The agar plate was transferred completely to a large NGM plate and worms were grown for at least two generations at RT. This allowed potential integrants to become homozygous by selffertilization. After $\sim 10$ days two large pieces of agar were cut out from each plate and transferred to fresh $90 \mathrm{~mm}$ NGM plates. The next day 15-20 hermaphrodites of each plate (exhibiting GFP expression without mosaicism) were singled on $50 \mathrm{~mm}$ NGM plates. The progeny of these hermaphrodites were then screened for $100 \%$ transmission of the transgene. Obtained stable transgenic lines were crossed back three times to wild type N2 worms to eliminate potential background mutations (2.4.9).

\subsubsection{DiI staining}

Dye-filling with the lipophilic fluorescent dye 1,1'-dioctadecyl-3,3,3',3'-tetramethylindocarbocyanine perchlorate (DiI) was performed to stain the sensory neurons of C. elegans in vivo based on the method described by Hedgecock [189]. After washing sir-2.3::gfp transgenic worms several times with M9 buffer the worm pellet was resuspended in M9 buffer containing $2 \mu \mathrm{g} / \mathrm{ml}$ DiI (Molecular Probes, 1:1000 dilution of $2 \mathrm{mg} / \mathrm{ml}$ DiI dissolved in DMSO) and incubated in the dark at $23^{\circ} \mathrm{C}$ with shaking. For recovery and destaining worms were transferred to fresh NGM plates and allowed to crawl for at least $1 \mathrm{~h}$. To analyze the staining of sensory neurons worms were mounted on $2 \%$ agarose pads and immobilized with $2 \%$ sodium azide in M9 buffer. Pictures were taken on a Leica TCS SP5 confocal laserscanning microscope (Leica).

\subsubsection{Microscopic analysis of $C$. elegans}

For standard handling and phenotypic analyses worms were monitored on NGM plates (Olympus SZX10 equipped with filters for green and red fluorescence). Differential interference contrast microscopy and fluorescence microscopy were performed on a Leica TCS SP5 confocal laser-scanning microscope (using $40 \mathrm{x}$ and $63 \mathrm{x}$ object lenses). Specimens were prepared by mounting worms on $2 \%$ agarose pads $\left(2 \%(\mathrm{w} / \mathrm{v})\right.$ agarose in $\left.\mathrm{H}_{2} \mathrm{O}\right)$ with a drop of $2 \%$ sodium azide to immobilize worms. Agarose pads were prepared by spotting a drop of molten $2 \%$ agarose on a coverslip, placing a second coverslip on top and flattening the drop with mild pressure to a thin film of agarose.

Immunoelectron microscopy of ultrathin cryosections was performed by Dirk Wenzel at the Electron Microscopy group of the Max Planck Institute for Biophysical Chemistry, Göttingen. Briefly, worms were cut, fixed with $2 \%$ paraformaldehyde in $0.1 \mathrm{M} \mathrm{Na-phosphate} \mathrm{buffer}(\mathrm{pH}$ 7.4) for $24 \mathrm{~h}$ at $4{ }^{\circ} \mathrm{C}$, and postfixed with $4 \%$ paraformaldehyde- $0.1 \%$ glutaraldehyde for $2 \mathrm{~h}$ on ice. Cryosections were prepared as previously described [190, 191], labeled for the indicated antigens, and examined with a Philips CM120 electron microscope and a TVIPS chargecoupled device camera system. 


\subsubsection{Oxidative stress assay}

Sensitivity towards oxidative stress was analyzed as described by Masse et al. [192] with some modifications. Worm strains were cultured synchronously for two generations on RNAi feeding plates $(2.4 .13)$ at $25^{\circ} \mathrm{C}$. $\mathrm{N} 2$, sir-2.2::gfp and sir-2.3::gfp transgenic worms were grown on control feeding plates seeded with E. coli HT115(DE3), transformed with the empty L4440 vector, sir-2.3(ok444) and sir-2.2(tm2648) mutant worms were maintained on sir-2.2 RNAi and sir-2.3 RNAi feeding plates, respectively. $200 \mu 1250 \mathrm{mM}$ paraquat solution (methylviologen-dichloride hydrat, Sigma, dissolved in $\mathrm{dH}_{2} \mathrm{O}$ ) were spread on top of already seeded RNAi feeding plates. Of each strain five plates with 20 worms (L4 larvae) per plate were prepared and survial of worms was checked every day. Worms were scored as dead when they did not respond to prodding with a pick. The mean life spans and average survival curves were determined from at least three independent experiments. A two-tailed Student's ttest was used to calculate the significance of differences in mean life span to wild type worms.

\subsection{Tissue culture based methods}

\subsubsection{Cultivation of cells}

HEK293 and HEK293T cells were grown in DMEM medium (supplemented with 10\% bovine growth serum (BGS), L-glutamine and Penicillin/Streptomycin) at $37^{\circ} \mathrm{C}$ and $5 \% \mathrm{CO}_{2}$. After reaching $90 \%$ confluence cells were split by washing them once with PBS and treating them with $0.05 \%$ Trypsin-EDTA for 5 to $10 \mathrm{~min}$. Trypsin digestion was stopped by addition of medium and the cells were plated in a dilutions appropriate for further maintenance or transfection.

\subsubsection{Transfection of cells}

HEK293 and HEK293T cells were transfected with plasmid DNA by $\mathrm{CaPO}_{4}$ precipitation using the CalPhos ${ }^{\mathrm{TM}}$ Mammalian Transfection Kit (Clontech, Mountain View, USA) according to manufacturer's protocol. To express C. elegans proteins in HEK293 cells transfection was performed with the jetPEI ${ }^{\mathrm{TM}}$ Transfection Reagent (Polyplus-transfection SA, Illkirch, France) as described in the instructions of the manufacturer.

\subsubsection{Immunoprecipitation of proteins from transfected cells}

Immunoprecipitation (IP) experiments were performed as described by Ahuja et al. [26] with some modifications. For each IP reaction HEK293 or HEK293T cells of 1-2 $15 \mathrm{~mm}$ cell culture dishes were co-transfected (2.5.2) with the plasmids of interest, harvested after 24-48 $\mathrm{h}$ and washed once with ice-cold PBS buffer $\left(137 \mathrm{mM} \mathrm{NaCl}, 2.7 \mathrm{mM} \mathrm{KCl}, 4.3 \mathrm{mM} \mathrm{Na} \mathrm{HPO}_{4}\right.$, $1.47 \mathrm{mM} \mathrm{KH}_{2} \mathrm{PO}_{4}, \mathrm{pH}$ 7.4). The cell pellet was lyzed with $500 \mu \mathrm{l}$ buffer A (50 mM Tris-HCl, $500 \mathrm{mM} \mathrm{NaCl}, 10 \mathrm{mM} \mathrm{CaCl} 2,0.5 \%$ (v/v) NP-40, $0.5 \mathrm{mM}$ EDTA, 10\% (v/v) glycerol, $1 \mathrm{x}$ Complete Protease inhibitor (EDTA free, Roche), pH 7.5) containing $20 \mathrm{U} / \mathrm{ml} \mathrm{micrococcal}$ nuclease (MNase, Calbiochem). The chromatin fraction of the lysates was digested for $30 \mathrm{~min}$ at $30^{\circ} \mathrm{C}$ with agitation. $500 \mu \mathrm{l}$ buffer B $(50 \mathrm{mM}$ Tris- $\mathrm{HCl}, 150 \mathrm{mM} \mathrm{NaCl}, 0.5 \%$ (v/v) NP-40, $0.5 \mathrm{mM}$ EDTA, $10 \%$ (v/v) glycerol, 1x Complete Protease inhibitor (EDTA free, Roche), $\mathrm{pH}$ 
7.5) were added and the lysate was clarified by centrifugation at $16000 \mathrm{x} \mathrm{g}$ for $30 \mathrm{~min}$ at $4{ }^{\circ} \mathrm{C}$. The supernatant was added to equilibrated beads.

For equilibration beads were washed three times each with $1 \mathrm{ml}$ buffer B or PBS and then blocked for at least $1 \mathrm{~h}$ with $0.1 \%(\mathrm{w} / \mathrm{v}) \mathrm{BSA}$ at $4^{\circ} \mathrm{C}$ with rotation. Beads were washed three times before adding the cellular extract. To immunoprecipitate GFP-tagged proteins $5 \mu \mathrm{l}$ GFP-Trap ${ }^{\circledR}$ A agarose beads (Chromotek) were used. Anti-FLAG-IPs were performed either with $15 \mu \mathrm{l}$ anti-FLAG ${ }^{\circledR}$ M2 agarose beads (Sigma) or with $30 \mu 1$ magnetic Dynabeads ${ }^{\circledR}$ M280 Sheep anti-mouse (Invitrogen) and $4 \mu 1$ anti-FLAG ${ }^{\circledR}$ M2 antibody (Sigma). For anti-Myc IP experiments $4 \mu \mathrm{l}$ anti-Myc antibody (Millipore) was bound to $20 \mu 1$ Dynabeads ${ }^{\circledR} \mathrm{M}-280$ Sheep anti-mouse (Invitrogen) for $3 \mathrm{~h}$ at $4{ }^{\circ} \mathrm{C}$ prior to blocking.

To immunoprecipitate tagged-proteins the beads were rotated at $4^{\circ} \mathrm{C}$ overnight. The beads were washed six times each with $1 \mathrm{ml}$ buffer A and then boiled in 40-60 $\mu$ l SDS sample buffer. Proteins were separated by SDS-PAGE (2.3.1) and analyzed by Western blotting (2.3.2.2).

\subsubsection{Analysis of protein acetylation using acetyllysine-specific antibodies}

Protein acetylation levels were analyzed by Linh Ho from the laboratory of our collaborator Prof. Eric Verdin (Gladstone Institute of Virology and Immunology, San Francisco, USA) as previously described [102, 193].

\subsection{Enzymatic activity assays}

\subsubsection{Histone deacetylase (HDAC) activity assay}

Histone deacetylase assays were essentially performed as described by Verdin et al. [194] using a chemically acetylated $\mathrm{H} 4$ peptide as a substrate. Recombinant C. elegans SIR-2 proteins as well as HP1 $\beta$ (negativ control) were translated in vitro using wheat germ extract [165] by Dimitry Agafonov and Timur Sumatov (Department of Cellular Biochemistry, Max Planck Institute for Biophysical Chemistry, Göttingen). For protein expression with wheat germ extract full-length sir-2.1, sir-2.2, sir-2.3 and sir-2.4 were cloned into pEU3-NIIStrepII. pEU3-NII-StrepII containing the cDNA of HP1ß was kindly provided by Szabolcs Sörös (Max Planck Institute for Biophysical Chemistry, Göttingen). Since wheat germ extract does not exhibit intrinsic deacetylase activity, in vitro-translated proteins were directly used for the enzymatic assay without further purification. The total reaction volume was $100 \mu 1$ containing $5 \mu \mathrm{l}$ of in vitro-translated protein, $1 \mu \mathrm{l}\left[{ }^{3} \mathrm{H}\right]$ peracetylated $\mathrm{H} 4$ peptide and $1 \mathrm{x}$ HDAC buffer (50 mM Tris, $4 \mathrm{mM} \mathrm{MgCl} 2,1 \mathrm{mM} \mathrm{NAD}^{+}, \mathrm{pH} 9.0$ ). Reactions were incubated at $25^{\circ} \mathrm{C}$ for $2 \mathrm{~h}$ or overnight with shaking. For quantification acetate was released from $\mathrm{O}$ acetyl-ADP-ribose by addition of $25 \mu 1$ Stop-mix ( $1 \mathrm{M} \mathrm{HCl}, 0.16 \mathrm{M} \mathrm{HAc}$ ) and extracted with $600 \mu 1$ organic solvent (Ethyl acetate). $550 \mu 1$ of the upper organic phase were analyzed by scintillation counting. The protein concentrations of the in vitro-translated proteins were determined by quantifying the incorporation of $\left[{ }^{14} \mathrm{C}\right]$ leucine into full-length protein bands using SDS-PAGE gel electrophoresis and autoradiography. 


\subsubsection{Spectrophotometric pyruvate carboxylase activity assay}

To analyze whether treatment of bovine pyruvate carboxylase (PC) with C. elegans or mammalian sirtuins changes its enzymatic activity, a photospectrometric pyruvate carboxylase activity assay [195] was used.

For the deacetylation assay of PC FLAG-tagged C. elegans proteins and Myc-tagged human proteins were expressed in HEK293T cells (2.5.2). Cells were lyzed in $750 \mu$ l buffer $\mathrm{C}$ (50 $\mathrm{mM}$ Tris- $\mathrm{HCl}, 150 \mathrm{mM} \mathrm{NaCl}, 10 \mathrm{mM} \mathrm{CaCl} 2,0.5 \%$ (v/v) NP-40, $0.5 \mathrm{mM}$ EDTA, $10 \%$ (v/v) glycerol, 1x Complete Protease inhibitor (EDTA free, Roche), $20 \mathrm{U} / \mathrm{ml}$ MNase (Calbiochem), $\mathrm{pH} 8.0$ ), incubated for $30 \mathrm{~min}$ at $30^{\circ} \mathrm{C}$ with agitation and sonicated $30 \mathrm{~min}$ (30 sec on, $30 \mathrm{sec}$ off). Then $200 \mu \mathrm{l}$ buffer $\mathrm{C}$ (without $\mathrm{CaCl}_{2}$ and $\mathrm{MNase}$ ) was added and the lysate was centrifuged at $16000 \mathrm{x} \mathrm{g}$ for $30 \mathrm{~min}$ at $4^{\circ} \mathrm{C}$. The supernatant was added to equilibrated magnetic Dynabeads ${ }^{\circledR}$ M-280 Sheep anti-mouse (Invitrogen) bound with anti-FLAG ${ }^{\circledR}$ M2 (Sigma) or anti-Myc (Millipore) antibody (2.5.3) and rotated at $4{ }^{\circ} \mathrm{C}$ overnight. Beads were washed three times with buffer $\mathrm{C}$ (without $\mathrm{CaCl}_{2}$ and MNase) and once with 1x DAC buffer (50 mM Tris, $4 \mathrm{mM} \mathrm{MgCl} 2,1 \mathrm{mM} \mathrm{NAD}{ }^{+}$, $\mathrm{pH}$ 8.0).

For the DAC assay beads were split into two reactions. Each reaction was incubated with 110 $\mu 1 \mathrm{DAC}$ buffer containing $0.55 \mu \mathrm{g}$ bovine pyruvate carboxylase (Sigma) at $25^{\circ} \mathrm{C}$ (C. elegans proteins) or $37^{\circ} \mathrm{C}$ (human proteins) for $1 \mathrm{~h}$ with shaking. The supernatant of each reaction was then immediately used for the photospectrometric pyruvate carboxylase assay.

The activity of pyruvate carboxylase was determined with a malate dehydrogenase coupled assay for oxaloacetate measuring the decrease in absorbance at $340 \mathrm{~nm}$ due to NADH oxidation. The assay was performed at $30^{\circ} \mathrm{C}$ in a total volume of $500.5 \mu 1 \mathrm{PC}$ reaction buffer containing $134 \mathrm{mM}$ triethanolamine hydrochloride-KOH buffer, $\mathrm{pH} 8.0,5 \mathrm{mM} \mathrm{MgSO}, 7 \mathrm{mM}$ pyruvic acid, 0.12\% (w/v) BSA, $0.23 \mathrm{mM} \mathrm{NADH,} 0.05 \mathrm{mM}$ acetyl-coenzyme A, 2.63 units malate dehydrogenase, $1 \mathrm{mM}$ ATP, $15 \mathrm{mM} \mathrm{KHCO}_{3}, 10 \mathrm{mM}$ Tris- $\mathrm{HCl}, \mathrm{pH} 8.0,0.8 \mathrm{mM}$ $\mathrm{MgCl}_{2}, 0.2 \mathrm{mM} \mathrm{NAD}{ }^{+}$and $0.5 \mu \mathrm{g}$ bovine pyruvate carboxylase (Sigma). $100 \mu \mathrm{l}$ supernatant of the DAC reaction were mixed with $384 \mu 11.3 x$ PC reaction buffer (without ATP and $\mathrm{KHCO}_{3}$ ) in a quartz cuvette and equilibrated to $30^{\circ} \mathrm{C}$ in a thermostatted Cary $100 \mathrm{UV}$-Vis Spectrophotometer (Varian, Palo Alto, USA). The reaction was started by addition of $16.5 \mu 1$ ATP/KHCO3 solution and decrease in absorbance at $340 \mathrm{~nm}$ was recorded for $15 \mathrm{~min}$. Measured linear range reaction velocities were used to calculate the enzymatic activities of bovine PC using the following formula:

$$
\text { units }[\mu \mathrm{mol} / \mathrm{min}]=\frac{\Delta A}{\Delta t \cdot \varepsilon_{N A D H} \cdot d} \cdot V
$$

(A = absorbance, $\mathrm{t}=$ time, $\varepsilon=$ extinction coefficient $\left(\varepsilon_{\mathrm{NADH}}\right.$ at $\left.340 \mathrm{~nm}=6220 \mathrm{~L} \mathrm{M}^{-1} \mathrm{~cm}^{-1}\right), \mathrm{d}=$ path length $(1 \mathrm{~cm}), \mathrm{V}=$ reaction volume).

\subsubsection{Deacetylase activity assay in combination with mass spectrometry}

In vitro deacetylase activity assays were performed with immunoprecipitated protein (for details see (2.6.2)) expressed in HEK293T cells. Proteins bound to beads were incubated with $1 \mu \mathrm{g}$ acetylated peptide in DAC buffer II (50 mM Tris, $150 \mathrm{mM} \mathrm{NaCl}, 4 \mathrm{mM} \mathrm{MgCl} 2,2 \mathrm{mM}$ $\left.\mathrm{NAD}^{+}, \mathrm{pH} 8.0\right)$ at $25^{\circ} \mathrm{C}\left(\right.$ C. elegans proteins) or at $37^{\circ} \mathrm{C}$ (mammalian proteins) overnight while shaking. The supernatant of the DAC reactions was analyzed by mass spectrometry in 
the group of Dr. Henning Urlaub (Max Planck Institute for Biophysical Chemistry, Göttingen) on a 4800 MALDI TOF/TOF ${ }^{\mathrm{TM}}$ Analyzer (Applied Biosystems, Darmstadt). 


\section{Results}

\subsection{Analysis of SIR-2 protein expression and localization in C. elegans}

\subsubsection{SIR-2.2 and SIR-2.3 do not localize to the cell nucleus}

To analyze the expression and localization of the different SIR-2 proteins I generated transgenic worms, expressing C-terminally GFP-tagged SIR-2 proteins under control of the endogenous promoter. The sir-2.1::gfp (HT822) strain was already existing and kindly provided by Heidi Tissenbaum [122]. To generate sir-2.2::gfp transgenic worms, the entire 5' untranslated region (UTR, $1.8 \mathrm{~kb}$ ) and genomic region of sir-2.2 were fused to a C-terminal Strep::GFP-tag and the 3' UTR of unc-54 in the vector pPD115.62. Transgenic worms were generated by microinjection into wild type N2 worms. Sir-2.3::gfp and sir-2.4::gfp transgenic worms were obtained by a PCR fusion-based approach, omitting time consuming cloning [184]. The 5' UTRs (sir-2.3: $0.9 \mathrm{~kb}$; sir-2.4: $0.7 \mathrm{~kb}$ ) and genomic sequences of sir-2.3 and sir2.4 were fused via PCR to a C-terminal HA::GFP-tag and unc-54 3' UTR via PCR and the linear fragments were injected into N2 worms. Extrachromosomal arrays of sir-2.2::gfp and sir-2.3::gfp transgenic worms were integrated by UV radiation resulting in one integrated transgenic line for sir-2.2 and in four integrated lines for sir-2.3. In sir-2.4::gfp transgenic worms protein expression was only observed in few generations after microinjection and no transgenic line stably propagating the extrachromosomal array could be established.

In accordance to the observations of Wang and Tissenbaum [122] SIR-2.1 is primarily a nuclear protein. It was expressed in most if not all neurons in the head and tail, in many pharyngeal cells, in the hypodermis and in body wall muscles. Interestingly, no SIR-2.1::GFP signal was observed in the intestine (Figure 3-1 A to C).

SIR-2.2 was expressed in many tissues (muscles, neurons, intestine, somatic gonad) of $C$. elegans and exhibited a particularly high expression in the pharynx, bodywall muscle cells and the posterior part of the intestine (Figure 3-1 D, E). Like SIR-2.1 [122] SIR-2.2::GFP expression was first seen in the three-fold stage of embryogenesis. However, SIR-2.2 was not targeted to the nucleus, but found localized to filamentous subcellular structures (Figure 3-1 F). The expression pattern of SIR-2.3::GFP was very similar to that of SIR-2.2 as it also did not localize to nuclei and showed prominent GFP-signals in the pharynx and bodywall muscles (Figure 3-1 G). In addition, strong SIR-2.3::GFP expression was detected in unidentified cells in the head (indicated by arrows) and in somatic cells of the gonad (Figure 3-1 G, H). Interestingly, I observed that expression of SIR-2.3::GFP started earlier in embryogenesis (approximately at the 100 cell stage) than expression of SIR-2.1 and SIR-2.2 (Figure 3-1 I). No SIR-2.2::GFP or SIR-2.3::GFP expression was detected in the germline, which might be due to transgene silencing effects $[181,196]$. SIR-2.4::GFP localized to the nucleus in intestinal cells of embryos and L1 stage larvae (Figure 3-1 J, K). In young adult worms I detected SIR-2.4::GFP in the spermatheca, but it exhibited no nucleus-specific localization (Figure 3-1 L). 

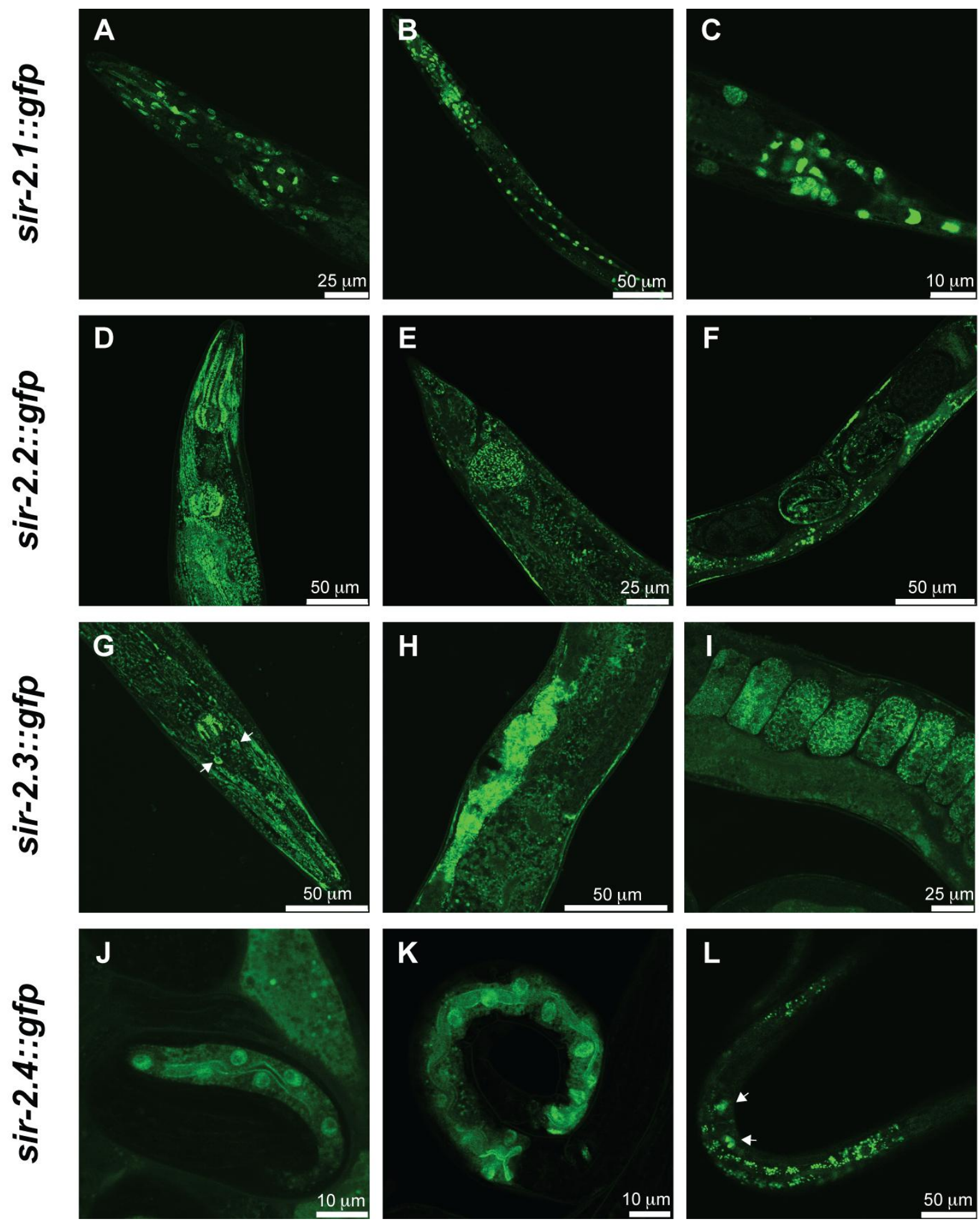

Figure 3-1: Expression and localization pattern of SIR-2 proteins in C. elegans.

GFP was fused C-terminally to the promoter and genomic sequence of each sir-2 variant. Transgenic strains were generated by microinjection. For sir-2.2 and sir-2.3 extrachromosomal arrays were integrated by treatment with UV radiation. The sir-2.1::gfp strain was kindly provided by Heidi Tissenbaum. Fluorescent photomicrographs were taken with a confocal laser scanning microscope. A. to C. SIR-2.1::GFP expression and localization in the head region (A) along the body axis $(\mathbf{B})$ and in the tail region $(\mathbf{C})$ of a representative young adult worms. D. to F. SIR-2.2::GFP expression and localization in the head (D) and tail (E) region and gonad (F) of adult C. elegans. G. to I. SIR-2.3::GFP expression and localization in head region (G) and gonad (H and I) of adult $C$. elegans. Arrows point at unidentified cells in the head. J. to L. SIR-2.4::GFP expression and localization in a representative three-fold stage egg $(\mathbf{J})$, L1 larvae $(\mathbf{K})$ and young adult worm $(\mathbf{L})$. Arrows indicate spermatheca. Scale bars represent level of magnification. 
Overall, these results show that the expression patterns of the different C. elegans SIR-2 proteins are diverse. Similar to the mammalian counterparts their localization is not only restricted to the cell nucleus.

\subsubsection{SIR-2.2 and SIR-2.3 expression and localization patterns partially overlap}

The primary structure of SIR-2.2 is very similar to the protein sequence of SIR-2.3 (75.3\% identity). The gene sequences of both proteins are located directly next to each other on chromosome $\mathrm{X}$, suggesting that one gene might have evolved from the other by gene duplication. Analysis of transgenic $g f p$-reporter strains showed that not only the expression patterns of SIR-2.2::GFP and SIR-2.3::GFP were very similar, but also that both proteins localized to filamentous subcellular structures.

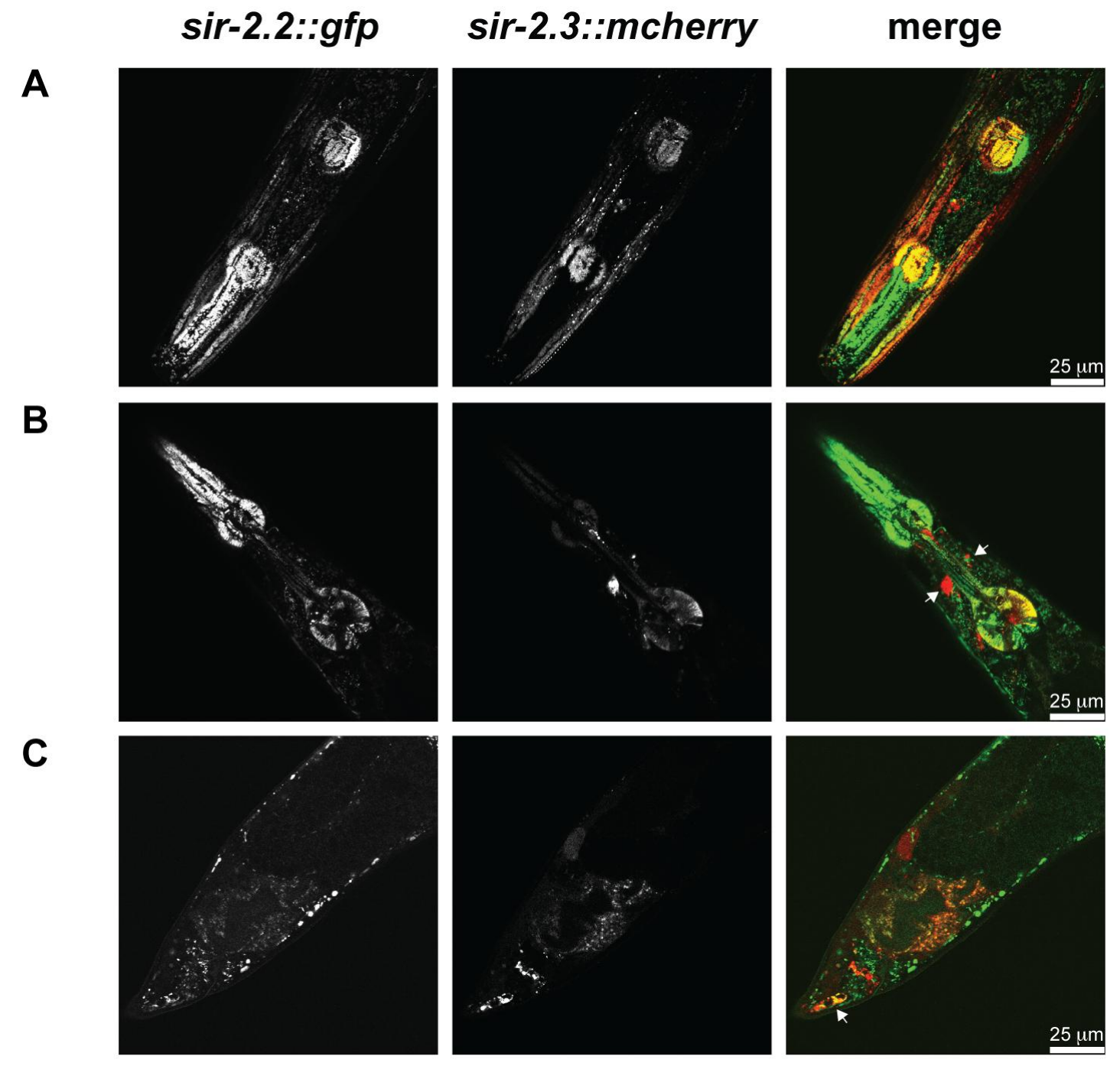

Figure 3-2: The expression and localization patterns of SIR-2.2 and SIR-2.3 partially overlap.

Double transgenic strains were generated by microinjecting a translational mCherry (C-terminal) fusion of SIR2.3 [184] into stable integrated sir-2.2::gfp transgenic worms. A. and B. Representative fluorescent photomicrographs showing the head region of sir-2.2::gfp; sir-2.3::mCherry double transgenic worms. Arrows point at unidentified cells around the pharynx. C. Expression and localization of SIR-2.2::GFP and SIR2.3::mCherry in the tail region of a representative worm. Arrow indicates unidentified cells in the tail. Scale bars represent level of magnification. 
To analyze whether both proteins are targeted to the same subcellular structures, I generated double transgenic worms by microinjecting a translational mCherry (C-terminal) fusion of SIR-2.3 [184] into stable integrated sir-2.2::gfp transgenic worms. Fluorescence microscopy analysis showed that both SIR-2.3::mCherry and SIR-2.2::GFP co-localized in body wall muscle cells, the pharynx, intestine and unidentified cells (possibly neurons) in the tail (indicated by an arrow) (Figure 3-2). These findings implicate that they function at the same subcellular structures.

However, the expression patterns of SIR-2.2 and SIR-2.3 only partially overlapped and there were also differences. No prominent GFP-Signal of SIR-2.2 was observed in unidentified cells located between the two pharyngeal bulbs (Figure 3-2 B, marked with arrows). In addition I detected only for SIR-2.3 a prominent expression in the somatic gonad (Figure 3-1 I) and observed first SIR-2.3 expression earlier in embryogenesis (Figure 3-1 H).

\subsubsection{Analysis of SIR-2.3 expression in head neurons by DiI staining}

Cells of the $C$. elegans nervous system are organized in various ganglia in the head, the tail and along the ventral cord. The majority of neurons are located in ganglia of the head surrounding the pharynx between the two pharyngeal bulbs (isthmus) and forming the nerve ring with their axon bundles. A large fraction of these neurons are sensory neurons that allow C. elegans to perceive environmental cues such as food stimuli, oxygen levels, temperature, $\mathrm{pH}$, light, or mechanic stimuli [197]. Since sirtuins are potential metabolic sensors and sir2.3::gfp transgenic worms showed a prominent SIR-2.3::GFP signal in cells that might be sensory neurons, I performed dye-filling experiments with DiI. DiI is a lipophilic dye that is specifically taken up by amphid neurons (ASI, ADL, ASK, AWB, ASH, ASJ) and inner labial neurons (IL1, IL2, IL sheath and socket cells) in the head and phasmid neurons (PHA, PHB) in the tail of hermaphrodites [189] (Figure 3-3 A). Sir-2.3::gfp transgenic worms stained with DiI (diluted in M9 buffer) were analyzed by fluorescence microscopy. In Figure 3-3 B and C SIR-2.3::GFP expression overlapped with DiI-filled inner labial neurons, however the DiI staining did not co-localize with the prominent SIR-2.3::GFP signal present in the unidentified cells that were located also anterior of the nerve ring close to inner labial neurons (marked with arrows). SIR-2.3::GFP was also expressed in amphid neurons (Figure 3-3 D) and in phasmid neurons (Figure 3-3 E) where it showed a high expression in the PHA neuron and a rather weak expression in the PHB neuron.

In summary, this experiment showed that SIR-2.3 and SIR-2.2 (data not shown) were expressed in many head neurons and co-localized with DiI-filled inner labial neurons, amphid neurons and phasmid neurons in the tail. DiI was not sufficient to determine the identity of the cells around the pharynx with the prominent SIR-2.3::GFP expression and this will be addressed by future experiments.

Figure 3-3: DiI staining of sir-2.3::gfp transgenic worms.

A. Illustration of the relative positions of ciliated neurons (cells bodies and their dendritic extensions) in the $C$. elegans hermaphrodite. Figure taken form [197]. B. to E. Sir-2.3::gfp transgenic worms were stained with DiI and analyzed by fluorescence microscopy. Representative fluorescent photomicrographs of DiI stained sir2.3::gfp transgenic L4 larvae, showing the head region (B and $\mathbf{C}$; Arrows point at unidentified cells, which exhibit prominent SIR-2.3::GFP expression), the region around the second pharyngeal bulb (D) and the tail region $(\mathbf{E})$. Scale bar represent the level of magnification. 
A

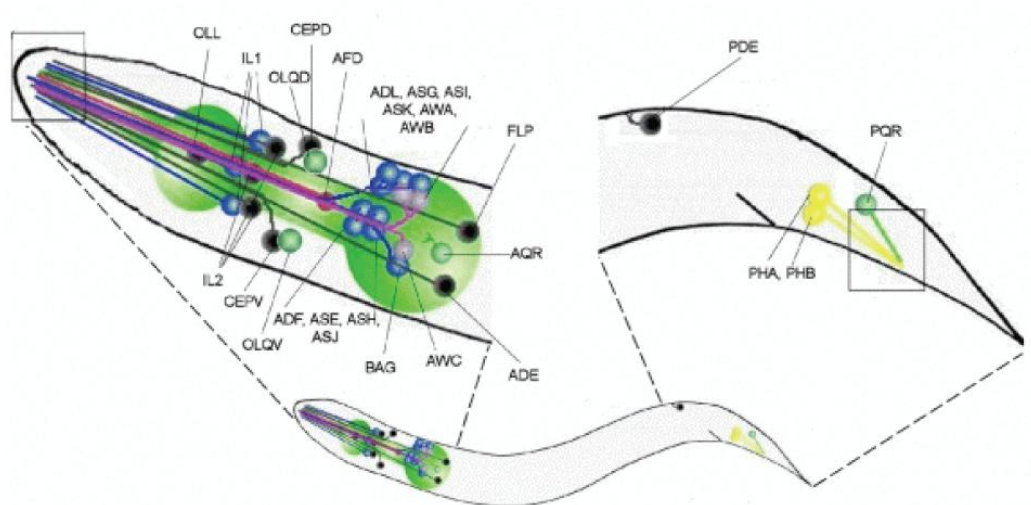

sir-2.3::gfp

B

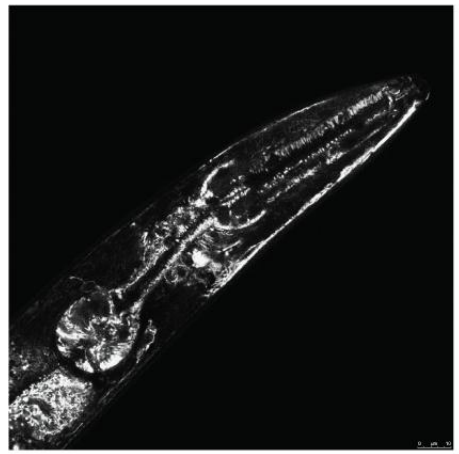

C

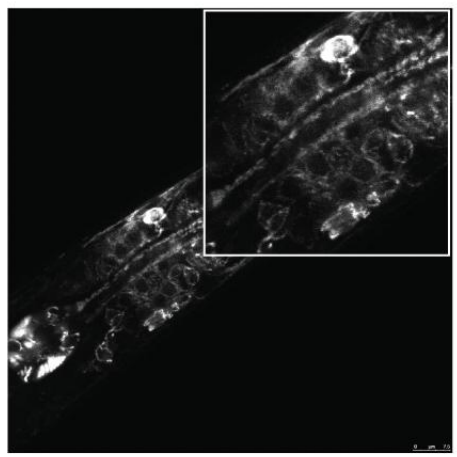

D

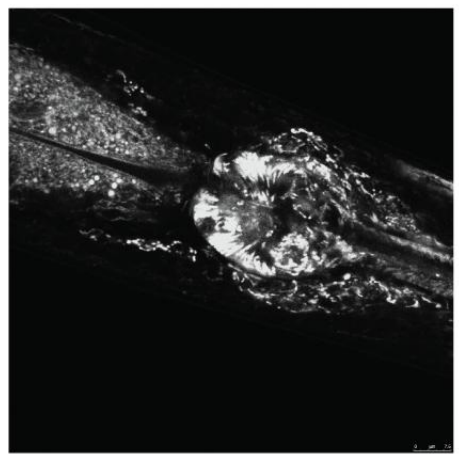

E

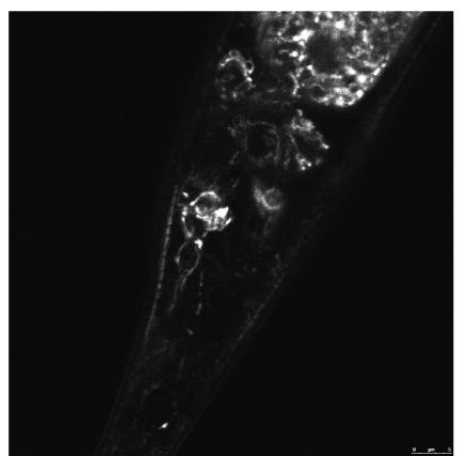

Dil
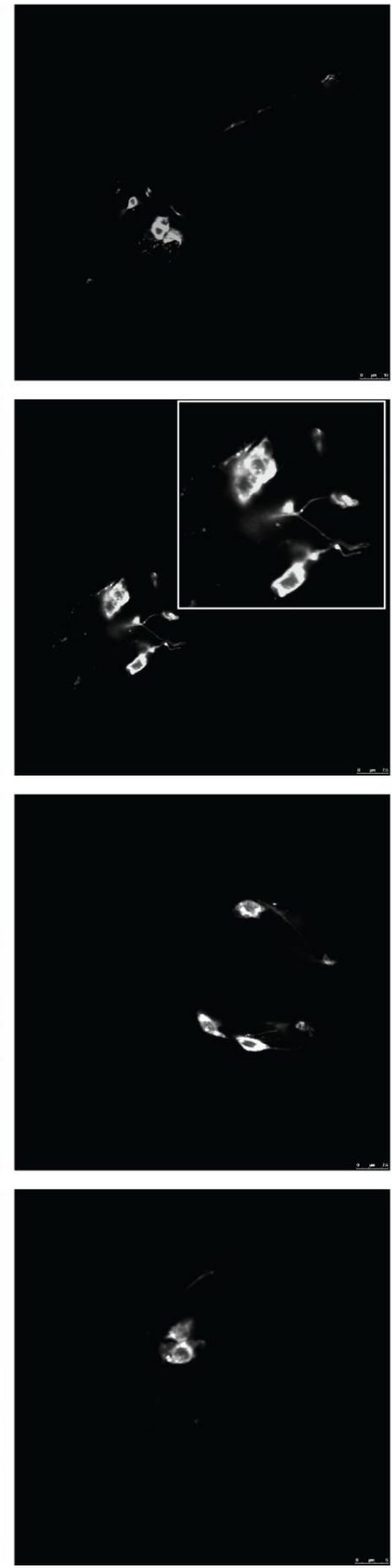

merge
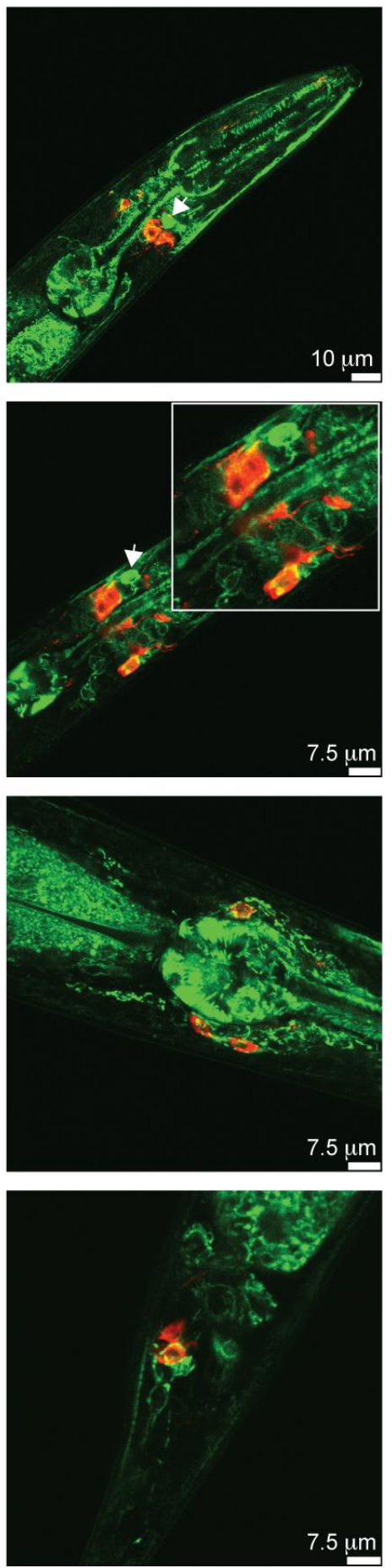


\subsubsection{SIR-2.2 and SIR-2.3 localize to mitochondria}

To determine the exact subcellular localization of SIR-2.2, I analyzed sir-2.2::gfp transgenic worms, using immunoelectron microscopy in collaboration with Dirk Wenzel from the Electron microscopy facility of the Max Planck Institute for Biophysical Chemistry (Göttingen). Immunogold labeling of cryo sections labeled with a GFP-specific antibody showed that the long filamentous structures SIR-2.2 localized to are not filaments of the cytoskeletal system but mitochondria (Figure 3-4 A and B). The mitochondrial localization of SIR-2.2 could be further confirmed by immunogold labeling of sir-2.2::gfp transgenic worms and wild type N2 worms with SIR-2.2-specific antibodies (Figure 3-4 C to F, for antibody characterization see Figure 2-1), demonstrating that both GFP-tagged and endogenous SIR2.2 were targeted to mitochondria. Fluorescence microscopy analysis of sir-2.2::gfp, sir2.3::mCherry double transgenic worms (3.1.2) indicated that both proteins localize to the same subcellular structures. Analysis of cryo sections of sir-2.3::gfp transgenic worms with a GFP-specific antibody showed that SIR-2.3 was also mitochondrial (Figure 3-4 G and H) and verified that both proteins are targeted to the same subcellular compartment.

To further confirm these findings, I isolated mitochondria of $\mathrm{N} 2$ worms by subcellular fractionation of $C$. elegans. In brief, worms were homogenized with a glass tissue grinder and the crude lysate was subjected to differential centrifugation steps. Firstly, nuclei and debris were removed by centrifugation at $800 \times \mathrm{g}$ (Figure 3-5 A). In a second centrifugation step mitochondria were separated from cytosolic compounds by centrifuging the post nuclear supernatant (PNS) at $12000 \mathrm{x}$ g. The resulting mitochondrial pellet (MP) and post mitochondrial supernatant (PMS), as well as the post nuclear supernatant (PNS), were analyzed by Western blotting using antibodies specific for mitochondrial and nonmitochondrial marker proteins (Figure 3-5 B). SIR-2.2 was depleted from the PMS and highly enriched in the MP together with the mitochondrial markers NUO-2 (subunit of complex I), cytochrome c and the $\alpha$-subunit of ATP-synthase. An antibody against histone H3 was used as a non-mitochondrial marker. During this study I could not obtain a SIR-2.3-specific antibody. Therefore, sir-2.3::gfp transgenic worms were fractionated and a GFP-specific antibody was used to detect the localization of SIR-2.3. Like SIR-2.2, SIR-2.3::GFP was also enriched in the MP and depleted from the PMS. Since folded GFP cannot be imported into mitochondria anymore a weak band of SIR-2.3::GFP was also detected in the PMS.

From these experiments I conclude that both SIR-2.2 and SIR-2.3 are like their mammalian homologue SIRT4 mitochondrial proteins.

Figure 3-4: Analysis of SIR-2.2 and SIR-2.3 subcellular localization by electron microscopy.

Representative cryo sections of worms were stained with an anti-GFP or the anti-SIR-2.2 antibodies and visualized with protein A-conjugated gold beads $(10 \mathrm{~nm})$. High-density black dots indicate the localization of SIR-2.2 and SIR-2.3 to mitochondria. A. and B. Immunogold labeling of sir-2.2::gfp transgenic worms with an anti-GFP antibody. C. to F. Analysis of sir-2.2::gfp transgenic worms (C and D) and wild type N2 worms (E and F) with the anti-SIR-2.2 antibodies. G. and H. Immunogold labeling of sir-2.3::gfp transgenic worms with an anti-GFP antibody. Scale bars represent level of magnification. 

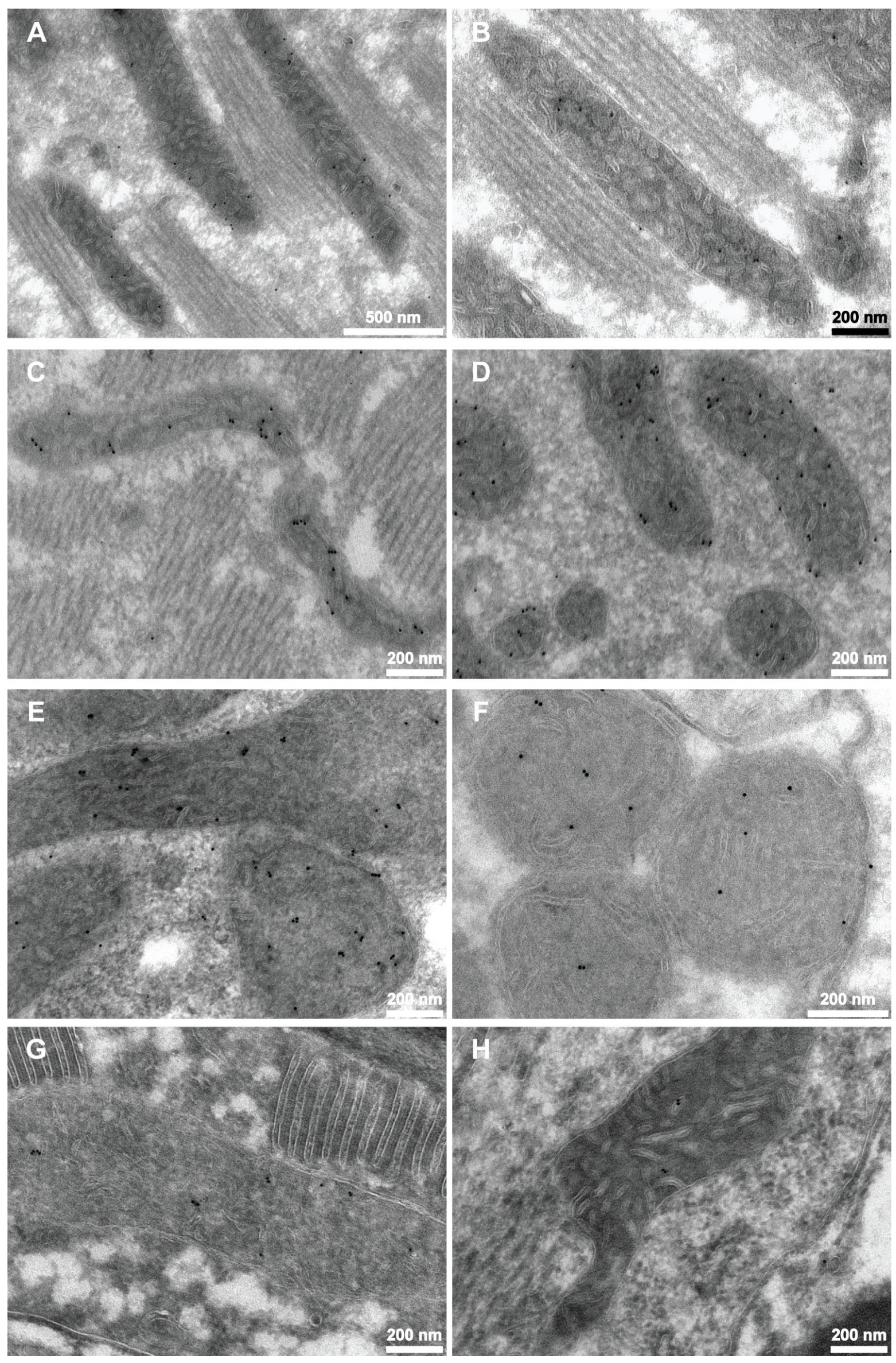
A

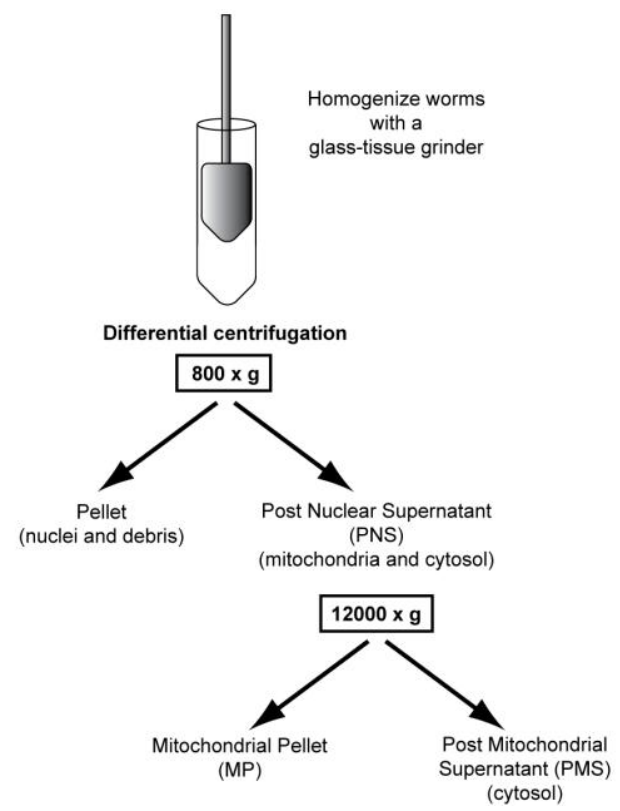

B

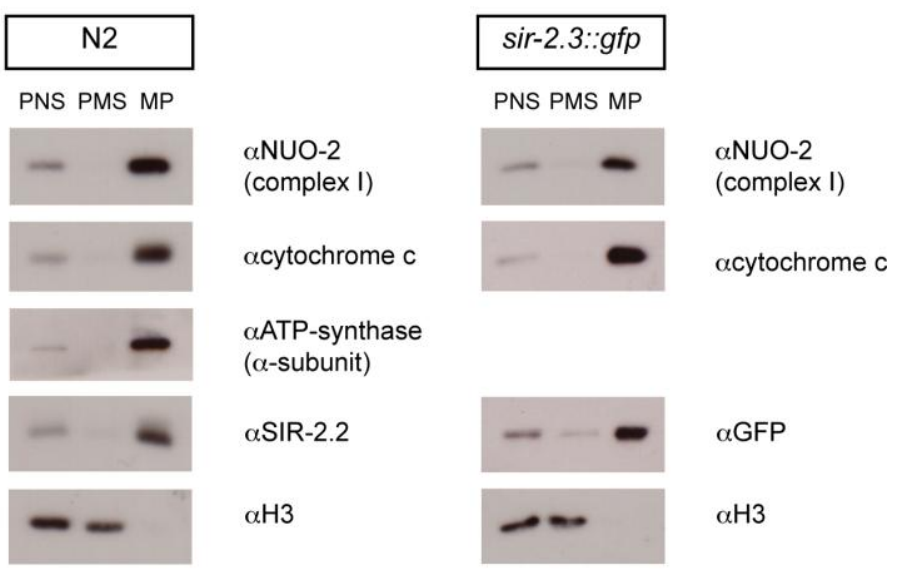

Figure 3-5: Subcellular fractionation of $\mathrm{N} 2$ and $s i r-2.3:: g f p$ transgenic worms by differential centrifugation.

A. Schematic overview on the subcellular fractionation procedure to isolate crude mitochondria from $C$. elegans. B. Wild type $\mathrm{N} 2$ worms and sir-2.3::gfp transgenic worms were homogenized and subjected to differential centrifugation. Equal protein amounts of the post nuclear supernatant (PNS), mitochondrial pellet (MP) and post mitochondrial supernatant (PMS) were analyzed by SDS-PAGE and Western blotting, using antibodies against the complex I subunit NUO-2 (mitochondria), cytochrome c (mitochondria), the $\alpha$-subunit of ATP-synthase (mitochondria), histone H3 (non-mitochondrial), SIR-2.2 and GFP.

\subsection{Characterization of sir-2.2 and sir-2.3 deletion mutant C. elegans strains}

To analyze the biological function of mitochondrial sirtuins in C. elegans, sir-2.2(tm2648), sir-2.2(tm2673) and sir-2.3(ok444) deletion mutant worm strains were phenotypically characterized.

\subsubsection{Sir-2.2 and sir-2.3 deletion mutant worms used in this study}

For all four $C$. elegans sir-2 genes deletion strains were generated by the $C$. elegans Gene Knockout Consortium or the National Bioresource Project for the Experimental Animal $C$. elegans (NBRP) using chemical mutagenesis (Table 3-1). For sir-2.2 I obtained two deletion strains (sir-2.2(tm2648) and sir-2.2(tm2673)) which had in the beginning severe developmental defects affecting growth, muscle function and germline. After crossing five times (sir-2.2(tm2673)) and six times (sir-2.2(tm2648)) to wild type N2 worms these strains did not show an obvious phenotype any more, suggesting that there were also background mutations. The mutant strains sir-2.3(ok444) and sir-2.1(ok434) kindly provided by the Caenorhabditis Genetics Center (CGC) also did not exhibit an obvious phenotype under normal growth conditions. Only worms of the sir-2.4(tm2817) mutant strain exhibited an embryonic lethal phenotype [198]. 
Table 3-1: Overview on available sir-2 mutant deletion strains.

\begin{tabular}{|c|c|c|c|c|}
\hline $\begin{array}{c}\text { SIR-2 } \\
\text { variant }\end{array}$ & Mutant strain & Source & Phenotype & $\begin{array}{c}\text { BlastP } \\
\text { Identities }\end{array}$ \\
\hline SIR-2.1 & sir-2.1(ok434)IV & C. elegans Gene Knockout Project & wild type & $\begin{array}{c}44 \% \\
\text { human SIRT1 }\end{array}$ \\
\hline SIR-2.2 & $\begin{array}{l}\text { sir-2.2(tm2648)X } \\
\text { sir-2.2(tm2673)X }\end{array}$ & $\begin{array}{l}\text { National BioResource Project } \\
\text { (NBRP) }\end{array}$ & wild type & $\begin{array}{c}49 \% \\
\text { human SIRT4 }\end{array}$ \\
\hline SIR-2.3 & sir-2.3(ok444)X & C. elegans Gene Knockout Project & wild type & $\begin{array}{c}42 \% \\
\text { human SIRT4 }\end{array}$ \\
\hline SIR-2.4 & sir-2.4(tm2817)I & $\begin{array}{l}\text { National BioResource Project } \\
\text { (NBRP) }\end{array}$ & embryonic lethal & $\begin{array}{c}38 \% \\
\text { human SIRT6 }\end{array}$ \\
\hline
\end{tabular}

A

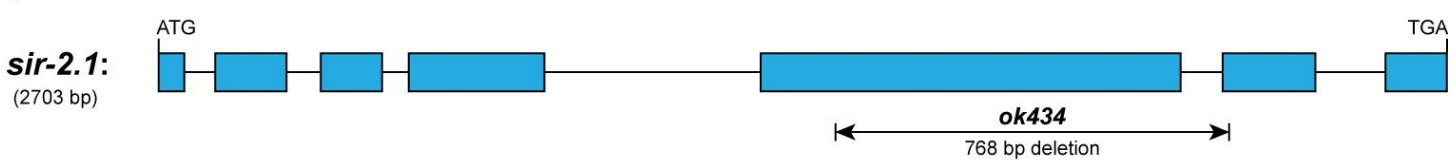

sir-2.2: (1839 bp)
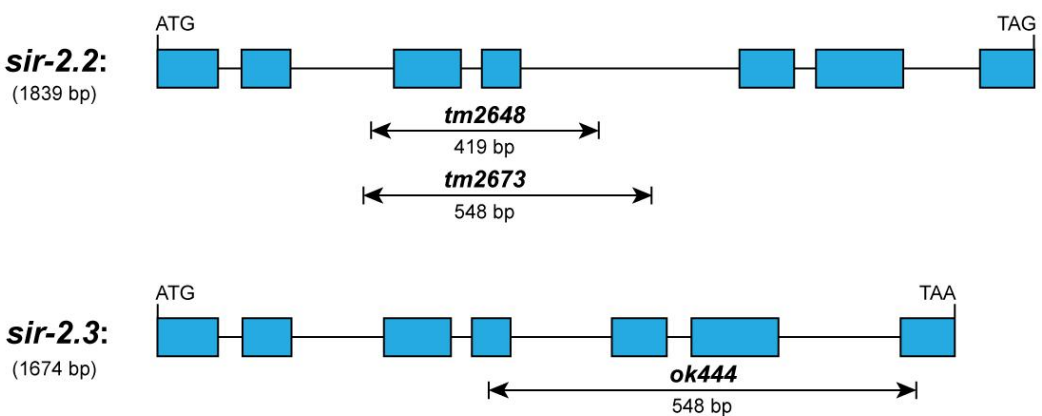

B

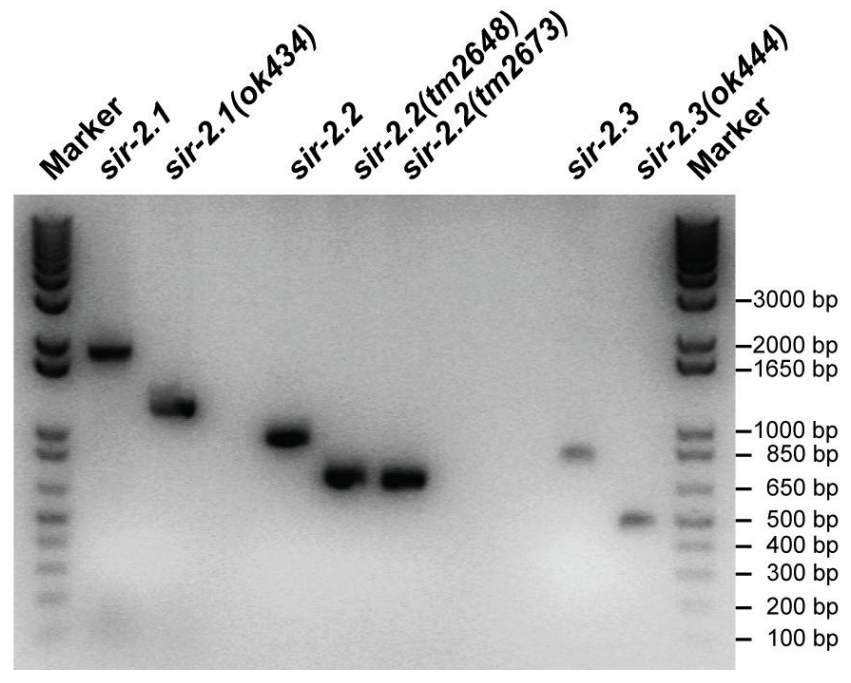

Figure 3-6: RT-PCR analysis of the sir-2 deletion mutant alleles

A. Schematic overview on the gene structure of the sir-2.1, sir-2.2 and sir-2.3 genes ranging from translation initiation codon (ATG) to the termination codon (TGA, TAG, TAA). Blue boxes indicate exons, black lines introns. Arrows mark the deleted regions within the deletion alleles. B. RNA was isolated from wild type N2 and $\operatorname{sir}-2.1(\mathrm{ok} 434), \operatorname{sir}-2.2(\operatorname{tm} 2648), \operatorname{sir}-2.2(\operatorname{tm} 2673), \operatorname{sir}-2.3(o k 444)$ deletion mutant worm strains. mRNA was reverse transcribed using oligo(dT) primers, and cDNAs were amplified by standard PCR reactions using primers that specifically bind to coding start and end of each gene. Obtained PCR fragments were separated on a $1 \%$ agarose gel and visualized by ethidium bromide staining. Running positions of size markers are indicated on the right. 
Since only parts and not the whole genomic sequences were deleted by chemical mutagenesis (Figure 3-6 A), it had to be determined whether these mutations result in null-mutations. I isolated RNA from sir-2.1(ok434), sir-2.2(tm2648), sir-2.2(tm2673) and sir-2.3(ok444) deletion mutant worms and performed reverse transcription PCR (RT-PCR) experiments using oligo(dT) primers. cDNAs were subjected to PCR reactions with primers specifically amplifying the complete coding sequence of each gene. PCR fragments were separated by agarose gel electrophoresis and visualized by ethidium bromide staining (Figure 3-6 B). mRNA encoding truncated SIR-2 protein was synthesized by all three sir-2 deletion strains, whereas no mRNA was detected in the $\operatorname{sir}$-2.4(tm2817) deletion strain producing a null allele [198].

Sequencing of the PCR products of the tm2648 and tm2673 mutant alleles showed that the $419 \mathrm{bp}$ and 548 bp deletions in the genomic sequence of sir-2.2 resulted in a loss of exons 3 and 4, and exon 2 was spliced in frame to exon 5. After translation 75 aa (encoded by exon 3 and 4) of 287 aa would be deleted in the truncated SIR-2.2 protein (212 aa) (Figure 3-7 A). To test whether truncated protein is produced, sir-2.2(tm2648) and sir-2.2(tm2673) crude protein extracts were analyzed by Western blotting using the anti-SIR-2.2-specific antibodies (Figure 3-7 C). In wild type $\mathrm{N} 2$ worms the antibody detected a double band at $\sim 33 \mathrm{kD}$. This double band I also observed with protein recombinantly expressed in E. coli. Since mass spectrometric analysis showed that both bands were SIR-2.2 protein, SIR-2.2 might be posttranslationally modified or proteolytically processed. In the sir-2.2(tm2648) and sir2.2(tm2673) mutant worms a protein band with the correct size of the corresponding truncated SIR-2.2 protein $(\sim 24 \mathrm{kD})$ was detected. In addition electron microscopic analysis of sir2.2(tm2648) mutant worms showed that the truncated SIR-2.2 protein also localized to mitochondria, indicating that the deletion mutation did not affect the mitochondrial targeting of the protein (Figure 3-7 D).

I do not have a SIR-2.3-specific antibody for Western blot analysis. However it is possible that a truncated SIR-2.3 protein is also produced in sir-2.3( ok444) mutant worms.

Figure 3-7: Characterization of truncated proteins resulting from sir-2 deletion mutant alleles.

A. Protein sequence of full-length (287 aa) and truncated SIR-2.2 (212 aa). Black box indicates the 75 aa that were deleted in the truncated protein. Residues of the catalytic sirtuin core domain are shown in blue (same for SIR-2.3 and SIR-2.1 in B and E, respectively). B. Protein sequence of full-length (287 aa) and hypothetical truncated SIR-2.3 protein (154 aa). In the truncated protein 141 aa (black box) were deleted and 8 aa (red) were added to the C-terminus due to the frame shift caused by the deletion. C. Western blot analysis of wild type N2, sir-2.2(tm2648) and sir-2.2(tm2673) crude protein extracts using the anti-SIR-2.2-specific and anti-H3 (loading control) antibodies. Running positions of the full-length and truncated SIR-2.2 protein are indicated on the right. D. Representative cryo section of sir-2.2(tm2648) deletion mutant worms immunogold labeled with the anti-SIR-2.2-specific antibodies and analyzed by electron microscopy. Scale bar represents $200 \mathrm{~nm}$. E. Protein sequence of full-length (607 aa) and hypothetical truncated SIR-2.1 protein (381 aa). The truncated SIR-2.1 protein lacked 229 aa encoded by a part of exon 5 (black box). Exon 6 was spliced in frame to the rest of the third exon, generating five additional amino acids in between (red). F. Recombinant full-length and truncated SIR-2.1 as well as HP1 were assayed for HDAC activity on a $\left[{ }^{3} \mathrm{H}\right]$ peracetylated histone $\mathrm{H} 4$ tail peptide. Deacetylation was determined by quantifying released acetyl by scintillation counting (for details see 2.6.1). Quantitative values, indicating HDAC activity, are means of three measurements; error bars represent standard deviation. 
A

MAQKFVPEAAELCENSLKKFISLIGTVDKLLVIS GAGISTESGIPDYRSKDVGLYARIAHKP I YFQDYMRSNRCRQR

YWSRNFLAWPRFGQAAPNINHYALSKWEAS DRFQWLITQNVDGLHLKAGSKMVTELHG SALQVKCTTCDYIESRQ

TYQDRLDYANPGFKEEHVAPGELAPDGDIILPL GTEKGFQIPECPSCGGLMKTDVTFFGENVNMD KVNFCYEKVNECDGILSLGTSLAVLSGFRFIHHAN MKKKPIFIVNIGPTRADHMATMKLDYKISDVLKEM

C

$\alpha$ SIR-2.2

$\alpha \mathrm{H} 3$

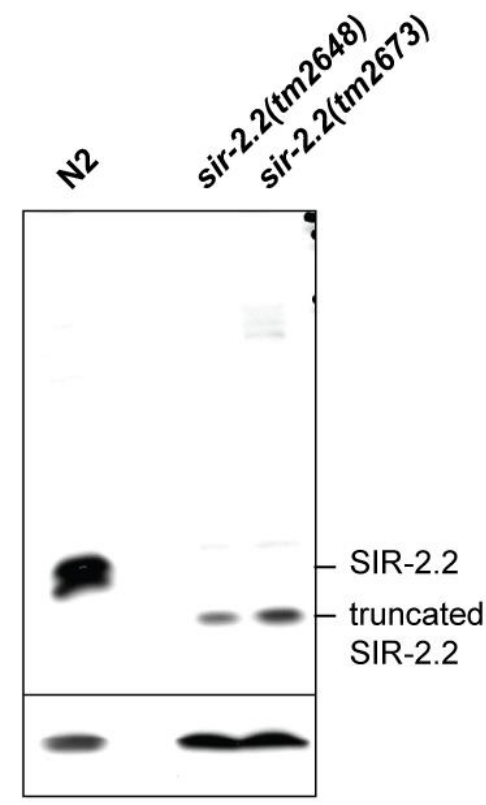

E

MSRDSGNDSEVAVTHGEVQEITEEN PEIGSMHITQETDISDAPETNTDSSRQRTESTTS VSSESWQNNDEMMSNLRRAQRLLDDGATPLQI IQQ IFPDFNASRIATMSENAHFAILS DLLERAPVRQKLTNYNSLADAVELFKTKKHILVLT GAGVSVSCGIPDFRSKDGIYARLRSEFPDLP DPTAMFDIRYFRENPAPFYNFAREIFPGQFVPS VSHRFIKELETSGRLLRNYTQNIDTLEHQTGIKRV VECHGSFSKCTCTRCGQKFFFLQ

YDGNEIREEVLAMRVAHCKRCEGVIKPNIVFF GEDLGREFHQHVTEDKHKVDLIVVIGSSLKVRPVA LIPHCVDKNVPQILINRESLPHYNADIELLGNCDDI IRDICFSLGGSFTELITSYDSIMEQQGKTKSQKP SQNKRQLISQEDFLNICMKEKRNDDSSDEPTLK KPRM SVADDSMDSEKNNFQEIQKHKSED DDDTRNSDDILKKIKHPRLLSITEMLHDNKCVA

ISAHQTVFPGAECSFDLETLKLVRDVHHETHCESS CGSSCSSNADSEANQLSRAQSLDDFVLSD EDRKNTIHLDLQRADSCDGDFQYELSETIDPETF SHLCEEMRI
B

MARKYVPHTTELCENSLKKFKSLVGTVDKLLIIT GAGISTESGIPDYRSKDVGLYTKTALEPIYFQDFMK SKKCRQRYWSRSYLNWPRFAQALPNFNHYALSK WEAANKFHWLITQNVDGLHLKAGSKMITELHG NALQVKCTSCE

YIETRQTYQDRLNYANPGFKEQFVSPGQQELDAD TALPLGSEQGFKIPECLNCGGLMKTDVTLFGEN LNTDKIKVCGKKVNECNGVLTLGTSLEVLSGYQI VNHAHMQNKPIFIVNIGPTRADQMATMKLDYRISD VLKEM

CKTNQFSS

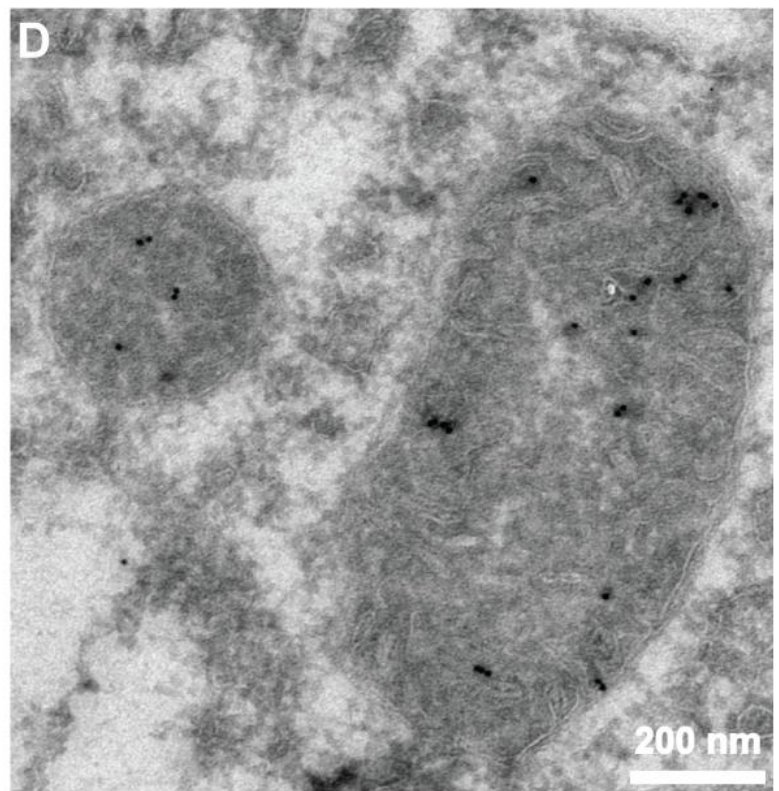

$\mathbf{F}$

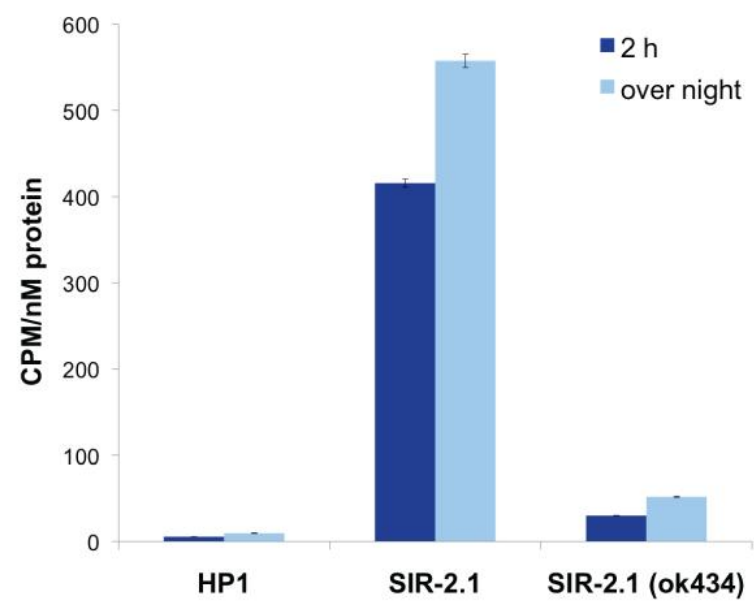


Here the deletion of $548 \mathrm{bp}$ in the genomic sequence of sir-2.3 caused a partial loss of exon 4 and the complete loss of exons 5, 6 and 7. Since the fusion of the residual parts of exon 4 and exon 7 resulted in a frame shift mutation, the hypothetical truncated SIR-2.3 protein (Figure 3-7 B) would lack 154 aa of its C-terminus (black box), and 8 new aa (CKTNQFSS, shown in red) would be added before the occurrence of a stop codon. In sir-2.1(ok434) mutant worms $768 \mathrm{bp}$ of the genomic sequence were deleted. A large region of exon 5 was gone and its residual 5' region was spliced in frame to exon 6, thereby 5 additional condons were generated in between. In the hypothetical truncated SIR-2.1 protein, therefore, 299 aa (encoded by exon 5, black box) would be missing and 5 additional aa (FFFLQ, shown in red) would be inserted at the site of the deletion (Figure 3-7 E). I also did not have a SIR-2.1specific antibody, but an in-vitro histone deacetylase (HDAC) activity assay (3.4.2.1) with recombinantly expressed protein showed that the deacetylase activity was abrogated in the truncated SIR-2.1 protein (Figure 3-7 F). Therefore, the $o k 434$ deletion allele generates a nonfunctional SIR-2.1 protein. Heterochromatin protein 1 (HP1) was used as negative control in this experiment. Since full-length SIR-2.2 and SIR-2.3 (3.4.2.1) did not exhibit deacetylase activity in this HDAC assay, it is not know whether truncated SIR-2.2 and SIR-2.3 are still functional.

Interestingly, the functional null mutation in the sir-2.1(ok434) mutant strains did not cause an obvious phenotype in these worms under normal growth conditions. Although in the sir2.2 and sir-2.3 mutant worms the deletion mutations removed large parts of the catalytic sirtuin core domain and important residues required for the $\mathrm{NAD}^{+}$-dependent deacetylase activity (Figure 3-7 A and B, shown in blue), no obvious phenotype was observed.

These results led me to the conclusion that there might be functional redundancy among the different SIR-2 variants in C. elegans.

\subsubsection{Knockdown of sir-2.2 in a sir-2.3 mutant background leads to a very mild phenotype}

To test whether there is functional redundancy among the mitochondrial SIR-2 variants, I knocked down sir-2.2 by RNAi in a sir-2.3(ok444) mutant background. As the sir-2.2 and sir2.3 genes are directly next to each other on chromosome $\mathrm{X}$ and homologous recombination is very rare in C. elegans, it was not possible to generate a sir-2.2(tm2648) sir-2.3(ok444) double mutant worm strain. Therefore, sir-2.2 was knocked down by microinjection of sir-2.2 dsRNA into sir-2.3(ok444) mutant hermaphrodites and subsequent sir-2.2 RNAi feeding of the injected hermaphrodites and their F1 progeny. For control wild type (N2) hermaphrodites were microinjected with M9 buffer and transferred to feeding plates seeded with $E$. coli HT115(DE3) containing an empty L4440 vector.

Knock down of sir-2.2 by RNAi in a sir-2.3 mutant background resulted in a very weak phenotype and only $4.5 \%$ of the worms exhibited growth and egg-laying defects. As $1.9 \%$ of wild type (N2) control worms were as well dumpy (Dpy, short fat worms) and egg-laying defective $(\mathrm{Egl})$, the difference were only minor and non-significant (with a p-value $>0.05$ in standard Student t-test for the data presented in Table 3-2).

Loss of sir-2.2 or sir-2.3 as well as knock down of sir-2.2 in a sir-2.3(ok444) mutant background did not cause a severe phenotype under normal growth conditions. Knockout 
mice of SIRT3, SIRT4 and SIRT5 also grow and develop normally under physiological conditions [25, 92, 114]. However, mitochondrial sirtuins function in stress responses [19], suggesting that SIR-2.2 and SIR-2.3 might play a role during stress.

Table 3-2: Knock down of sir-2.2 in sir-2.3(ok444) mutant worms did not cause an obvious phenotype.

\begin{tabular}{lcc}
\hline Genotype & \% Dpy and Egl \pm S.E.M & $\mathrm{n}(\mathrm{F} 1)$ \\
\hline wild type (N2) & $1.9 \pm 0.3$ & $5(518)$ \\
sir-2.3(ok444); sir-2.2(RNAi) & $4.5 \pm 1.3$ & $7(1012)$ \\
\hline
\end{tabular}

For knock down, sir-2.2 dsRNA was microinjected into sir-2.3(ok444) mutant hermaphrodites. Injected hermaphrodites were subsequently singled onto sir-2.2 RNAi feeding plates. For control, wild type (N2) hermaphrodites were microinjected with M9 buffer and transferred to feeding plates seeded with E. coli HT115(DE3) containing an empty L4440 vector. The F1 generation was analyzed for dumpy (Dpy) and egglaying defective (Egl) phenotypes. S.E.M: standard error of mean; n: number of microinjected hermaphrodites, F1: number of analyzed F1 generation progeny; a p-value $>0.05(0.05003)$ was calculated using the standard Student t-test.

\subsubsection{Sensitivity towards oxidative stress}

Mitochondria are the central organelle for cellular energy production, but also the major site of ROS generation within cells. If uncontrolled, ROS can seriously damage macromolecules (DNA, protein and lipids) and cause mitochondrial dysfunction, which is thought to be a major determinant of life span (free radical theory) [199, 200]. Because of the mitochondrial subcellular localization of SIR-2.2 and SIR-2.3, I analyzed the tolerance of sir-2.2(tm2648) and sir-2.3(ok444) mutant worms to oxidative stress. Since there might be functional redundancy between sir-2.2 and sir-2.3, I also performed this analysis on worms grown on sir-2.2 or sir-2.3 feeding plates. To test whether overexpression of SIR-2.2 and SIR-2.3 affects the sensitivity to oxidative stress, I assayed sir-2.2::gfp and sir-2.3::gfp transgenic worms that express GFP-tagged SIR-2 proteins in a wild type background as well. (For analysis of SIR-2.2 protein levels see Appendix A.1, Figure A-1.)

Oxidative stress resistance was investigated by assaying daily the survival of worms (starting with L4 larvae) on RNAi feeding plates containing paraquat, which is known to generate superoxide anions. Worms were scored as dead when they did not respond to prodding with a pick. The highest sensitivity towards oxidative stress was observed in sir-2.2::gfp and sir$2.3: \because g f p$ transgenic worms having a mean survival of $5.07 \pm 0.16$ (S.E.M.) and $5.16 \pm 0.21$ (S.E.M.), respectively, compared to wild type N2 worms $7.86 \pm 0.21$ (S.E.M.) (Figure 3-8 A and B). Sir-2.2(tm2648) (6.66 \pm 0.16 (S.E.M.)) and sir-2.3(ok444) (6.26 \pm 0.18 (S.E.M.)) mutant worms were also significantly more sensitive to oxidative stress than wild type worms (Figure 3-8 A and C). Knockdown of sir-2.3 in sir-2.2(tm2648) mutant worms led to a slight increase in sensitivity (5.86 \pm 0.15 (S.E.M.)). However, no increased sensitivity was observed when knocking down sir-2.2 in a sir-2.3(ok444) mutant background (6.42 \pm 0.18 (S.E.M.)), suggesting that there is no functional redundancy between sir-2.2 and sir-2.3.

Overall, this data shows that both loss and overexpresssion of SIR-2.2 and SIR-2.3 leads to an increased sensitivity to oxidative stress and both proteins seem to function in oxidative stress resistance pathways. 
A

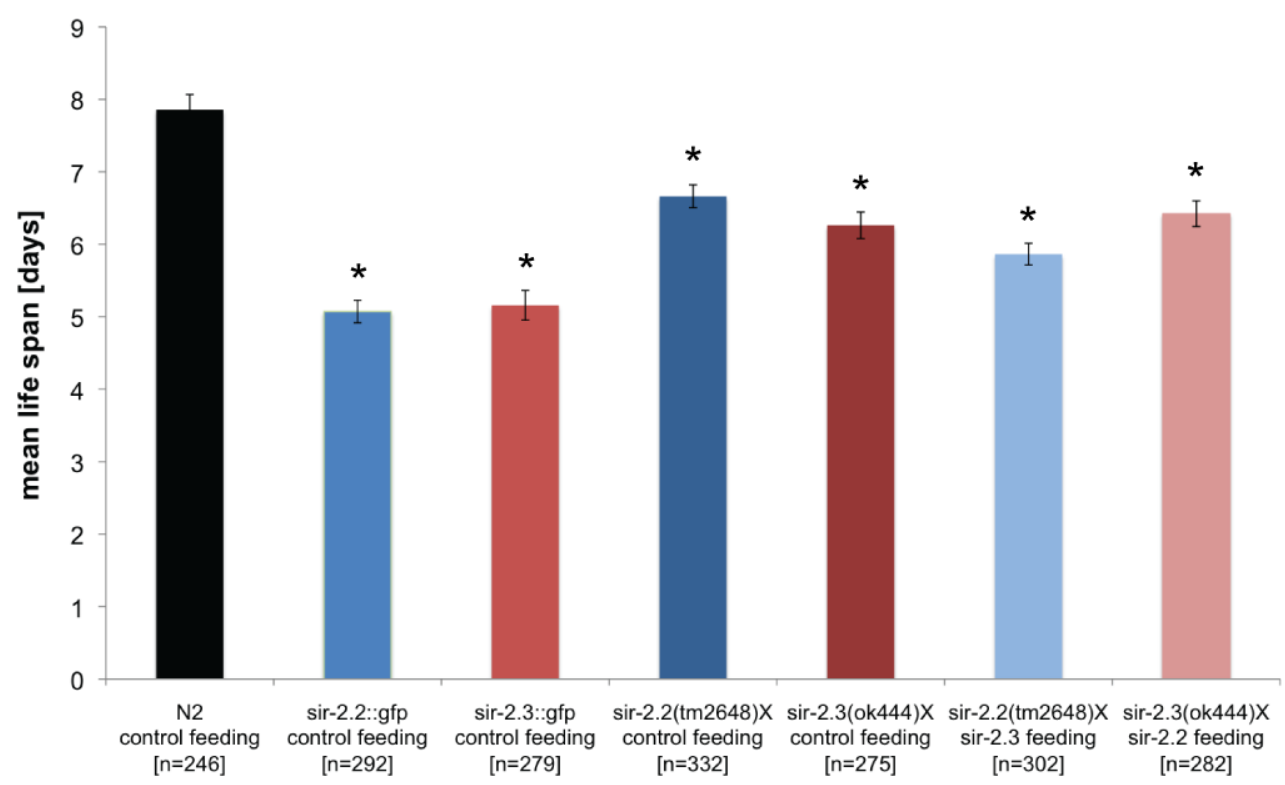

B

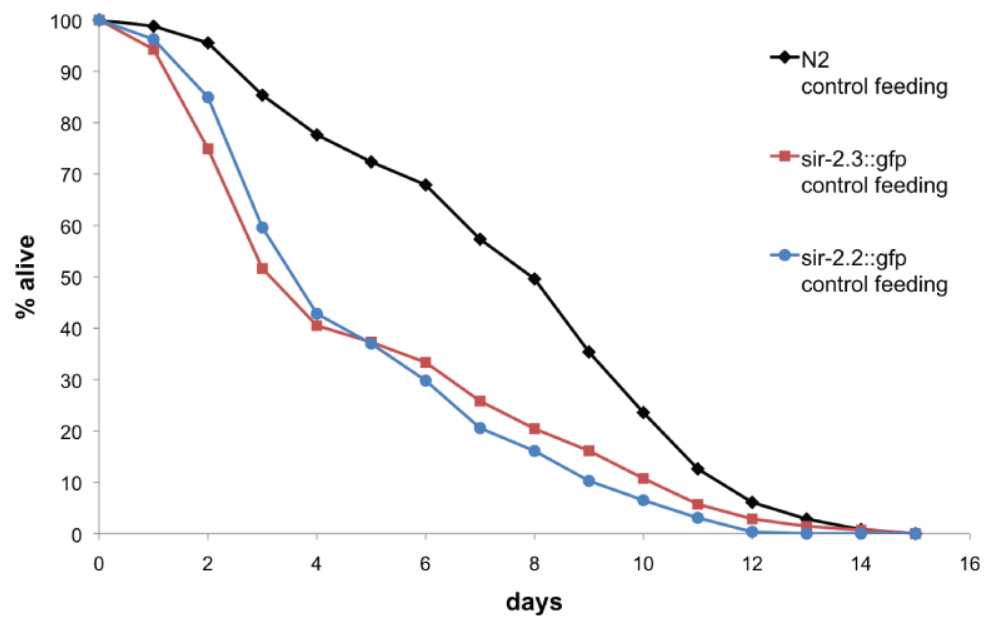

C

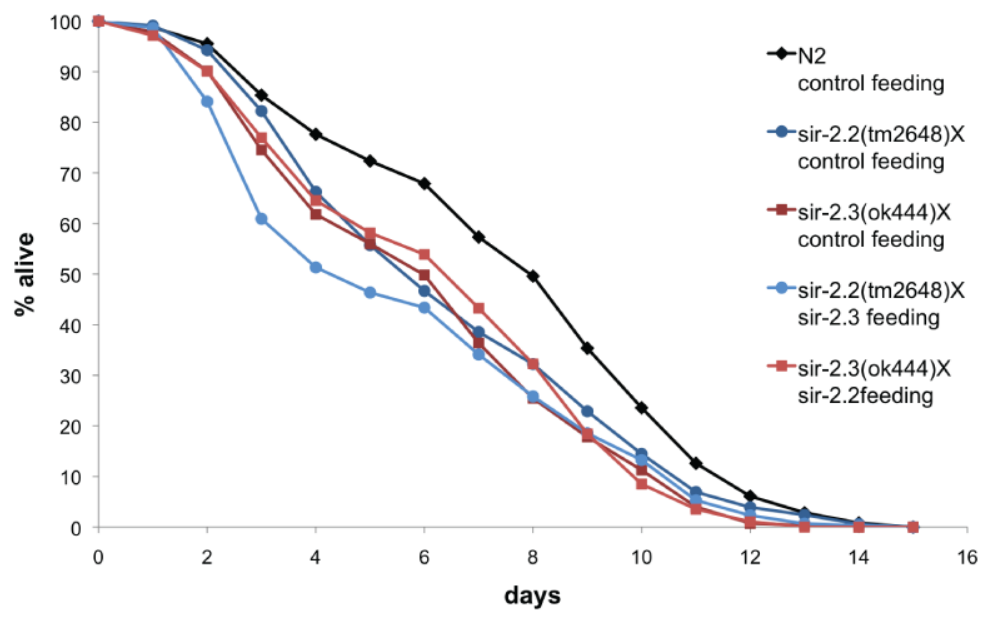

Figure 3-8: Increased sensitivity to oxidative stress in worms overexpressing or deficient in SIR-2.2 and SIR-2.3.

A. Mean life span of worms grown at $24.5^{\circ} \mathrm{C}$ on RNAi feeding plates containing paraquat $(200 \mu 1$ of $250 \mathrm{mM}$ paraquat solution/plate). At least 3 trials were conducted per strain. Error bars show standard error of mean (S.E.M.); asterisks indicate a significant difference (p-value < 0.001) to average life span of wild type (N2) worms; p-values were calculated using standard Student t-test; n: number of analyzed worms. B. Average survival curve of wild type (N2) and worms overexpressing SIR-2.2 (sir-2.2::gfp) or SIR-2.3 (sir-2.3::gfp). C. Average survival curve of wild type (N2) worms and worms deficient in sir-2.2, sir-2.3 or both. 


\subsection{Identification of SIR-2.2 and SIR-2.3 interaction partners}

\subsubsection{Identification of mitochondrial biotin carboxylases as factors interacting with SIR-2.2 and SIR-2.3}

To identify factors interacting with SIR-2.2, the promoter and genomic sequence of SIR-2.2 was fused to a modified version of the so-called localization and affinity purification (LAP)tag [177] using a C-terminal Strep-GFP-tag. A stable integrated transgenic worm strain expressing SIR-2.2::Strep::GFP was generated by microinjection and UV treatment. Since the tagged protein could not be recovered from C. elegans lysates in sufficient amounts by Streptag purification (data not shown), I could not use a tandem affinity purification approach. Thus, SIR-2.2::Strep::GFP was immunoprecipitated from total worm lysates with different antibodies raised against GFP and the SIR-2.2-specific antibodies (Figure 3-9 A). Because of the mitochondrial localization of SIR-2.2 (3.1.4), I also isolated mitochondria from C. elegans and used mitochondrial extracts for the immunoprecipitation experiments. As a negative control immunoprecipitation experiments were performed with total worm lysates prepared from the transgenic worm strains BC15074 and BC14289 (expressing GFP under control of the endogenous sir-2.2 promoter) and with mitochondrial lysates of the transgenic strains SJ4104 and SJ4143 (expressing GFP with a mitochondrial targeting sequence). Bound proteins were subjected to SDS-PAGE and complete lanes were analyzed by mass spectrometry in the group of Dr. Henning Urlaub (MPI of Biophysical Chemistry, Göttingen). Proteins that were identified with at least two peptides or a protein score of at least 80 and were present only in the SIR-2.2::GFP bound fraction but not in the control IP, were extracted from the data with the statistical program $\mathrm{R}$ (for details on the $\mathrm{R}$ protocol and a list of factors see Appendix A.2 and A.3). Five different immunoprecipitation experiments were performed and SIR-2.2-specific factors that showed the highest occurrence in these experiments were further analyzed. Among the identified factors D2023.2 (pyc-1, pyruvate carboxylase), F27D9.5 ( pcca-1, propionyl-coenzyme A (-CoA) carboxylase alpha subunit), and F32B6.2 (ortholog to human alpha methylcrotonoyl-coenzyme A (-CoA) carboxylase 1, in this study referred to as $m c c c$-1) were particularly interesting as the proteins represent the three mitochondrial members of the biotin-dependent carboxylase protein family. The best sequence coverage obtained for these proteins were $48 \%$ with 107 identified peptides for PYC-1 (Figure 3-9 B), 32\% with 18 peptides for PCCA-1 (Figure 3-9 C) and 13\% with 9 peptides for MCCC-1 (Figure 3-9 D).

In mammals pyruvate carboxylase (PC) has an important anaplerotic function for the tricarboxylic acid (TCA) cycle as the enzyme catalyzes the carboxylation of pyruvate to oxaloacetate, an important TCA cycle intermediate [201] (Figure 3-10). Propionyl-CoA carboxylase (PCC) is essential for the catabolism of branched chain amino acids (Thr, Val, Ile, and Met), odd-chain length fatty acids and cholesterol. Since it carboxylates propionylCoA to methylmalony-CoA, which feeds into the TCA cycle after conversion to succinylCoA, it is also important for anaplerosis [202, 203]. Methylcrotonyl-CoA carboxylase (MCC) catalyzes the carboxylation of 3-methylcrotonyl-CoA to 3-methylglutaconyl-CoA, the fourth step in catabolism of the essential amino acid (aa) leucine. Leucine, as a exclusively ketogenic aa, is degraded to acetoacetate and acetyl-CoA. Therefore, MCC does not function in 
anaplerosis but formation of ketone bodies [203, 204]. Anaplerosis and formation of ketone bodies are essential for maintaining energy homeostasis during nutrient deprivation such as fasting. Sirtuins are potential energy sensors $[19,20]$ and C. elegans SIR-2.2 and SIR-2.3 might regulate the enzymatic activities of mitochondrial biotin-dependent carboxylases during metabolic stress. Thus, I selected mitochondrial biotin carboxylases for further studies.

A

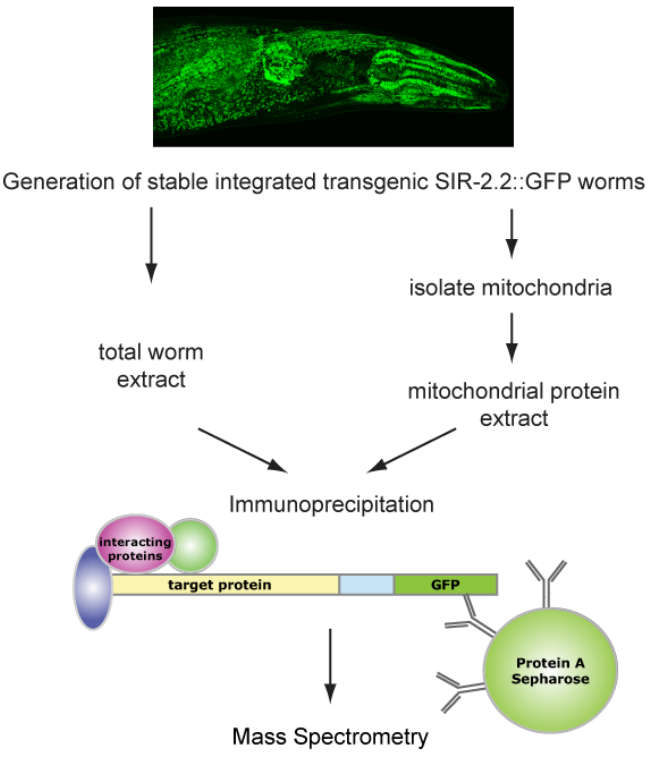

C

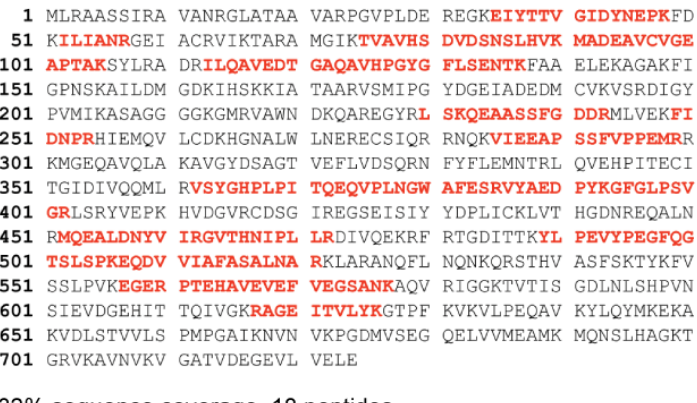

$32 \%$ sequence coverage, 18 peptides
B

1 MRESRIPPIF ANVVRQTHYR NYANGVIKPR EFNKVMVANR GEIAIRVERA 51 LTELNKTSVA IYAEQDKNSM HRLKADEAYL VGKGLPPVAA YLTIDQIIET 101 ALKHNIDAIH PGYGLLSERS DFAAACQNAG IVFIGPSPDV MARMGDKVAA 151 RQAAIEAGVQ VVPGTPGPIT TADEAVEFAK QYGTPIILKA AYGGGGRGIR

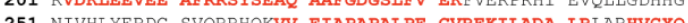

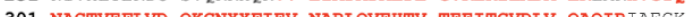
351 SIDDIKOSQ TIQTIN 351 SIDDLKL 401 RLDSASATG SVISPHYSL MUKVIASARN HPIAMKUIR DLKKERIRGV 451 KTNTPELLNV LRQPSELDAS VDTYFIDEHP ELEQEKPSEN RAQKLENTLG 501 ENKNGPTP WATDLKPAV SPPIPYIPAG AKPPIGLDV LVQRGPIEFA 551 KEVRSRPGCM ITDTTFRDAB QSLLATRVRT YDMAAISPEV AQSFNGLFSL 601 ENWGGATFDV SMRFLHECPW ERLQTLRKLI PNIPFQCLIR GANAMGYSNY 651 PDNVIYKFCE LAVKNGMDVF RVEDSLNYLP NLLVGMEAVG KAGGVVEAAI 701 AYTGDVTDKS RDKYDLKYYL NLADQLVKAQ AHILSIKDMA GVLKPEAAKL 751 LIGALRDKFP DIPIHVHTHD TSGAGVAAML ECAKAGADVV DAAVDSMSGM 801 TSQPSMGAIV ASLQGTKHDT GLSLDDISKY SAYWESTRQI YAPFECATTM 851 KSGNADVYKH EIPGGQYTNL QFQAFSLGLG PQFDEVKRMY REANLVLGDI 901 IKVTPSSKIV GDLAOFMVON NLTRETLVDR ADDISFPKSV VDFMOGNVGO 951 PPYGFPEPLR TKVLRGKPKV DGRPGENAKP VDLDAVKVEL EEKHGRTLSE 1001 EDVMSYSMFP TVFDEFETFR OOYGPVDKLP TRLFLTGLEI AEEVDVETES 1051 GKTLAIOLLA EGKLNKRGER EVFFDINGOM RSIFVYDKKEA SKETVTRPRA 1101 IPGVRGHTCA PMPGDVIELK TKEGDKVTKK OPT FVI SAMK MEMVIDSPTA 1151 GTVKAIHAPQ GTKCSAGDLV VEVEP

$48 \%$ sequence coverage, 107 peptides

D

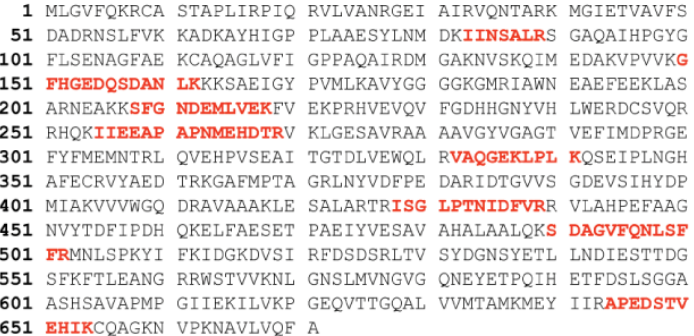
651 EHIKCQAGKN VPKNAVLVQE A

$13 \%$ sequence coverage, 9 peptides

Figure 3-9: Identification of mitochondrial biotin carboxylases as factors interacting with SIR-2.2.

A. Schematic overview on strategy used to identify interaction partners of SIR-2.2. A stable integrated transgenic worm strain expressing SIR-2.2 with a C-terminal Strep-GFP-tag under control of the endogenous promoter was generated and used for extract preparation. GFP-tagged SIR-2.2 was immunoprecipitated with anti-GFP-specific antibodies or the anti-SIR-2.2-specific antibodies from total or mitochondrial worm extracts. Isolated proteins were subjected to SDS-PAGE and analyzed by mass spectrometry. B. Protein sequence of $C$. elegans D2023.2 (PYC-1). C. Protein sequence of C. elegans F27D9.5 (PCCA-1) D. Protein sequence of F32B6.2 (MCCC-1). Best sequence coverage of PYC-1, PCCA-1 and MCCC-1 and peptides identified by mass spectrometric analyses (highlighted in red) are shown. 


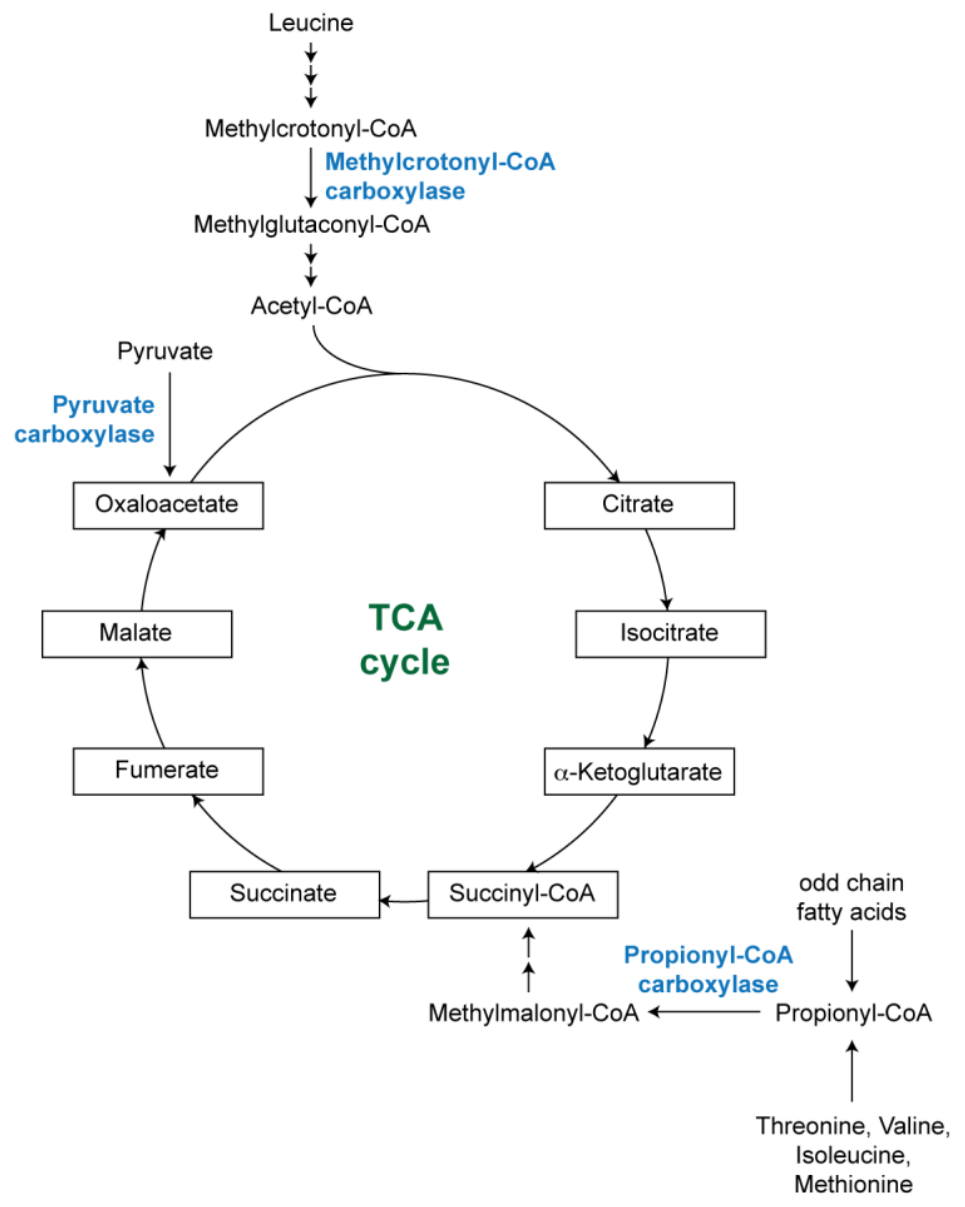

Figure 3-10: Role of mitochondrial biotin-dependent carboxylases in anaplerosis and generation of ketone bodies.

In mammals pyruvate carboxylase (PC) catalyzes the important anaplerotic reaction of carboxylating pyruvate to oxaloacetate, an TCA cycle intermediate. Propionyl-CoA carboxylase (PCC) carboxylates propionyl-CoA to methylmalony-CoA, which feeds into the TCA cycle after conversion to succinyl-CoA. This reaction is essential for the catabolism of branched chain amino acids (Thr, Val, Ile, and Met) and odd-chain length fatty acids. Methylcrotonyl-CoA carboxylase (MCC) catalyzes the carboxylation of 3-methylcrotonyl-CoA to 3methylglutaconyl-CoA, the fourth step in catabolism of the essential amino acid (aa) leucine. Leucine being an exclusively ketogenic aa is degraded to acetoacetate and acetyl-CoA, which is oxidized in the TCA cycle. MCC does not function in anaplerosis but formation of ketone bodies.

Since there were no $g f p$-transgenic strains of these factors existing to verify their interaction with SIR-2.2, I cloned the cDNAs of all three biotin carboxylases into a mammalian expression vector with a C-terminal double FLAG-tag. GFP-tagged SIR-2.2 was expressed together with the corresponding FLAG-tagged proteins in HEK293 cells, immunoprecipitated with GFP-Trap ${ }^{\circledR} \mathrm{A}$, and analyzed by SDS-PAGE and Western blotting. PYC-1, PCCA-1 and MCCC-1 co-immunoprecipitated specifically with GFP-tagged SIR-2.2, but not with GFP alone (Figure 3-11 A). Importantly, the mitochondrial protein ACDH-3 (acyl-CoA dehydrogenase) and the nuclear protein HP1ß did not associate with SIR-2.2::GFP in the same experiment.

SIR-2.2 and SIR-2.3 were both mitochondrial (3.1.4) and share a high sequence homology (75.3\% identity) with each other. To test whether SIR-2.3 also interacts with these factors, coimmunoprecipitation experiments were performed with GFP-tagged SIR-2.3 and FLAG- 
tagged biotin carboxylases. Interestingly, SIR-2.3 also specifically interacted with the three factors. Again, no interaction with HP1ß was observed (Figure 3-11 B).

Since I was able to generate stable integrated worm strains expressing SIR-2.3 with a Cterminal HA-GFP-tag, I also performed immunoprecipitation experiments with GFP-specific antibodies and mitochondrial extracts of sir-2.3::gfp transgenic worms. Bound proteins were separated by SDS PAGE and analyzed by mass spectrometry (using same strategy as described above). Peptides of all three biotin carboxylases were identified in the SIR-2.3 bound protein fraction, indicating that SIR-2.3 also interacts with the endogenous proteins. The best sequence coverage obtained for these proteins are shown in Figure 3-12 (for a list of identified factors see Appendix A.3). PYC-1 was identified with a sequence coverage of $48 \%$ with 50 identified peptides (Figure 3-12A). The highest sequence coverage for PCCA-1 and MCCC-1 were $17 \%$ with 13 peptides (Figure 3-12 B) and 21\% with 14 peptides (Figure 3-12 C), respectively.

In summary, mass spectrometric and Western blot analyses of immunoprecipitation experiments showed that both, SIR-2.2 and SIR-2.3, interact with the mitochondrial proteins, PYC-1, PCCA-1 and MCCC-1, which might be biological substrates of these proteins.

A

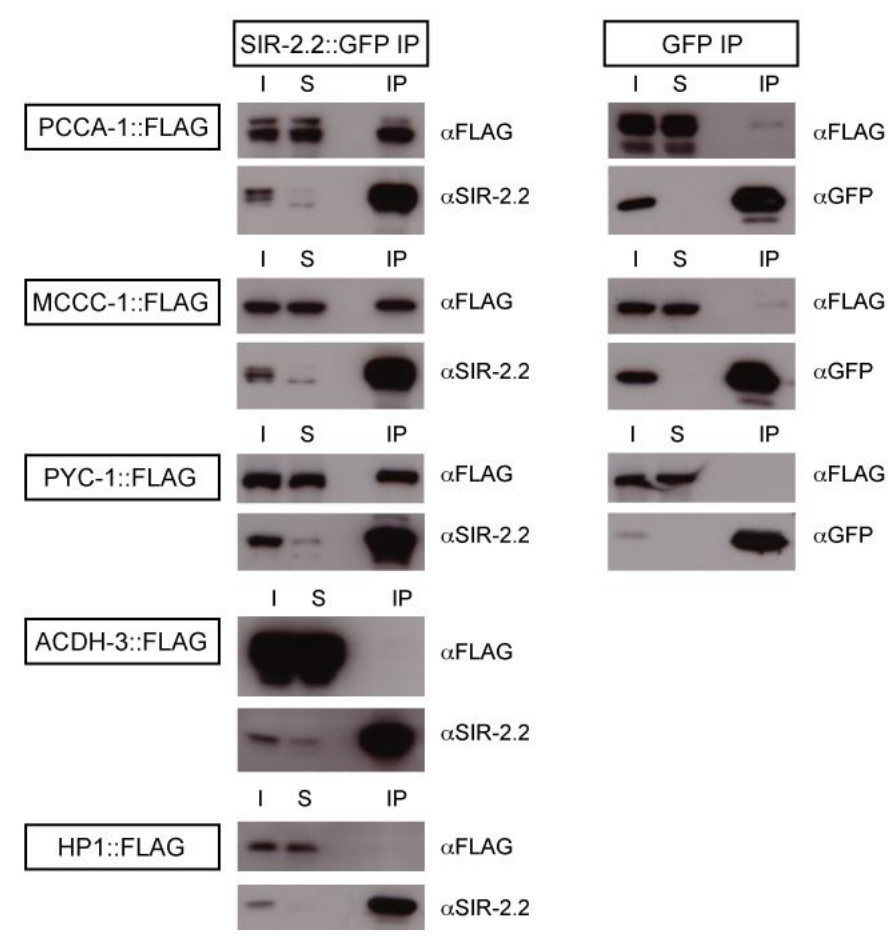

B

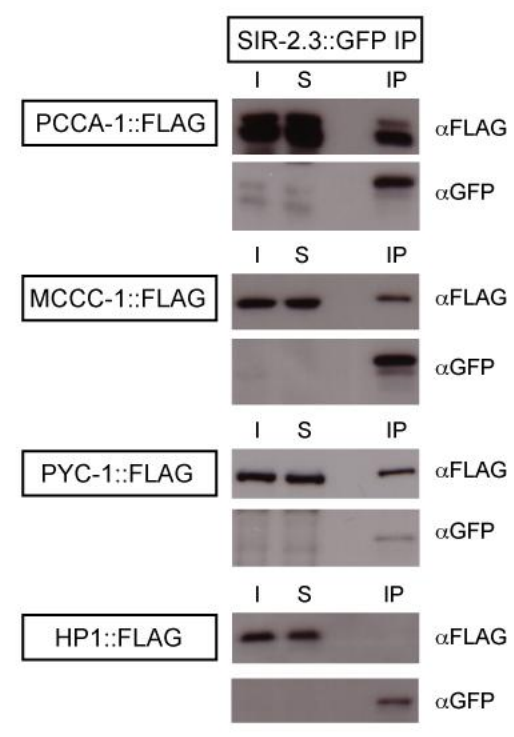

Figure 3-11: Verification of mitochondrial biotin-dependent carboxylases as interaction partners of C. elegans SIR-2.2 and SIR-2.3.

Expression vectors encoding SIR-2.2::GFP, SIR-2.3::GFP or GFP alone were co-transfected in HEK293 cells with an expression vector for either FLAG-tagged PCCA-1, MCCC-1, PYC-1, ACDH-3 or HP1. GFP-tagged proteins were immunoprecipitated with GFP-Trap ${ }^{\circledR} \mathrm{A}$ and analyzed by SDS-PAGE and Western blotting using anti-GFP and anti-FLAG antibodies. I: input (2\%), S: supernatant after IP (2\%), IP: immunoprecipitated protein fraction. A. Representative Western blot analyses of proteins bound to immunoprecipitated SIR-2.2::GFP (left panel) and GFP (right panel). B. Representative Western blot analyses of proteins bound to immunoprecipitated SIR-2.3::GFP. 
A

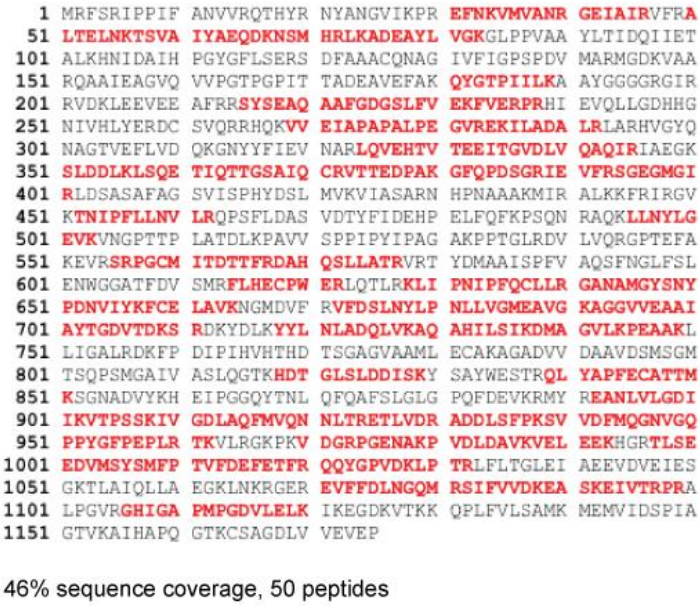

B

1 MLRAASSIRA VANRGLATAA VARPGVPLDE REGKEIYTTV GIDYNEPKFD 51 KILIANRGEI ACRVIKTARA MGIKTVAVHS DVDSNSLHVK MADEAVCVG 101 APTAKSYLRA DRILOAVEDT GADAVHPGYG FLSENTKFAA ELEKAGAKFI 151 GPNSKAILDM GDKIHSKKIA TAARVSMIPG YDGEIADEDM CVKVSRDIGY 201 PVMIKASAGG GGKGMRVAWN DKQAREGYRL SKQEAASSFG DDRMLVEKEI 251 DNPRHIEMQV LCDKHGNALW LNERECSIOR RNOKVIEEAP SSFVPPEMRR 301 KMGEQAVQLA KAVGYDSAGT VEFLVDSQRN FYFLEMNTRL QVEHPITECI 351 TGIDIVQQML RVSYGHPLPI TQEQVPLNGW AFESRVYAED PYKGFGLPSV 401 GRLSRYVEPK HVDGVRCDSG IREGSEISTY YDPLICKLVT HGDNREQALN 451 RMQEALDNYV IRGVTHNIPL LRDIVQEKRE RTGDITTKYL PEVYPEGEQG 501 TSLSPKEQDV VIAFASALNA RKLARANQFL NQNKQRSTHV ASFSKTYKFV 551 SSLPVKEGER PTEHAVEVEF VEGSANKAQV RIGGKTVTIS GDLNLSHPVN 601 SIEVDGEHIT TQIVGKRAGE ITVLYKGTPF KVKVLPEQAV KYLOYMKEKA 651 KVDLSTVVLS PMPGAIKNVN VKPGDMVSEG QELVVMEAMK MQNSLHAGK? 701 GRVKAVNVKV GATVDEGEVL VELE

$17 \%$ sequence coverage, 13 peptides

C

1 MLGVFQKRCA STAPLIRPIQ RVLVANRGEI AIRVQNTARK MGIETVAVFS 51 DADRNSLFVK KADKAYHIGP PLAAESYLNM DKI INSALRS GAQAIHPGYG 101 FLSENAGFAE KCAQAGLVII GPPAQAIRDM GAKNVSKQIM EDAKVPVVKG 151 FHGEDQSDAN LKKKSAEIGY PVMLKAVYGG GGKGMRIAWWN EAEFEEKLAS 201 ARNEAKKSFG NDEMLVEKFV EKPRHVEVQV FGDHHGNYVH LWERDCSVQR 251 RHQKIIEEAP APNMEHDTRV KLGESAVRAA AAVGYVGAGT VEFIMDPRGE 301 FYFMEMNTRL QVEHPVSEAI TGTDLVEWQL RVAQGEKLPL RQSEIPLNGH 351 AFECRVYAED TRKGAMPTA GRLNYVDFPE DARIDTGNS GDEVSTHYDP 401 MIAKVVVWGQ DRAVAAAKCEE SALARTRISG LPTNIDFVRR VLAHPEEAAG 451 NVYTDFTPDH QKELFAESET PAETYVESAV AHALAALLKS DAGVFQNLSF 501 FRMNLSPKY FKIDGKDVSI RFDSDSRLTV SYDGNSYETL LNDIESTTDG 551 SFKFTLEANG RRWSTVVKNL GNSLMNONG QNETETPQIH ETFDSLSGGA 651 EHIKCQAGK 651 EHIKCOAGKN VPKNAVLVOE A

$21 \%$ sequence coverage, 14 peptides

Figure 3-12: Identification of endogenous mitochondrial biotin-dependent carboxylases as interacting factors of SIR-2.3.

Immunoprecipitation experiments using mitochondrial extracts of $s i r-2.3: \because g f p$ transgenic worms and anti-GFP antibodies were performed and analyzed by mass spectrometry. Best sequence coverage of PYC-1, PCCA-1 and MCCC-1 are shown. A. Protein sequence of C. elegans D2023.2 (PYC-1). B. Protein sequence of C. elegans F27D9.5 (PCCA-1) C. Protein sequence of F32B6.2 (MCCC-1). Peptides identified by mass spectrometric analyses are highlighted in red.

\subsubsection{Evolutionarily conserved interaction of mammalian SIRT4 with mitochondrial biotin-dependent carboxylases}

Both SIR-2.2 and SIR-2.3 show high sequence similarity with the mammalian sirtuin variant SIRT4 (49\% and $42 \%$ identity to human SIRT4, respectively). It has been reported that SIRT4 is targeted to the mitochondrial matrix and regulates insulin secretion by modifying glutamate dehydrogenase [25], and possibly also by interacting with the ADP/ATP carrier protein (ANT2/3) and insulin-degrading enzyme (IDE) [26]. These findings indicate an important role for SIRT4 in regulation of energy metabolism. I therefore hypothesized that mitochondrial biotin carboxylases might be as well substrates for mammalian SIRT4. To test whether the observed interaction is conserved between $C$. elegans and mammals, I performed co-immunoprecipitation experiments with GFP-tagged mouse SIRT4 (mSIRT4) and FLAGtagged mouse propionyl-CoA carboxylase $\alpha$-subunit (mPCCA), mouse methylcrotonyl-CoA carboxylase $\alpha$-subunit (mMCCC-1), and mouse pyruvate carboxylase (mPC). All three mouse biotin carboxylases (as well as the $C$. elegans biotin carboxylases, data not shown) associated specifically with mSIRT4 (Figure 3-13), indicating an evolutionarily conserved interaction. 


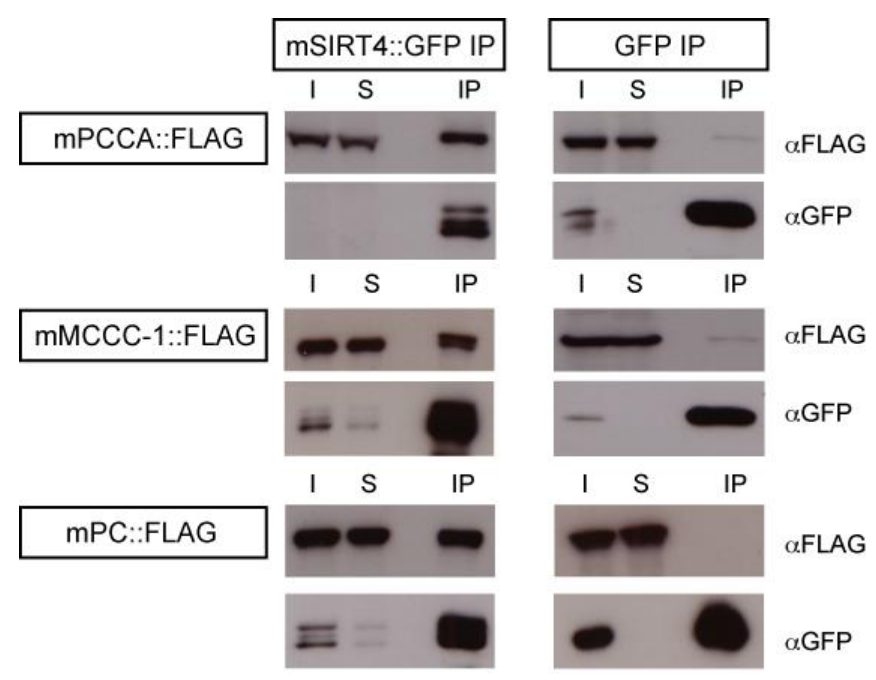

Figure 3-13: Evolutionarily conserved interaction of mammalian SIRT4 with mitochondrial biotin carboxylases.

GFP-tagged murine SIRT4 (mSIRT4) was expressed together with murine PCCA (mPCCA), MCCC1 (mMCCC1), and PC (mPC) in HEK293 cells and immunoprecipitated with GFP-Trap ${ }^{\circledR}$ A. Bound proteins were separated by SDS-PAGE and analyzed by Western blotting using anti-GFP and anti-FLAG antibodies. Representative Western blot analyses of proteins bound to immunoprecipitated SIRT4::GFP (left panel) and GFP (right panel) are shown. I: input (2\%), S: supernatant after IP (2\%), IP: immunoprecipitated protein fraction.

\subsubsection{Analysis of the interaction specificity of $C$. elegans and mammalian sirtuins with mitochondrial biotin-dependent carboxylases}

C. elegans SIR-2.2 and SIR-2.3 share high sequence similarity with each other. Both proteins were localized to mitochondria and interacted with mitochondrial biotin carboxylases. In contrast to SIR-2.2 and SIR-2.3, the structure of nuclear SIR-2.1 exhibits next to the conserved catalytic core domain long $\mathrm{N}$-terminal and $\mathrm{C}$-terminal regions, which also differ in sequence composition (Figure 3-14 A). To analyze whether there are differences in the interaction strength and specificity of different $C$. elegans SIR-2 proteins, I co-transfected FLAG-tagged biotin carboxylase expression vectors together with an expression vector for either GFP-tagged SIR-2.1, SIR-2.2, or SIR-2.3 in HEK293 cells, and performed coimmunoprecipitation experiments with GFP-Trap ${ }^{\circledR}$ A beads. Since SIR-2.2::GFP and SIR2.3::GFP showed a higher protein degradation rate than SIR-2.1::GFP, equal amounts of fulllength immunoprecipitated protein were loaded on SDS-PAGE gels and analyzed by Western blotting with anti-GFP and anti-FLAG antibodies (Figure 3-14 B, asterisks indicate degraded protein). GFP alone served as a negative control.

SIR-2.2 showed the strongest interaction with all three biotin carboxylases. SIR-2.3 also associated strongly with FLAG-tagged biotin carboxylases. SIR-2.1 did not interact with PCCA-1. Considerably less of MCCC-1 and PYC-1 was associated with SIR-2.1 than with SIR-2.2 and SIR-2.3. These results suggest that the regions $\mathrm{N}$ - and C-terminal to the catalytic core domain of SIR-2.1 seem to mainly influence the ability to interact with mitochondrial biotincarboxylases.

In sir-2.2 and sir-2.3 mutant worms truncated SIR-2.2 ( $\Delta$ SIR-2.2::GFP) and SIR-2.3 ( $\Delta$ SIR$2.3:: \mathrm{GFP})$ proteins, which are encoded by the sir-2.2(tm2648)/(tm2673) and sir-2.3(ok444) 
deletion alleles, different regions of the conserved sirtuin catalytic core domain (Figure 3-7 A and B) were missing. To test whether these deletions affect the interaction with mitochondrial biotin carboxylases, I also performed co-immunoprecipitation experiments with GFP-tagged truncated SIR-2.2 ( $\Delta$ SIR-2.2::GFP) and SIR-2.3 ( $\Delta$ SIR-2.3::GFP). $\Delta$ SIR-2.2, lacking 75 aa in the central region of the sirtuin catalytic core domain (Figure 3-14 A and Figure 3-7 A) showed like SIR-2.2 and SIR-2.3 strong interaction with PCCA-1, MCCC-1 and a weaker interaction with PYC-1. In $\Delta$ SIR-2.3 a large part (141 aa) of the catalytic core domain is deleted at the C-terminus (Figure 3-14 A and Figure 3-7 B). The interaction of $\Delta$ SIR-2.3 with all three biotin carboxylases was very weak, suggesting that aa residues located at the Cterminus of the catalytic sirtuin core domain contribute more to the interaction than aa residues located in the middle of the protein sequence of SIR-2.3 and SIR-2.2.

A

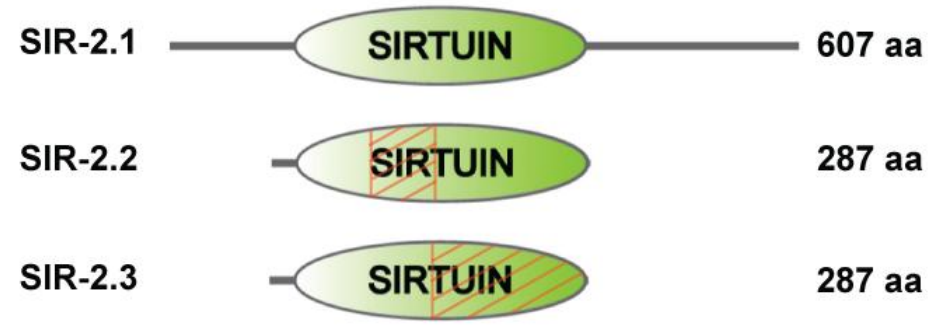

B

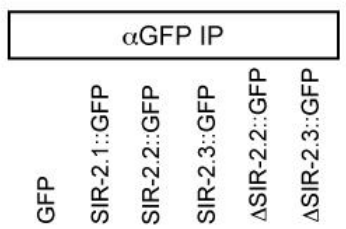

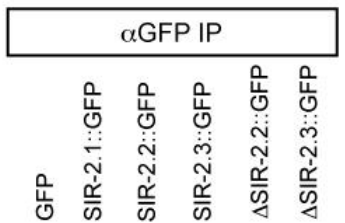

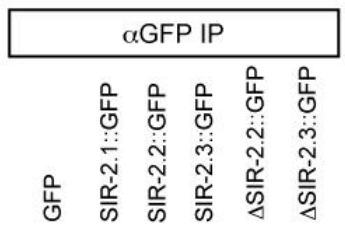

$\alpha$ FLAG
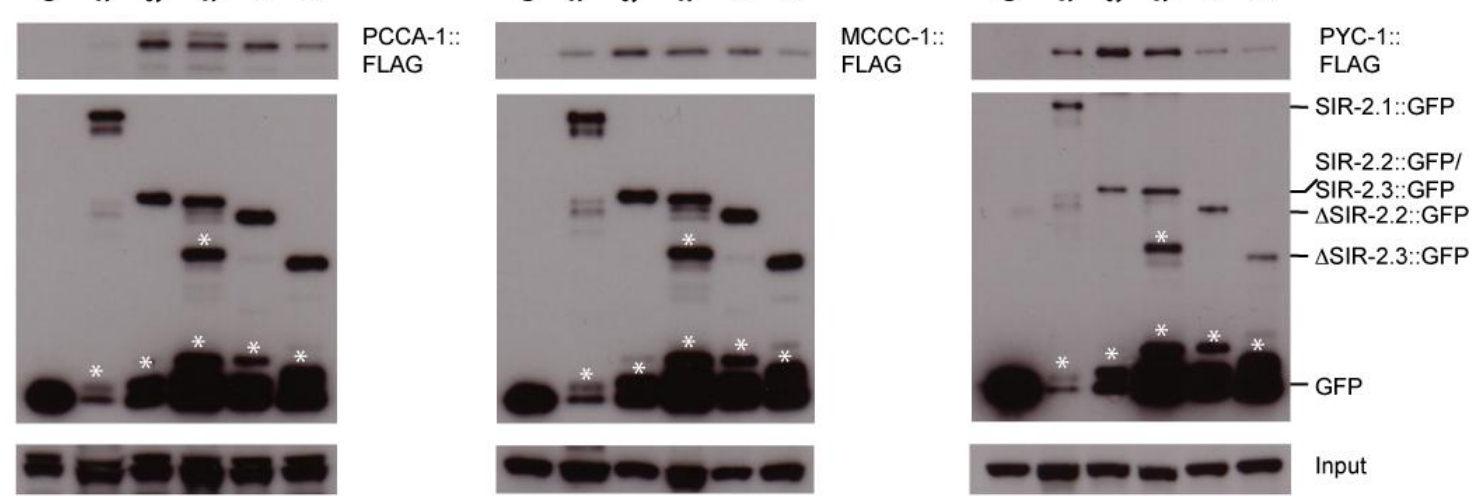

Figure 3-14: Analysis of specificity of interaction with C. elegans SIR-2.1, SIR-2.2 and SIR-2.3.

A. Schematic view of the structural organization of $C$. elegans SIR-2.1, SIR-2.2 and SIR-2.3. Conserved sirtuin catalytic core domain is shown in green. $\mathrm{N}$ - and C-terminal regions, which are variable in length and sequence compositon, are represented by grey lines. Regions deleted in $\Delta$ SIR-2.2 and $\Delta$ SIR-2.3 are shaded in red. B. FLAG-tagged mitochondrial biotin carboxylases were expressed together with GFP-tagged SIR-2.1, SIR-2.2, SIR-2.3, $\Delta$ SIR-2.2 or $\Delta$ SIR-2.3 in HEK293 cells and immunoprecipitated with GFP-Trap ${ }^{\circledR}$ A. Due to the high protein degradation of SIR-2.2::GFP and SIR-2.3::GFP equal amounts of full-length immunoprecipitated protein was loaded on SDS-PAGE gels and analyzed by Western blotting with anti-GFP and anti-FLAG antibodies. The results of the co-immunoprecipitation experiments are shown in the left panel for PCCA$1::$ FLAG, in the middle panel for MCCC-1::FLAG, and in the right panel for PYC-1::FLAG. Running positions of GFP-tagged proteins are shown on the right side of the right panel. Inputs were loaded to confirm that FLAG-tagged proteins were expressed in each experiment. Asterisks indicate degraded protein. 
Taken together, these results show that both SIR-2.2 and SIR-2.3 strongly interact with mitochondrial biotin carboxylases. The interaction seems to be mainly mediated by aa located at the $\mathrm{C}$-terminus (and maybe also at the $\mathrm{N}$-terminus) of their conserved sirtuin catalytic core domain.

Mammalian mitochondria possess three sirtuin variants (SIRT3 to SIRT5). To test whether SIRT4 interacts specifically with the mammalian biotin carboxylases FLAG-tagged mPC, mMCCC1 and mPCCA were expressed together with human Myc-tagged SIRT3, SIRT4 or SIRT5 in HEK293T cells. Proteins were immunoprecipitated with FLAG-M2 agarose beads and analyzed by SDS-PAGE and Western blotting using anti-Myc and anti-FLAG antibodies (Figure 3-15). SIRT4 specifically co-immunoprecipitated with FLAG-tagged MPC and mMCCC1, and no interaction with both SIRT3 and SIRT5 was detected. However, I did not observe a SIRT4-specific interaction with mPCCA. Both SIRT3 (full-length variant) and SIRT4 strongly associated with the protein, suggesting that there might be functional overlap between SIRT3 and SIRT4.

Nevertheless, SIRT4 showed strong association with all three mitochondrial biotin carboxylases, indicating that they might be as well modified by SIRT4.

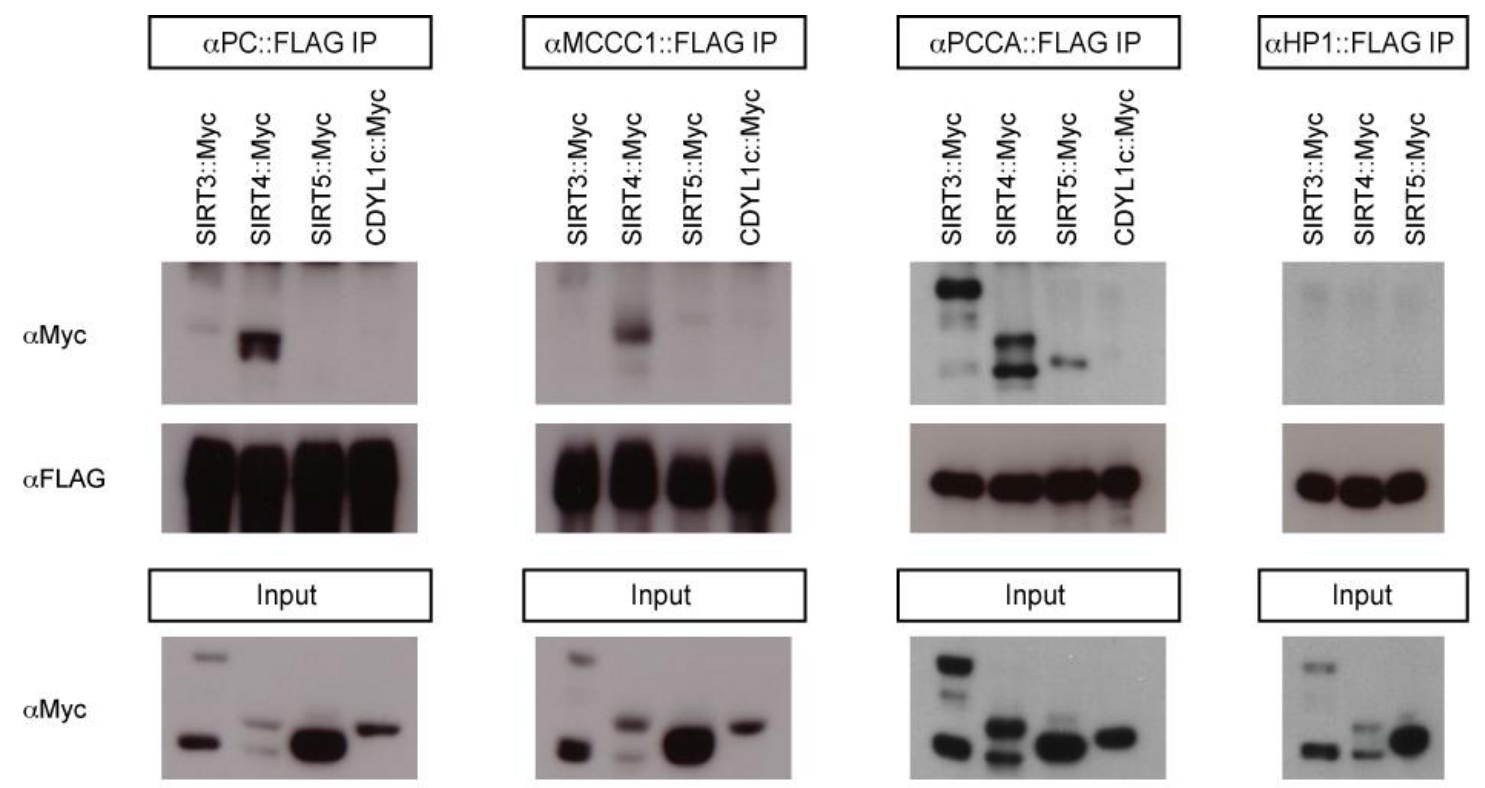

Figure 3-15: Interaction specificity of human mitochondrial sirtuins with mitochondrial biotin-dependent carboxylases.

Expression vectors for human SIRT3, SIRT4, SIRT5 and CDYL1c (Myc-tagged) were co-transfected with expression vectors encoding either murine PC, MCCC1, or PCCA (FLAG-tagged) in HEK293T cells. FLAGtagged HP1 was used as negative control. Proteins were immunoprecipitated with FLAG-M2 agarose beads and analyzed by Western blotting with anti-Myc and anti-FLAG antibodies. Inputs were loaded to confirm that Myc-tagged proteins were expressed in each experiment. Co-Immunoprecipitation experiments with CDYL1c::Myc or HP1::FLAG served as negative controls.

\subsubsection{Mapping of the biotin carboxylase domain mediating interaction with SIRT4}

All three mitochondrial biotin carboxylases catalyze metabolically important carboxyl group transfer reactions and possess a highly conserved $\mathrm{N}$-terminal biotin carboxylase domain and C-terminal biotin carboxyl carrier protein (BCCP) domain (Figure 3-16 A). To determine, 
which domain mediates the interaction with SIRT4, various deletion constructs of mPC, mMCCC-1 and mPCCA were cloned.

In mammals PC is comprised of four identical subunits ( $\alpha_{4}$-form) and each subunit of approximately 120-130 kD contains all three functional domains. The biotin carboxylase domain (BC) featuring a conserved ATPgrasp domain (ATP) (Figure 3-16 A) catalyzes the first step of the carboxylation reaction, i.e. the ATP-driven carboxylation of biotin to form carboxybiotin. The pyruvate carboxyltransferase domain, catalyzing the second step of the reaction (the transfer of the carboxyl group of the carboxybiotin to pyruvate), is located in the middle of the polypeptide chain. At the $\mathrm{C}$-terminus the biotin carboxyl carrier protein (BCCP) domain, also referred to as the biotinyl-lipoyl domain, is found. This domain containing biotin covalently attached to a highly conserved lysine residue is present in all biotin-dependent enzymes and facilitates the carboxylation of a substrate by transferring $\mathrm{CO}_{2}$ from one subsite to the other [203, 205].

To map the interaction domain of mPC, I generated the following five constructs with an Nterminal FLAG-tag (Figure 3-16 A):

- biotin carboxylase domain (BC)

- ATPgrasp domain (ATP)

- pyruvate carboxyltransferase domain (PCT)

- C-terminal domain containing biotin carboxyl carrier protein (BCCP) domain, BCCP domain large (BCCPL)

- biotin carboxyl carrier protein domain alone, BCCP

Each construct was expressed together with human Myc-tagged SIRT4 in HEK293T cells and co-immunoprecipitation experiments were performed with an antibody against the Myc-tag. Since the expression levels and consequently also the recovery rates of SIRT4 were not equal when co-expressed with the different mPC constructs, I subjected equal amounts of immunoprecipitated SIRT4-Myc to SDS-PAGE and Western blot analysis. Next to full-length mPC only the biotin carboxylase domain associated with SIRT4, indicating that the Nterminal region of mPC mediates the interaction with SIRT4 (Figure 3-16 B). As no binding of the ATPgrasp domain was observed, amino acid residues outside this domain must be sufficient for the interaction with SIRT4.

Both propionyl-CoA carboxylase and methylcrotonyl-CoA carboxylase are heteropolymeric enzymes with six heterodimers of one $\alpha$ - and one $\beta$-subunit arranged in an $(\alpha \beta)_{6}$ configuration [202-204]. The $\alpha$-subunits contain the $\mathrm{N}$-terminal biotin carboxylase (BC) domains and the Cterminal biotin carboxyl carrier protein (BCCP) domain (Figure 3-16 A). The carboxyltransferase (CT) activities catalyzed by the propionyl-CoA carboxyltransferase domain and the methylcrotonyl-CoA carboxyltransferase domain, respectively, are located on separated B-chains [203] and were not detected as binding partners of C. elegans SIR-2.2 in mass spectrometric analyses. To test whether the interactions of SIRT4 with mPCCA and mMCCC1 were mediated by the same conserved domain a $\mathrm{N}$-terminal and C-terminal deletion construct of each protein was generated (Figure 3-16 A) and analyzed by coimmunoprecipitation experiments as described above. Figure 3-16 C and D show that binding to SIRT4 was again depending on the N-terminal BC domains of both PCCA and MCCC1 but not on the $\mathrm{C}$-terminal regions containing the BCCP domain. 
A
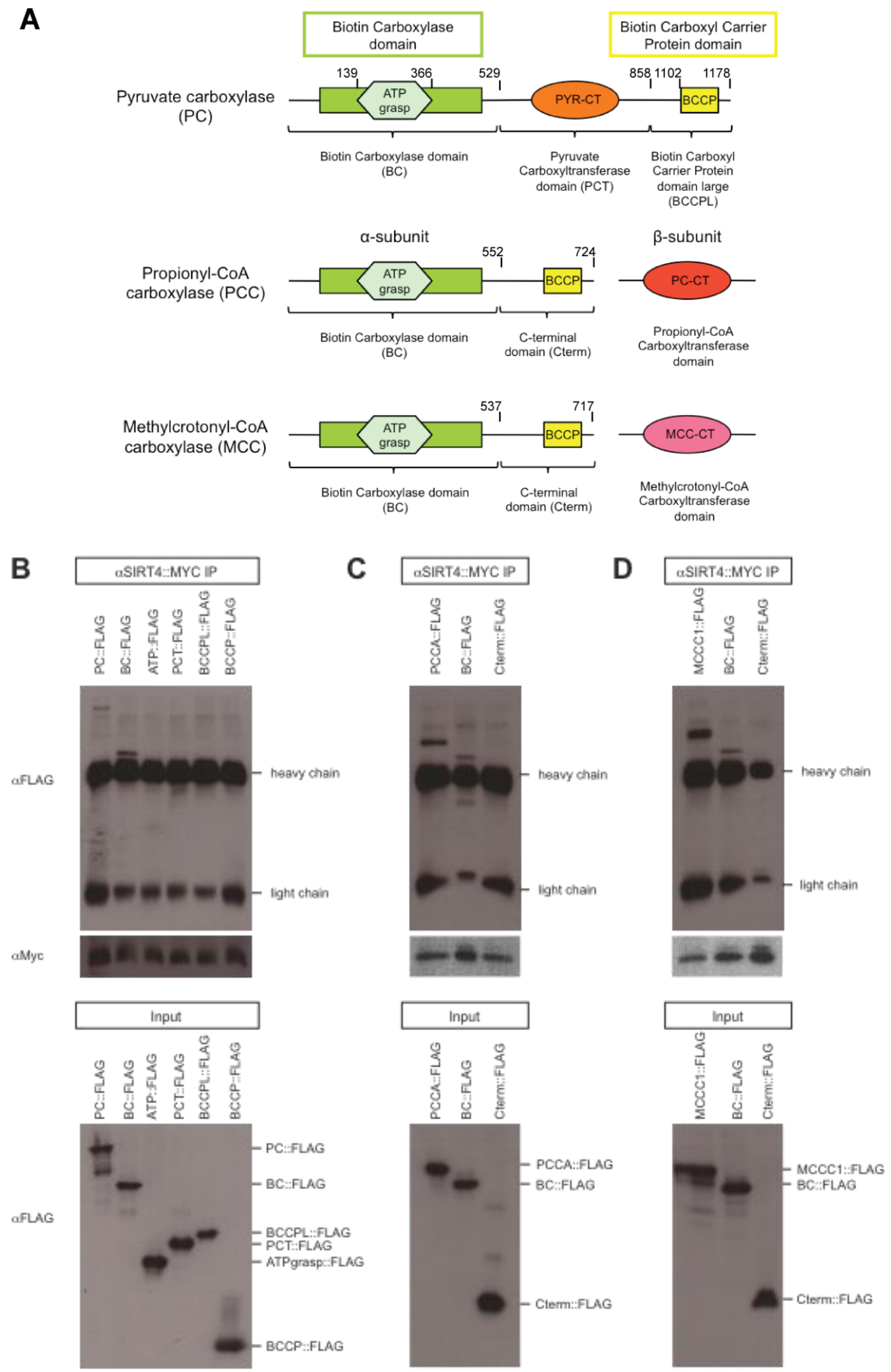
Figure 3-16: Mapping of the domain of PC, PCCA and MCCC1 mediating interaction with SIRT4.

A. Schematic representation of the domain organization of mitochondrial biotin carboxylases. All three proteins have a highly conserved $\mathrm{N}$-terminal biotin carboxylase domain (BC) and a C-terminal biotin carboxyl carrier protein domain (BCCP). The following deletion constructs were generated for $\mathrm{mPC}$ : biotin carboxylase (BC) domain (marked by bracket), ATPgrasp (ATP) domain, pyruvate carboxyltransferase (PCT) domain (marked by bracket), C-terminal domain containing biotin carboxyl carrier protein domain (BCCP domain large) (BCCPL, marked with bracket), biotin carboxyl carrier protein domain alone (BCCP). For both mPCCA and mMCCC1 a $\mathrm{N}$-terminal construct comprising the biotin carboxylase domain (BC, indicated by brackets) and a $\mathrm{C}$-terminal construct containing the BCCP domain (Cterm, indicated by brackets) were generated. Domain boundaries of the mutant proteins are indicated by the aa positions. B. to D. For co-immunoprecipitation (Co-IP) experiments, FLAG-tagged deletion constructs were expressed together with human SIRT4 (Myc-tag) in HEK293T cells. Equal amounts of immunoprecipitated Myc-tagged SIRT4 were loaded on SDS-PAGE gels and analyzed by Western blotting with anti-FLAG and anti-Myc antibodies. Inputs confirm expression of FLAG-tagged proteins in each experiment. Running positions of FLAG-tagged proteins and of the antibody's heavy and light chains are indicated on the right. Representative Western blot analyses of Co-IP experiments using full-length and mutated murine PC proteins $(\mathbf{B})$, full-length and mutated murine PCCA proteins $(\mathbf{C})$ and full-length and mutated murine MCCC1 proteins (D) are shown.

This leads to the conclusion that SIRT4 interacts with PC, PCCA and MCCC1 via the Nterminal biotin carboxylase domain. Residues located outside the ATP-grasp domain mediate the interaction.

\subsection{Regulation of biotin carboxylase function by mitochondrial sirtuins}

\subsubsection{Mitochondrial biotin carboxylases are acetylated proteins}

There has been growing evidence in recent years that lysine acetylation is an important posttranslational modification to regulate metabolic enzymes. A proteomic survey by Kim et al. [98] found that approximately $20 \%$ of all mitochondrial proteins are acetylated. Together with two other proteomic studies [99, 146] acetylation sites were identified in mitochondrial proteins of all major metabolic pathways including TCA cycle, oxidative phosphorylation, $\beta$ oxidation, amino acid catabolism and urea cycle.

As mitochondrial biotin carboxylases might be acetylated proteins, I surveyed the published candidate lists of all three proteomic screens for identified acetylated peptides of these factors. Indeed, I found three different acetylation sites in PC and one acetylation site in PCCA (marked by orange boxes, Figure 3-17 A and B). In the mouse sequence of PC these residues map to K316, K992 and K1090 [98, 99, 146]. In human PCCA K528 was acetylated [146], this residue corresponds to R549 in mouse PCCA and K545 in C. elegans.

Additional acetylation sites of all three biotin carboxylases were also detected in an unpublished mass spectrometric screen performed in the laboratory of our collaborator Prof. Eric Verdin (Gladstone Institute, San Francisco, USA) (marked by yellow boxes, Figure 3-17 A, B, and C). In their screen three sites namely K434, K1106 and K1109 were found in mouse PC. Seven acetylation sites were detected in mouse PCCA (K128, K150, K223, K403, K460, K492 and K509) and two acetylation sites in mouse MCCC1 (K180 and K717).

To further map putative acetylation sites, I also obtained commercial PC isolated from bovine liver (Sigma, P7173) and analyzed it for protein acetylation (Dr. Henning Urlaub, MPI of Biophysical Chemistry, Göttingen). Nine different acetylation sites were found in bovine PC (marked with green boxes, Figure 3-17 A). These residues map to K35, K107, K148, K273, K297, K319, K741, K748 and K1090 in the sequence of mouse pyruvate carboxylase. Only 
one of the sites, K1090 overlapped with findings of the previous mass spectrometric screens, which were all based on anti-acetyllysine-specific antibodies. Due to certain sequence specificities, different anti-acetyllysine pan-antibodies seem to immunoprecipitate different acetylated lysine peptides.

A

\section{Pyruvate Carboxylase}

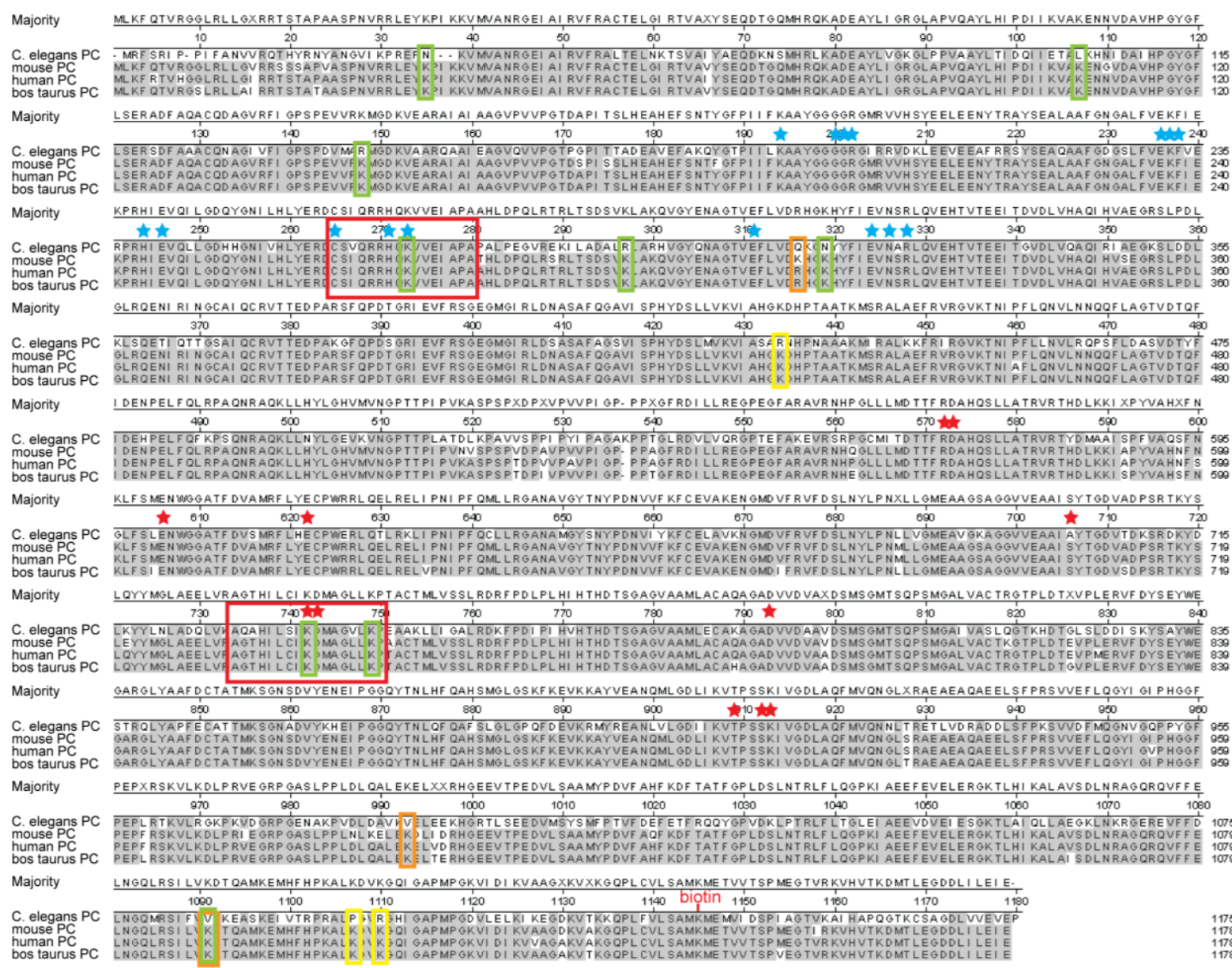

\section{B}

\section{Propionyl-CoA Carboxylase}

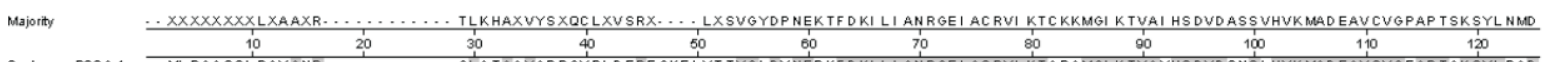

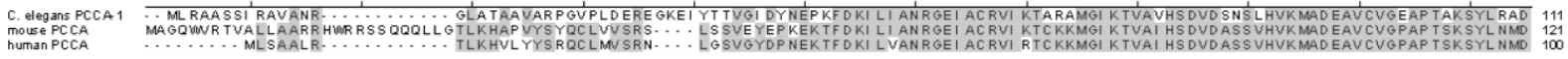
Majority AI MEAI KKTRAQAVHP GYGFLSENKEFAXXLAAEDVXFI GPDTHAI QAMGOKI ESKLLAKXAXVNTI PGF DGVVKDADEAVRI AREI OYPVMI KASAGGGGKGMRI AWDDEETRDGF RL SSQEAA

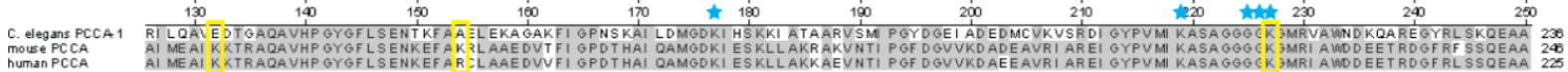
Majority SSF GDDRLLI EKFI DNPRHI EI QVL GDKHONALWLNERECSI QRRN QKVVEEAPSI FLDPETRRAMGERAVALAKAVKYSSAGTVEFLVDS QKNFYFLEMNTRLQVEHPVTECI TOLDLVQE MI R

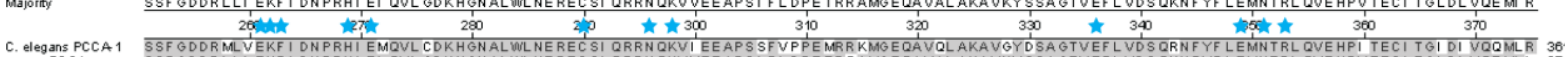

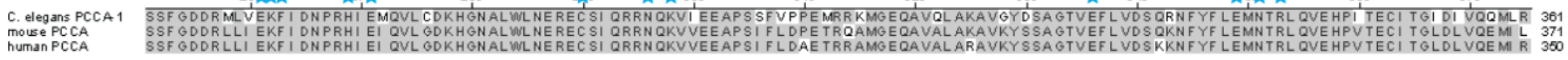
Majority $\quad$ VAKGYPLRHKQEDI PI NGWAVE CRVYAEDPYKSF GLPSI GRLSQYQEPXHLP QVRVDSGI QPGSDI SI YYDPMI SKLVTYGSDRXEALKRMXDALDNYVI RQVTHNI PLLREVII NXRF VKGDIS

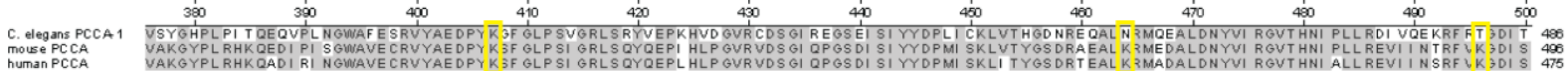

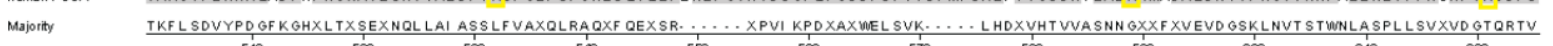

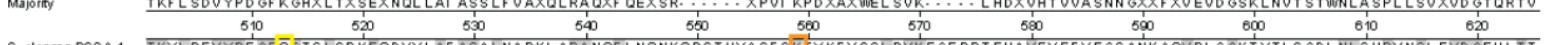

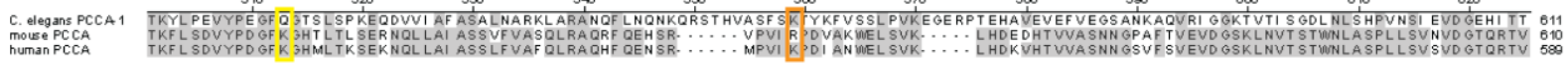
Majority QCLSREAGGNMSI QF L GTVYKVXI LTXLAAELNKFMLEKVXXDTSSVLXSPMP QVVVVAVSVKPGDMNAEGQEI CVI EAMKMONSMTAGKT GXVKXVHCKAGDTVGEGDLLVELE

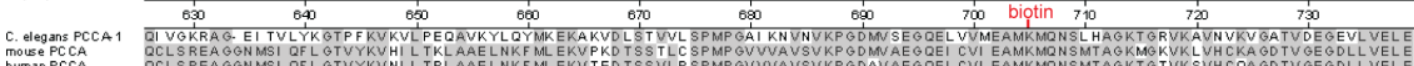


C

Methylcrotonyl-CoA Carboxylase

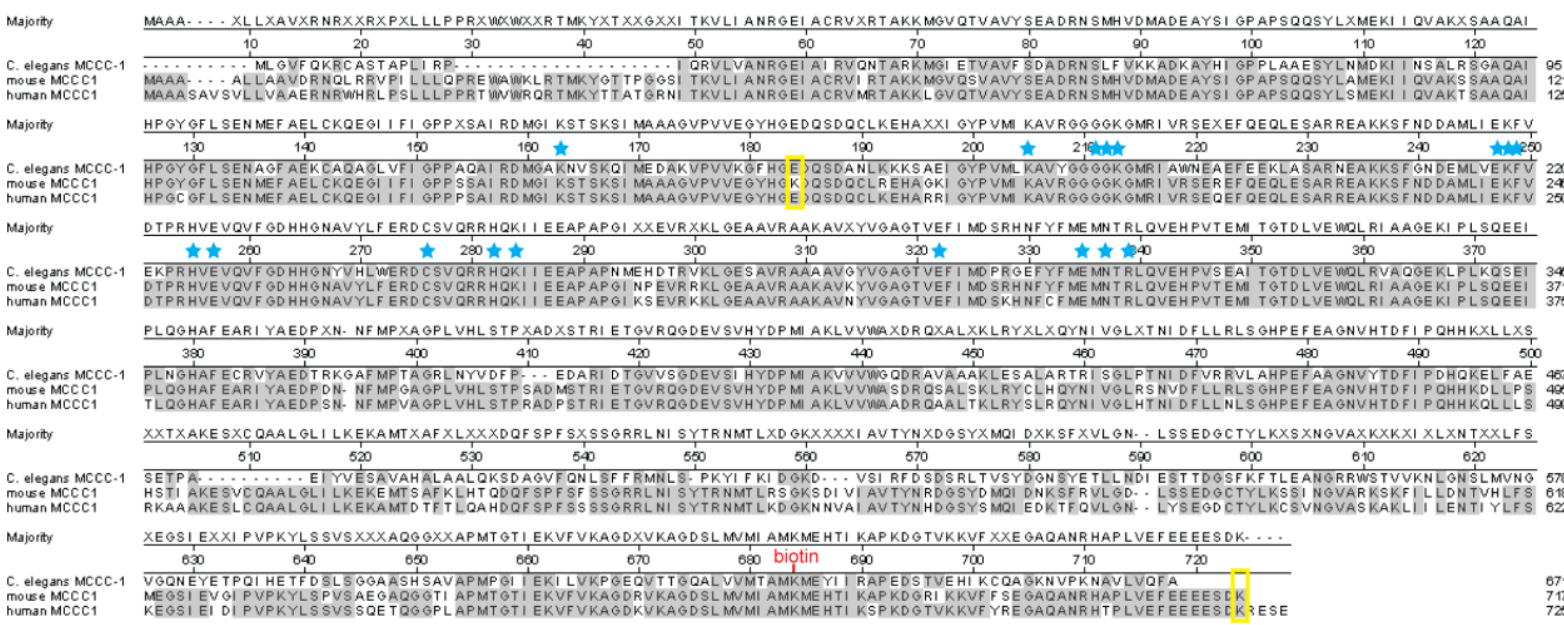

Figure 3-17: Lysine acetylation sites identified in PC, PCCA and MCCC1 by different mass spectrometric approaches.

A. Sequence alignment (Clustal W) of C. elegans, mouse, human and bovine pyruvate carboxylase. B. Sequence alignment (Clustal W) of C. elegans, mouse, and human PCCA. C. Sequence alignment (Clustal W) C. elegans, mouse, and human MCCC1. Matching residues are shaded with gray; acetylation sites found in published screens by $[98,99,146]$ are boxed in orange; yellow boxes mark acetylation sites found by our collaborator Prof. Eric Verdin (Gladstone Institute, San Francisco, USA); green boxes label acetylation sites found in commercial bovine PC by mass spectrometric analysis; blue stars mark residues implicated in biotin carboxylase reaction [203]; red stars mark residues important for pyruvate transcarboxylase reaction [203, 205]; red boxes indicate localization of the peptides MPIG-47 and MPIG-48; biotin indicates highly conserved lysine residue to which biotin is covalently attached.

In summary, all three mitochondrial biotin carboxylases are acetylated. PC and PCCA seem to be highly acetylated protein as 14 and 8 acetylation sites, respectively, have been identified in total so far.

To further confirm these results, I investigated in collaboration with the laboratory of Prof. Eric Verdin the acetylation levels of the biotin-dependent carboxylases by Western blot analysis using anti-acetyllysine-specific antibodies (Figure 3-18). FLAG-tagged mPC, mPCCA and mMCCC1 were expressed in HEK293T cells and immunoprecipitated with FLAG-M2 agarose beads. As positive control cells were also transfected with a vector encoding FLAG-tagged acetyl-CoA synthetase 2 (AceCS2), which was shown to be acetylated and which is regulated by SIRT3 [101, 102]. Cells transfected with an empty vector served as negative control. Like AceCS2 all three proteins were detected with antiacetyllysine-specific antibodies $(\alpha \mathrm{AcK})$ after immunoprecipitation, further supporting the finding that PC, PCCA and MCCC1 are acetylated mitochondrial proteins. 


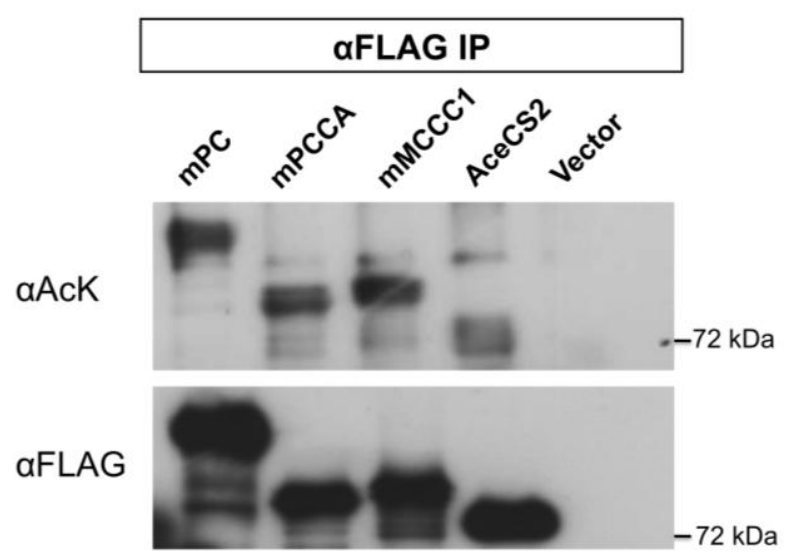

Figure 3-18: Analysis of protein acetylation levels by Western blotting with anti-acetyllysine-specific antibodies.

Expression vectors encoding FLAG-tagged mPC, mPCCA and mMCCC1 were transfected into HEK293T cells. Proteins were immunoprecipitated with FLAG-M2 beads (anti-FLAG IP) and protein acetylation levels were analyzed using anti-acetyllysine-specific antibodies $(\alpha \mathrm{AcK})$. Cells transfected with an empty vector (vector) were used for negative control. Western blot analysis using anti-acetyllysine and anti-FLAG antibodies are shown. Running position of molecular weight marker is indicated on the right.

\subsubsection{Analysis of the enzymatic activities of $C$. elegans SIR-2.2, SIR-2.3 and mammalian SIRT4}

Mass spectrometric analyses have not only identified acetylation sites in many metabolic enzymes but also detected changes in acetylation levels upon fasting [98, 146]. Therefore, deacetylation of mitochondrial biotin carboxylases by SIRT4, SIR-2.2 and/or SIR-2.3 might be an important regulatory mechanism to modulate the activity of these enzymes and energy metabolism in response to changing energy demands.

Apart from SIR-2.1 [18], no analysis on the enzymatic activities of C. elegans SIR-2.2, SIR2.3 and SIR-2.4 has been reported so far. All four sirtuins share a conserved catalytic core domain, but differ in length and sequence composition in their $\mathrm{N}$ - and $\mathrm{C}$-terminal regions (Figure 3-19 A). This difference might contribute to their substrate specificity. The structure of SIR-2.2 and SIR-2.3 seems to be primarily made up by the sirtuin catalytic core region and exhibits only a short $\mathrm{N}$-terminal region and no C-terminal region. Compared to SIR-2.1, SIR2.4 also possesses only short $\mathrm{N}$ - and $\mathrm{C}$-terminal regions.

Figure 3-19: Highly conserved catalytic core domain of $C$. elegans sirtuins.

A. Schematic overview of the structural organization of $C$. elegans sirtuins. All four SIR-2 proteins contain a highly conserved catalytic sirtuin core domain (shown in green), but differ in length and sequence composition in their N-and C-terminal regions (indicated by grey lines). B. Three dimensional structure of a sirtuin bound with an acetylated peptide (red) and $\mathrm{NAD}^{+}$(blue). The Rossman-fold domain is shown in yellow, the small $\mathrm{Zn}^{2+}-$ binding domain in blue and the cofactor binding loop is indicated by blue dots; Green dot represents $\mathrm{Zn}^{2+}$ ion; Figure taken from [27]. C. Multiple sequence alignment (ClustalW) of the catalytic core domain of S. cerevisiae Hst2 and SIR2, C. elegans SIR-2.1, SIR-2.2, SIR-2.3 and SIR-2.4, and human SIRT1, SIRT4 and SIRT6. Conserved residues are highlighted in red; similar residues in yellow; the secondary structure elements above the sequence alignment follow the coloring of the structural domains shown in $\mathbf{B}$; green stars: NAD ${ }^{+}$-binding residues; red stars: residues involved in acetyllysine peptide binding; orange dot: histidine in active site; black dots: $\mathrm{Zn}^{2+}$ binding residues. 
A

SIR-2.1

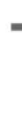

SIR-2.2

SIR-2.3

SIR-2.4

2.3

yeast Hst?

ye ast $\mathrm{Sir} 2$

C. elegans SIR-2.1

C. elegans SIR-2.

C. elegans SIR-2.3

C. elegans SIR- 2.4

human SIRT1

human SIRT4

human SIRTE

yeast Hst2

yeast $\mathrm{Si} 2$

C. elegans SIR-2.1

C. elegans SIR- 2.2

C. elegans SIR-23

c. elegans SIR- 2.4

human SIRT1

human SIRT4

human SIRTE

ye ast $\mathrm{Hs} 2$

reast $\mathrm{Sir} 2$

C. elegans SIR- 2.1

C. elegans SIR-2.2

C. elegans SIR- 2.3

C. elegans SIR- 2.4

human SIRT1

human SIRT4

human SIRTE

yeast $\mathrm{Hst} 2$

yeast $\mathrm{Sir}$

C. elegans SIR- 2.1

C. elegans SIR- 2.2

C. elegans SIR- 2.3

C. elegans SIR-2.4

human SIRT1

human SIRT4

human SIRTE

yeast Hst2

yeast $\mathrm{Sir}$

C. elegans SIR-2.1

C. elegans SIR- 2.2

C. elegans SIR- 23

C. elegans SIR- 2.4

human SIRT1

human SIRT4

human SIRTE

ye ast Hst2

yeast $\mathrm{Sir}$

C. elegans SIR-2.1

C. elegans SIR- 2 .2

C. elegans SIR- 2.3

C. elegans SIR- 2.4

human SIRT1

human SIRT4

human SIRTE
B

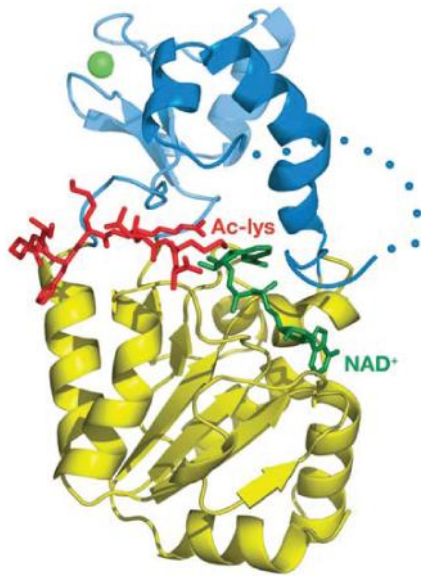

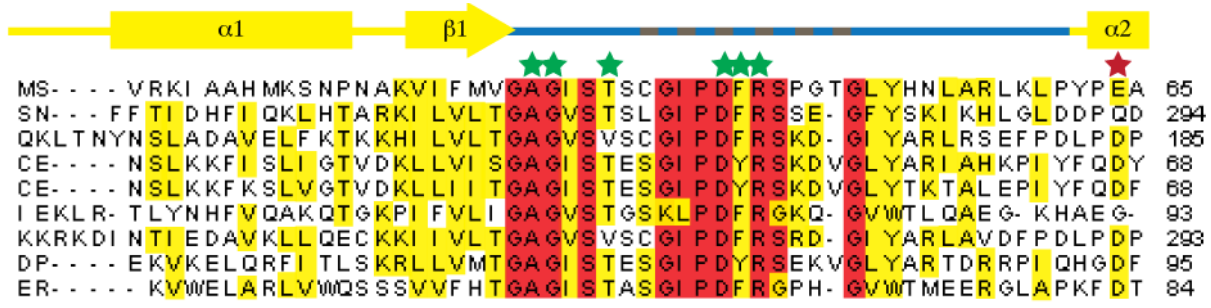

$$
\begin{array}{l|l|l|l|l|l}
\alpha 2 & \alpha 3 & \alpha 4 & \alpha 6 & \beta 2 & \alpha 7
\end{array}
$$

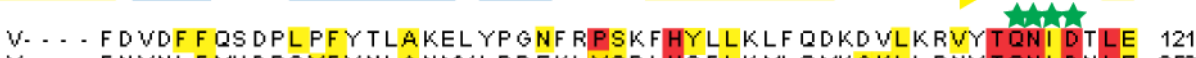
V. . . FNYNI F MH DPSVF YNI ANWULPPEKI YSPLHSFI KMLQMKGKLLRNYT QNI DNLE 350 T. - AMF DI RYFRENPAPFYNFAREI FPGQF UPSUSHRFI KELETSGRLLRNYTQNI DTLE 243 MR SNRCR QRYMSR NF LAMP RF G. . . . DAAPNI NHYALS KUEASDRF QUMLI TQNVDGLH 122 MKSKKCR QRYMSR SYL NMP RF A. . . . QALPNF NHYALS KME AAN KF HWLI T QNVDGLH 122 .......... VDF QVAR. ........... PGVSHKSI LALHKAGYIKTI I TQNVDGLD 120 Q. - AMFDI EYFRKDPRPFF KFAKEI YPGQF OPSL CHKFI ALSDKEGKLLRNYTQNI DTLE 351 VRSAPI R ERYMARNF VGMP QF S.

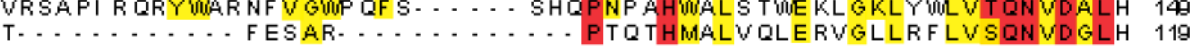

$\begin{array}{llllll}\alpha 7 & \end{array}$

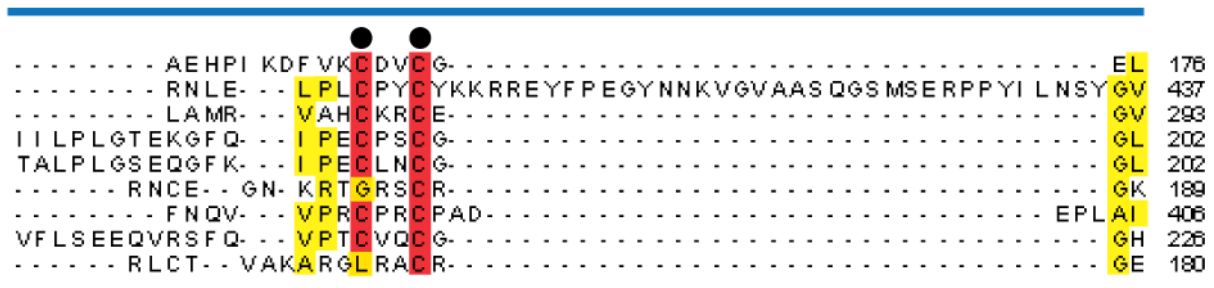

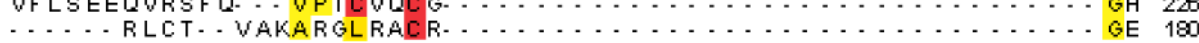

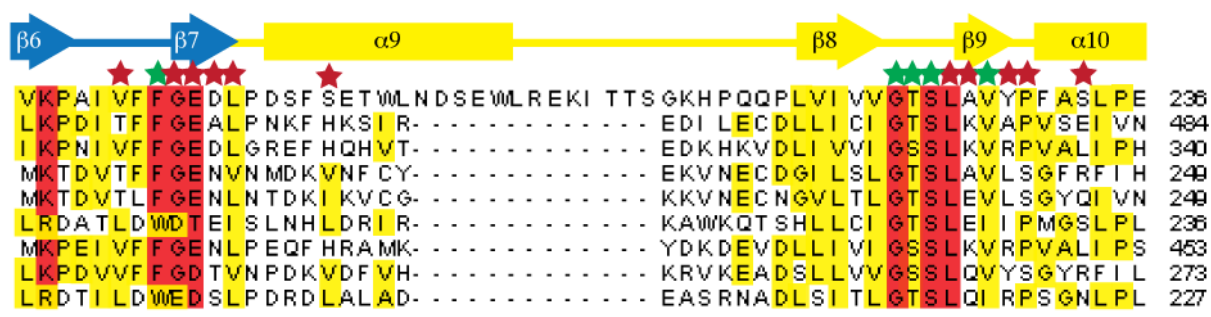
\begin{tabular}{l|l|l|l|}
$\alpha 10$ & $\beta 10$ & $\alpha 11$ & $\beta 11$
\end{tabular}

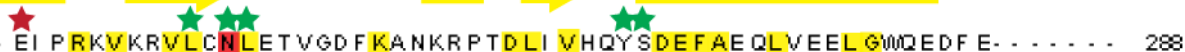

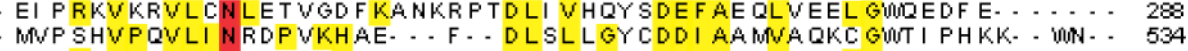
CUDKNVPQI LI NRESLPHYNA. . . . DI ELLGNCDDI I RDI CFSLGGSFTELI TSYDSI 394 HANMKKKPI F I VNI GP TRADH- - MA- TMKLDYKI SDVLKEM HAHMQNKPI FI VNI GP TRADQ- - MA- TMKLDYRI SDVLKEM 287 DAKSKGI KTT TI NYQE TAHEK. - . I V. ETAI HADVKLI LYSLCNAL GVNVDL GD - D - L 280 - SI PHEVPQI LI NREPLPHLHF. . . . DVELLGDCDVI I NELCHRL GGEYAKLCCNPVKL 507 TAMUE KKLPI AI LNI GP TRSDD. - L LA- CLKLNSR CGELLPLI DP. C ATKRRGGRLVI VNLQPTKHDR. - HA- DLRI HGYVDEVMT RLMKHL GLEI PAMD. - GPRV 281 
A multiple sequence alignment (ClustalW) of the catalytic core domain of C. elegans SIR-2 proteins with $S$. cerevisiae Hst2 and SIR2 as well as human SIRT1, SIRT4 and SIRT6 showed a high degree of sequence conservation (Figure 3-19 C). Residues important for the enzymatic activity such as the active site histidine (Figure 3-19 C, marked with an orange dot) as well as the majority of residues involved in $\mathrm{NAD}^{+}$and acetyllysine peptide binding were also conserved in C. elegans SIR-2 proteins. In addition, structurally important residues, such as the $\mathrm{Zn}^{2+}$ binding motif (Figure 3-19 C, indicated by black dots) located in the small domain of the sirtuin catalytic core region (Figure 3-19 B), were also present in SIR-2.2 and SIR-2.3. The high degree of sequence conservation within the catalytic sirtuin core domain of $C$. elegans SIR-2 protein suggests that these proteins also might exhibit $\mathrm{NAD}^{+}$-dependent deacetylase activity. To analyze the enzymatic activity of $C$. elegans sirtuins as well as SIRT4 I used several assays.

\subsubsection{In vitro histone deacetylase activity (HDAC) assay}

A standard assay to analyze the $\mathrm{NAD}^{+}$-dependent enzymatic activity of sirtuins is an in vitro histone deacetylase (HDAC) activity assay using a ${ }^{3} \mathrm{H}$-acetylated histone 4 (H4) tail peptide as substrate. While the C. elegans variant SIR-2.1 has been shown to possess HDAC activity [18]), the enzymatic activities of SIR-2.2, SIR-2.3 as well as SIR-2.4 still need to be determined. In collaboration with the group of Prof. Lührmann (MPI of Biophysical Chemistry, Göttingen) recombinant SIR-2 protein was expressed in wheat germ extract, a cell-free in vitro translation system. Since the wheat germ extract did not exhibit intrinsic deacetylase activity, in vitro-translated proteins were directly used for the enzymatic assay without any further purification. Reactions were incubated at $25^{\circ} \mathrm{C}$ for $2 \mathrm{~h}$ or overnight and after acidification released acetate was quantified by scintillation counting (Figure 3-20 A). HDAC activity was only detected for SIR-2.1, but not for the other three variants (Figure 3-20 B). Since stable transgenic $g f p$-strains could be generated for SIR-2.2 and SIR-2.3, I also isolated GFP-tagged protein from $C$. elegans by immunoprecipitation and performed the HDAC assay with immunoprecipitated protein bound to beads (Figure 3-20 C). Again, only SIR-2.1::GFP showed detectable HDAC activity.

Using the same HDAC assay as described above, HDAC activity could be demonstrated for human SIRT1, SIRT2, SIRT3 and SIRT5, but not for SIRT4, SIRT6 and SIRT7 [29, 91]. For a long time only ADP-ribosyltransferase activity had been reported for SIRT6 [25, 26, 30], however Michishita et al. [31] recently showed that SIRT6 is a histone 3 lysine 9 (H3K9) specific deacetylase, suggesting a high substrate specificity for these proteins. SIRT4 also has been shown to exhibit ADP-ribosyltransferase activity [25, 26], but it might also exhibit protein deacetylase activity with very strict substrate specificity. Since soluble $C$. elegans SIR-2.2 and SIR-2.3 could not be expressed recombinantly in E. coli, I was not able to obtain sufficient amounts of protein to test whether these proteins possess ADP-ribosyltransferase activity in $\left[{ }^{32} \mathrm{P}\right] \mathrm{NAD}^{+}$-labeling experiments.

In summary, I did not observe $\mathrm{NAD}^{+}$-dependent HDAC activity of $C$. elegans SIR-2.2 and SIR-2.3. SIR-2.2 and SIR-2.3 were localized to mitochondria (3.1.4) and an acetylated histone $\mathrm{H} 4$ tail peptide is not a natural substrate of these proteins. Thus, the lack of detectable HDAC activity does not allow the conclusion that C. elegans SIR-2.2 and SIR-2.3 as well as 
mammalian SIRT4 are not true $\mathrm{NAD}^{+}$-dependent deacetylases. To determine, whether these proteins are $\mathrm{NAD}^{+}$-dependent protein deacetylases with high substrate specificity, I analyzed additional acetylated substrates for deacetylation by $C$. elegans SIR-2.2 and SIR-2.3 as well as mammalian SIRT4 in deacetylase activity assays.

A

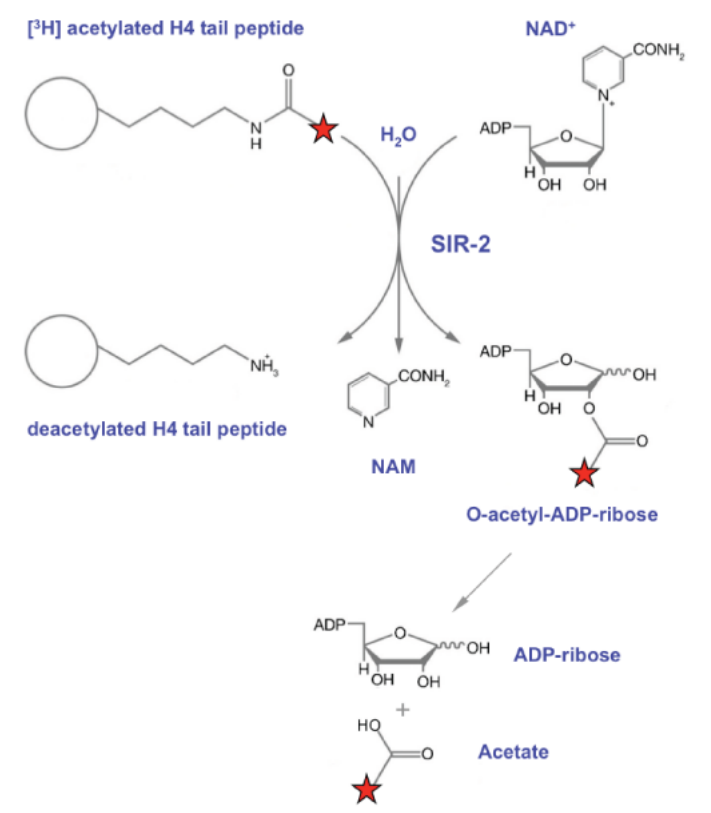

B
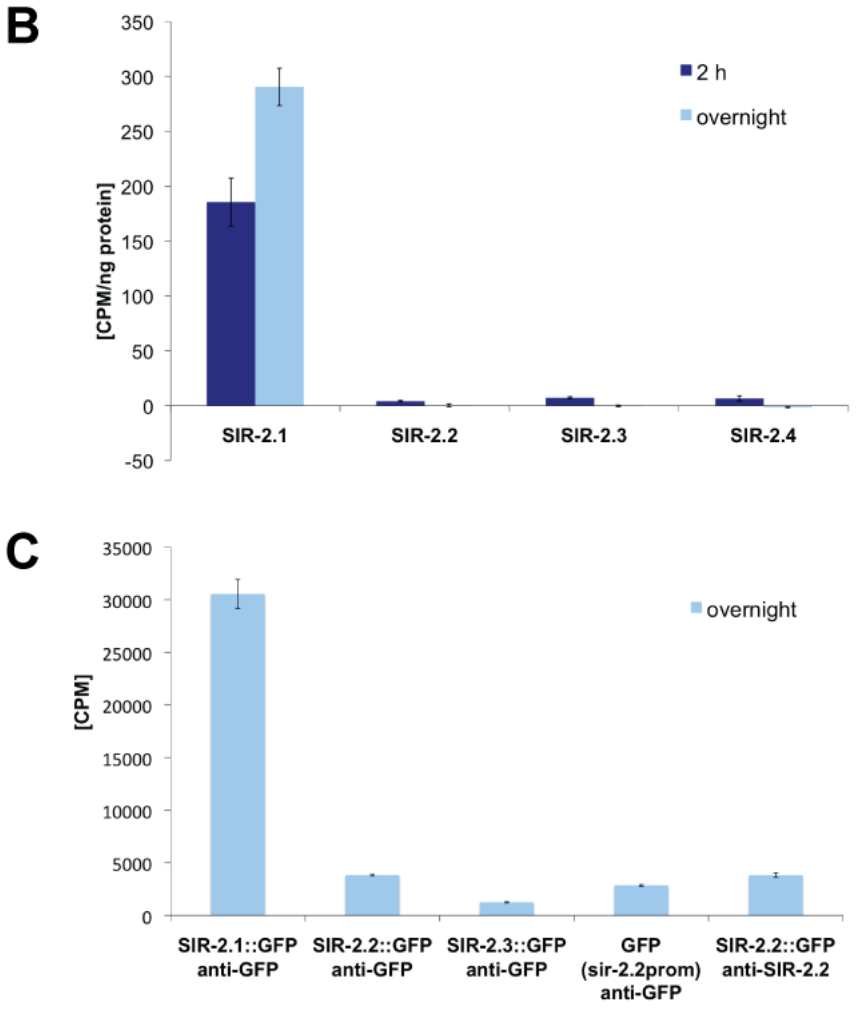

Figure 3-20: Analysis of $\mathrm{NAD}^{+}$-dependent HDAC activity.

A. Overview on the enzymatic reaction catalyzed by SIR-2 proteins. The deacetylation of a $\left[{ }^{3} \mathrm{H}\right]$ acetylated lysine residue on a histone $\mathrm{H} 4$ tail peptide is coupled to hydrolysis of $\mathrm{NAD}^{+}$, yielding nicotinamide (NAM) and $\mathrm{O}$-acetyl-ADP-ribose. For quantification by scintillation counting, acetate is released from O-acetyl-ADP-ribose by addition of acid and extracted with organic solvent. Figure taken from [27] and further modified. B. All four C. elegans SIR-2 proteins were translated in vitro using wheat germ extract and analyzed for HDAC activity on a $\left[{ }^{3} \mathrm{H}\right]$ peracetylated $\mathrm{H} 4$ tail peptide. C. GFP-tagged SIR-2 proteins were immunoprecipitated from worm lysates of sir-2::gfp transgenic worm strains using anti-GFP antibodies (and for SIR-2.2 also the anti-SIR-2.2 antibodies). HDAC activity assays were performed with protein bound to beads and a $\left[{ }^{3} \mathrm{H}\right]$ peracetylated $\mathrm{H} 4$ tail peptide as substrate. Quantitative values, indicating HDAC activity, are means of three measurements; error bars represent standard deviation; overnight and $2 \mathrm{~h}$ incubation times of the enzymatic reactions are indicated by light blue and dark blue bars, respectively.

\subsubsection{Mass spectrometry based in vitro deacetylase activity assay}

Mammalian SIRT4 and C. elegans SIR-2.2 and SIR-2.3 interacted with mitochondrial biotin carboxylases in co-immunoprecipitation experiments. Different mass spectrometric analyses detected a total of 14 lysine acetylation sites in PC (Figure 3-17 A). Among these only three lysine residues (K273, K741 and K748, numbers are mapped to human and mouse PC) were conserved from $C$. elegans to human. Interestingly, K273, located in the biotin carboxylase domain of PC, and K741, located in the pyruvate carboxyltransferase domain, are important for the enzymatic activity of PC. I hypothesized that SIRT4, SIR-2.2 and SIR-2.3 might deacetylate these residues and thereby regulate the activity of pyruvate carboxylase. Therefore, I obtained two peptides, one with acetylated K273 (MPIG-47) and one with acetylated K741 (MPIG-48) (red boxes Figure 3-17 A) for in vitro deacetylase activity assays. 
Myc-tagged human SIRT3, SIRT4 and SIRT5 and FLAG-tagged $C$. elegans SIR-2.1, SIR2.2, and SIR-2.3 were expressed in HEK293T cells, immunoprecipitated and immediately subjected to in vitro deacetylase activity assays using the acetylated peptides as substrate. $\mathrm{NAD}^{+}$-dependent deacetylation of the peptides was then determined by mass spectrometry.

No deacetylation of MPIG-47 (K273ac) and MPIG-48 (K741ac) was observed for SIR-2.2 (Figure 3-21 C), SIR-2.3 (Figure 3-21 D), SIRT4 (Figure 3-21 F), and SIRT5 (Figure 3-21 G) (Table 3-3). However, both peptides were deacetylated by SIR-2.1 (Figure 3-21 B) and SIRT3 (Figure 3-21 E) leading to a $42 \mathrm{kD}$ reduction of the peptide mass (indicated by black arrows). SIR-2.1 being a nuclear protein also showed strong activity on H4K16ac and H3K9ac peptides (Table 3-3). Interestingly, SIRT3, although it is a mitochondrial protein, deacetylated histone 4 lysine 16 (H4K16ac) and histone 3 lysine 9 (H3K9ac) acetylated peptides as well. For negative control (Mock) deacetylase reactions were performed without immunoprecipitated protein (Figure 3-21 A, H to J).

Table 3-3: Summary on observed $\mathrm{NAD}^{+}$-dependent deacetylase activity on acetylated peptides analyzed by mass spectrometry.

\begin{tabular}{lcccccc}
\hline peptide & SIRT3 & SIRT4 & SIRT5 & SIR-2.1 & SIR-2.2 & SIR-2.3 \\
\hline MPIG-47 (K273ac) & + & - & - & + & - & - \\
MPIG-48 (K741ac) & + & - & - & + & - & - \\
H4K16ac & + & - & - & + & - & - \\
H3K9ac & + & - & - & + & - & - \\
\hline
\end{tabular}

(+ indicates activity, - no activity)

Figure 3-21: Mass spectrometric analysis of in vitro deacetylase reactions using acetylated peptides.

Myc-tagged human SIRT3, SIRT4 and SIRT5 as well as FLAG-tagged C. elegans SIR-2.1, SIR-2.2, and SIR-2.3 were expressed in HEK293T cells, immunoprecipitated and immediately subjected to in vitro deacetylase activity assays using different acetylated peptides as substrate. For negative control (Mock) peptides were incubated in deacetylase reaction buffer without immunoprecipitated protein. $\mathrm{NAD}^{+}$-dependent deacetylation of the peptides was determined by mass spectrometry (MS). A. to G. Representative MS spectra of MPIG-47 $(\mathrm{K} 273 \mathrm{ac})$ peptide after deacetylase (DAC) reaction using: Mock (A), SIR-2.1 (B), SIR-2.2 (C), SIR-2.3 (D), SIRT3 (E), SIRT4 (F) and SIRT5 (G). H. to J. Representative MS spectra of MPIG-48 (K741ac) (H), H4K16ac (I) and H3K9ac (J) peptides after control DAC reactions. Red arrow: mass peak corresponding to the acetylated peptide; black arrow: mass peak corresponding to the deacetylated peptide; for details on aa sequence of substrate peptides see Table 2-7 in section 2.1.7.
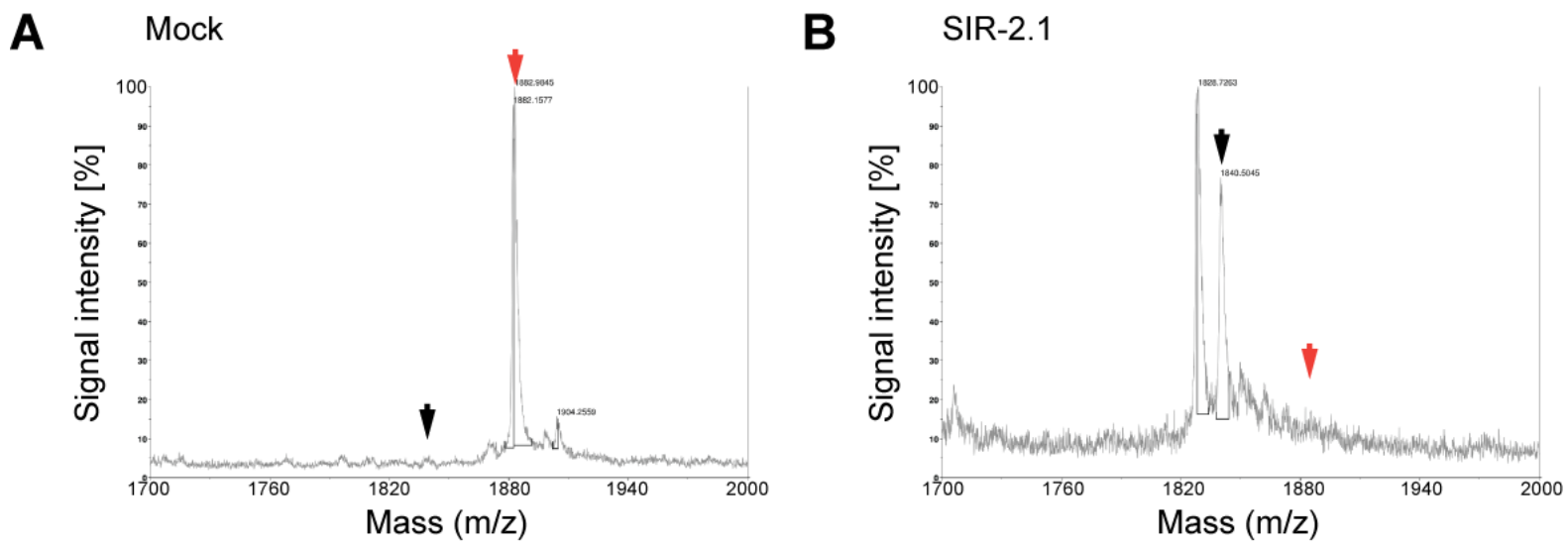
C SIR-2.2

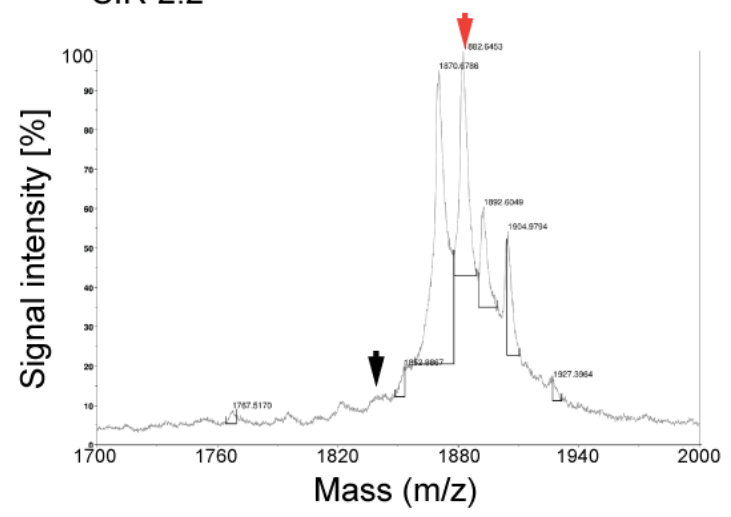

E SIRT3

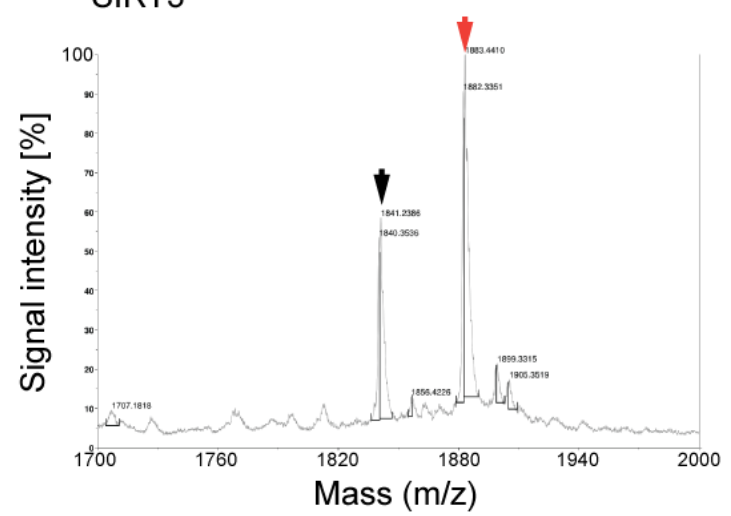

G SIRT5

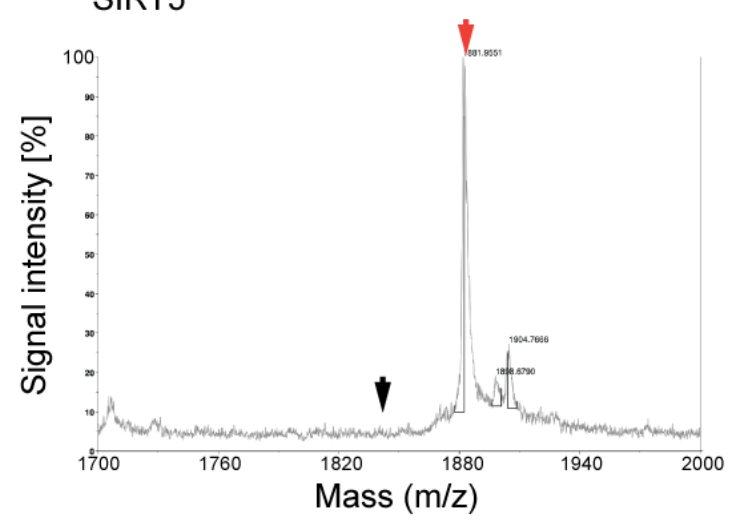

I

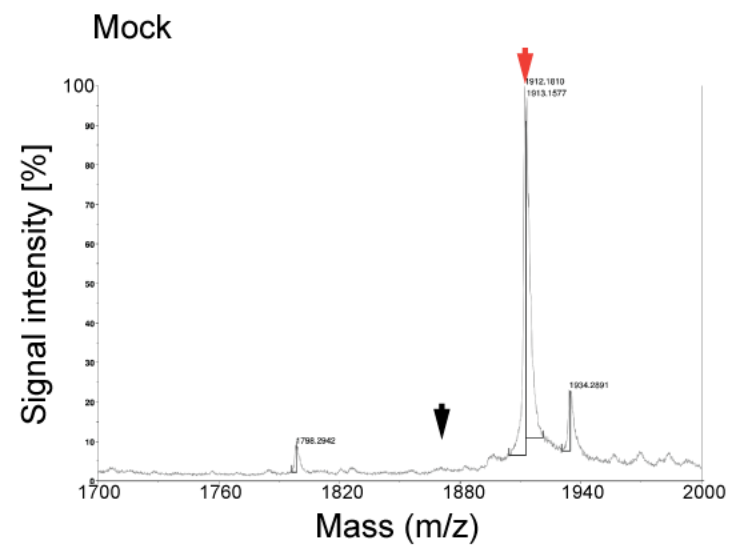

D $\quad$ SIR-2.3

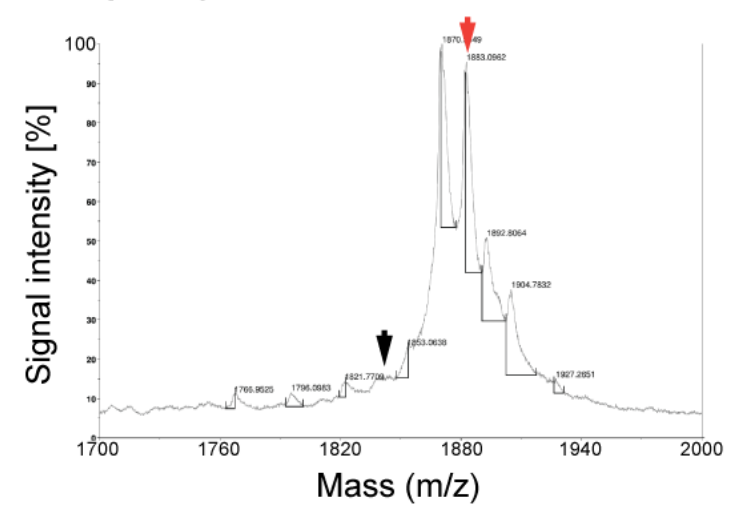

F $\quad$ SIRT4

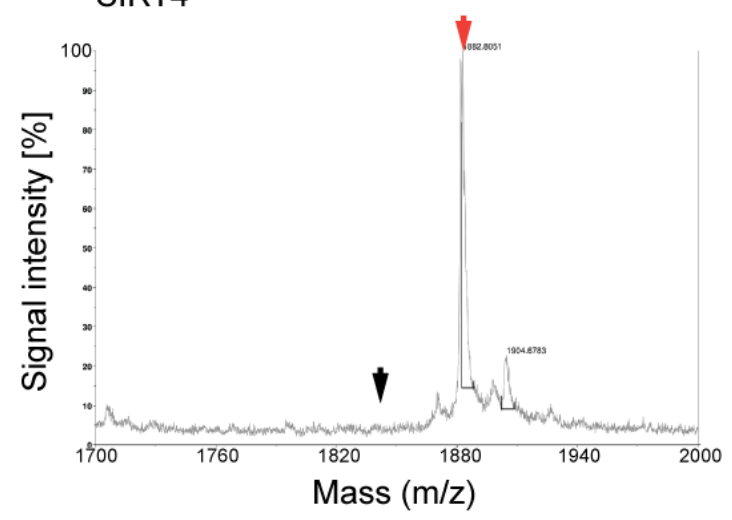

H Mock

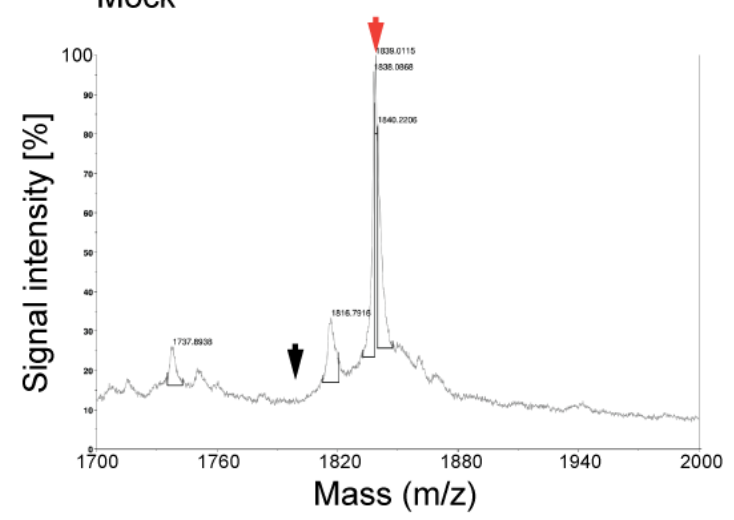

J Mock

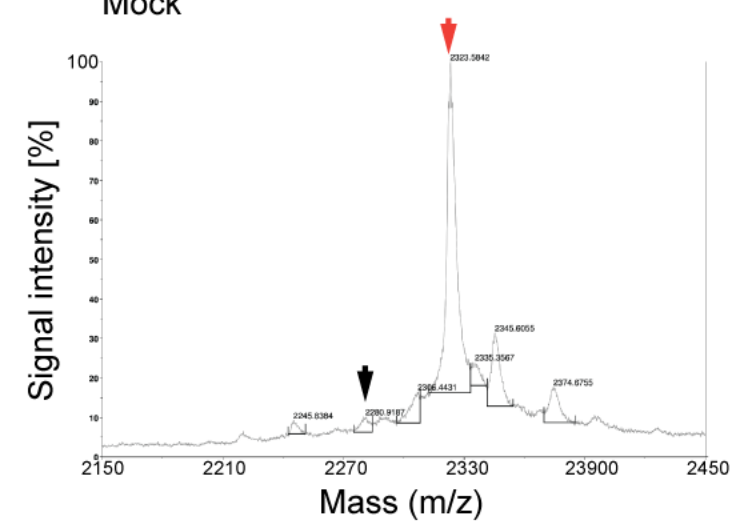


These results show that both SIR-2.1 and SIRT3 are protein deacetylases with low substrate specificity on different acetylated peptides. I did not observe deacetylase activity of SIR-2.2, SIR-2.3 and SIRT4, suggesting that acetylated K273 and K741 are not substrates of them.

\subsubsection{Analysis of bovine $\mathrm{PC}$ activity after deacetylase reaction with $C$. elegans sirtuins}

Since next to K273ac and K741ac six additional acetylated lysine residues were identified in bovine PC by mass spectrometry (Figure 3-17 A), I tested in parallel to the peptide deacetylase activity assays, whether $C$. elegans SIR-2.2, SIR-2.3 or human SIRT4 can modulate the enzymatic activity of bovine PC.

A

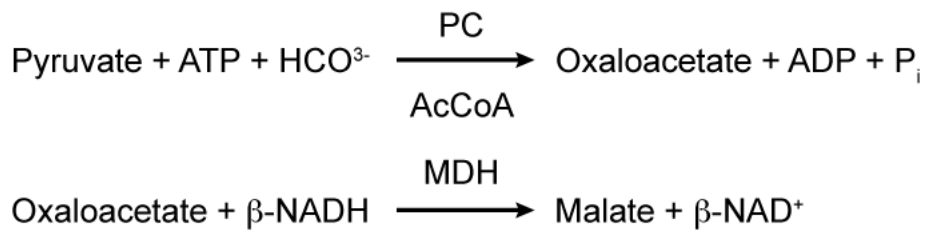

B

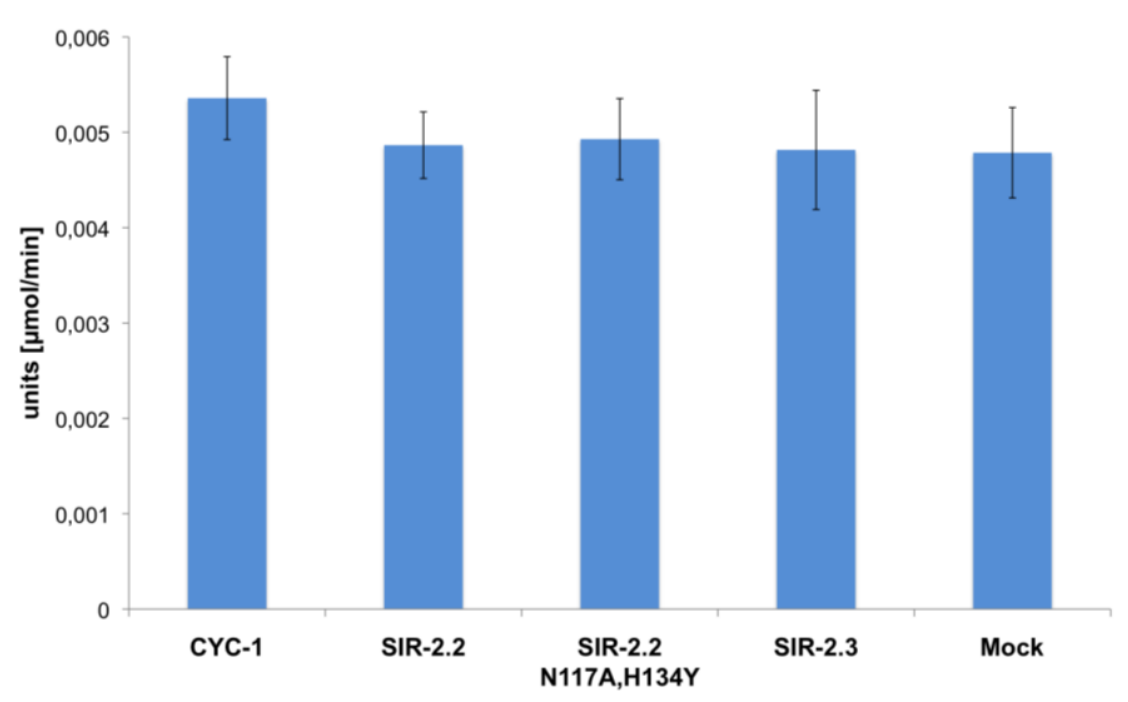

Figure 3-22: No changes in bovine PC activity after treatment with C. elegans SIR-2.2 and SIR-2.3.

A. Principle of the spectrophotometric assay used to assay the enzymatic activity of PC. The carboxylation of pyruvate by PC is coupled to the conversion of oxaloacetate to malate by malate dehydrogenase and recorded by measuring the decrease in NADH absorbance at $340 \mathrm{~nm}$. B. FLAG-tagged C. elegans proteins were expressed in HEK293T cells and immunoprecipitated proteins bound to beads were immediately used for an in vitro deacetylase activity assay using bovine PC as substrate. Subsequently, the supernatants of the deacetylase reactions were analyzed for PC activity. The enzymatic activity of PC was calculated from measured reaction velocities. Mean activities were determined from four measurements of two independent immunoprecipitation experiments; error bars represent the standard deviation. 
A spectrophotometric assay was used to assay the enzymatic activity of PC after incubation with mitochondrial sirtuins. FLAG-tagged C. elegans and Myc-tagged human proteins were expressed in HEK293T cells and immunoprecipitated. The proteins bound to beads were immediately used for an in vitro deacetylase activity assay using bovine PC as substrate. The supernatants of the deacetylase reactions were analyzed for PC activity using a malate dehydrogenase coupled system. The conversion of pyruvate to oxaloacetate (by PC) and finally to malate (by malate dehydrogenase) was measured by recording the decrease in absorbance at $340 \mathrm{~nm}$ due to oxidation of NADH (Figure 3-22 A). The enzymatic activity of $\mathrm{PC}$ was then determined from measured reaction velocities.

No changes in bovine PC activity were observed after incubation with SIR-2.2 and SIR-2.3 (Figure 3-22 B). PC deacetylation reactions using CYC-1 (C. elegans cytochrome c), SIR-2.2N117A/H134Y carrying point mutations in residues essential for the catalytic activity of sirtuins as well as beads incubated with protein lysate of non-transfected cells (Mock) served as negative control. Treatment of bovine PC with human SIRT4 and SIRT3 (data not shown) also did not lead to changes in activity.

I could not detect reliable acetylation of bovine PC with anti-acetyllysine antibodies, and therefore I could not use Western blot analyses to investigate changes in acetylation levels of bovine PC after treatment with sirtuins. Thus, it is possible that I did not observe changes in activity because of lack of deacetylase activity. However, it is also possible that the acetylation sites, which were present in commercial bovine PC, did not have a regulatory function and affected the catalytic activity of PC.

\subsubsection{Reduced acetylation levels of MCCC1 and PCCA in cells overexpressing SIRT4}

It is possible that I did not observe protein deacetylase activity for mammalian SIRT4 (as well as C. elegans SIR-2.2 and SIR-2.3) because of non-optimal reaction conditions (e.g. buffer conditions, missing co-factor/s) present in the in vitro deacetylase activity assays.

Since mitochondrial biotin carboxylases, expressed in HEK293T cells, were lysine acetylated (Figure 3-18), I decided to test in collaboration with the laboratory of Prof. Eric Verdin (Gladstone Institute, San Francisco, USA) whether SIRT4 can deacetylate these proteins in vivo. Expression vectors encoding FLAG-tagged murine PCCA or MCCC1 were cotransfected with expression vectors for human Myc-tagged SIRT3, SIRT4, or SIRT5 into HEK293T cells. For negative control cells were co-transfected with an empty vector. FLAGtagged PCCA and MCCC1 were immunoprecipitated with FLAG-M2 beads and acetylation levels were measured by Western blotting with anti-acetyllysine antibodies.

The acetylation levels of both mPCCA (Figure 3-23 A) and mMCCC1 (Figure 3-23 B) were specifically reduced in cells overexpressing SIRT4, but not SIRT3 or SIRT5. It remains to be tested, whether SIRT4 is also able to deacetylate mPC.

These results indicate for the first time that SIRT4 might indeed be a NAD ${ }^{+}$-dependent protein deacetylase that specifically deacetylates PCCA and MCCC1. 
A

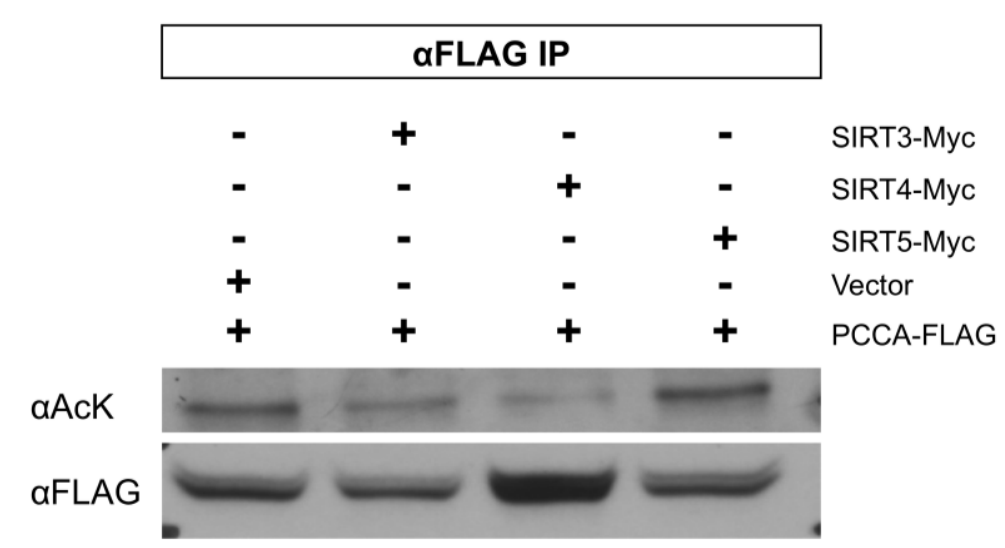

B

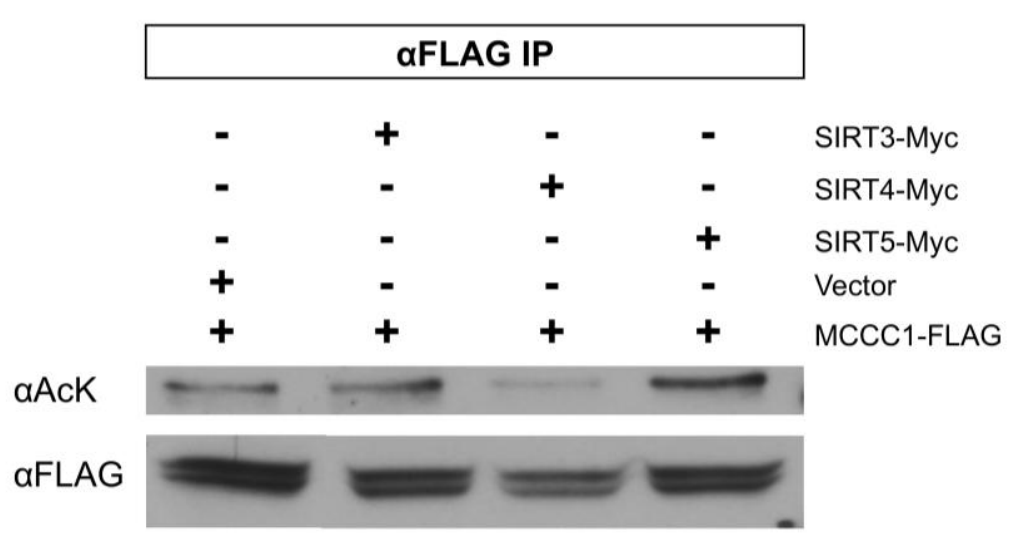

Figure 3-23: Overexpression of SIRT4 specifically reduces the acetylation levels of PCCA and MCCC1 in vivo.

FLAG-tagged murine PCCA or MCCC1 were expressed together with human Myc-tagged SIRT3, SIRT4, or SIRT5 in HEK293T cells. For negative control the cells were co-transfected with an empty vector (carrying a Myc-tag). FLAG-tagged PCCA and MCCC1 were immunoprecipitated with FLAG-M2 beads and analyzed by Western blotting with anti-acetyllysine $(\alpha \mathrm{AcK})$ and anti-FLAG antibodies. A. and B. Western blot analyses of immunoprecipitated PCCA::FLAG (A) and MCCC1::FLAG (B) using anti-acetyllysine and anti-FLAG antibodies are shown. Doublet bands of PCCA::FLAG and MCCC1::FLAG in anti-FLAG Western blots correspond to full-length protein (upper band) and protein, which was proteolytically processed after mitochondrial import (lower band). 


\section{Discussion}

\subsection{SIR-2.2 and SIR-2.3 are mitochondrial proteins strongly expressed in tissue with high metabolic demand}

SIR-2 proteins are a highly conserved protein family and play an important role in chromatin regulation, metabolism and aging in eukaryotes [1]. The nematode $C$. elegans possesses four different SIR-2 variants with high sequence conservation to mammalian sirtuins. Whereas the great majority of studies have focused on SIR-2.1, the other three variants remained virtually uncharacterized so far. SIR-2.2 and SIR-2.3 are most homologous to mammalian SIRT4 (49\% and $42 \%$ identity), suggesting that they might also localize to mitochondria. However, in a genome wide RNAi screen SIR-2.2 was identified to be required for genome stability, next to many chromatin, DNA repair and cell cycle factors. Since these proteins are nuclear and/or cytoplasmic, SIR-2.2 might not be targeted to mitochondria and might not share conserved functions with mammalian SIRT4.

In this study I investigated for the first time the expression and localization pattern of SIR-2.2 and SIR-2.3 by generating translational sir-2::gfp-reporter strains, expressing SIR-2.2 and SIR-2.3 under control of the endogenous promoters. Electron microscopic analysis as well as cellular subfractionation showed that both SIR-2.2 and SIR-2.3 are targeted to mitochondria. SIR-2.2 and SIR-2.3 are highly expressed in the pharynx, body wall muscles, neurons, and intestine, which are all tissues with high energy demand. Interestingly, mammalian SIRT4 also shows higher expression levels in the major metabolic tissues including heart, liver, kidney, pancreatic B-cells, brain and skeletal muscle.

The $C$. elegans pharynx is analogous to the vertebrate heart, since both are tubular organs pumping continuously to keep the organism alive [206]. The intestine of C. elegans is a multifunctional organ, that not only has an enormous digestive power and is important for defecation, but is also the major organ for synthesis, storage (gut granules containing lipids, carbohydrates, and protein) and metabolism of nutrients, nurturing germ cells (particularly with produced yolk) and other tissues [207]. In mammals distinct organs including intestine, kidney, liver and adipose tissue carry out these miscellaneous functions. Insulin secretion in C. elegans is not executed by a specific cell type like pancreatic $\beta$-cells in mammals, but both neuronal cells as well as intestinal cells were shown to secrete insulin-like proteins [208]. $C$. elegans body wall muscles are, like mammalian skeletal muscles, striated muscle tissue important for locomotion and therefore rich in mitochondria [209].

Due to this conserved subcellular localization to mitochondria as well as the high expression in functionally equivalent tissues with high energy demand, C. elegans SIR-2.2 and SIR-2.3 and mammalian SIRT4 seem to have conserved functions. Therefore, analysis of SIR-2.2 and SIR-2.3 function in C. elegans is likely to provide insights into sirtuin function in mammals. 


\subsection{Is there genetic redundancy between SIR-2.2 and SIR-2.3 in C. elegans?}

SIR-2.2 and SIR-2.3 share high sequence similarity (75.3\% identity) and are located next to each other on chromosome $\mathrm{X}$, suggesting that one gene might have evolved from the other by sequence duplication and that there might be genetic redundancy between sir-2.2 and sir-2.3. In $C$. elegans gene duplications seem to occur with a rate of $\sim 0.02$ duplications per gene per million years more frequently than in Drosophila $(\sim 0.002)$ and yeast $(\sim 0.008)$ [210]. In the case of sirtuins $C$. elegans possesses two genes, SIR-2.2 and SIR-2.3, whereas the $D$. melanogaster genome encodes only one gene most homologous to mammalian SIRT4 [3]. Gene duplications are an evolutionarily important source for new gene functions and expression patterns. As fully functional redundant genes should not be evolutionarily stable and are not protected against deleterious mutations, duplicated genes have three possible fates during evolution: firstly, nonfunctionalization and silencing of one copy; secondly, neofunctinalization, where one copy obtains novel, beneficial functions; thirdly, subfunctionalization, where both copies become partially compromised and are necessary for the overall function provided by the single ancestral gene [210, 211].

RT-PCR experiments (Figure 3-6 B) show that both sir-2.2 and sir-2.3 are expressed in $C$. elegans. In case of the sir-2.2 gene, I also know from Western blot analysis with the anti-SIR2.2-specific antibodies (Figure 3-7 C) that protein is made. In addition, a multiple sequence alignment of $C$. elegans sirtuins with yeast and mammalian sirtuins (Figure 3-19 C) shows that residues important for the enzymatic activity are also highly conserved in both SIR-2.2 and SIR-2.3. Although I currently do not have experimental proof of enzymatic activity of SIR-2.2 and SIR-2.3, this high degree of sequence conservation and lack of detrimental mutations in important amino acid residues suggests, that both proteins most probably retained their catalytic activity. Therefore, I exclude that sir-2.2 or sir-2.3 became nonfunctionalized during evolution.

A variation of neofunctionalization is that both genes acquired divergent functions but still retained overlapping functions. The genes would be then maintained by selection due to their independent functions [212].

This model is supported by the observed expression patterns of SIR-2.2 and SIR-2.3. Analysis of double transgenic sir-2.2::gfp;sir-2.3::mcherry worms shows that both proteins are coexpressed in the pharynx, body wall muscle cells, neurons and intestine. However, SIR-2.3 also shows distinct prominent expression in undefined cells in the head as well as in the somatic gonad, which is not observed for SIR-2.2. Moreover, SIR-2.3 expression starts earlier in embryogenesis approximately at the 100 cell stage, whereas the first SIR-2.2 expression is observed in the three fold-stage.

Both, SIR-2.2 and SIR-2.3, seem to function in oxidative stress responses. Since knock down of either variant in a sir-2.2(tm2648) or sir-2.3(ok444) mutant background does not significantly enhance the phenotype, they do not seem to be functionally redundant and might act on different factors. SIR-2.2 and SIR-2.3 therefore might have divergent functions in mediating oxidative stress resistance. However, it might be also possible that both proteins became subfunctionalized. This would mean that the function of both, SIR-2.2 and SIR-2.3, is 
needed to mediate resistance to stress. Then loss of one gene can already result in reduced stress tolerance, and this will not be further enhanced by disrupting the other gene.

SIR-2.2 and SIR-2.3 are both interacting with mitochondrial biotin carboxylases. Currently, I do not know whether either one or both proteins are able to modulate the enzymatic activity of these biotin carboxylases in vivo. At present the data are not sufficient to clearly define whether there is functional redundancy between SIR-2.2 and SIR-2.3, or whether both genes are required to regulate the enzymatic activities of mitochondrial biotin carboxylases.

Knock down of sir- 2.2 by RNAi was shown to augment huntingtin polyglutamine toxicity whereas sir-2.3 RNAi did not have any effect [127]. In addition, only sir-2.2 but not sir-2.3 was identified in a genome wide RNAi screen to contribute to genome stability [129], demonstrating independent functions of sir-2.2.

No SIR-2.3-specific functions have been reported so far. However, e.g. the prominent expression of SIR-2.3::GFP in unidentified cells located between the two pharyngeal bulbs, indicates a distinct function of SIR-2.3. DiI staining alone has not been sufficient to determine the identity of these cells (Figure 3-3 B and C). (This will require more detailed analyses of all head neurons with Nomarski optics including comprehensive mapping of relative positions of neurons to DiI-filled neurons and neurons that express cell-specific transgenes.). DiI-filling labels specifically amphid, inner labial and phasmid neurons, which are chemosensory neurons, but represent only a subset of the C. elegans sensory nervous system. C. elegans hermaphrodites possess 60 ciliated neurons and also several non-ciliated neurons to perceive environmental cues, such as food stimuli, oxygen levels, $\mathrm{pH}$, ambient osmolarity, temperature, light, and mechanical stimuli [197]. Both SIR-2.3 (Figure 3-3) and SIR-2.2 (data not shown) are expressed in amphid, inner labial and phasmid neurons, suggesting that both might function in chemosensation. The cells with prominent SIR-2.3::GFP expression might be sensory neurons as well, and SIR-2.3 might play a role in sensing a specific environmental cue.

Interestingly, genes involved in regulating responses to environmental stress and pathogens seem to be most prone to gene duplications in organisms that are confronted with challenging and dynamic environments [213]. This further supports the idea that sirtuins have a key function in adapting cells and tissues to changes in the environment.

In C. elegans mitochondrial SIR-2.2 and SIR-2.3 might be important regulators of various stress responses and in my opinion sir-2.2 and sir-2.3 have thereby overlapping but not completely redundant functions.

\subsection{SIR-2.2 and SIR-2.3 mediate resistance to oxidative stress}

Under normal growth conditions sir-2.2(tm2648), sir-2.2(tm2673) and sir-2.3(ok444) deletion mutant worms do not show any obvious phenotype. To test whether there is functional redundancy, I also have knocked down sir-2.2 in sir-2.3(ok444) mutant worms by RNAi (microinjection and feeding), but do not observe any obvious phenotype. Knockout mice of the mitochondrial sirtuins SIRT3, SIRT4 and SIRT5 are also viable and fertile, develop and grow normally under standard physiological conditions [25, 92, 114]. However, the functions 
of SIRT3, SIRT4 and SIRT5 are important during stress [50]. Because of the mitochondrial localization of SIR-2.2 and SIR-2.3, I have tested whether they play a role during oxidative stress. Both sir-2.2(tm2648) and sir-2.3(ok444) mutant worms are more sensitive to oxidative stress than wild type worms, indicating that SIR-2.2 and SIR-2.3 regulate responses to oxidative stress. Knock down of sir-2.2 or sir-2.3 by RNAi in sir-2.3(ok444) and sir2.2(tm2648) mutant worms, respectively, does not cause a significant decrease in survival. This suggests that the genes are not functionally redundant or that both genes need to be functional to mediate resistance to oxidative stress. Overexpression of both SIR-2.2 and SIR2.3 , as it occurs in the corresponding $g f p$ transgenic worm strains, results in even higher sensitivity to oxidative stress and does not increase stress resistance as it might be expected. Why does both overexpression and loss of SIR-2.2 and SIR-2.3 increase the sensitivity to oxidative stress?

The catalytic activity of sirtuins requires $\mathrm{NAD}^{+}$as cofactor. Currently, I do not know whether GFP-tagged SIR-2.2 and SIR-2.3 are enzymatically functional. Therefore, it is possible that these proteins act as dominant negatives antagonizing the function of wild type SIR-2.2 and SIR-2.3 in mediating stress resistance.

On the other hand, it is also possible that overexpression of catalytically active SIR-2.2 and SIR-2.3, which are NAD ${ }^{+}$consumers, might lead to severe consumption and reduction of $\mathrm{NAD}^{+}$levels in mitochondria. Mitochondrial NAD ${ }^{+}$levels were shown to be essential for cell survival during genotoxic stress and nutrient deprivation [108]. Consistently, there is growing evidence that $\mathrm{NAD}^{+}$salvage pathways leading to increased cellular $\mathrm{NAD}^{+}$levels promote cell survival. Worms mutant for the nicotinamidase $p n c$-1, which catalyzes the first rate-limiting step of $\mathrm{NAD}^{+}$synthesis from NAM, are more sensitive to oxidative stress. Overexpression of pnc-1 increases stress resistance [135].

Therefore, I think it would be interesting to test whether overexpression of pnc-1 in sir$2.2 .: g f p$ and sir-2.3::gfp transgenic worms has opposing effects and can rescue the observed sensitivity to oxidative stress by restoring mitochondrial $\mathrm{NAD}^{+}$levels.

Oxidative stress might lead to an increase in mitochondrial $\mathrm{NAD}^{+}$levels, which activate SIR2.2 and SIR-2.3 to trigger protective pathways. In mammals Nampt promotes increased mitochondrial $\mathrm{NAD}^{+}$levels and survival during stress in a SIRT3 and SIRT4 dependent manner [108]. Moreover, increased dosage of Nampt was shown to upregulate SIRT1 activity [214]. In C. elegans increased stress resistance of pnc-1 overexpressing worms depends on sir-2.1 [135], suggesting that mitochondrial sir-2.2 and sir-2.3 might be important as well. Thus, another intriguing question is whether the augmented oxidative stress resistance of worms overexpressing pnc-1 depends on sir-2.2. and sir-2.3.

Mass spectrometric analyses showed that $20 \%$ of mitochondrial proteins are lysine acetylated. Among these factors were proteins of the respiratory chain, antioxidant enzymes such as superoxide dismutase, heat shock proteins, and chaperones [98-100], suggesting that lysine acetylation is an important posttranslational modification in regulating stress responses. The vast majority (approximately 90\%) of reactive oxygen species (ROS) is produced in mitochondria as a consequence of oxidative phosphorylation by the electron transport chain. SIRT3 was shown to deacetylate subunits of complex I and to regulate the activity of complex I [104], which notably seems to be the major source of cellular ROS together with complex 
III [199]. Moreover, SIRT3 was reported to suppress ROS formation in cardiomyocytes [215], $\mathrm{C}_{2} \mathrm{C}_{12}$ myotubes [216] and brown adipocytes [97]. Recently SIRT3-deficient mouse embryonic fibroblasts (MEFs) were shown to exhibit increased stress-induced ROS levels and genomic instability, contributing partly to a tumor-permissive phenotype [109]. These studies implicate a key role for mitochondrial sirtuins, particularly SIRT3, in regulating oxidative stress responses. Since SIR-2.2 and SIR-2.3 also function during oxidative stress, the role of mitochondrial sirtuins in coordinating stress responses seems to be conserved from C. elegans to human.

Interestingly, sir-2.2 was identified as a factor promoting genome stability [129]. There is growing evidence that mitochondrial dysfunction, caused by oxidative damage of mtDNA, proteins and lipids, leads to nuclear genomic instability [217, 218]. Therefore, sir-2.2 might protect against mutations and genome instability by maintaining mitochondrial integrity.

\subsection{Evolutionary conserved interaction with mitochondrial biotin carboxylases}

Much of our understanding of sirtuin biology in mammals and C. elegans is based on studies of nuclear SIRT1 and sir-2.1. Although mitochondrial sirtuins might be key regulators of metabolic pathways, few studies have investigated their function. Glutamate dehydrogenase is the only physiological substrate that was described for mammalian SIRT4 [25]. No factors regulated by $C$. elegans SIR-2.2 and SIR-2.3 have been reported in the literature so far. Thus, it was not known whether SIR-2.2 and SIR-2.3 regulate conserved pathways in C. elegans. Such results could also provide insights into the biological function of mammalian SIRT4.

As described in section 3.3, I have identified mitochondrial biotin carboxylases as factors specifically interacting with both SIR-2.2 and SIR-2.3 in C. elegans. Because of the high sequence conservation to mammalian SIRT4, I also have tested whether the interaction is conserved and specific for mammalian SIRT4. SIRT4 also associates with pyruvate carboxylase (PC), propionyl-CoA carboxylase (PCCA) and methylcrotonyl-CoA carboxylase1 (MCCC-1) of mammals as well as of C. elegans (data not shown), demonstrating that it is a highly conserved interaction. The interaction with mitochondrial biotin carboxylases seems to be SIRT4-specific with exception of PCCA. SIRT3 (full-length form) as well shows strong interaction suggesting that there might be functional overlap between SIRT3 and SIRT4. It therefore has to be tested by further immunoprecipitation experiments and Western blot analyses with antibodies specific for the endogenous proteins, whether endogenous SIRT3 and SIRT4 associate with endogenous PCCA. However, preliminary results show that only overexpression of SIRT4 reduces the acetylation levels of PCCA, suggesting that PCCA is specifically regulated by SIRT4.

In this study $C$. elegans has provided a useful model system to identify novel interaction partners of mammalian SIRT4, and is therefore a well-suited model system to analyze the biological function of mitochondrial sirtuins. 


\subsection{Mitochondrial biotin-dependent carboxylases are acetylated proteins}

Mass spectrometric analyses and a Western blot analysis with anti-acetyllysine specific antibodies (3.4.1) show that all three mitochondrial biotin-dependent carboxylases are acetylated proteins (see also [98, 99, 146]). PC and PCCA with a total of 14 and 8 acetylation sites, respectively, seem to be highly acetylated whereas only two acetylation sites have been found for MCCC1.

There is growing evidence that lysine acetylation is an important posttranslational modification in regulating metabolic enzymes and highly abundant in mitochondrial proteins. The global identification of lysine acetylation is still not complete. All published proteomic analyses used different pan-antibodies against acetyllysine, which exhibit certain sequence specificities and which in general have lower binding affinities than anti-pan-phosphorylation antibodies [98, 99, 146]. Therefore, different anti-acetyllysine pan-antibodies seem to immunoprecipitate different acetylated lysine peptides. Moreover, not all acetylation sites might have been identified so far, especially those of proteins with lower abundance. Consistently, PC has been identified as acetylated protein by all mass spectrometric screens (Figure 3-17 A in section 3.4.1), but none of the acetylation sites, which were detected using different anti-acetyllysine antibodies, overlap. Thus, MCCC1 might be as well highly acetylated, but these sites have not been identified so far. In addition there might be more unknown lysine acetylation sites present in PC and PCCA.

PC and PCCA seem to be highly acetylated, but only few of the identified acetylated lysine residues are conserved from $C$. elegans to human. Since acetylation can also occur in a nonenzymatic manner $[154,155]$, not all of the identified acetylation sites will probably have a regulatory function. Mapping of acetylated lysines in substrates regulated by SIRT3 also showed that not all sites were regulated by SIRT3 [106, 107]. Nevertheless, since all three proteins interact with mitochondrial sirtuins and possess acetylated lysine residues it is very likely that their enzymatic activity is regulated by reversible lysine acetylation. Interestingly, in contrast to the cytosolic biotin-dependent carboxylase, acetyl-CoA carboxylase (ACC), PC was shown to be not regulated by phosphorylation [219].

\subsection{Are mammalian SIRT4 and $C$. elegans SIR-2.2 and SIR-2.3 protein deacetylases?}

SIRT4 is the only mammalian sirtuin for which no protein deacetylase activity could be demonstrated. In C. elegans no studies reported on the enzymatic activity of SIR-2.2 and SIR2.3 so far. This raises the question whether SIRT4 as well as C. elegans SIR-2.2 and SIR-2.3 are $\mathrm{NAD}^{+}$-dependent protein deacetylases.

A multiple sequence alignment of the catalytic core domains (Figure 3-19 C) shows that SIRT4, SIR-2.2 and SIR-2.3 share a high degree of sequence conservation in residues important for the enzymatic activity of sirtuins, suggesting that these proteins retained activity as NAD ${ }^{+}$-dependent deacetylases during evolution (Figure 3-19 C). 
However, no enzymatic activity of $C$. elegans SIR-2.2 and SIR-2.3 has been observed when using a chemically acetylated histone $\mathrm{H} 4$ tail peptide as substrate (3.4.2.1). Using the same assay, other groups could not detect histone deacetylase activity for SIRT4 either, but they observed in $\left[{ }^{32} \mathrm{P}\right] \mathrm{NAD}^{+}$-labeling experiments that SIRT4 can ADP-ribosylate histones, BSA and GDH $[25,26]$. Because of difficulties in expressing sufficient amounts of recombinant $C$. elegans SIR-2.2 and SIR-2.3, I could not test whether these proteins also possess ADPribosyltransferase activity in $\left[{ }^{32} \mathrm{P}\right] \mathrm{NAD}^{+}$-labeling experiments.

Currently, ADP-ribosylation of GDH by SIRT4, inhibiting GDH activity, is the only reported sirtuin-catalyzed ADP-ribosylation with physiological relevance [25]. Nevertheless, there are still many open questions regarding the ADP-ribosyltransferase activity of SIRT4 and other sirtuins.

ADP-ribosylation of GDH by SIRT4 was demonstrated using $\left[{ }^{32} \mathrm{P}\right] \mathrm{NAD}^{+}$-labeling experiments, but the specific ADP-ribosylated residue has not been mapped and the catalytic mechanism is still unknown [21]. Analysis of the NAD ${ }^{+}$-dependent ADP-ribosyltransferase activity of the $T$. brucei SIR2-like protein TbSIR2rp1 showed that ADP-ribosylation by TbSIR2rp1 requires an acetylated substrate, is mainly enzymatic and only to a small extend non-enzymatic [35]. The ADP-ribosyltransferase activity of TbSIR2rp1 is approximately 5 orders of magnitude lower than its deacetylase activity raising the question whether ADPribosylation by sirtuins has a physiological role. A recent report doubted the physiological relevance of the ADP-ribosyltransferase activity of sirtuins (including SIRT4) due to the weak efficiency compared to a bacterial ADP-ribosyltransferase and/or their own NAD ${ }^{+}$-dependent deacetylase activity (if detectable) [36]. The authors suggested that the ADPribosyltransferase activity of sirtuins is rather an inefficient side reaction.

Initially, SIRT6 was reported to exhibit auto-ADP-ribosyltransferase activity [30], but was recently shown to specifically deacetylate $\mathrm{H} 3 \mathrm{~K} 9 \mathrm{ac}$ and none of the other twelve tested peptides [31]. Therefore, it is very likely that SIRT4 acts also as $\mathrm{NAD}^{+}$-dependent deacetylase with very strict substrate specificity.

Mitochondrial biotin carboxylases are acetylated proteins, which might be regulated by deacetylation through SIRT4, SIR-2.2 and SIR-2.3. Although the highly conserved acetylated lysine residues K273ac or K741ac (residue numbers are mapped to human and mouse PC) were promising candidates, I could not detect $\mathrm{NAD}^{+}$-dependent protein deacetylase activity for mammalian SIRT4 and C. elegans SIR-2.2 and SIR-2.3 in an in vitro deacetylase activity assay (3.4.2.2). K273ac and K741ac might not be substrates of SIRT4, SIR-2.2 and SIR-2.3. However, it is also possible that I have not observed protein deacetylase activity because the reaction conditions (e.g. buffer conditions, missing co-factor/s) have not been optimal in the in vitro deacetylase activity assays.

Western blot analysis of lysine acetylation levels show that overexpression of SIRT4 specifically reduces the acetylation levels of both MCCC1 and PCCA in vivo (Figure 3-23 in section 3.4.4). These results demonstrate for the first time that SIRT4 also exhibits $\mathrm{NAD}^{+}-$ dependent deacetylase activity.

It still needs to be determined which lysine residues of mitochondrial biotin carboxylases are specifically deacetylated by SIRT4. These might be other lysine residues than K273ac and K741ac. Interaction domain mapping shows that SIRT4 interacts specifically with all three 
mitochondrial biotin carboxylases via the highly conserved $\mathrm{N}$-terminal biotin-carboxylation domain. The biotin carboxylation domain contains a highly conserved ATP grasp domain and catalyzes ATP driven carboxylation of biotin, the first step of the carboxylation reaction. Next to the conserved K273 are two additional highly conserved lysines (K194, K237) within the ATP grasp domain, which are important for the enzymatic activity.

Although acetylated lysine residues within the interaction domain are not necessarily substrates, it will be interesting to test whether these can be deacetylated by SIRT4 and $C$. elegans SIR-2.2 and SIR-2.3.

In my opinion mammalian SIRT4 and $C$. elegans SIR-2.2 and SIR-2.3 are NAD ${ }^{+}$-dependent protein deacetylases. This study provides first evidence that SIRT4 is indeed a protein deacetylase that acts on mitochondrial biotin carboxylases and that this interaction might also modulate their enzymatic activities.

\subsection{Possible physiological role of interaction}

The interaction of SIRT4 and C. elegans SIR-2.2 and SIR-2.3 with the mitochondrial biotindependent carboxylases suggests that these sirtuins play a central role in regulating metabolic pathways, which maintain energy homeostasis in response to nutrient deprivation.

Glucose is the primary fuel in mammalian tissues and blood glucose concentration has to be kept within a narrow range by coordinated homeostatic mechanisms [201]. Starvation promotes glucose synthesis in liver and kidney cortex by gluconeogenetic pathways to maintain serum glucose levels. PC converting pyruvate to oxaloacetate catalyzes an important anaplerotic reaction for the tricarboxylic acid (TCA) cycle in liver and kidney. Fasting induces hepatic gluconeogenesis in rats and mice by upregulating PC activity [220, 221]. Insulin secreted from pancreatic B-cells tightly regulates blood glucose levels after dietary carbohydrate uptake. Interestingly, although ß-cells lack gluconeogenesis, PC is highly abundant and required for glucose-stimulated insulin secretion [201, 222].

Propionyl-CoA carboxylase (PCC) also acts in anaplerosis and catalyzes the carboxylation of propionyl-CoA to methylmalonyl-CoA that feeds into the TCA cycle after conversion to succinyl-CoA. PCC has essential functions in the catabolism of branched chain amino acids (Thr, Val, Ile and Met), odd-chain length fatty acids and cholesterol [202].

Methylcrotonyl-CoA carboxylase (MCC) carboxylates 3-methylcrotonyl-CoA to 3methylglutaconyl-CoA which is the fourth step in catabolism of the essential amino acid leucine [204]. Leucine is a strictly ketogenic amino acid as it is degraded to acetoacetate and acetyl-CoA, which is subsequently oxidized in the TCA cycle [223]. Therefore, MCC does not function in anaplerosis, but plays a role in formation of ketone bodies under starvation conditions.

All three mitochondrial biotin carboxylases play an important role during nutrient deprivation. Since PC, PCCA and MCCC1 are acetylated proteins, it is very likely that their enzymatic activity is regulated by reversible lysine acetylation.

There is growing evidence that reversible lysine acetylation of metabolic enzymes regulates the catalytic activity and/or protein stability of metabolic enzymes and allows cells to respond 
to changes in nutrient availability [146, 147]. A recent study in Salmonella enterica showed that reversible lysine acetylation mediates adaption to different carbon sources [147]. Key enzymes of glycolysis and gluconeogenesis are lysine acetylated and regulated by reversible lysine acetylation/deacetylation in S. enterica. Whereas acetylation of proteins through the acetyltransferase Pat promotes carbon flux towards glycolysis, deacetylation through the $\mathrm{NAD}^{+}$-dependent protein deacetylase CobB (SIR-2-like protein) stimulates gluconeogenesis. This finding is further supported by another recent study demonstrating that nearly every enzyme of the major metabolic pathways, i.e. glycolysis, gluconeogenesis, the TCA cycle, fatty acid and glycogen metabolism was acetylated in human liver tissue [146]. Moreover, this study showed that high glucose levels inhibit amino acid catabolism and gluconeogenesis by increased acetylation of representative proteins. In the presence of high glucose concentrations argininosuccinate lyase (ASL) and phosphoenolpyruvate carboxykinase (PEPCK1) are highly acetylated, decreasing their catalytic activity and protein stability, respectively. In contrast to allosteric effects that specifically modulate the catalytic activities of individual metabolic enzymes, reversible lysine acetylation seems to be a global mechanism in coordinating energy metabolism. Two molecules closely linked to energy metabolism thereby seem to facilitate energy sensing. Acetyl-CoA, used for acetylation, is abundant during high cellular energy levels and $\mathrm{NAD}^{+}$, required for deacetylation, increases during nutrient deprivation [108, 147].

Since deacetylation of mitochondrial biotin carboxylases by SIRT4, SIR-2.2 and SIR-2.3 might modulate their catalytic activity during nutrient deprivation, I have established conditions to assay the enzymatic activities of all three biotin carboxylases in liver lysates. Liver tissue of starved and fed SIRT4 knockout mice will be provided by our collaborator Prof. Eric Verdin. In addition, I am also going to test mitochondrial lysates of sir-2.2, sir-2.3 mutant worms and sir-2.3, sir-2.2RNAi worms for changes in biotin carboxylase activity.

In collaboration with the laboratory of Prof. Eric Verdin we observe reduced acetylation levels of PCCA and MCCC1 in cells overexpressing SIRT4. Starvation is shown to enhance the enzymatic activity of PC in mouse and rat livers [224, 225] and deacetylation of PC by SIRT4 might mediate this increase in activity.

\section{Working hypothesis I.}

Based on the findings described above, I propose the following working hypothesis for the regulation of mitochondrial biotin-dependent carboxylases by mammalian SIRT4 and $C$. elegans SIR-2.2 and SIR-2.3 (Figure 4-1).

Starvation or fasting reduces cellular energy levels and leads to an increase in mitochondrial $\mathrm{NAD}^{+}$levels. Elevated NAD ${ }^{+}$activates mitochondrial SIRT4 or C. elegans SIR-2.2 and SIR2.3, which deacetylate mitochondrial biotin-dependent carboxylases. Deacetylation of PC, PCC and MCC increases their catalytic activities and upregulates gluconeogenesis, amino acid catabolism and fatty acid oxidation. Increased glucose and ketone body formation provides energy fuels for other tissues and promotes cell survival. In mammals this mechanism would take place in the liver and kidney cortex, in C. elegans probably in the intestine and muscles. 


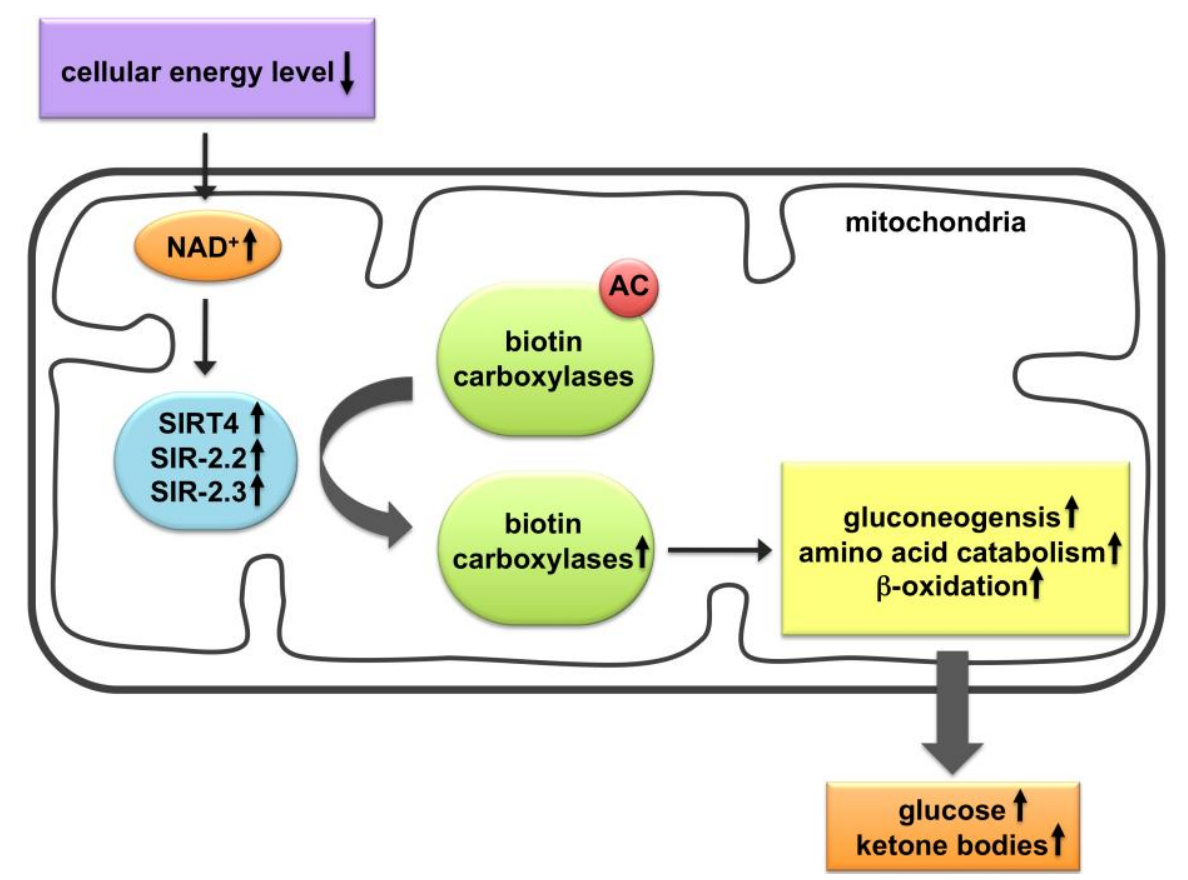

Figure 4-1: Working hypothesis I.

Deacetylation of mitochondrial biotin-dependent carboxylases by mammalian SIRT4 (in C. elegans SIR-2.2 and SIR-2.3) upregulates their activities and promotes gluconeogenesis and ketone body formation in liver and kidney (in C. elegans intestine and muscle) during nutrient deprivation. AC indicates acetylation.

\section{Negative regulation of insulin secretion in pancreatic B-cells by SIRT4}

In addition to the proposed function of SIRT4 in the liver, SIRT4 also seems to play an important role in the pancreas. This role is discussed in the following and will lead to a second working hypothesis, that complements working hypothesis I.

In the pancreas, which functions as fuel sensor, SIRT4 is highly expressed specifically in Bcells. Interestingly, pancreatic islets isolated from SIRT4 knockout mice exhibit increased insulin secretion, which is caused by augmented GDH activity increasing ATP production. SIRT4 was shown to negatively regulate insulin secretion by ADP-ribosylating and inhibiting GDH activity [25]. GDH was also reported to be lysine acetylated [98, 99]. SIRT3 deacetylates (in vivo and in vitro) $[92,106]$ and activates GDH (in vitro) [106].

There might be functional redundancy between SIRT3 and SIRT4, and SIRT4 might as well regulate GDH by protein deacetylation. However, most interestingly, interaction of GDH with SIRT3 and SIRT4 seems to have opposing consequences in different tissues. Whereas deacetylation of GDH by SIRT3 and/or SIRT4 might increase its catalytic activity in liver promoting anaplerosis, ADP-ribosylation of GDH by SIRT4 seems to repress its enzymatic activity, inhibiting insulin secretion. Mitochondrial biotin-dependent carboxylases might be as well differentially regulated. I hypothesize that SIRT4 negatively regulates insulin secretion by having contrary effects on these enzymes in pancreatic $ß$-cells compared to liver and kidney.

Mitochondrial metabolism plays a key role in insulin secretion stimulated by fuels (secretagogues such as glucose and amino acids). The rise of intracellular ATP produced in mitochondria leads to closure of the ATP-sensitive potassium channels and to depolarization of the plasma membrane, triggering $\mathrm{Ca}^{2+}$ influx and exocytosis of insulin granulae. 
Mitochondria also synthesize metabolites via anaplerosis that have intra- and extramitochondrial signaling functions. Next to ATP these anaplerotic metabolites are needed to couple glucose sensing to stimulation and enhancement of insulin secretion in B-cells [205, 226, 227].

PC was shown to be necessary for glucose-induced insulin secretion [201] (Figure 4-2). Although pancreatic $\beta$-cells lack cytosolic phosphoenolpyruvate carboxykinase and are not able to carry out gluconeogenesis, $\mathrm{PC}$ is expressed in high levels comparable to those of the gluconeogenic organs liver and kidney cortex [227]. Approximately half of glucose-derived pyruvate is converted into oxaloacetate by PC [226, 227]. Oxaloacetate provided by PC feeds into the TCA cycle, allowing rapid oxidation of pyruvate and generation of large amounts of the reducing equivalent NADH for ATP production via oxidative phosphorylation.

PC also plays an important role in generating high levels of NADPH, a metabolic coupling factor for insulin secretion. Mitochondrial oxaloacetate generated by PC can be converted into either malate or citrate, which is then exported into the cytosol via the pyruvate/malate [222] or pyruvate/citrate shuttle [228]. Conversion of malate and citrate back to pyruvate results in production of high levels of NADPH in the cytosol. Cytosolic pyruvate then re-enters the mitochondrion and can be carboxylated again by PC. This shuttle mechanism also referred to as pyruvate cycling produces more NADPH than the pentose phosphate shunt pathway and contributes significantly to glucose-stimulated insulin secretion [222, 228]. Interestingly, the rate of pyruvate carboxylation but not pyruvate oxidation correlates with the rate of insulin release in rat pancreatic islets, suggesting that anaplerosis via PC has a critical function in supporting insulin secretion [229].

Catabolism of dietary amino acids provides another energy source for ATP and anaplerotic products. PCC is involved in the catabolism of the branched chain amino acids threonine, valine, isoleucine, and methione, which provide the anaplerotic intermediate succinyl-CoA. Succinate metabolism was shown to have an important function in insulin secretion, since methylesters of succinate, which are converted to succinate in B-cells, are as potent in stimulating insulin release as glucose. Since succinyl-CoA is thereby a key intermediate and source for the generation of the metabolic coupling factors GTP, mevalonate as well as NADPH [230, 231], the anaplerotic function of PCC seems to be also important for insulin secretion in response to amino acids.

The amino acid leucine is another potent insulin secretagogue (one third as potent as glucose) [232]. Next to allosterically activating GDH and enhancing the conversion of glutamate to $\alpha$ ketoglutarate, leucine can be metabolized to $\alpha$-ketoisocaproic acid (KIC), the first intermediate in leucine catabolism, and finally to acetyl-CoA and acetoacetate. Interestingly, KIC stimulates insulin secretion more potently than leucine (as potent as glucose), which in part seems to be caused by providing faster acetoacetate and acetyl-CoA. Therefore, leucine catabolism, generating acetoacetate and Acetyl-CoA, and MCC, catalyzing the fourth step in this pathway, seem to contribute to leucine-stimulated insulin release.

SIRT4 was shown to negatively regulate both glucose and amino acid stimulated insulin secretion $[25,26]$ and this might be mediated by modulating the enzymatic activities of PC, PCC and MCC. 


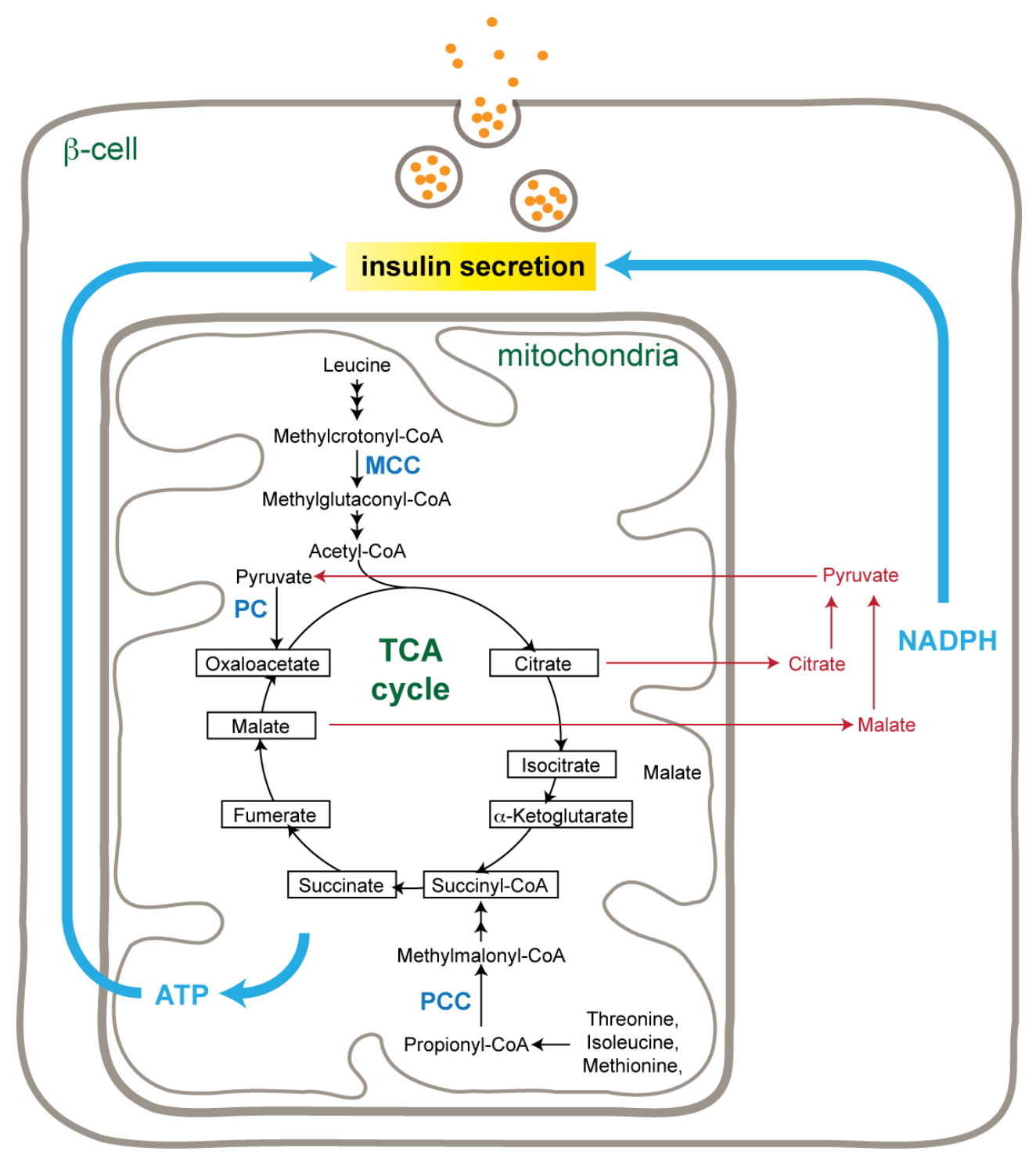

Figure 4-2: Role of mitochondrial biotin carboxylases in insulin secretion.

Pyruvate carboxylase (PC), propionyl-CoA carboxylase (PCC) and methylcrotonyl-CoA (MCC) carboxylase catalyze anaplerotic and catabolic reactions involved in insulin secretion. ATP and NADPH (shown in blue) are important coupling factors for triggering insulin release. Large amounts of ATP are produced via the TCA cycle and oxidative phosphorylation. The pyruvate/malate and pyruvate/citrate shuttle generate high levels of NADPH and are shown in red.

\section{Working hypothesis II.}

In my proposed model (Figure 4-3) absence of dietary glucose and amino acids results in increasing mitochondrial $\mathrm{NAD}^{+}$levels. These activate SIRT4, which subsequently inhibits mitochondrial biotin-dependent carboxylases and GDH in pancreatic B-cells. ADPribosylation of GDH by SIRT4 was shown to inhibit its activity [25]. In the case of mitochondrial biotin carboxylases it has to be determined whether acetylation or ADPribosylation downregulates their activities. It is possible that SIRT4 mediates this contrary effect on the catalytic activities of these enzymes in pancreatic B-cells and liver/kidney, by interacting with different accessory proteins or metabolites that modulate sirtuin activity. Inhibition of PC, PCC, MCC contributes together with inhibition of GDH to a decrease in ATP synthesis, anaplerosis and leucine catabolism, downregulating insulin secretion. 


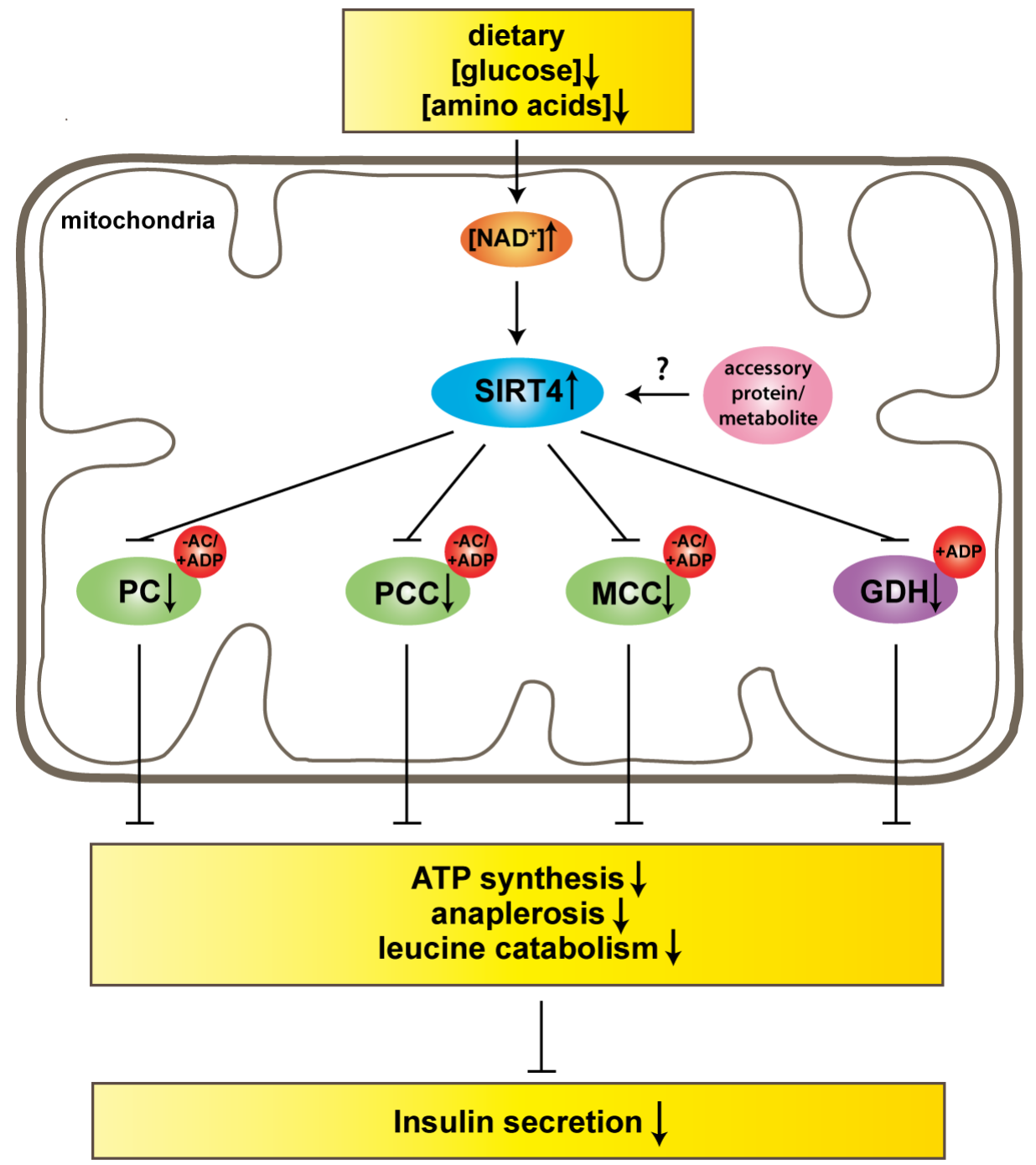

Figure 4-3: Working hypothesis II.

SIRT4 negatively regulates insulin secretion by inhibiting the catalytic activities of mitochondrial biotindependent carboxylases, thereby downregulating ATP synthesis, anaplerosis, leucine catabolism and consequently insulin release. Red dots indicate deacetylation (-Ac) or ADP-ribosylation (+ADP).

A gain of function mutation in GDH, rendering the protein hyperactive, causes hyperinsulinism and hyperammonemia [233]. In humans PC activity and expression was shown to be lower in individuals with type 2 diabetes [234]. Dysregulation of leucinemetabolic-induced insulin secretion also has been linked to progression of B-cell dysfunction and development of type 2 diabetes [235]. Therefore, SIRT4 interacting with biotindependent carboxylases and GDH might as well play a role in the pathogenesis of diabetes.

SIRT4 is not the only sirtuin that has been linked to insulin secretion. Mice overexpressing SIRT1 specifically in pancreatic $\beta$-cells (BESTO) exhibit increased glucose-stimulated insulin release and improved glucose tolerance [67, 236]. Intriguingly, decreased insulin secretion in aging BESTO mice was accompanied by declined $\mathrm{NAD}^{+}$biosynthesis, suggesting that $\mathrm{NAD}^{+}$ is a central molecule in modulating sirtuin activity and insulin release in pancreatic $\beta$-cells $[67,236]$. 
SIRT1 and SIRT4 seem to have opposing effects on insulin secretion. B-cell insulin secretion involving nutrient signaling is complex and needs to be tightly regulated under a broad range of food availability $[19,25]$. SIRT1 and SIRT4 might therefore function during different conditions of food limitation, such as acute starvation and chronic nutrient deprivation.

Moreover, for efficient insulin release $\beta$-cells need to synchronize mitochondrial metabolism, including ATP synthesis and anaplerosis, with cytoplasmic pathways, such as glycolysis and plasma membrane activity. Reversible protein lysine acetylation might be a potential regulatory mechanism to globally coordinate pathways that contribute to insulin release. Thereby, a potential interplay between mitochondrial SIRT4 (acting directly on metabolic enzymes) and SIRT1 (modulating transcriptional levels of metabolic enzymes) might coordinate mitochondrial metabolism with transcription and protein expression in the nucleus. 


\section{Summary and Conclusion}

Sirtuins are highly conserved $\mathrm{NAD}^{+}$-dependent protein deacetylases involved in many cellular processes including genome stability, cell survival, stress responses, metabolism, and aging. Three sirtuins, SIRT3, SIRT4 and SIRT5, of the seven mammalian sirtuins are located in mitochondria and are emerging to be important energy sensors and regulators of mitochondrial metabolism.

We are just beginning to understand the role of mitochondrial SIRT4 in regulating energy metabolism. The nematode $C$. elegans possesses two genes, sir-2.2 and sir-2.3, which are homologous to SIRT4, but there are no homologous genes to SIRT3 and SIRT5. In this study I have shown that both SIR-2.2 and SIR-2.3 localize to mitochondria and are highly expressed in tissues with high energy demand, suggesting conserved functions to mammalian SIRT4. Both SIR-2.2 and SIR-2.3 seem to function in oxidative stress responses. Moreover, C. elegans provided a useful model system to identify the mitochondrial biotin-dependent carboxylases PC, PCC and MCC as interaction partners of SIR-2.2, SIR-2.3 and mammalian SIRT4. The fact that mitochondrial biotin carboxylases play an important role in gluconeogenesis, amino acid catabolism, $\beta$-oxidation and ketone body formation, strengthens the idea that sirtuins regulate metabolic adaptations during nutrient deprivation.

All three biotin carboxylases exhibit lysine acetylation and preliminary results indicate that PCC and MCC might be the first substrates of SIRT4, where the protein displays $\mathrm{NAD}^{+}$dependent deacetylase activity. Therefore, SIRT4 might be an important regulator of the enzymatic activities of mitochondrial biotin carboxylases in pancreatic B-cells and liver. SIRT4 negatively regulates insulin secretion. Insulin inhibits gluconeogenesis in the liver and B-cell activity needs to be tightly coupled to the metabolic activity of the liver for efficient utilization of energy fuels.

Based on these considerations, I propose that SIRT4 plays an important role in coordinating ß-cell activity with liver metabolism. Thereby, SIRT4's interaction with mitochondrial biotin carboxylases might couple downregulation of insulin secretion in $\beta$-cells to upregulation of gluconeogenesis and ketone body formation in the liver during nutrient deprivation. 


\section{Appendix}

\section{A.1 SIR-2.2 protein levels in sir-2.2::gfp and sir-2.3(ok444); sir-2.2RNAi worms}

To determine the SIR-2.2 protein levels in sir-2.2::gfp transgenic worms (overexpressing SIR-2.2) and in sir-2.3(ok444); sir-2.2RNAi worms (knock down of sir-2.2), crude C. elegans lysates were analyzed by Western blotting using the anti-SIR-2.2 antibodies. The protein levels of SIR-2.3 could not be analyzed, since I do not have a SIR-2.3-specific antibody.

A

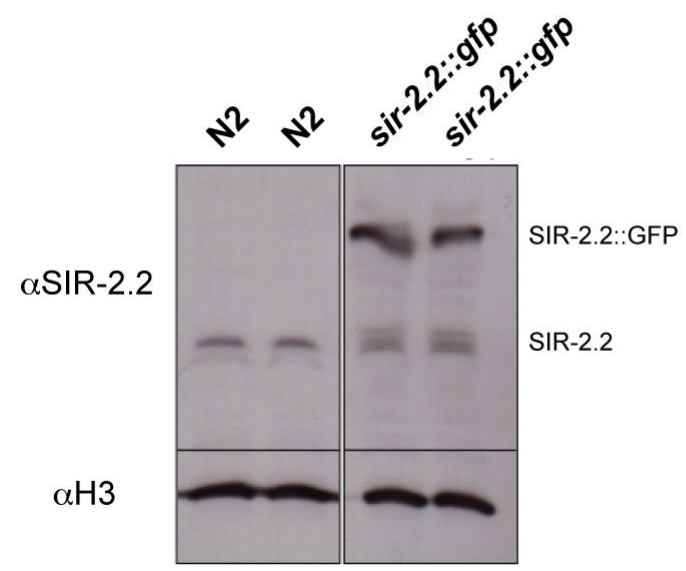

B

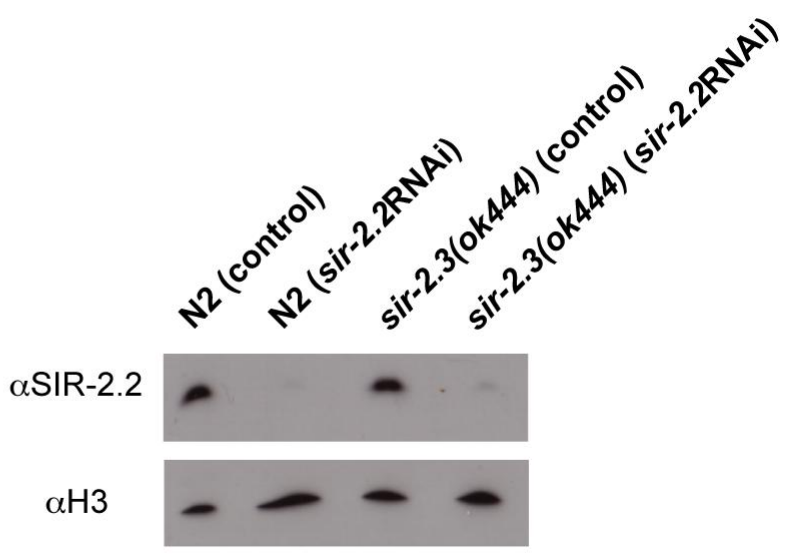

Figure A-1: Analysis of SIR-2.2 protein levels in sir-2.2::gfp and sir-2.3(ok444); sir-2.2RNAi worms.

C. elegans crude lysates were separated by SDS-PAGE and analysed by Western blotting using anti-SIR-2.2 antibodies and anti-H3 antibodies (loading control). A. Western blot analysis of SIR-2.2 protein levels in wild type N2 and sir-2.2::gfp transgenic worms. Running positions of SIR-2.2 ( 33 kD) and SIR-2.2::GFP ( 63 kD) are indicated on the right. B. Western blot analysis of SIR-2.2 protein levels in wild type N2 and sir-2.3(ok444) mutant worms, which were grown on sir-2.2 RNAi feeding plates or control (E. coli HT115(DE) containing empty L4440 vector) feeding plates.

\section{A.2 R programming for mass spectrometry analysis}

Representative program used to analyze mass spectrometric data of immunoprecipitation (IP) experiments

Open "R” (D1=IP1, D2=IP2, D3=IP3, D4=IP4)

> D1=read.table("/Users/mwirth/Desktop/M_Wirth_110509_L1.txt", sep="It", header=T)

> D2=read.table("/Users/mwirth/Desktop/M_Wirth_110509_L2.txt", sep="lt", header=T)

> D3=read.table("/Users/mwirth/Desktop/M_Wirth_110509_L3.txt", sep="lt", header=T)

> D4=read.table("/Users/mwirth/Desktop/M_Wirth_110509_L4.txt", sep="\t", header=T)

$>\operatorname{dim}(\mathrm{D} 1)$

$>\operatorname{dim}(\mathrm{D} 2)$

$>\operatorname{dim}(\mathrm{D} 3)$

$>\operatorname{dim}(\mathrm{D} 4)$

$>$ D1_D2=merge(D1,D2, by.x=1, by.y=1)

$>$ D1_D3=merge(D1,D3, by.x=1, by.y=1) 
$>$ D1_D4=merge(D1,D4, by.x=1, by.y=1)

$>\operatorname{dim}\left(\mathrm{D} 1 \_\mathrm{D} 2\right)$

$>\operatorname{dim}\left(\mathrm{D} 1 \_\mathrm{D} 3\right)$

$>\operatorname{dim}\left(\mathrm{D} 1 \_\mathrm{D} 4\right)$

$>$ D2_unique=subset $(\mathrm{D} 2$, is.element $($ prot_acc,D1_D2\$prot_acc) $==$ FALSE)

$>\operatorname{dim}(\mathrm{D} 2$ _unique $)$

$>$ D3_unique=subset(D3,is.element $($ prot_acc,D1_D3\$prot_acc $)==$ FALSE $)$

$>\operatorname{dim}(\mathrm{D} 3$ _unique $)$

$>$ D4_unique=subset $($ D4,is.element $($ prot_acc,D1_D4\$prot_acc $)==F A L S E)$

$>\operatorname{dim}(\mathrm{D} 4$ _unique $)$

$>$ D2_unique_gr80=D2_unique[D2_unique[,3] > 79,]

$>\operatorname{dim}(\mathrm{D} 2$ _unique_gr80)

$>$ D3_unique_gr80=D3_unique[D3_unique[,3] >79,]

$>$ dim(D3_unique_gr80)

$>$ D4_unique_gr80=D4_unique[D3_unique[,3] > 79,]

$>\operatorname{dim}(\mathrm{D} 3$ _unique_gr80)

$>$ D2gr80_D3gr80=merge(D2_unique_gr80,D3_unique_gr80, by.x=1,by.y=1)

$>\operatorname{dim}\left(\mathrm{D} 2 \mathrm{gr} 80 \_\mathrm{D} 3 \mathrm{gr} 80\right)$

> D2gr80_D3gr80andD3gr80=merge(D2gr80_D3gr80,D4_unique_gr80, by.x=1,by.y=1)

$>$ dim(D2gr80_D3gr80andD3gr80)

>write.table(D2gr80_D3gr80andD4gr80,file="/Users/mwirth/Desktop/D2_D3andD4.txt", sep="\t")

\section{A.3 Mass Spectrometry results}

\section{Representative list of factors identified to interact with SIR-2.2.}

(Red indicates SIR-2.2; F46G10.7a and F46G10.7b are two different splice variants of SIR-2.2; yellow marks mitochondrial biotin carboxylases)

\begin{tabular}{|c|c|c|c|}
\hline prot_acc & prot_desc & $\begin{array}{l}\text { prot_s } \\
\text { core }\end{array}$ & $\begin{array}{l}\text { pep_d } \\
\text { ups_n } \\
\text { umber }\end{array}$ \\
\hline gi|71990482 & F46G10.7a [Caenorhabditis elegans], (sir-2.2) & 3822 & 159 \\
\hline gi|71990487 & F46G10.7b [Caenorhabditis elegans], (sir-2.2) & 3759 & 159 \\
\hline gi|17562816 & PYruvate Carboxylase family member (pyc-1) [Caenorhabditis elegans] & 2924 & 107 \\
\hline gi|71985184 & E04F6.5a [Caenorhabditis elegans] & 1660 & 49 \\
\hline gi|604515 & $\mathrm{Na}, \mathrm{K}-\mathrm{ATP}$ ase alpha subunit & 1592 & 70 \\
\hline gi|17551436 & ATP Synthase B homolog family member (asb-2) [Caenorhabditis elegans] & 870 & 30 \\
\hline gi|450496 & Iamin [Caenorhabditis elegans] & 820 & 34 \\
\hline gi|17553678 & Ubiquinol-Cytochrome c oxidoReductase complex family member (ucr-1) [Caenorhabditis elegans] & 795 & 26 \\
\hline gi|71994394 & T22D1.4 [Caenorhabditis elegans] & 729 & 29 \\
\hline gi|17536479 & T24H7.1 [Caenorhabditis elegans] & 654 & 19 \\
\hline gi|17561814 & GEX Interacting protein family member (gei-7) [Caenorhabditis elegans] & 605 & 24 \\
\hline gi|17507183 & F36A2.7 [Caenorhabditis elegans] & 562 & 27 \\
\hline gi|32564386 & Worm AIF (apoptosis inducing factor) Homolog family member (wah-1) [Caenorhabditis elegans] & 530 & 23 \\
\hline gi|1255199 & sel-1 gene product & 499 & 15 \\
\hline gi|17551802 & B0303.3 [Caenorhabditis elegans] & 490 & 24 \\
\hline gil17555006 & T12A2.2 [Caenorhabditis elegans] & 471 & 13 \\
\hline gi|17553980 & Tubulin, Beta family member (tbb-1) [Caenorhabditis elegans] & 470 & 16 \\
\hline gi|71992778 & Y105E8A.2 [Caenorhabditis elegans] & 460 & 19 \\
\hline gi|1181593 & elongation factor Tu homologue precursor [Caenorhabditis elegans] & 452 & 27 \\
\hline gi|17557498 & C02E11.1a [Caenorhabditis elegans] & 450 & 24 \\
\hline gi|71982905 & D2030.2a [Caenorhabditis elegans] & 449 & 20 \\
\hline gi|17557316 & B0250.5 [Caenorhabditis elegans] & 430 & 13 \\
\hline gi|17569737 & Ubiquinol-Cytochrome c oxidoReductase complex family member (ucr-2.2) [Caenorhabditis elegans] & 423 & 17 \\
\hline gi| 17539560 & DIFferentiation abnormal family member (dif-1) [Caenorhabditis elegans] & 415 & 19 \\
\hline gi|32564064 & B0432.4 [Caenorhabditis elegans] & 390 & 18 \\
\hline gi|17567343 & Propionyl Coenzyme A Carboxylase Alpha subunit family member (pcca-1) [Caenorhabditis elegans] & 384 & 18 \\
\hline gi|17569967 & $\mathrm{T} 22 \mathrm{H} 6.2 \mathrm{a}$ [Caenorhabditis elegans] & 377 & 19 \\
\hline gi|17535649 & R53.4 [Caenorhabditis elegans] & 366 & 17 \\
\hline gi|17557712 & ATP synthase subunit family member (atp-5) [Caenorhabditis elegans] & 362 & 16 \\
\hline gi| 17554158 & SERCA (Sarco-Endoplasmic Reticulum Calcium ATPase) family member (sca-1) [Caenorhabditis elegans] & 358 & 17 \\
\hline gi|17570205 & Ubiquinol-Cytochrome c oxidoReductase complex family member (ucr-2.1) [Caenorhabditis elegans] & 339 & 9 \\
\hline gi|17534029 & TuBulin, Alpha family member (tba-4) [Caenorhabditis elegans] & 335 & 15 \\
\hline gi|115534052 & K02F3.2 [Caenorhabditis elegans] & 330 & 16 \\
\hline gi|17505833 & C34B2.7 [Caenorhabditis elegans] & 309 & 12 \\
\hline gi|17535181 & M05D6.6 [Caenorhabditis elegans] & 309 & 11 \\
\hline gi|17555336 & TuBulin, Alpha family member (tba-7) [Caenorhabditis elegans] & 301 & 13 \\
\hline gi|17507897 & G protein, $\mathrm{O}$, Alpha subunit family member (goa-1) [Caenorhabditis elegans] & 297 & 10 \\
\hline
\end{tabular}


General Anaesthetic Sensitivity abnormal family member (gas-1) [Caenorhabditis elegans] calcium ATPase [Caenorhabditis elegans]

Y56A3A.21 [Caenorhabditis elegans]

gi|17556298 gi|71999758

Iron-Sulfur Protein family member (isp-1) [Caenorhabditis elegans] K07G5.6 [Caenorhabditis elegans]

ATP synthase subunit family member (atp-4) [Caenorhabditis elegans]

ZK370.8 [Caenorhabditis elegans]

DeHydrogenases, Short chain family member (dhs-24) [Caenorhabditis elegans]

T09A5.11 [Caenorhabditis elegans]

W02F12.5 [Caenorhabditis elegans]

DIsorganized Muscle family member (dim-1) [Caenorhabditis elegans]

TPA: TPA_exp: ANC-1 [Caenorhabditis elegans]

F07C3.2 [Caenorhabditis elegans]

53G8AL.2 [Caenorhabditis elegans]

F15D3.7 [Caenorhabditis elegans]

G protein, Subunit Alpha family member (gsa-1) [Caenorhabditis elegans]

NADH Ubiquinone Oxidoreductase family member (nuo-4) [Caenorhabditis elegans]

hypothetical protein $\mathrm{K} 11 \mathrm{H} 3.3$ - Caenorhabditis elegans

F58F12.1 [Caenorhabditis elegans]

22B11.5 [Caenorhabditis elegans]

K05C4.2 [Caenorhabditis elegans]

T04A8.6 [Caenorhabditis elegans]

F32B6.2 [Caenorhabditis elegans] (mccc-1)

HisTone variant $\mathrm{H} 2 \mathrm{AZ}$ homolog family member (htz-1) [Caenorhabditis elegans]

P-GlycoProtein related family member (pgp-2) [Caenorhabditis elegans]

C.Elegans Y-box family member (cey-4) [Caenorhabditis elegans]

ZK836.2 [Caenorhabditis elegans]

H25P06.1 [Caenorhabditis elegans]

76A2B.3 [Caenorhabditis elegans]

F29C12.4 [Caenorhabditis elegans]

C01F1.2 [Caenorhabditis elegans]

F11C1.5b [Caenorhabditis elegans]

F20D1.9 [Caenorhabditis elegans]

F44E5.1 [Caenorhabditis elegans]

22B7.7 [Caenorhabditis elegans]

steroid Alpha ReducTase family member (art-1) [Caenorhabditis elegans]

Fatty Acid SyNthase family member (fasn-1) [Caenorhabditis elegans]

F37C12.7 [Caenorhabditis elegans]

Y65B4BL.5 [Caenorhabditis elegans]

MethylMalonic Aciduria type A protein family member (mmaa-1) [Caenorhabditis elegans]

$\mathrm{DNa}$ domain (prokaryotic heat shock protein) family member (dnj-10) [Caenorhabditis elegans]

Y67H2A.5 [Caenorhabditis elegans]

hypothetical protein D1037.4 - Caenorhabditis elegans

Y17G9B.5 [Caenorhabditis elegans]

C54G4.8 [Caenorhabditis elegans]

Y119D3B.14 [Caenorhabditis elegans]

F22B8.7 [Caenorhabditis elegans]

T08G11.1a [Caenorhabditis elegans]

F22B5.4 [Caenorhabditis elegans]

ZK669.4 [Caenorhabditis elegans]

C02B10.3 [Caenorhabditis elegans]

hypothetical protein C28C12.9 - Caenorhabditis elegans

beta-G spectrin [Caenorhabditis elegans]

FZO (Fzo mitochondrial fusion protein) related family member (fzo-1) [Caenorhabditis elegans]

Temporarily Assigned Gene name family member (tag-174) [Caenorhabditis elegans]

F28A10.6 [Caenorhabditis elegans]

F02H6.5 [Caenorhabditis elegans]

ZK829.7 [Caenorhabditis elegans]

K11G12.5 [Caenorhabditis elegans]

K10C2.1 [Caenorhabditis elegans]

T09B4.9 [Caenorhabditis elegans]

F28C6.8 [Caenorhabditis elegans]

Heat Shock Protein family member (hsp-16.1) [Caenorhabditis elegans]

Temporarily Assigned Gene name family member (tag-252) [Caenorhabditis elegans]

GLutaRedoXin family member (glrx-5) [Caenorhabditis elegans]

T05H4.5 [Caenorhabditis elegans] 
gi|71997968 gi|17553276 gi|32564577 gi|32563621 gi|17556096 gi|17555666 gi|17552648 gi|17509233 gi|17562364 gi|25143064 gil 17542706 gi|17556130 gi|17562892 gi|17550468 gi|17560918 gi|17552202 gi|71998231 gi|17509681 gi|17550124 gi|71999501 gi|17561402 gi|17536829 gi|17541894 gi|17509253 gi|17538940 gi|7495955 gi|17510361 gi|115534188 gi|17560096 gi|6686276 gi|71983876 gi|71998175 gi|17535241 gi|17540238 gi|17506935 gi|71990294 gi|17537053 gi|7209577 gi|71997402 gi|17556801 gi|17555956 gi|17542570 gi|71999402 gi|17536635 gi|17536047 gi|17556907 gi|71982617 gi|72000917 gi|17564522 gi|32565091 gi|17554998 gi|32565766 gi|7507437 gi|17562104 gi|17553976 gi|17563798
Y54G2A.2a [Caenorhabditis elegans] ATP Synthase B homolog family member (asb-1) [Caenorhabditis elegans] T07D3.9a [Caenorhabditis elegans] NADH Ubiquinone Oxidoreductase family member (nuo-2) [Caenorhabditis elegans] Alkyl-Dihydroxyacetonephosphate Synthase family member (ads-1) [Caenorhabditis elegans] Cytochrome C Oxidase family member (cco-2) [Caenorhabditis elegans] C48B4.1 [Caenorhabditis elegans] T23H2.5 [Caenorhabditis elegans] K08D9.4 [Caenorhabditis elegans] B0205.6 [Caenorhabditis elegans]

Vacuolar H ATPase family member (vha-5) [Caenorhabditis elegans] RAL (Ras-related GTPase) homolog family member (ral-1) [Caenorhabditis elegans] R04F11.2 [Caenorhabditis elegans]

PeRoXisome assembly factor family member (prx-3) [Caenorhabditis elegans] F43H9.4 [Caenorhabditis elegans]

C16A3.5 [Caenorhabditis elegans]

Carnitine Palmitoyl Transferase family member (cpt-1) [Caenorhabditis elegans] W10C8.5 [Caenorhabditis elegans]

C04C11.2 [Caenorhabditis elegans]

Y69A2AR. 5 [Caenorhabditis elegans] F54F3.4 [Caenorhabditis elegans] W09H1.5 [Caenorhabditis elegans] R11A8.5 [Caenorhabditis elegans] T25G3.4 [Caenorhabditis elegans] C33A12.1 [Caenorhabditis elegans]

hypothetical protein C14A4.2 - Caenorhabditis elegans

DNaJ domain (prokaryotic heat shock protein) family member (dnj-29) [Caenorhabditis elegans] T07E3.3 [Caenorhabditis elegans]

23H12.2 [Caenorhabditis elegans] Histone $\mathrm{H} 3$

C41C4.10 [Caenorhabditis elegans]

Y55F3AR.2 [Caenorhabditis elegans] M176.3 [Caenorhabditis elegans] F37C4.6 [Caenorhabditis elegans]

Temporarily Assigned Gene name family member (tag-173) [Caenorhabditis elegans] F54B3.3 [Caenorhabditis elegans] Y38F1A.6 [Caenorhabditis elegans]

kinesin like protein [Caenorhabditis elegans]

T25G12.7 [Caenorhabditis elegans]

Temporarily Assigned Gene name family member (tag-354) [Caenorhabditis elegans]

fabily member (rab-35) [Caenorhabditis elegans]

T26C12.1 [Caenorhabditis elegans]

Y66H1A.2 [Caenorhabditis elegans]

Vacuolar H ATPase family member (vha-6) [Caenorhabditis elegans]

T05H10.6a [Caenorhabditis elegans]

UBX-containing protein in Nematode family member (ubxn-4) [Caenorhabditis elegans]

Serine Palmitoyl Transferase famiLy family member (sptl-1) [Caenorhabditis elegans]

TiTiN family member (ttn-1) [Caenorhabditis elegans]

LiPid Depleted family member (Ipd-9) [Caenorhabditis elegans]

EATing: abnormal pharyngeal pumping family member (eat-3) [Caenorhabditis elegans]

T10F2.2 [Caenorhabditis elegans]

LLC1.3 [Caenorhabditis elegans]

hypothetical protein T08B2.10 - Caenorhabditis elegans

K03B4.1 [Caenorhabditis elegans]

associated with RAN (nuclear import/export) function family member (ran-1) [Caenorhabditis elegans]

CathePsin L family member (cpl-1) [Caenorhabditis elegans]

\section{Representative list of factors identified to interact with SIR-2.3.}

(Red indicates SIR-2.3; yellow marks mitochondrial biotin carboxylases)

\begin{tabular}{|c|c|c|c|}
\hline prot_acc & prot_desc & $\begin{array}{l}\text { prot_s } \\
\text { core }\end{array}$ & $\begin{array}{l}\text { pep_d } \\
\text { ups_n } \\
\text { umber }\end{array}$ \\
\hline gi|17509401 & UNCoordinated family member (unc-54) [Caenorhabditis elegans] & 5204 & 86 \\
\hline gi|25150292 & MYOsin heavy chain structural genes family member (myo-2) [Caenorhabditis elegans] & 1447 & 22 \\
\hline gi|469483 & CCT-1 & 965 & \\
\hline gi|25151802 & ASpartyl Protease family member (asp-1) [Caenorhabditis elegans] & 895 & 14 \\
\hline gi|17562816 & PYruvate Carboxylase family member (pyc-1) [Caenorhabditis elegans] & 886 & 28 \\
\hline gi|14278147 & $\begin{array}{l}\text { Chain A, Crystal Structure Of Caenorhabditis Elegans Mg-Atp Actin Complexed With Human Gelsolin Segment } 1 \\
\text { At } 1.75 \text { A Resolution }\end{array}$ & 872 & 21 \\
\hline gi|17564182 & Chaperonin Containing TCP-1 family member (cct-7) [Caenorhabditis elegans] & 854 & 14 \\
\hline gi|17567771 & yeast SIR related family member (sir-2.3) [Caenorhabditis elegans] & 831 & 19 \\
\hline gi|17508449 & LEThal family member (let-75) [Caenorhabditis elegans] & 817 & 27 \\
\hline gi|71993203 & PolyA Binding protein family member (pab-1) [Caenorhabditis elegans] & 608 & 15 \\
\hline gi|17532603 & Chaperonin Containing TCP-1 family member (cct-4) [Caenorhabditis elegans] & 390 & 19 \\
\hline gi|17554158 & SERCA (Sarco-Endoplasmic Reticulum Calcium ATPase) family member (sca-1) [Caenorhabditis elegans] & 343 & 16 \\
\hline
\end{tabular}


HELicase family member (hel-1) [Caenorhabditis elegans]

Chaperonin Containing TCP-1 family member (cct-6) [Caenorhabditis elegans]

hypothetical protein C25A11.4a - Caenorhabditis elegans

Valyl tRNA Synthetase family member (vrs-2) [Caenorhabditis elegans]

human HnRNP A1 homolog family member (hrp-2) [Caenorhabditis elegans]

hypothetical protein $\mathrm{C} 28 \mathrm{H} 8.3$ [Caenorhabditis elegans]

Propionyl Coenzyme A Carboxylase Alpha subunit family member (pcca-1) [Caenorhabditis elegans]

hypothetical protein F35G12.2 [Caenorhabditis elegans]

gpd-2 gene product [Caenorhabditis elegans]

Fatty Acid SyNthase family member (fasn-1) [Caenorhabditis elegans]

Cytokinesis, Apoptosis, RNA-associated family member (car-1) [Caenorhabditis elegans]

Proteasome regulatory particle, non-atpase-like protein 2, isoform a [Caenorhabditis elegans]

Temporarily Assigned Gene name family member (tag-210) [Caenorhabditis elegans]

proteasome Regulatory Particle, ATPase-like family member (rpt-4) [Caenorhabditis elegans]

GEX Interacting protein family member (gei-7) [Caenorhabditis elegans]

hypothetical protein T10D4.3 [Caenorhabditis elegans]

hypothetical protein Y48G9A.3 [Caenorhabditis elegans]

MYOsin heavy chain structural genes family member (myo-3) [Caenorhabditis elegans]

hypothetical protein T28D6.6 [Caenorhabditis elegans]

Leucyl tRNA Synthetase family member (Irs-1) [Caenorhabditis elegans]

14-3-3 protein

Argonaute (plant)-Like Gene family member (alg-2) [Caenorhabditis elegans]

hypothetical protein F26B1.2 [Caenorhabditis elegans]

UNCoordinated family member (unc-116) [Caenorhabditis elegans]

hypothetical protein C25A1.4 [Caenorhabditis elegans]

hypothetical protein ZK829.7 [Caenorhabditis elegans]

hypothetical protein Y43F4B.5 [Caenorhabditis elegans]

proteasome Regulatory Particle, Non-ATPase-like family member (rpn-9) [Caenorhabditis elegans]

hypothetical protein T25C12.3 [Caenorhabditis elegans]

Tudor Staphylococcal Nuclease homolog family member (tsn-1) [Caenorhabditis elegans]

proteasome Regulatory Particle, ATPase-like family member (rpt-3) [Caenorhabditis elegans]

Isoleucyl tRNA Synthetase family member (irs-1) [Caenorhabditis elegans]

hypothetical protein F32B6.2 [Caenorhabditis elegans]

RUVB (recombination protein) homolog family member (ruvb-2) [Caenorhabditis elegans]

hypothetical protein C30F12.7 [Caenorhabditis elegans]

Y-box family member (cey-2) [Caenorhabditis elegans]

ALIX (Apoptosis-linked gene 2 interacting protein X) homolog family member (alX-1) [Caenorhabditis elegans]

proteasome Regulatory Particle, ATPase-like family member (rpt-6) [Caenorhabditis elegans]

hypothetical protein C30G12.2 [Caenorhabditis elegans]

hypothetical protein F33D11.10 [Caenorhabditis elegans]

Acyl CoA DeHydrogenase family member (acdh-9) [Caenorhabditis elegans]

proteasome Regulatory Particle, ATPase-like family member (rpt-1) [Caenorhabditis elegans]

PYRimidine biosynthesis family member (pyr-1) [Caenorhabditis elegans]

proteasome Regulatory Particle, Non-ATPase-like family member (rpn-1) [Caenorhabditis elegans]

hypothetical protein T22F3.3 [Caenorhabditis elegans]

$\mathrm{Na}, \mathrm{K}-\mathrm{ATPa}$ e alpha subunit

hypothetical protein F49C12.7 [Caenorhabditis elegans]

hypothetical protein Y39G10AR.8 [Caenorhabditis elegans]

Eukaryotic Initiation Factor family member (eif-3.B) [Caenorhabditis elegans]

Cell Division Cycle related family member (cdc-48.1) [Caenorhabditis elegans]

COP9/Signalosome and eIF3 complex shared subunit family member (cif-1) [Caenorhabditis elegans] putative

SKN-1 Dependent Zygotic transcript family member (sdz-8) [Caenorhabditis elegans]

proteasome Regulatory Particle, Non-ATPase-like family member (rpn-8) [Caenorhabditis elegans] IMportin Beta family member (imb-3) [Caenorhabditis elegans]

proteasome Regulatory Particle, Non-ATPase-like family member (rpn-6) [Caenorhabditis elegans] Eukaryotic Initiation Factor family member (eif-3.H) [Caenorhabditis elegans]

MAP kinase kinase or Erk Kinase family member (mek-2) [Caenorhabditis elegans]

dynamin [Caenorhabditis elegans]

RecName: Full=Probable coatomer subunit beta ; AltName: Full=Beta -coat protein; Short=Beta -COP

Ribosomal Protein, Small subunit family member (rps-6) [Caenorhabditis elegans]

aRginyl aa-tRNA syntheTase family member (rrt-1) [Caenorhabditis elegans]

Puromycin-sensitive AMinopeptidase family member (pam-1) [Caenorhabditis elegans]

hypothetical protein Y54H5A.2 [Caenorhabditis elegans]

Stress Induced Protein family member (sip-1) [Caenorhabditis elegans]

UDP-GALactose 4-Epimerase family member (gale-1) [Caenorhabditis elegans]

proteasome Regulatory Particle, ATPase-like family member (rpt-5) [Caenorhabditis elegans]

Ribosomal Protein, Large subunit family member (rpl-32) [Caenorhabditis elegans]

hypothetical protein $\mathrm{F} 46 \mathrm{H} 5.7$ [Caenorhabditis elegans]

hypothetical protein $\mathrm{F} 53 \mathrm{C} 11.3$ [Caenorhabditis elegans]

eIFTwoBeta (eIF2beta translation initiation factor) family member (iftb-1) [Caenorhabditis elegans]

Y-box family member (cey-4) [Caenorhabditis elegans]

elongation factor Tu homologue precursor [Caenorhabditis elegans]

hypothetical protein Y66H1B.2 [Caenorhabditis elegans]

hypothetical protein $\mathrm{Y} 67 \mathrm{H} 2 \mathrm{~A} .2$ [Caenorhabditis elegans]

hypothetical protein C17G10.8 - Caenorhabditis elegans

eXPOrtin (nuclear export receptor) family member (xpo-1) [Caenorhabditis elegans] 


\section{References}

[1] G. Blander, L. Guarente, The Sir2 family of protein deacetylases, Annu Rev Biochem 73 (2004) 417-435.

[2] C.B. Brachmann, J.M. Sherman, S.E. Devine, E.E. Cameron, L. Pillus, J.D. Boeke, The SIR2 gene family, conserved from bacteria to humans, functions in silencing, cell cycle progression, and chromosome stability, Genes Dev 9 (1995) 2888-2902.

[3] R.A. Frye, Phylogenetic classification of prokaryotic and eukaryotic Sir2-like proteins, Biochem Biophys Res Commun 273 (2000) 793-798.

[4] S. Imai, C.M. Armstrong, M. Kaeberlein, L. Guarente, Transcriptional silencing and longevity protein Sir2 is an NAD-dependent histone deacetylase, Nature 403 (2000) 795-800.

[5] J. Landry, A. Sutton, S.T. Tafrov, R.C. Heller, J. Stebbins, L. Pillus, R. Sternglanz, The silencing protein SIR2 and its homologs are NAD-dependent protein deacetylases, Proc Natl Acad Sci U S A 97 (2000) 5807-5811.

[6] J.S. Smith, C.B. Brachmann, I. Celic, M.A. Kenna, S. Muhammad, V.J. Starai, J.L. Avalos, J.C. Escalante-Semerena, C. Grubmeyer, C. Wolberger, J.D. Boeke, A phylogenetically conserved NAD+-dependent protein deacetylase activity in the Sir2 protein family, Proc Natl Acad Sci U S A 97 (2000) 6658-6663.

[7] K.G. Tanner, J. Landry, R. Sternglanz, J.M. Denu, Silent information regulator 2 family of NAD- dependent histone/protein deacetylases generates a unique product, 1-O-acetyl-ADPribose, Proc Natl Acad Sci U S A 97 (2000) 14178-14182.

[8] J.C. Tanny, D. Moazed, Coupling of histone deacetylation to NAD breakdown by the yeast silencing protein Sir2: Evidence for acetyl transfer from substrate to an NAD breakdown product, Proc Natl Acad Sci U S A 98 (2001) 415-420.

[9] S.M. Gasser, M.M. Cockell, The molecular biology of the SIR proteins, Gene 279 (2001) 116.

[10] D.L. Pappas, Jr., R. Frisch, M. Weinreich, The NAD(+)-dependent Sir2p histone deacetylase is a negative regulator of chromosomal DNA replication, Genes Dev 18 (2004) 769-781.

[11] Y. Tsukamoto, J. Kato, H. Ikeda, Silencing factors participate in DNA repair and recombination in Saccharomyces cerevisiae, Nature 388 (1997) 900-903.

[12] M. Kaeberlein, M. McVey, L. Guarente, The SIR2/3/4 complex and SIR2 alone promote longevity in Saccharomyces cerevisiae by two different mechanisms, Genes Dev 13 (1999) 2570-2580.

[13] S.J. Lin, P.A. Defossez, L. Guarente, Requirement of NAD and SIR2 for life-span extension by calorie restriction in Saccharomyces cerevisiae, Science 289 (2000) 2126-2128.

[14] K.T. Howitz, K.J. Bitterman, H.Y. Cohen, D.W. Lamming, S. Lavu, J.G. Wood, R.E. Zipkin, P. Chung, A. Kisielewski, L.L. Zhang, B. Scherer, D.A. Sinclair, Small molecule activators of sirtuins extend Saccharomyces cerevisiae lifespan, Nature 425 (2003) 191-196.

[15] H.A. Tissenbaum, L. Guarente, Increased dosage of a sir-2 gene extends lifespan in Caenorhabditis elegans, Nature 410 (2001) 227-230.

[16] B. Rogina, S.L. Helfand, Sir2 mediates longevity in the fly through a pathway related to calorie restriction, Proc Natl Acad Sci U S A 101 (2004) 15998-16003.

[17] S.U. Astrom, T.W. Cline, J. Rine, The Drosophila melanogaster sir2+ gene is nonessential and has only minor effects on position-effect variegation, Genetics 163 (2003) 931-937.

[18] J.G. Wood, B. Rogina, S. Lavu, K. Howitz, S.L. Helfand, M. Tatar, D. Sinclair, Sirtuin activators mimic caloric restriction and delay ageing in metazoans, Nature 430 (2004) 686689.

[19] M.C. Haigis, D.A. Sinclair, Mammalian sirtuins: biological insights and disease relevance, Annu Rev Pathol 5 (2010) 253-295.

[20] S. Imai, L. Guarente, Ten years of NAD-dependent SIR2 family deacetylases: implications for metabolic diseases, Trends Pharmacol Sci 31 (2010) 212-220.

[21] A.A. Sauve, Sirtuin chemical mechanisms, Biochim Biophys Acta 1804 (2010) 1591-1603. 
[22] A.W. Tsang, J.C. Escalante-Semerena, CobB, a new member of the SIR2 family of eucaryotic regulatory proteins, is required to compensate for the lack of nicotinate mononucleotide:5,6dimethylbenzimidazole phosphoribosyltransferase activity in cobT mutants during cobalamin biosynthesis in Salmonella typhimurium LT2, J Biol Chem 273 (1998) 31788-31794.

[23] R.A. Frye, Characterization of five human cDNAs with homology to the yeast SIR2 gene: Sir2-like proteins (sirtuins) metabolize NAD and may have protein ADP-ribosyltransferase activity, Biochem Biophys Res Commun 260 (1999) 273-279.

[24] J.C. Tanny, G.J. Dowd, J. Huang, H. Hilz, D. Moazed, An enzymatic activity in the yeast Sir2 protein that is essential for gene silencing, Cell 99 (1999) 735-745.

[25] M.C. Haigis, R. Mostoslavsky, K.M. Haigis, K. Fahie, D.C. Christodoulou, A.J. Murphy, D.M. Valenzuela, G.D. Yancopoulos, M. Karow, G. Blander, C. Wolberger, T.A. Prolla, R. Weindruch, F.W. Alt, L. Guarente, SIRT4 inhibits glutamate dehydrogenase and opposes the effects of calorie restriction in pancreatic beta cells, Cell 126 (2006) 941-954.

[26] N. Ahuja, B. Schwer, S. Carobbio, D. Waltregny, B.J. North, V. Castronovo, P. Maechler, E. Verdin, Regulation of insulin secretion by SIRT4, a mitochondrial ADP-ribosyltransferase, J Biol Chem 282 (2007) 33583-33592.

[27] A.A. Sauve, C. Wolberger, V.L. Schramm, J.D. Boeke, The biochemistry of sirtuins, Annu Rev Biochem 75 (2006) 435-465.

[28] B.C. Smith, W.C. Hallows, J.M. Denu, Mechanisms and molecular probes of sirtuins, Chem Biol 15 (2008) 1002-1013.

[29] B.J. North, B.L. Marshall, M.T. Borra, J.M. Denu, E. Verdin, The human Sir2 ortholog, SIRT2, is an NAD+-dependent tubulin deacetylase, Mol Cell 11 (2003) 437-444.

[30] G. Liszt, E. Ford, M. Kurtev, L. Guarente, Mouse Sir2 homolog SIRT6 is a nuclear ADPribosyltransferase, J Biol Chem 280 (2005) 21313-21320.

[31] E. Michishita, R.A. McCord, E. Berber, M. Kioi, H. Padilla-Nash, M. Damian, P. Cheung, R. Kusumoto, T.L. Kawahara, J.C. Barrett, H.Y. Chang, V.A. Bohr, T. Ried, O. Gozani, K.F. Chua, SIRT6 is a histone H3 lysine 9 deacetylase that modulates telomeric chromatin, Nature 452 (2008) 492-496.

[32] J.A. Garcia-Salcedo, P. Gijon, D.P. Nolan, P. Tebabi, E. Pays, A chromosomal SIR2 homologue with both histone NAD-dependent ADP-ribosyltransferase and deacetylase activities is involved in DNA repair in Trypanosoma brucei, EMBO J 22 (2003) 5851-5862.

[33] E.L. Jacobson, D. Cervantes-Laurean, M.K. Jacobson, ADP-ribose in glycation and glycoxidation reactions, Adv Exp Med Biol 419 (1997) 371-379.

[34] D. Cervantes-Laurean, D.E. Minter, E.L. Jacobson, M.K. Jacobson, Protein glycation by ADP-ribose: studies of model conjugates, Biochemistry 32 (1993) 1528-1534.

[35] T.M. Kowieski, S. Lee, J.M. Denu, Acetylation-dependent ADP-ribosylation by Trypanosoma brucei Sir2, J Biol Chem 283 (2008) 5317-5326.

[36] J. Du, H. Jiang, H. Lin, Investigating the ADP-ribosyltransferase activity of sirtuins with NAD analogues and 32P-NAD, Biochemistry 48 (2009) 2878-2890.

[37] W.F. Hawse, C. Wolberger, Structure-based mechanism of ADP-ribosylation by sirtuins, J Biol Chem 284 (2009) 33654-33661.

[38] K.J. Bitterman, R.M. Anderson, H.Y. Cohen, M. Latorre-Esteves, D.A. Sinclair, Inhibition of silencing and accelerated aging by nicotinamide, a putative negative regulator of yeast sir2 and human SIRT1, J Biol Chem 277 (2002) 45099-45107.

[39] M.D. Jackson, M.T. Schmidt, N.J. Oppenheimer, J.M. Denu, Mechanism of nicotinamide inhibition and transglycosidation by Sir2 histone/protein deacetylases, J Biol Chem 278 (2003) 50985-50998.

[40] A.A. Sauve, V.L. Schramm, Sir2 regulation by nicotinamide results from switching between base exchange and deacetylation chemistry, Biochemistry 42 (2003) 9249-9256.

[41] L. Tong, J.M. Denu, Function and metabolism of sirtuin metabolite O-acetyl-ADP-ribose, Biochim Biophys Acta 1804 (2010) 1617-1625.

[42] G.G. Liou, J.C. Tanny, R.G. Kruger, T. Walz, D. Moazed, Assembly of the SIR complex and its regulation by O-acetyl-ADP-ribose, a product of NAD-dependent histone deacetylation, Cell 121 (2005) 515-527.

[43] G. Kustatscher, M. Hothorn, C. Pugieux, K. Scheffzek, A.G. Ladurner, Splicing regulates NAD metabolite binding to histone macroH2A, Nat Struct Mol Biol 12 (2005) 624-625. 
[44] B.D. Sanders, B. Jackson, R. Marmorstein, Structural basis for sirtuin function: what we know and what we don't, Biochim Biophys Acta 1804 (2010) 1604-1616.

[45] M.S. Finnin, J.R. Donigian, N.P. Pavletich, Structure of the histone deacetylase SIRT2, Nat Struct Biol 8 (2001) 621-625.

[46] J. Min, J. Landry, R. Sternglanz, R.M. Xu, Crystal structure of a SIR2 homolog-NAD complex, Cell 105 (2001) 269-279.

[47] A. Schuetz, J. Min, T. Antoshenko, C.L. Wang, A. Allali-Hassani, A. Dong, P. Loppnau, M. Vedadi, A. Bochkarev, R. Sternglanz, A.N. Plotnikov, Structural basis of inhibition of the human NAD+-dependent deacetylase SIRT5 by suramin, Structure 15 (2007) 377-389.

[48] K. Zhao, X. Chai, A. Clements, R. Marmorstein, Structure and autoregulation of the yeast Hst2 homolog of Sir2, Nat Struct Biol 10 (2003) 864-871.

[49] K. Zhao, X. Chai, R. Marmorstein, Structure of the yeast Hst2 protein deacetylase in ternary complex with 2'-O-acetyl ADP ribose and histone peptide, Structure 11 (2003) 1403-1411.

[50] J.Y. Huang, M.D. Hirschey, T. Shimazu, L. Ho, E. Verdin, Mitochondrial sirtuins, Biochim Biophys Acta 1804 (2010) 1645-1651.

[51] E. Michishita, J.Y. Park, J.M. Burneskis, J.C. Barrett, I. Horikawa, Evolutionarily conserved and nonconserved cellular localizations and functions of human SIRT proteins, Mol Biol Cell 16 (2005) 4623-4635.

[52] A. Vaquero, M. Scher, D. Lee, H. Erdjument-Bromage, P. Tempst, D. Reinberg, Human SirT1 interacts with histone $\mathrm{H} 1$ and promotes formation of facultative heterochromatin, Mol Cell 16 (2004) 93-105.

[53] T. Bouras, M. Fu, A.A. Sauve, F. Wang, A.A. Quong, N.D. Perkins, R.T. Hay, W. Gu, R.G. Pestell, SIRT1 deacetylation and repression of p300 involves lysine residues 1020/1024 within the cell cycle regulatory domain 1, J Biol Chem 280 (2005) 10264-10276.

[54] A. Vaquero, M. Scher, H. Erdjument-Bromage, P. Tempst, L. Serrano, D. Reinberg, SIRT1 regulates the histone methyl-transferase SUV39H1 during heterochromatin formation, Nature 450 (2007) 440-444.

[55] H. Vaziri, S.K. Dessain, E. Ng Eaton, S.I. Imai, R.A. Frye, T.K. Pandita, L. Guarente, R.A. Weinberg, hSIR2(SIRT1) functions as an NAD-dependent p53 deacetylase, Cell 107 (2001) 149-159.

[56] J. Luo, A.Y. Nikolaev, S. Imai, D. Chen, F. Su, A. Shiloh, L. Guarente, W. Gu, Negative control of p53 by Sir2alpha promotes cell survival under stress, Cell 107 (2001) 137-148.

[57] C. Wang, L. Chen, X. Hou, Z. Li, N. Kabra, Y. Ma, S. Nemoto, T. Finkel, W. Gu, W.D. Cress, J. Chen, Interactions between E2F1 and SirT1 regulate apoptotic response to DNA damage, Nat Cell Biol 8 (2006) 1025-1031.

[58] J. Nakae, Y. Cao, H. Daitoku, A. Fukamizu, W. Ogawa, Y. Yano, Y. Hayashi, The LXXLL motif of murine forkhead transcription factor FoxO1 mediates Sirt1-dependent transcriptional activity, J Clin Invest 116 (2006) 2473-2483.

[59] M.C. Motta, N. Divecha, M. Lemieux, C. Kamel, D. Chen, W. Gu, Y. Bultsma, M. McBurney, L. Guarente, Mammalian SIRT1 represses forkhead transcription factors, Cell 116 (2004) 551-563.

[60] A. Brunet, L.B. Sweeney, J.F. Sturgill, K.F. Chua, P.L. Greer, Y. Lin, H. Tran, S.E. Ross, R. Mostoslavsky, H.Y. Cohen, L.S. Hu, H.L. Cheng, M.P. Jedrychowski, S.P. Gygi, D.A. Sinclair, F.W. Alt, M.E. Greenberg, Stress-dependent regulation of FOXO transcription factors by the SIRT1 deacetylase, Science 303 (2004) 2011-2015.

[61] A. van der Horst, L.G. Tertoolen, L.M. de Vries-Smits, R.A. Frye, R.H. Medema, B.M. Burgering, FOXO4 is acetylated upon peroxide stress and deacetylated by the longevity protein hSir2(SIRT1), J Biol Chem 279 (2004) 28873-28879.

[62] F. Gao, J. Cheng, T. Shi, E.T. Yeh, Neddylation of a breast cancer-associated protein recruits a class III histone deacetylase that represses NFkappaB-dependent transcription, Nat Cell Biol 8 (2006) 1171-1177.

[63] T. Takata, F. Ishikawa, Human Sir2-related protein SIRT1 associates with the bHLH repressors HES1 and HEY2 and is involved in HES1- and HEY2-mediated transcriptional repression, Biochem Biophys Res Commun 301 (2003) 250-257. 
[64] F. Picard, M. Kurtev, N. Chung, A. Topark-Ngarm, T. Senawong, R. Machado De Oliveira, M. Leid, M.W. McBurney, L. Guarente, Sirt1 promotes fat mobilization in white adipocytes by repressing PPAR-gamma, Nature 429 (2004) 771-776.

[65] J.T. Rodgers, C. Lerin, W. Haas, S.P. Gygi, B.M. Spiegelman, P. Puigserver, Nutrient control of glucose homeostasis through a complex of PGC-1alpha and SIRT1, Nature 434 (2005) 113118.

[66] X. Li, S. Zhang, G. Blander, J.G. Tse, M. Krieger, L. Guarente, SIRT1 deacetylates and positively regulates the nuclear receptor LXR, Mol Cell 28 (2007) 91-106.

[67] K.M. Ramsey, K.F. Mills, A. Satoh, S. Imai, Age-associated loss of Sirt1-mediated enhancement of glucose-stimulated insulin secretion in beta cell-specific Sirt1-overexpressing (BESTO) mice, Aging Cell 7 (2008) 78-88.

[68] J.A. Baur, K.J. Pearson, N.L. Price, H.A. Jamieson, C. Lerin, A. Kalra, V.V. Prabhu, J.S. Allard, G. Lopez-Lluch, K. Lewis, P.J. Pistell, S. Poosala, K.G. Becker, O. Boss, D. Gwinn, M. Wang, S. Ramaswamy, K.W. Fishbein, R.G. Spencer, E.G. Lakatta, D. Le Couteur, R.J. Shaw, P. Navas, P. Puigserver, D.K. Ingram, R. de Cabo, D.A. Sinclair, Resveratrol improves health and survival of mice on a high-calorie diet, Nature 444 (2006) 337-342.

[69] J.N. Feige, M. Lagouge, C. Canto, A. Strehle, S.M. Houten, J.C. Milne, P.D. Lambert, C. Mataki, P.J. Elliott, J. Auwerx, Specific SIRT1 activation mimics low energy levels and protects against diet-induced metabolic disorders by enhancing fat oxidation, Cell Metab 8 (2008) 347-358.

[70] M. Lagouge, C. Argmann, Z. Gerhart-Hines, H. Meziane, C. Lerin, F. Daussin, N. Messadeq, J. Milne, P. Lambert, P. Elliott, B. Geny, M. Laakso, P. Puigserver, J. Auwerx, Resveratrol improves mitochondrial function and protects against metabolic disease by activating SIRT1 and PGC-1alpha, Cell 127 (2006) 1109-1122.

[71] J.C. Milne, P.D. Lambert, S. Schenk, D.P. Carney, J.J. Smith, D.J. Gagne, L. Jin, O. Boss, R.B. Perni, C.B. Vu, J.E. Bemis, R. Xie, J.S. Disch, P.Y. Ng, J.J. Nunes, A.V. Lynch, H. Yang, H. Galonek, K. Israelian, W. Choy, A. Iffland, S. Lavu, O. Medvedik, D.A. Sinclair, J.M. Olefsky, M.R. Jirousek, P.J. Elliott, C.H. Westphal, Small molecule activators of SIRT1 as therapeutics for the treatment of type 2 diabetes, Nature 450 (2007) 712-716.

[72] Y. Yamazaki, I. Usui, Y. Kanatani, Y. Matsuya, K. Tsuneyama, S. Fujisaka, A. Bukhari, H. Suzuki, S. Senda, S. Imanishi, K. Hirata, M. Ishiki, R. Hayashi, M. Urakaze, H. Nemoto, M. Kobayashi, K. Tobe, Treatment with SRT1720, a SIRT1 Activator, Ameliorates Fatty Liver with Reduced Expression of Lipogenic Enzymes in MSG Mice, Am J Physiol Endocrinol Metab (2009).

[73] B. Yang, B.M. Zwaans, M. Eckersdorff, D.B. Lombard, The sirtuin SIRT6 deacetylates H3 K56Ac in vivo to promote genomic stability, Cell Cycle 8 (2009) 2662-2663.

[74] R. Mostoslavsky, K.F. Chua, D.B. Lombard, W.W. Pang, M.R. Fischer, L. Gellon, P. Liu, G. Mostoslavsky, S. Franco, M.M. Murphy, K.D. Mills, P. Patel, J.T. Hsu, A.L. Hong, E. Ford, H.L. Cheng, C. Kennedy, N. Nunez, R. Bronson, D. Frendewey, W. Auerbach, D. Valenzuela, M. Karow, M.O. Hottiger, S. Hursting, J.C. Barrett, L. Guarente, R. Mulligan, B. Demple, G.D. Yancopoulos, F.W. Alt, Genomic instability and aging-like phenotype in the absence of mammalian SIRT6, Cell 124 (2006) 315-329.

[75] T.L. Kawahara, E. Michishita, A.S. Adler, M. Damian, E. Berber, M. Lin, R.A. McCord, K.C. Ongaigui, L.D. Boxer, H.Y. Chang, K.F. Chua, SIRT6 links histone H3 lysine 9 deacetylation to NF-kappaB-dependent gene expression and organismal life span, Cell 136 (2009) 62-74.

[76] O. Vakhrusheva, C. Smolka, P. Gajawada, S. Kostin, T. Boettger, T. Kubin, T. Braun, E. Bober, Sirt7 increases stress resistance of cardiomyocytes and prevents apoptosis and inflammatory cardiomyopathy in mice, Circ Res 102 (2008) 703-710.

[77] E. Ford, R. Voit, G. Liszt, C. Magin, I. Grummt, L. Guarente, Mammalian Sir2 homolog SIRT7 is an activator of RNA polymerase I transcription, Genes Dev 20 (2006) 1075-1080.

[78] R.R. Alcendor, L.A. Kirshenbaum, S. Imai, S.F. Vatner, J. Sadoshima, Silent information regulator 2alpha, a longevity factor and class III histone deacetylase, is an essential endogenous apoptosis inhibitor in cardiac myocytes, Circ Res 95 (2004) 971-980.

[79] V. Muth, S. Nadaud, I. Grummt, R. Voit, Acetylation of TAF(I)68, a subunit of TIF-IB/SL1, activates RNA polymerase I transcription, EMBO J 20 (2001) 1353-1362. 
[80] B.J. North, E. Verdin, Interphase nucleo-cytoplasmic shuttling and localization of SIRT2 during mitosis, PLoS One 2 (2007) e784.

[81] A. Vaquero, M.B. Scher, D.H. Lee, A. Sutton, H.L. Cheng, F.W. Alt, L. Serrano, R. Sternglanz, D. Reinberg, SirT2 is a histone deacetylase with preference for histone H4 Lys 16 during mitosis, Genes Dev 20 (2006) 1256-1261.

[82] M.T. Borra, F.J. O'Neill, M.D. Jackson, B. Marshall, E. Verdin, K.R. Foltz, J.M. Denu, Conserved enzymatic production and biological effect of O-acetyl-ADP-ribose by silent information regulator 2-like NAD+-dependent deacetylases, J Biol Chem 277 (2002) 1263212641.

[83] V. Lennerz, M. Fatho, C. Gentilini, R.A. Frye, A. Lifke, D. Ferel, C. Wolfel, C. Huber, T. Wolfel, The response of autologous $\mathrm{T}$ cells to a human melanoma is dominated by mutated neoantigens, Proc Natl Acad Sci U S A 102 (2005) 16013-16018.

[84] M. Hiratsuka, T. Inoue, T. Toda, N. Kimura, Y. Shirayoshi, H. Kamitani, T. Watanabe, E. Ohama, C.G. Tahimic, A. Kurimasa, M. Oshimura, Proteomics-based identification of differentially expressed genes in human gliomas: down-regulation of SIRT2 gene, Biochem Biophys Res Commun 309 (2003) 558-566.

[85] T. Inoue, M. Hiratsuka, M. Osaki, H. Yamada, I. Kishimoto, S. Yamaguchi, S. Nakano, M. Katoh, H. Ito, M. Oshimura, SIRT2, a tubulin deacetylase, acts to block the entry to chromosome condensation in response to mitotic stress, Oncogene 26 (2007) 945-957.

[86] W. Li, B. Zhang, J. Tang, Q. Cao, Y. Wu, C. Wu, J. Guo, E.A. Ling, F. Liang, Sirtuin 2, a mammalian homolog of yeast silent information regulator-2 longevity regulator, is an oligodendroglial protein that decelerates cell differentiation through deacetylating alphatubulin, J Neurosci 27 (2007) 2606-2616.

[87] K. Suzuki, T. Koike, Mammalian Sir2-related protein (SIRT) 2-mediated modulation of resistance to axonal degeneration in slow Wallerian degeneration mice: a crucial role of tubulin deacetylation, Neuroscience 147 (2007) 599-612.

[88] T.F. Outeiro, E. Kontopoulos, S.M. Altmann, I. Kufareva, K.E. Strathearn, A.M. Amore, C.B. Volk, M.M. Maxwell, J.C. Rochet, P.J. McLean, A.B. Young, R. Abagyan, M.B. Feany, B.T. Hyman, A.G. Kazantsev, Sirtuin 2 inhibitors rescue alpha-synuclein-mediated toxicity in models of Parkinson's disease, Science 317 (2007) 516-519.

[89] F. Wang, Q. Tong, SIRT2 suppresses adipocyte differentiation by deacetylating FOXO1 and enhancing FOXO1's repressive interaction with PPARgamma, Mol Biol Cell 20 (2009) 801808.

[90] E. Jing, S. Gesta, C.R. Kahn, SIRT2 regulates adipocyte differentiation through FoxO1 acetylation/deacetylation, Cell Metab 6 (2007) 105-114.

[91] B. Schwer, B.J. North, R.A. Frye, M. Ott, E. Verdin, The human silent information regulator (Sir)2 homologue hSIRT3 is a mitochondrial nicotinamide adenine dinucleotide-dependent deacetylase, J Cell Biol 158 (2002) 647-657.

[92] D.B. Lombard, F.W. Alt, H.L. Cheng, J. Bunkenborg, R.S. Streeper, R. Mostoslavsky, J. Kim, G. Yancopoulos, D. Valenzuela, A. Murphy, Y. Yang, Y. Chen, M.D. Hirschey, R.T. Bronson, M. Haigis, L.P. Guarente, R.V. Farese, Jr., S. Weissman, E. Verdin, B. Schwer, Mammalian Sir2 homolog SIRT3 regulates global mitochondrial lysine acetylation, Mol Cell Biol 27 (2007) 8807-8814.

[93] P. Onyango, I. Celic, J.M. McCaffery, J.D. Boeke, A.P. Feinberg, SIRT3, a human SIR2 homologue, is an NAD-dependent deacetylase localized to mitochondria, Proc Natl Acad Sci U S A 99 (2002) 13653-13658.

[94] N.R. Sundaresan, S.A. Samant, V.B. Pillai, S.B. Rajamohan, M.P. Gupta, SIRT3 is a stressresponsive deacetylase in cardiomyocytes that protects cells from stress-mediated cell death by deacetylation of Ku70, Mol Cell Biol 28 (2008) 6384-6401.

[95] M.B. Scher, A. Vaquero, D. Reinberg, SirT3 is a nuclear NAD+-dependent histone deacetylase that translocates to the mitochondria upon cellular stress, Genes Dev 21 (2007) 920-928.

[96] Y. Nakamura, M. Ogura, D. Tanaka, N. Inagaki, Localization of mouse mitochondrial SIRT proteins: shift of SIRT3 to nucleus by co-expression with SIRT5, Biochem Biophys Res Commun 366 (2008) 174-179. 
[97] T. Shi, F. Wang, E. Stieren, Q. Tong, SIRT3, a mitochondrial sirtuin deacetylase, regulates mitochondrial function and thermogenesis in brown adipocytes, J Biol Chem 280 (2005) 13560-13567.

[98] S.C. Kim, R. Sprung, Y. Chen, Y. Xu, H. Ball, J. Pei, T. Cheng, Y. Kho, H. Xiao, L. Xiao, N.V. Grishin, M. White, X.J. Yang, Y. Zhao, Substrate and functional diversity of lysine acetylation revealed by a proteomics survey, Mol Cell 23 (2006) 607-618.

[99] C. Choudhary, C. Kumar, F. Gnad, M.L. Nielsen, M. Rehman, T.C. Walther, J.V. Olsen, M. Mann, Lysine acetylation targets protein complexes and co-regulates major cellular functions, Science 325 (2009) 834-840.

[100] J. Zhang, R. Sprung, J. Pei, X. Tan, S. Kim, H. Zhu, C.F. Liu, N.V. Grishin, Y. Zhao, Lysine acetylation is a highly abundant and evolutionarily conserved modification in Escherichia coli, Mol Cell Proteomics 8 (2009) 215-225.

[101] W.C. Hallows, S. Lee, J.M. Denu, Sirtuins deacetylate and activate mammalian acetyl-CoA synthetases, Proc Natl Acad Sci U S A 103 (2006) 10230-10235.

[102] B. Schwer, J. Bunkenborg, R.O. Verdin, J.S. Andersen, E. Verdin, Reversible lysine acetylation controls the activity of the mitochondrial enzyme acetyl-CoA synthetase 2, Proc Natl Acad Sci U S A 103 (2006) 10224-10229.

[103] I. Sakakibara, T. Fujino, M. Ishii, T. Tanaka, T. Shimosawa, S. Miura, W. Zhang, Y. Tokutake, J. Yamamoto, M. Awano, S. Iwasaki, T. Motoike, M. Okamura, T. Inagaki, K. Kita, O. Ezaki, M. Naito, T. Kuwaki, S. Chohnan, T.T. Yamamoto, R.E. Hammer, T. Kodama, M. Yanagisawa, J. Sakai, Fasting-induced hypothermia and reduced energy production in mice lacking acetyl-CoA synthetase 2, Cell Metab 9 (2009) 191-202.

[104] B.H. Ahn, H.S. Kim, S. Song, I.H. Lee, J. Liu, A. Vassilopoulos, C.X. Deng, T. Finkel, A role for the mitochondrial deacetylase Sirt3 in regulating energy homeostasis, Proc Natl Acad Sci U S A 105 (2008) 14447-14452.

[105] H. Cimen, M.J. Han, Y. Yang, Q. Tong, H. Koc, E.C. Koc, Regulation of succinate dehydrogenase activity by SIRT3 in mammalian mitochondria, Biochemistry 49 (2010) 304311.

[106] C. Schlicker, M. Gertz, P. Papatheodorou, B. Kachholz, C.F. Becker, C. Steegborn, Substrates and regulation mechanisms for the human mitochondrial sirtuins Sirt3 and Sirt5, J Mol Biol 382 (2008) 790-801.

[107] M.D. Hirschey, T. Shimazu, E. Goetzman, E. Jing, B. Schwer, D.B. Lombard, C.A. Grueter, C. Harris, S. Biddinger, O.R. Ilkayeva, R.D. Stevens, Y. Li, A.K. Saha, N.B. Ruderman, J.R. Bain, C.B. Newgard, R.V. Farese, Jr., F.W. Alt, C.R. Kahn, E. Verdin, SIRT3 regulates mitochondrial fatty-acid oxidation by reversible enzyme deacetylation, Nature 464 (2010) 121-125.

[108] H. Yang, T. Yang, J.A. Baur, E. Perez, T. Matsui, J.J. Carmona, D.W. Lamming, N.C. SouzaPinto, V.A. Bohr, A. Rosenzweig, R. de Cabo, A.A. Sauve, D.A. Sinclair, Nutrient-sensitive mitochondrial NAD+ levels dictate cell survival, Cell 130 (2007) 1095-1107.

[109] H.S. Kim, K. Patel, K. Muldoon-Jacobs, K.S. Bisht, N. Aykin-Burns, J.D. Pennington, R. van der Meer, P. Nguyen, J. Savage, K.M. Owens, A. Vassilopoulos, O. Ozden, S.H. Park, K.K. Singh, S.A. Abdulkadir, D.R. Spitz, C.X. Deng, D. Gius, SIRT3 is a mitochondria-localized tumor suppressor required for maintenance of mitochondrial integrity and metabolism during stress, Cancer Cell 17 (2010) 41-52.

[110] D. Bellizzi, S. Dato, P. Cavalcante, G. Covello, F. Di Cianni, G. Passarino, G. Rose, G. De Benedictis, Characterization of a bidirectional promoter shared between two human genes related to aging: SIRT3 and PSMD13, Genomics 89 (2007) 143-150.

[111] D. Bellizzi, G. Rose, P. Cavalcante, G. Covello, S. Dato, F. De Rango, V. Greco, M. Maggiolini, E. Feraco, V. Mari, C. Franceschi, G. Passarino, G. De Benedictis, A novel VNTR enhancer within the SIRT3 gene, a human homologue of SIR2, is associated with survival at oldest ages, Genomics 85 (2005) 258-263.

[112] C.A. Stanley, Hyperinsulinism/hyperammonemia syndrome: insights into the regulatory role of glutamate dehydrogenase in ammonia metabolism, Mol Genet Metab 81 Suppl 1 (2004) S45-51.

[113] B.J. North, B. Schwer, N. Ahuja, B. Marshall, E. Verdin, Preparation of enzymatically active recombinant class III protein deacetylases, Methods 36 (2005) 338-345. 
[114] T. Nakagawa, D.J. Lomb, M.C. Haigis, L. Guarente, SIRT5 Deacetylates carbamoyl phosphate synthetase 1 and regulates the urea cycle, Cell 137 (2009) 560-570.

[115] D. Haussinger, Nitrogen metabolism in liver: structural and functional organization and physiological relevance, Biochem J 267 (1990) 281-290.

[116] A.J. Meijer, W.H. Lamers, R.A. Chamuleau, Nitrogen metabolism and ornithine cycle function, Physiol Rev 70 (1990) 701-748.

[117] R.T. Schimke, Differential effects of fasting and protein-free diets on levels of urea cycle enzymes in rat liver, J Biol Chem 237 (1962) 1921-1924.

[118] J.E. Sulston, E. Schierenberg, J.G. White, J.N. Thomson, The embryonic cell lineage of the nematode Caenorhabditis elegans, Dev Biol 100 (1983) 64-119.

[119] J. Ahringer, Reverse Genetics, WormBook (2006) 1-43.

[120] A. Berdichevsky, M. Viswanathan, H.R. Horvitz, L. Guarente, C. elegans SIR-2.1 interacts with 14-3-3 proteins to activate DAF-16 and extend life span, Cell 125 (2006) 1165-1177.

[121] Y. Wang, S.W. Oh, B. Deplancke, J. Luo, A.J. Walhout, H.A. Tissenbaum, C. elegans 14-3-3 proteins regulate life span and interact with SIR-2.1 and DAF-16/FOXO, Mech Ageing Dev 127 (2006) 741-747.

[122] Y. Wang, H.A. Tissenbaum, Overlapping and distinct functions for a Caenorhabditis elegans SIR2 and DAF-16/FOXO, Mech Ageing Dev 127 (2006) 48-56.

[123] M.A. Jedrusik, E. Schulze, Telomeric position effect variegation in Saccharomyces cerevisiae by Caenorhabditis elegans linker histones suggests a mechanistic connection between germ line and telomeric silencing, Mol Cell Biol 23 (2003) 3681-3691.

[124] M.A. Jedrusik, E. Schulze, Linker histone HIS-24 (H1.1) cytoplasmic retention promotes germ line development and influences histone H3 methylation in Caenorhabditis elegans, Mol Cell Biol 27 (2007) 2229-2239.

[125] M. Wirth, F. Paap, W. Fischle, D. Wenzel, D.E. Agafonov, T.R. Samatov, J.R. Wisniewski, M. Jedrusik-Bode, HIS-24 linker histone and SIR-2.1 deacetylase induce H3K27me3 in the Caenorhabditis elegans germ line, Mol Cell Biol 29 (2009) 3700-3709.

[126] S. Greiss, J. Hall, S. Ahmed, A. Gartner, C. elegans SIR-2.1 translocation is linked to a proapoptotic pathway parallel to cep-1/p53 during DNA damage-induced apoptosis, Genes Dev 22 (2008) 2831-2842.

[127] E.A. Bates, M. Victor, A.K. Jones, Y. Shi, A.C. Hart, Differential contributions of Caenorhabditis elegans histone deacetylases to huntingtin polyglutamine toxicity, J Neurosci 26 (2006) 2830-2838.

[128] N. Bizat, J.M. Peyrin, S. Haik, V. Cochois, P. Beaudry, J.L. Laplanche, C. Neri, Neuron dysfunction is induced by prion protein with an insertional mutation via a Fyn kinase and reversed by sirtuin activation in Caenorhabditis elegans, J Neurosci 30 (2010) 5394-5403.

[129] J. Pothof, G. van Haaften, K. Thijssen, R.S. Kamath, A.G. Fraser, J. Ahringer, R.H. Plasterk, M. Tijsterman, Identification of genes that protect the C. elegans genome against mutations by genome-wide RNAi, Genes Dev 17 (2003) 443-448.

[130] W. Mair, S.H. Panowski, R.J. Shaw, A. Dillin, Optimizing dietary restriction for genetic epistasis analysis and gene discovery in C. elegans, PLoS One 4 (2009) e4535.

[131] N.D.L.a.C. M.M., Lehninger Principles of Biochemistry (4th edition), W. H. Freemann 2005.

[132] A.A. Sauve, NAD+ and vitamin B3: from metabolism to therapies, J Pharmacol Exp Ther 324 (2008) 883-893.

[133] J.J. Sandmeier, I. Celic, J.D. Boeke, J.S. Smith, Telomeric and rDNA silencing in Saccharomyces cerevisiae are dependent on a nuclear NAD(+) salvage pathway, Genetics 160 (2002) 877-889.

[134] R.M. Anderson, K.J. Bitterman, J.G. Wood, O. Medvedik, H. Cohen, S.S. Lin, J.K. Manchester, J.I. Gordon, D.A. Sinclair, Manipulation of a nuclear NAD+ salvage pathway delays aging without altering steady-state NAD+ levels, J Biol Chem 277 (2002) 1888118890.

[135] A. van der Horst, J.M. Schavemaker, W. Pellis-van Berkel, B.M. Burgering, The Caenorhabditis elegans nicotinamidase PNC-1 enhances survival, Mech Ageing Dev 128 (2007) 346-349. 
[136] J.W. Foster, Y.K. Park, T. Penfound, T. Fenger, M.P. Spector, Regulation of NAD metabolism in Salmonella typhimurium: molecular sequence analysis of the bifunctional nadR regulator and the nadA-pnuC operon, J Bacteriol 172 (1990) 4187-4196.

[137] R.M. Anderson, K.J. Bitterman, J.G. Wood, O. Medvedik, D.A. Sinclair, Nicotinamide and PNC1 govern lifespan extension by calorie restriction in Saccharomyces cerevisiae, Nature 423 (2003) 181-185.

[138] C.M. Gallo, D.L. Smith, Jr., J.S. Smith, Nicotinamide clearance by Pnc1 directly regulates Sir2-mediated silencing and longevity, Mol Cell Biol 24 (2004) 1301-1312.

[139] L. Virag, C. Szabo, The therapeutic potential of poly(ADP-ribose) polymerase inhibitors, Pharmacol Rev 54 (2002) 375-429.

[140] E.A. Gale, P.J. Bingley, C.L. Emmett, T. Collier, European Nicotinamide Diabetes Intervention Trial (ENDIT): a randomised controlled trial of intervention before the onset of type 1 diabetes, Lancet 363 (2004) 925-931.

[141] T.M. Jackson, J.M. Rawling, B.D. Roebuck, J.B. Kirkland, Large supplements of nicotinic acid and nicotinamide increase tissue NAD+ and poly(ADP-ribose) levels but do not affect diethylnitrosamine-induced altered hepatic foci in Fischer-344 rats, J Nutr 125 (1995) 14551461.

[142] A.C. Boyonoski, J.C. Spronck, R.M. Jacobs, G.M. Shah, G.G. Poirier, J.B. Kirkland, Pharmacological intakes of niacin increase bone marrow poly(ADP-ribose) and the latency of ethylnitrosourea-induced carcinogenesis in rats, J Nutr 132 (2002) 115-120.

[143] S. Imai, The NAD World: a new systemic regulatory network for metabolism and aging-Sirt1, systemic NAD biosynthesis, and their importance, Cell Biochem Biophys 53 (2009) 6574.

[144] I.E. Scheffler, A century of mitochondrial research: achievements and perspectives, Mitochondrion 1 (2001) 3-31.

[145] B. Van Houten, V. Woshner, J.H. Santos, Role of mitochondrial DNA in toxic responses to oxidative stress, DNA Repair (Amst) 5 (2006) 145-152.

[146] S. Zhao, W. Xu, W. Jiang, W. Yu, Y. Lin, T. Zhang, J. Yao, L. Zhou, Y. Zeng, H. Li, Y. Li, J. Shi, W. An, S.M. Hancock, F. He, L. Qin, J. Chin, P. Yang, X. Chen, Q. Lei, Y. Xiong, K.L. Guan, Regulation of cellular metabolism by protein lysine acetylation, Science 327 (2010) 1000-1004.

[147] Q. Wang, Y. Zhang, C. Yang, H. Xiong, Y. Lin, J. Yao, H. Li, L. Xie, W. Zhao, Y. Yao, Z.B. Ning, R. Zeng, Y. Xiong, K.L. Guan, S. Zhao, G.P. Zhao, Acetylation of metabolic enzymes coordinates carbon source utilization and metabolic flux, Science 327 (2010) 1004-1007.

[148] B. Schwer, M. Eckersdorff, Y. Li, J.C. Silva, D. Fermin, M.V. Kurtev, C. Giallourakis, M.J. Comb, F.W. Alt, D.B. Lombard, Calorie restriction alters mitochondrial protein acetylation, Aging Cell 8 (2009) 604-606.

[149] M.W. Gray, G. Burger, B.F. Lang, Mitochondrial evolution, Science 283 (1999) 1476-1481.

[150] B.J. Yu, J.A. Kim, J.H. Moon, S.E. Ryu, J.G. Pan, The diversity of lysine-acetylated proteins in Escherichia coli, J Microbiol Biotechnol 18 (2008) 1529-1536.

[151] V.J. Starai, J.C. Escalante-Semerena, Identification of the protein acetyltransferase (Pat) enzyme that acetylates acetyl-CoA synthetase in Salmonella enterica, J Mol Biol 340 (2004) $1005-1012$.

[152] V.J. Starai, I. Celic, R.N. Cole, J.D. Boeke, J.C. Escalante-Semerena, Sir2-dependent activation of acetyl-CoA synthetase by deacetylation of active lysine, Science 298 (2002) 2390-2392.

[153] V.J. Starai, H. Takahashi, J.D. Boeke, J.C. Escalante-Semerena, Short-chain fatty acid activation by acyl-coenzyme A synthetases requires SIR2 protein function in Salmonella enterica and Saccharomyces cerevisiae, Genetics 163 (2003) 545-555.

[154] G. Ramponi, G. Manao, G. Camici, Nonenzymatic acetylation of histones with acetyl phosphate and acetyl adenylate, Biochemistry 14 (1975) 2681-2685.

[155] W.K. Paik, D. Pearson, H.W. Lee, S. Kim, Nonenzymatic acetylation of histones with acetylCoA, Biochim Biophys Acta 213 (1970) 513-522.

[156] N. Koester-Eiserfunke, Characterization of Lin-61 methyl mark binding and its function in C. elegans vulva development. , $\mathrm{PhD}$ thesis in the Group of Chromatin Biochemistry (Goettingen, Max Planck Institute of Biophysical Chemistry) (2010). 
[157] C.C. Mello, J.M. Kramer, D. Stinchcomb, V. Ambros, Efficient gene transfer in C.elegans: extrachromosomal maintenance and integration of transforming sequences, EMBO J 10 (1991) 3959-3970.

[158] S. Brenner, The genetics of Caenorhabditis elegans, Genetics 77 (1974) 71-94.

[159] R. Hunt-Newbury, R. Viveiros, R. Johnsen, A. Mah, D. Anastas, L. Fang, E. Halfnight, D. Lee, J. Lin, A. Lorch, S. McKay, H.M. Okada, J. Pan, A.K. Schulz, D. Tu, K. Wong, Z. Zhao, A. Alexeyenko, T. Burglin, E. Sonnhammer, R. Schnabel, S.J. Jones, M.A. Marra, D.L. Baillie, D.G. Moerman, High-throughput in vivo analysis of gene expression in Caenorhabditis elegans, PLoS Biol 5 (2007) e237.

[160] S.J. McKay, R. Johnsen, J. Khattra, J. Asano, D.L. Baillie, S. Chan, N. Dube, L. Fang, B. Goszczynski, E. Ha, E. Halfnight, R. Hollebakken, P. Huang, K. Hung, V. Jensen, S.J. Jones, H. Kai, D. Li, A. Mah, M. Marra, J. McGhee, R. Newbury, A. Pouzyrev, D.L. Riddle, E. Sonnhammer, H. Tian, D. Tu, J.R. Tyson, G. Vatcher, A. Warner, K. Wong, Z. Zhao, D.G. Moerman, Gene expression profiling of cells, tissues, and developmental stages of the nematode C. elegans, Cold Spring Harb Symp Quant Biol 68 (2003) 159-169.

[161] D. Dupuy, N. Bertin, C.A. Hidalgo, K. Venkatesan, D. Tu, D. Lee, J. Rosenberg, N. Svrzikapa, A. Blanc, A. Carnec, A.R. Carvunis, R. Pulak, J. Shingles, J. Reece-Hoyes, R. Hunt-Newbury, R. Viveiros, W.A. Mohler, M. Tasan, F.P. Roth, C. Le Peuch, I.A. Hope, R. Johnsen, D.G. Moerman, A.L. Barabasi, D. Baillie, M. Vidal, Genome-scale analysis of in vivo spatiotemporal promoter activity in Caenorhabditis elegans, Nat Biotechnol 25 (2007) 663-668.

[162] C. Benedetti, C.M. Haynes, Y. Yang, H.P. Harding, D. Ron, Ubiquitin-like protein 5 positively regulates chaperone gene expression in the mitochondrial unfolded protein response, Genetics 174 (2006) 229-239.

[163] I. New England Biolabs, Catalog and technical reference. 2007/2008.

[164] J.a.R. Sambrook, D. , Molecular Cloning. A laboratory Manual. , Cold Spring Harbour, New York: Cold Spring Harbour press 3rd ed. (2001).

[165] A.S. Spirin, and J. R. Swartz (ed.), Cell-free protein synthesis: methods and protocols, WileyVCH Verlag GmbH, Weinheim, Germany (2008).

[166] U.K. Laemmli, Cleavage of structural proteins during the assembly of the head of bacteriophage T4, Nature 227 (1970) 680-685.

[167] S.R. Gallagher, One-dimensional SDS gel electrophoresis of proteins, Curr Protoc Immunol Chapter 8 (2006) Unit 84.

[168] A. Shevchenko, M. Wilm, O. Vorm, M. Mann, Mass spectrometric sequencing of proteins silver-stained polyacrylamide gels, Anal Chem 68 (1996) 850-858.

[169] F.W. Studier, Protein production by auto-induction in high density shaking cultures, Protein Expr Purif 41 (2005) 207-234.

[170] K. Luger, T.J. Rechsteiner, T.J. Richmond, Preparation of nucleosome core particle from recombinant histones, Methods Enzymol 304 (1999) 3-19.

[171] D.E. Smith, P.A. Fisher, Identification, developmental regulation, and response to heat shock of two antigenically related forms of a major nuclear envelope protein in Drosophila embryos: application of an improved method for affinity purification of antibodies using polypeptides immobilized on nitrocellulose blots, J Cell Biol 99 (1984) 20-28.

[172] J.S. Duerr, D.L. Frisby, J. Gaskin, A. Duke, K. Asermely, D. Huddleston, L.E. Eiden, J.B. Rand, The cat-1 gene of Caenorhabditis elegans encodes a vesicular monoamine transporter required for specific monoamine-dependent behaviors, J Neurosci 19 (1999) 72-84.

[173] T. Stiernagle, Maintenance of C. elegans, WormBook (2006) 1-11.

[174] T.C. Evans, Transformation and microinjection WormBook, The C. elegans Research Community (2006).

[175] J.A.a.F.J.F. Lewis, Basic culture methods, Methods in Cell Biology, Caenorhabditis elegans, Modern Biological Analysis of an Organism, E. H. F. a. S. D. C., Editor. (1995).

[176] J. Li, T. Cai, P. Wu, Z. Cui, X. Chen, J. Hou, Z. Xie, P. Xue, L. Shi, P. Liu, J.R. Yates, 3rd, F. Yang, Proteomic analysis of mitochondria from Caenorhabditis elegans, Proteomics 9 (2009) 4539-4553. 
[177] I.M. Cheeseman, S. Niessen, S. Anderson, F. Hyndman, J.R. Yates, 3rd, K. Oegema, A. Desai, A conserved protein network controls assembly of the outer kinetochore and its ability to sustain tension, Genes Dev 18 (2004) 2255-2268.

[178] S. Gandre, A.M. van der Bliek, Mitochondrial division in Caenorhabditis elegans, Methods Mol Biol 372 (2007) 485-501.

[179] J.S. Duerr, Immunohistochemistry, WormBook (2006) 1-61.

[180] D.T. Stinchcomb, J.E. Shaw, S.H. Carr, D. Hirsh, Extrachromosomal DNA transformation of Caenorhabditis elegans, Mol Cell Biol 5 (1985) 3484-3496.

[181] C.a.F. Mello, A., DNA transformation, Methods Cell Biol 48 (1995) 451-482.

[182] J.M. Kramer, R.P. French, E.C. Park, J.J. Johnson, The Caenorhabditis elegans rol-6 gene, which interacts with the sqt-1 collagen gene to determine organismal morphology, encodes a collagen, Mol Cell Biol 10 (1990) 2081-2089.

[183] A. Fire, R.H. Waterston, Proper expression of myosin genes in transgenic nematodes, EMBO J 8 (1989) 3419-3428.

[184] O. Hobert, PCR fusion-based approach to create reporter gene constructs for expression analysis in transgenic C. elegans, Biotechniques 32 (2002) 728-730.

[185] T. Boulin, J.F. Etchberger, O. Hobert, Reporter gene fusions, WormBook (2006) 1-23.

[186] M.A. Jedrusik, E. Schulze, Analysis of germline chromatin silencing by double-stranded RNA-mediated interference (RNAi) in Caenorhabditis elegans, Methods Mol Biol 254 (2004) $35-48$.

[187] L. Timmons, A. Fire, Specific interference by ingested dsRNA, Nature 395 (1998) 854.

[188] L. Timmons, D.L. Court, A. Fire, Ingestion of bacterially expressed dsRNAs can produce specific and potent genetic interference in Caenorhabditis elegans, Gene 263 (2001) 103-112.

[189] E.M. Hedgecock, J.G. Culotti, J.N. Thomson, L.A. Perkins, Axonal guidance mutants of Caenorhabditis elegans identified by filling sensory neurons with fluorescein dyes, Dev Biol 111 (1985) 158-170.

[190] W. Liou, H.J. Geuze, J.W. Slot, Improving structural integrity of cryosections for immunogold labeling, Histochem Cell Biol 106 (1996) 41-58.

[191] D. Wenzel, G. Schauermann, A. von Lupke, G. Hinz, The cargo in vacuolar storage protein transport vesicles is stratified, Traffic 6 (2005) 45-55.

[192] I. Masse, L. Molin, L. Mouchiroud, P. Vanhems, F. Palladino, M. Billaud, F. Solari, A novel role for the SMG-1 kinase in lifespan and oxidative stress resistance in Caenorhabditis elegans, PLoS One 3 (2008) e3354.

[193] M.D. Hirschey, T. Shimazu, J.Y. Huang, E. Verdin, Acetylation of mitochondrial proteins, Methods Enzymol 457 (2009) 137-147.

[194] E. Verdin, F. Dequiedt, W. Fischle, R. Frye, B. Marshall, B. North, Measurement of mammalian histone deacetylase activity, Methods Enzymol 377 (2004) 180-196.

[195] G.B. Warren, K.F. Tipton, Pig liver pyruvate carboxylase. Purification, properties and cation specificity, Biochem J 139 (1974) 297-310.

[196] P.G. Okkema, S.W. Harrison, V. Plunger, A. Aryana, A. Fire, Sequence requirements for myosin gene expression and regulation in Caenorhabditis elegans, Genetics 135 (1993) 385404.

[197] P.N. Inglis, G. Ou, M.R. Leroux, J.M. Scholey, The sensory cilia of Caenorhabditis elegans, WormBook (2007) 1-22.

[198] F. Paap, Molekulare und funktionale Analyse der NAD+-abhaengigen Histon-Deacetylase SIR-2.4 in C. elegans, Diploma thesis in the group of Chromatin Biochemistry (Goettingen, Max Planck Institute of Biophysical Chemistry) (2008).

[199] R.S. Balaban, S. Nemoto, T. Finkel, Mitochondria, oxidants, and aging, Cell 120 (2005) 483495.

[200] C. Kenyon, The plasticity of aging: insights from long-lived mutants, Cell 120 (2005) 449460.

[201] S. Jitrapakdee, A. Vidal-Puig, J.C. Wallace, Anaplerotic roles of pyruvate carboxylase in mammalian tissues, Cell Mol Life Sci 63 (2006) 843-854.

[202] R.A. Gravel, K.F. Lam, D. Mahuran, A. Kronis, Purification of human liver propionyl-CoA carboxylase by carbon tetrachloride extraction and monomeric avidin affinity chromatography, Arch Biochem Biophys 201 (1980) 669-673. 
[203] S. Jitrapakdee, J.C. Wallace, The biotin enzyme family: conserved structural motifs and domain rearrangements, Curr Protein Pept Sci 4 (2003) 217-229.

[204] E.P. Lau, B.C. Cochran, R.R. Fall, Isolation of 3-methylcrotonyl-coenzyme A carboxylase from bovine kidney, Arch Biochem Biophys 205 (1980) 352-359.

[205] S. Jitrapakdee, M. St Maurice, I. Rayment, W.W. Cleland, J.C. Wallace, P.V. Attwood, Structure, mechanism and regulation of pyruvate carboxylase, Biochem J 413 (2008) 369-387.

[206] S.E. Mango, The C. elegans pharynx: a model for organogenesis, WormBook (2007) 1-26.

[207] J.D. McGhee, The C. elegans intestine, WormBook (2007) 1-36.

[208] S.B. Pierce, M. Costa, R. Wisotzkey, S. Devadhar, S.A. Homburger, A.R. Buchman, K.C. Ferguson, J. Heller, D.M. Platt, A.A. Pasquinelli, L.X. Liu, S.K. Doberstein, G. Ruvkun, Regulation of DAF-2 receptor signaling by human insulin and ins-1, a member of the unusually large and diverse C. elegans insulin gene family, Genes Dev 15 (2001) 672-686.

[209] D.G. Moerman, B.D. Williams, Sarcomere assembly in C. elegans muscle, WormBook (2006) 1-16.

[210] M. Lynch, J.S. Conery, The evolutionary fate and consequences of duplicate genes, Science 290 (2000) 1151-1155.

[211] A. Woollard, Gene duplications and genetic redundancy in C. elegans, WormBook (2005) 16.

[212] J.H. Thomas, Thinking about genetic redundancy, Trends Genet 9 (1993) 395-399.

[213] O. Lespinet, Y.I. Wolf, E.V. Koonin, L. Aravind, The role of lineage-specific gene family expansion in the evolution of eukaryotes, Genome Res 12 (2002) 1048-1059.

[214] J.R. Revollo, A.A. Grimm, S. Imai, The NAD biosynthesis pathway mediated by nicotinamide phosphoribosyltransferase regulates Sir2 activity in mammalian cells, J Biol Chem 279 (2004) 50754-50763.

[215] N.R. Sundaresan, M. Gupta, G. Kim, S.B. Rajamohan, A. Isbatan, M.P. Gupta, Sirt3 blocks the cardiac hypertrophic response by augmenting Foxo3a-dependent antioxidant defense mechanisms in mice, J Clin Invest 119 (2009) 2758-2771.

[216] X. Kong, R. Wang, Y. Xue, X. Liu, H. Zhang, Y. Chen, F. Fang, Y. Chang, Sirtuin 3, a new target of PGC-1alpha, plays an important role in the suppression of ROS and mitochondrial biogenesis, PLoS One 5 (2010) e11707.

[217] F. Weinberg, N.S. Chandel, Reactive oxygen species-dependent signaling regulates cancer, Cell Mol Life Sci 66 (2009) 3663-3673.

[218] K.K. Singh, Mitochondria damage checkpoint in apoptosis and genome stability, FEMS Yeast Res 5 (2004) 127-132.

[219] A.B. Leiter, M. Weinberg, F. Isohashi, M.F. Utter, Relationshiop between phosphorylation and activity of pyruvate dehydrogenase in rat liver mitochondria and the absence of such a relationship for pyruvate carboxylase, J Biol Chem 253 (1978) 2716-2723.

[220] V. Large, M. Beylot, Modifications of citric acid cycle activity and gluconeogenesis in streptozotocin-induced diabetes and effects of metformin, Diabetes 48 (1999) 1251-1257.

[221] K. Hagopian, J.J. Ramsey, R. Weindruch, Caloric restriction increases gluconeogenic and transaminase enzyme activities in mouse liver, Exp Gerontol 38 (2003) 267-278.

[222] M.J. MacDonald, Feasibility of a mitochondrial pyruvate malate shuttle in pancreatic islets. Further implication of cytosolic NADPH in insulin secretion, J Biol Chem 270 (1995) 2005120058.

[223] O.E. Owen, S.C. Kalhan, R.W. Hanson, The key role of anaplerosis and cataplerosis for citric acid cycle function, J Biol Chem 277 (2002) 30409-30412.

[224] M.E. Bizeau, C. Short, J.S. Thresher, S.R. Commerford, W.T. Willis, M.J. Pagliassotti, Increased pyruvate flux capacities account for diet-induced increases in gluconeogenesis in vitro, Am J Physiol Regul Integr Comp Physiol 281 (2001) R427-433.

[225] K. Hagopian, J.J. Ramsey, R. Weindruch, Krebs cycle enzymes from livers of old mice are differentially regulated by caloric restriction, Exp Gerontol 39 (2004) 1145-1154.

[226] S. Jitrapakdee, A. Wutthisathapornchai, J.C. Wallace, M.J. MacDonald, Regulation of insulin secretion: role of mitochondrial signalling, Diabetologia 53 (2010) 1019-1032.

[227] M.J. MacDonald, L.A. Fahien, L.J. Brown, N.M. Hasan, J.D. Buss, M.A. Kendrick, Perspective: emerging evidence for signaling roles of mitochondrial anaplerotic products in insulin secretion, Am J Physiol Endocrinol Metab 288 (2005) E1-15. 
[228] S. Farfari, V. Schulz, B. Corkey, M. Prentki, Glucose-regulated anaplerosis and cataplerosis in pancreatic beta-cells: possible implication of a pyruvate/citrate shuttle in insulin secretion, Diabetes 49 (2000) 718-726.

[229] D. Lu, H. Mulder, P. Zhao, S.C. Burgess, M.V. Jensen, S. Kamzolova, C.B. Newgard, A.D. Sherry, 13C NMR isotopomer analysis reveals a connection between pyruvate cycling and glucose-stimulated insulin secretion (GSIS), Proc Natl Acad Sci U S A 99 (2002) 2708-2713.

[230] L.A. Fahien, M.J. MacDonald, The succinate mechanism of insulin release, Diabetes 51 (2002) 2669-2676.

[231] R.G. Kibbey, R.L. Pongratz, A.J. Romanelli, C.B. Wollheim, G.W. Cline, G.I. Shulman, Mitochondrial GTP regulates glucose-stimulated insulin secretion, Cell Metab 5 (2007) 253264.

[232] L.A. Fahien, M.J. MacDonald, E.H. Kmiotek, R.J. Mertz, C.M. Fahien, Regulation of insulin release by factors that also modify glutamate dehydrogenase, J Biol Chem 263 (1988) 1361013614.

[233] C. MacMullen, J. Fang, B.Y. Hsu, A. Kelly, P. de Lonlay-Debeney, J.M. Saudubray, A. Ganguly, T.J. Smith, C.A. Stanley, Hyperinsulinism/hyperammonemia syndrome in children with regulatory mutations in the inhibitory guanosine triphosphate-binding domain of glutamate dehydrogenase, J Clin Endocrinol Metab 86 (2001) 1782-1787.

[234] M.J. MacDonald, M.J. Longacre, E.C. Langberg, A. Tibell, M.A. Kendrick, T. Fukao, C.G. Ostenson, Decreased levels of metabolic enzymes in pancreatic islets of patients with type 2 diabetes, Diabetologia 52 (2009) 1087-1091.

[235] J. Yang, Y. Chi, B.R. Burkhardt, Y. Guan, B.A. Wolf, Leucine metabolism in regulation of insulin secretion from pancreatic beta cells, Nutr Rev 68 (2010) 270-279.

[236] L. Bordone, L. Guarente, Sirtuins and beta-cell function, Diabetes Obes Metab 9 Suppl 2 (2007) 23-27. 


\section{Curriculum vitae}

\section{Personal information}

Name:

Martina Barbara Wirth

Date of birth:

17.01.1982

Place of birth:

Lauingen a.d. Donau, Germany

Nationality:

German

\section{Education}

1988-1992

Volksschule Bissingen (primary school)

1992-2001

$06 / 2001$

Theodor-Heuss Gymnasium Nördlingen

Theodor-Heuss Gymnasium Nördlingen

Abitur

$10 / 2002-08 / 2005$

Biochemistry (Bachelor of Science)

Technical University of Munich

Bachelor thesis: "ChIP analysis of STATs in macrophages"

since $10 / 2005$

Molecular Biology

(International Max Planck Research School, MSc/PhD Program)

Georg-August-University Göttingen

since $10 / 2006$

$\mathrm{PhD}$ thesis project at the Max Planck Institute for Biophysical Chemistry, Göttingen

Thesis supervisors: Dr. W. Fischle and Dr. M. Jedrusik-Bode

\section{Stipends}

$10 / 2005-08 / 2006$

Stipend of the International Max Planck Research School

Georg-August-University Göttingen

\section{International Conferences}

$16^{\text {th }}$ International C. elegans Meeting, June 2007, University of California, Los Angeles, CA, USA (Epigenome Network of Excellence travel award)

$4^{\text {th }}$ International PhD Student Symposium "Horizons in Molecular Biology", September 2007, Göttingen, Germany (Organizer)

$59^{\text {th }}$ Mosbacher Kolloquium on "Epigenetics - Molecular Principles and Mechanisms", March 2008, Mosbach, Germany

$5^{\text {th }}$ International PhD Student Symposium "Horizons in Molecular Biology", September 2008, Göttingen, Germany (Organizer) 
“Development Now", Prof. Alvin Kaye Student-Hosted Meetings, March 2009, Weizmann Institute, Rehovot, Israel

$6^{\text {th }}$ International PhD Student Symposium "Horizons in Molecular Biology", September 2009, Göttingen, Germany (Organizer)

$61^{\text {st }}$ Mosbacher Kolloquium on "The Biology of Aging: Mechanisms and Intervention", April 2010, Mosbach, Germany

$7^{\text {th }}$ International PhD Student Symposium "Horizons in Molecular Biology", September 2010, Göttingen, Germany

\section{Practical Work experience}

08/2003-09/2003

03/2004-06/2004

08/2004-09/2004

04/2005-07/2005

01/2006-02/2006

02/2006-04/2006

05/2006-06/2006
Practical work

Max Planck Institute for Biochemistry, Department of Structure

Research, Prof. Dr. R. Huber, supervised by Dr. T. Krojer

Project work and student assistant

Technical University of Munich, Institute of Organic Chemistry and Biochemistry, Prof. Dr. A. Bacher, supervised by Dr. B. Illarionov Practical work

Technical University of Munich, Institute for Medical Microbiology, Immunology and Hygiene, Prof. Dr. H. Wagner, supervised by Dr. R. Lang

Bachelor thesis

Technical University of Munich, Institute for Medical Microbiology, Immunology and Hygiene, Prof. Dr. H. Wagner, supervised by Dr. R. Lang

Lab rotation

Georg-August-University Göttingen, DFG Research Center for Molecular Physiology of the Brain (CMPB), Dr. D. Klopfenstein, supervised by Dr. O. Wagner

Lab rotation

Georg-August-University Göttingen, Institute for Medical Microbiology, Prof. Dr. U. Gross, supervised by Prof. C. Lüder Lab rotation Max Planck Institute for Biophysical Chemistry, Chromatin Biochemistry Group, Dr. W. Fischle, supervised by Dr. M. JedrusikBode

\section{Non-Scientific Activities}

09/2001-05/2002
Work and Travel in Australia 